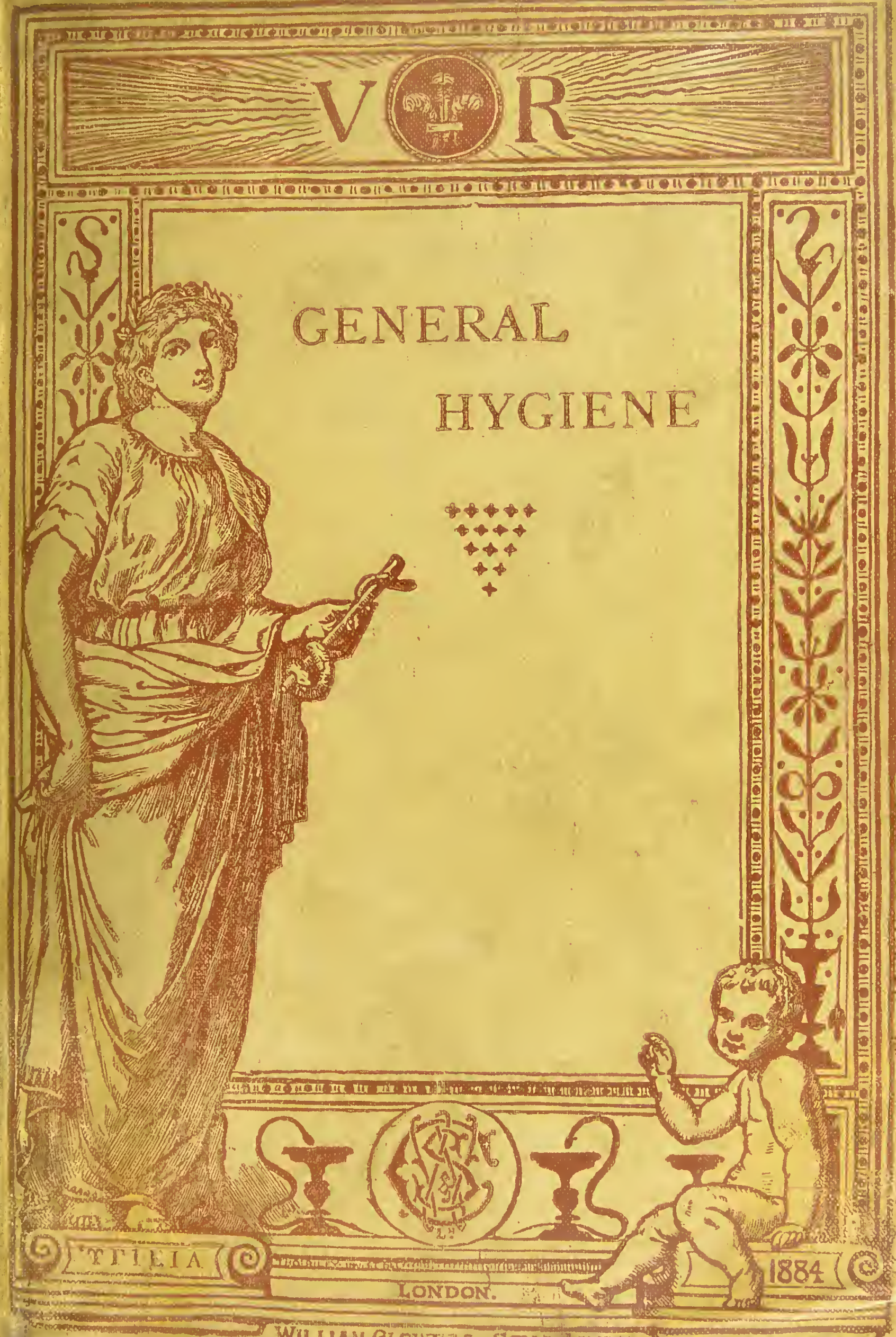

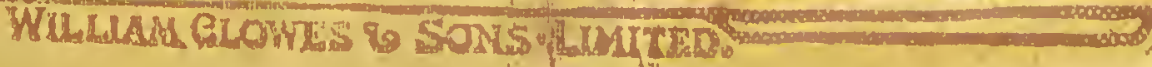


Don .5258

b Aw

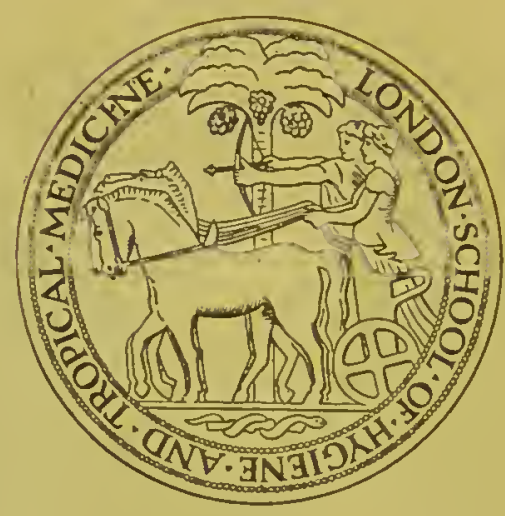

Presented to the Library

BY

Royal Sanitary Institute Date June 3 $\frac{\text { td }}{1932}$

b. AW.

Accession No, 18618

AP S 

, , 


\title{
SANITARY INSTITUTE
}

\section{BEC. 81}

International Health Exhibition, LONDON, 1884

THE

\section{HEALTH EXHIBITION LITERATURE.}

\author{
VOLUME XII. \\ GENERAL HYGIENE.
}

\section{LECTURES.}

THE PARASITES OF MEAT AND PREPARED FLESH FOOD.

CANDLES. SOAP.

THE HISTORY OF ENGLISH DRESS. CHILDREN'S DRESS. TEXTILE FABRICS. PHYSICAL EDUCATION OF GIRLS. OLD AND MODERN POISON LORE.

\section{PRINTED AND PUBLISHED FOR THE}

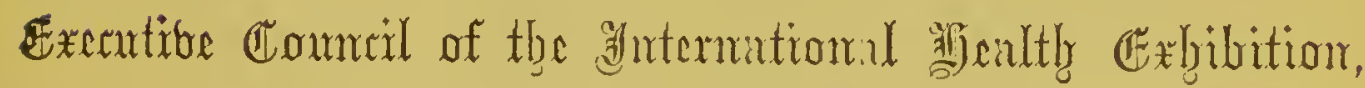
and for thre Coumril of the socictur of Aerts, BY

WILLIAM CLOWES AND SONS, LIMITED, INTERNATIONAL HEALTH EXHIBITION, AND 13, CHARING CROSS, S.W. 
16618

LONDON:
BY WILLIAM CLONES AND SONS,
STAMFORD STREET, AND CARING CROSS 


\section{LECTURES.}

THE PARASITES OF MEAT AND PREPARED FLESH FOOD.

By T. Spkncer CobBold, M.D., F.R.S. . . . • • I

CANDLES. By LEOPOLd Field, F.C.S. • • • • 53

SOAP. By C. F. CRoss . . . . . . . 75

THE HISTORY OF ENGLISH DRESS. By the Hon. Lewis S.

WINGFIELD • • • • • • • • • . II5

CHILDREN'S DRESS. By Miss ADA S. BALlIN • • • . I45

TEXTILE FABRICS. By William MORRis • • • . 173

PHYSICAL EDUCATION OF GIRLS. By Miss ChreIMAN · 203

OLD AND MODERN POISON LORE. By A. Wynter

BLyth, M.R.C.S. • • • • • • • • . 229 



\section{THE PARASITES OF MEAT}

\section{AND \\ PREPARED FLESH FOOD.}

\section{WITH AN APPENDIX}

CONTAINiNg A DESCRIPTIVE CATAlogue OF ONE HUNDRED DRAWINGS OF PARASITES EXHIBITED IN THE SOUTH GALLERY, CLASS VIII., NO. 206.

BY

T. SPENCER COBBOLD, M.D., F.R.S.

CORRESPONDENT OF THE ACADEMY OF SCIENCES OF PHILADELPHIA. 



\section{JUNE I8Th, I 884.}

FIRST LECTURE ON

\section{PARASITES OF MEAT AND PREPARED FLESH FOOD.}

By Dr. CoBbold, F.R.S.

SiR JosepH Lister, Bart., F.R.S., in the chair.

I HAVE the honour to introduce to your notice this afternoon a subject of high importance in relation to the public health, a subject too often disregarded on account of its supposed unpleasantness; but that is a prejudice which is entirely misplaced. In order to profit by these studies, it is important that we should dispossess ourselves of all preconceived opinions, and approach the subject in an attitude of simplicity, with an anxious desire to ascertain the truth; for unless the mind be absolutely. free and unbiased it is impossible to deduce conclusions which shall have substantial and practical value.

This afternoon I propose to deal with a group of little creatures, which we may call earthworm-like parasites, because they happen to have the form and configuration of earthworms. They are for the most part minute. Especially is this the case with the trichina spiralis, which will occupy a considerable part of our time. Now in the little trichina you have an admirable example of a parasite which is directly injurious to man, and I hope before the close of the lecture to be able to find time to say a few. words 
about other little creatures, which are indirectly injurious to man. We can best approach this subject by explaining the origin of our knowledge of it. Nearly fifty years ago, in 1835 , a student engaged in anatomical studies in one of our metropolitan schools observed in human muscles a number of minute specks. These specks excited his attention, and being more earnest than others of his fellows, he went off to see the celebrated botanist Robert Brown, who possessed a microscope, which was a, scarce thing in those days. By means of that microscope he succeeded in extracting from one of these little specks a minute creature. He immediately sent specimens far and wide, and certain of them were sent to the already distinguished zoologist Professor Owen. Professor Owen published an elaborate memoir in the Zoological Society's Transactions, in which he described this little creature, and called it trichina spiralis, a name which must be retained. Hence arose not unnaturally the persuasion on the part of many abroad as well as at home that Professor Owen had actually discovered the worm, and nine persons out of every ten whom we meet still entertain that opinion; it is however the fact, that the parasite was discovered by the present Vice-Chairman of the Executive Committee of the International Health Exhibition, Sir James Paget. I am happy to have been instrumental by careful search into this question in convincing many of the later foreign writers on this point. Previous published statements, especially in Germany, were certainly wrong. It is not often Germans make mistakes, but here they were misled. In the work of M. Chatin, in the recent United States Report by Dr. Glazier, and in other standard works, it is at length acknowledged that the discovery of trichina lay with Sir James Paget. But little did the early investigators imagine that the tiny worm was destined to play so important a rôle in questions of hygiene, of public health, and of state medicine. Indeed, it may be said that even now we should not be in a position to know the full value of these earlier discoveries, had it not been for the subse- 
quent discoveries made by other workers, more particularly by Professor Zenker, who found these little creatures in the act of migration in the human frame, and was the first to demonstrate that they gave rise to serious disease. Science is also indebted more particularly to Professor Virchow, who by his physiological experiments, by his worm-feedings, first of all on a dog, proved to demonstration whence these creatures come, and whither they go. He reared the full grown worm in 1859 . The whole course of development was thus worked out by a series of helminthologists, or workers amongst parasites, and by their joint labours we have now arrived at a positively exhaustive knowledge of the history of the development of this minute organism. But here it occurs to me to remark that if some of those well-intentioned individuals who would put a stop to all experimental researches, because they involve cruelty to a few animals, knew and could realise the horrible sufferings entailed upon those persons who have eaten meat containing these parasites-if they could, I say, witness these sufferings-they would think twice before they again tried to put a stop to those researches by means of legislative interference. Experiments have already been of immense service in regard to the checking of disease. Further investigations, moreover, may yet enable us to stamp out some of the known parasitic disorders, which I do not exaggerate when I say that they afflict not merely hundreds of thousands, but millions of the human race.

I can best, perhaps, make known to you the position in which we are in this relation, if in

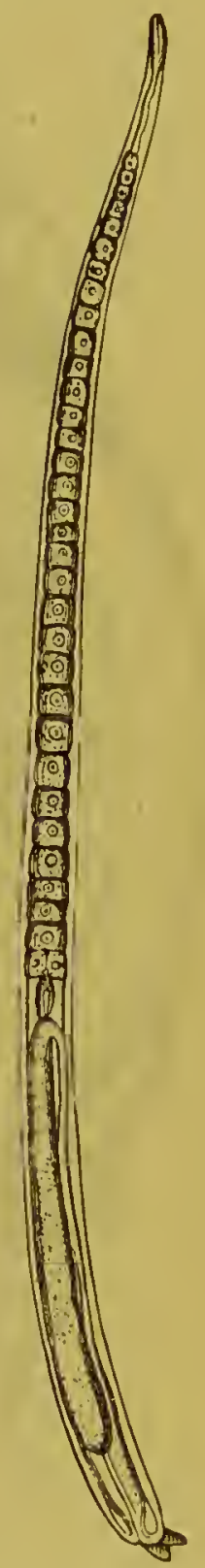

FIG.I.-Trichina spiralis; male, full grown. After Leuckart. the first instance I point to the diagrams on the wall. Herc are two of the six sheets which I prepared during 
the winter for this Exhibition, and the frrst one shows the devclopment of the trichina. Fig. 2 shows these specks

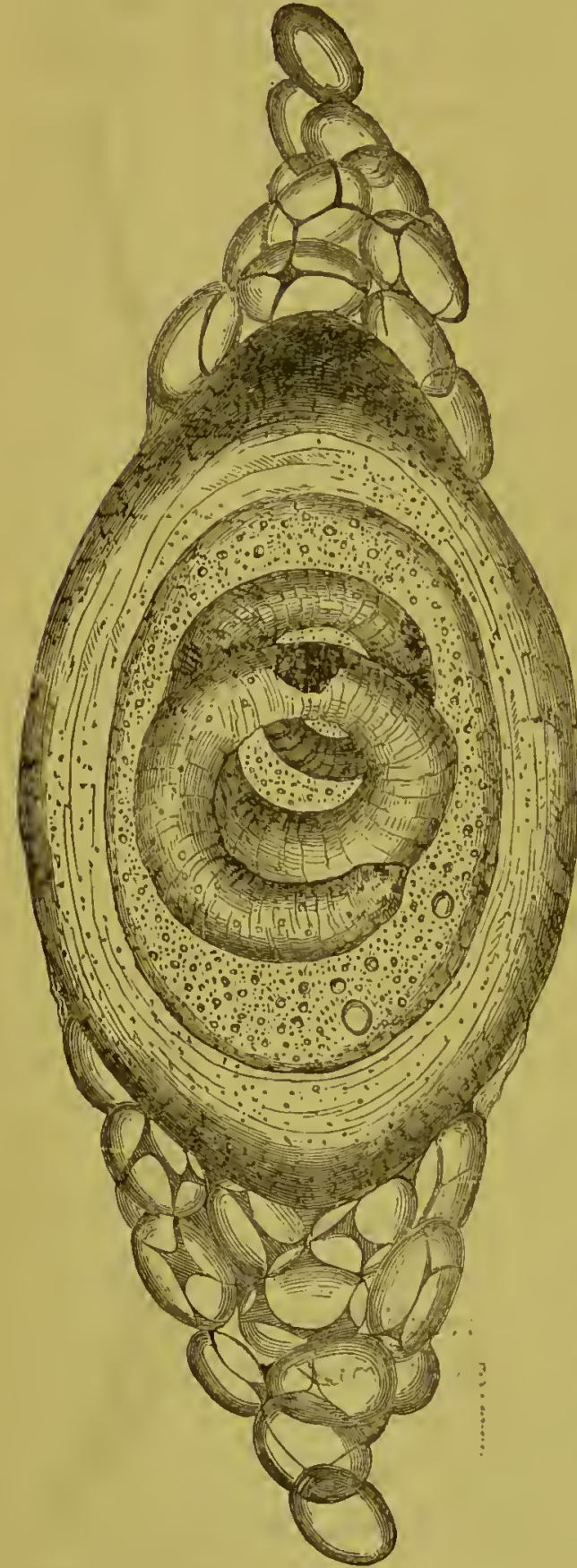

FiG. 2.-Trichina spiralis; larva coiled and Rainey. within its capsule. After Bristowe

enlarged; there are little lemon-shaped particles, and in the interior of each of those is a single worm coiled up, as is indicated by the circular figure at the upper part of the diagram. This is the condition of things which Sir James Paget discovered in the subject to which I have alluded, and to give you an idea how numerous the capsules are, I have here a little piece of human muscle, which I put up some twenty years ago. It is not very thickly infested, but yet if you were to take the trouble to count the number of these capsules, even in this square inch, flattened by the covered glass, you would be able to count upwards of a hundred. But that is a very small number. Please observe that the trichina, as ordinarily known, has a lemon-shaped form. In the diagram you will see that I have two apparently large worms represented, because they are magnified about one thousand eight hundred times. They are the adult or sexually mature forms of the trichina, the male being to the left, and the female to 
the right. What is the size of those specks? About oneeightieth of an inch long only. The little parasites inside the specks are about the one-twenty-fifth of an inch in length. But what of the full grown creature? The male is one-eighteenth of an inch in length; the female being very much larger; she is one-eighth of an inch in length, but that is a creature of gigantic proportions compared with many of the parasitic organisms with which we have to deal.

Now, having explained to you the ordinary appearances presented by the trichinæ in flesh, it will be easy to make

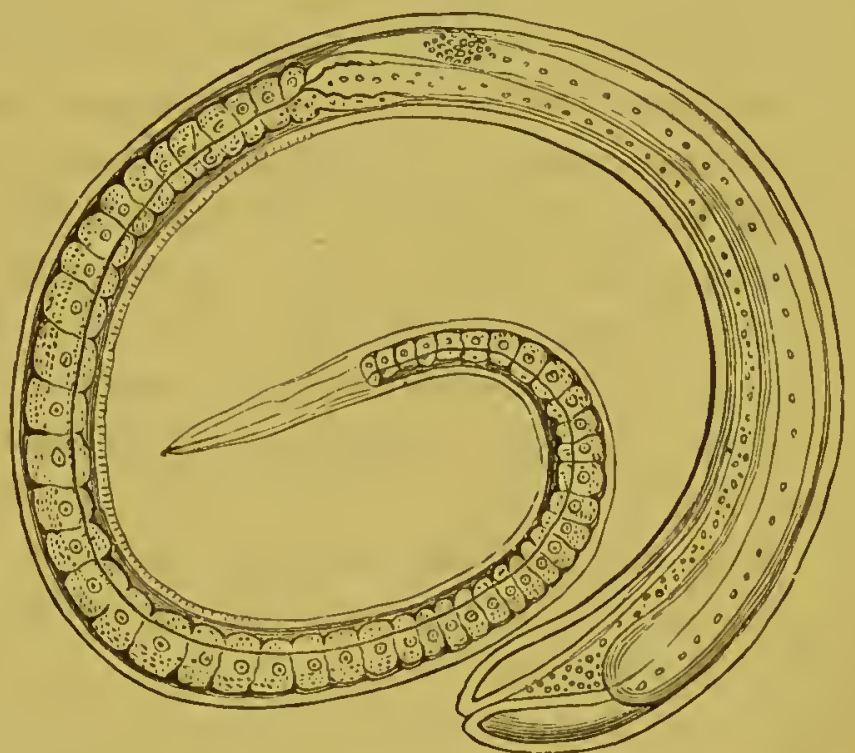

FIG. 3.-Trichina spiralis; young female, or complete larva, from muscle. After Leuckart.

clear to you the life history of the creature; but before I do so, observe that I have enlarged some of the little specks to an immense size. Here you will notice a malformed capsule, not of the ordinary lemon shape, and inside this double capsule there are several parasites rolled up. Such capsules are called poly-trichinous, five, six, or even seven worms being sometimes found in one capsule. These malformed specimens are copied from a recent work by M. Chatin who has been largely investigating this meat question in France. These are from American pork. What 
happens is this:- Supposing you and I indulge ourselves by eating underdone trichinous pork; these little capsules -if there be capsules present, for they are not essential by any means-are digested. Two days (forty-eight hours) after we have swallowed these specks, the little creature becomes matured; it has grown into a full sexually mature worm. There are, in short, males and females. In another six days the eggs and their living contents (which you see there represented on a very large scale), escape in prodigious numbers, myriads, tens of thousands, and they proceed immediately to pass through the walls of the alimentary canal. They stop at nothing except hard bone, and they freely penetrate all those muscles which are nearest to the viscera, those of the thorax and abdomen especially becoming largely infested. In fourteen days more they have acquired the complete larval form, such as is shown in the diagram, and capsules are commencing to form around them. What happens as a consequence of this? You will have five or ten, fifteen or twenty, or for that matter you may have one hundred millions of these little creatures as the result of a single feeding. Let us be modest in our calculations, say ten millions of these creaures are perforating the muscles, groping their way in order to find a resting-place in the host, that is to say, in our frames. The wounds inflicted by these little Lilliputian creatures when collectively considered are sufficient to produce the most distressing symptoms and agonising pains, besides a variety of other phenomena upon which it is quite unnecessary for us to dwell. Here then we have a disorder arising directly from the consumption of meat containing these little trichinæ or specks.

Having explained to you the injurious effects which thus arise, I shall now proceed to speak of certain epidemics. Here let me throw out a general hint that parasites are obnoxious, or distressing to individuals, as a rule only when they occur in great numbers. You understand, it is a question of overcrowding. As distress arises in a city from the overcrowding of its human occupants, so distress arises 
in the human territory itself, when it is overcrowded with Lilliputian inhabitants of this description. Now you are aware that we have what are called epidemics or outbreaks, due to the consumption of these parasites. Let me refer to a few figures here, because it is desirable to be absolutely accurate. I only go to the most recently published memoirs that I have received within the last few days from Germany, and I find that the latest calculations with regard to these epidemics have been made by Dr. Wurtz. According to Wurtz they have had thirty-three epidemics on the Continent, and these epidemics involved one thousand seven hundred and eighty-six sufferers; of this number only one hundred and seventy-three died. You will further find in this connection, that out of thirtythree epidemics no less than twenty-five were distinctly traceable to home-fed swine slaughtered in the Fatherland, and two others of the thirty-three were due to the consumption of the meat of forest animals-boars; the other outbreaks were not traced to their sources. Now you are aware that quite recently we have had an outcry against the consumption of American pork. Why? It has been found that about eight per cent. of American hogs contain trichina, and those persons, it is said, who cat of this pork will suffer. But it must be some satisfaction to you to be told authoritatively that no single case of trichinosis in the human subject has been traced to the consumption of American pork on the Continent, and further it will be interesting to you to know, if you do not already know it, that $M$. Colin has instituted experiments, and has shown that you cannot give an animal trichinosis, even if you feed it with imported American pork known to contain trichina. Why is this? It is because all the trichinæ found in the salted pork sent over from America to this country, to France, and to Germany, are dead. Salting destroys trichinæ, if it is only sufficiently prolonged.

So much for foreign outbreaks, but what about the outbreaks in this country? Have there been any true out- 
breaks of trichinosis in the United Kingdom? If you were to believe what has been written, you would say, oh yes, many instances! Permit me to say that there has been only one genuine outbreak of trichinosis, and that occurred in Cumberland, and was witnessed by Dr. Dickinson. That gentleman was good enough to send for my inspection specimens of the home-fed pork which had been eaten by the family, and I found abundant specimens of trichinæ in it. Now, there is but this one solitary instance, full particulars of which have been placed on record in the Journal of the Society of Arts, as I gave them in a course of Cantor Lectures, which I delivered there some ten or twelve years ago. I need not say more, therefore, on the point. But you will say, have we not heard that there was an outbreak of trichinosis on board the Government Training Ship, "Cornwall," and have we not heard that there was another outbreak from eating sausages at Thaxstead, in Essex? Yes, you have, but neither the one nor the other was a case of trichinosis at all. It is very unpleasant ever to have to correct the errors of other persons, but where one has the interest of the community at heart, and where one above all things is desirous that the truth only should be eliminated, in all such instances one must take upon oneself, after thirty years' toil in this subject, the prerogative of venturing to differ from authorities, who do not happen to have paid any attention to the subject, but yet have pronounced such cases to be trichinosis. Take the case of the "Cornwall," in I879. It was said that a lad died of this disease on board the "Cornwall," and that a great many others were affected with trichinosis. A young gentleman connected with the Local Government Board made what he thought was a discovery, and so it was a discovery, but unfortunately it was stated to be trichinosis. It was not until five months after this outbreak occurred, which was in September I879, that we were favoured with the Government report, and I can state that if the specimens of this alleged trichina had been forwarded to any of us who have any acquaintance with 
the first rudiments of helminthology, we could have settled the question in five minutes. However, we waited patiently for five months, and at length we got the Government report, of which I have a copy in my pocket. I will read the title of it. Here is the report, and you will observe that it is in the usual official Blue Book form. It says, "Report on an outbreak of fever, which proved to be trichinosis, on board the training ship, 'Cornwall."' This was an unfortunate title, because it was not trichinosis at all. That was issued on March 15 th, I880, and very shortly afterwards I wrote to the Times newspaper, stating that the little parasite in question was a totally different creature. I called it a rhabditiform worm-that is a little creature which bears some resemblance to a trichina. If we were to go into the matter scientifically I should be able to convince you that it really had scarcely anything in common with the trichina. Now the mischief did not end there, as my letter to the Times brought down on me a wrathful literary castigation, which I am happy to say I have survived. Unfortunately certain foreign journals, including a New York Medical paper, all followed suit, and reported this as trichinosis. It is really painful to point out these errors, but is it not one's duty? That was the question which presented itself to me, and so the matter was further investigated, and we now all know what the creature was.* It is called Leptodera teres. But another outbreak of trichinosis was said to have occurred in I879 at Thaxstead, in Essex. Unquestionably there was great distress, there was poisoning from eating sausages, and with light heartedness it was at once pronounced to be trichinosis by those who were not really acquainted with the subject. But there was not a single trichina found in that instance, nor any parasite whatever in the sausages. The outbreak was

* In a paper communicated to the Quekett Microscopical Club (of which I was at the time acting as President) I designated the worm Rhabditis Cornavalli, but it has since been shown by Dr. L. Oerley that this rhabditiform worm is the same as that described by Schneider, of Berlin, as the Leptodercteres.-T. S. C. 
due to sausage poisoning, the result of decomposition; for there is a peculiar organic compound formed in putrid sausages, which gives rise to a disease, which has been well described on the Continent, and it is called botalismus. And here let me remark by the way that we are constantly hearing of cases of poisoning from putrid meat, and putrid animal foods of various kinds. Only yesterday evening I read of two deaths from eating tinned salmon in Wolverhampton, as reported in the Pall Mall Gazette. This was a case of disease, due to decomposition and the formation of a poisonous compound in the flesh, consequent upon an opening occurring in the tin, which let in the air, and caused the state of things that resulted in the death of two persons. There are a vast number of little creatures apt to be mistaken for trichina by those who have not studied the subject properly. Some of you may remember that we were favoured a little while ago with accounts of the so-called tunnel trichinosis affecting the labourers in the St. Gothard Tunnel, when it was being constructed. That was a disorder due to a parasite, which has very little in common with the trichina, although it was called "tunnel trichinosis." Here is a representation of the parasite, the ancylostomum; thus, the disease ought to have been called ancylostomosis instead of trichinosis, which is a totally distinct disorder.

We have also had numbers of animals every now and then swept off by disorders which are put down to trichinosis, although the diseases in question have no sort of connection with the subject. If you could realise the numbers of communications one receives asking anxious questions on this subject, you would get a notion of the confusion that exists in the minds of the public generally upon this subject. Trichinæ have been discovered in the pike, in the eel, in mackerel, and in this, that, and the other fish-supposed trichinæ, not one of which has any genetic relation whatever with that dangerous parasite. These have been described as genuine cases of trichince, and it may be some satisfaction to those of you who are fond of 
fish to know that with regard to these little filariæ (these little earthworm-like creatures of which you see an enormous number sometimes in fish that are brought to table), you may swallow any amount of them you please, cooked or uncooked, and no harm can possibly result. I do not say that every parasite in fish is harmless; it does so happen that there are one or two which are not so; but you need pay no regard to these, as they are extremely rare. I was once called upon to give an opinion upon a supposed outbreak of trichinosis near the mouth of the Thames, where a family was severely affected; and, curiously enough, the domestic cat died from what they supposed to be the same disease. I examined the cat, and found it had died of a parasite very like the trichina in its behaviour. It was a totally different parasite, namely, olulanus. The disease, therefore, which sweeps off cats is olulanosis, not trichinosis. Swarms of animals are carried off by these and other destructive little organisms, and the diseases are set down to wrong causes by persons who have not acquainted themselves with all the multitudinous intricacies and nice distinctions which abound in this really complicated and extraordinary subject.

Now we come to another aspect of this question, and that is prevention. How shall we prevent any harm arising from these affections? It is easy enough. Years ago I instituted a few experiments, and Dr. Timothy Richard Lewis did the same in Calcutta, with the view of determining this point, and we came to the conclusion that trichinæ submitted to a heat of $140^{\circ}$ Fahrenheit, would be killed. In this way we ascertained that meat comparatively underdone would be pretty safe, though raw meat, of course, would not be so. But our experiments were rough and poor compared with some recently instituted by Professor Perroncito of Turin. Those temperatureexperiments were made with extreme care, and he found, greatly to our satisfaction, that $48^{\circ}$ Cent. (which is rather less than $120^{\circ}$ Fahr.) is sufficient to kill the trichina. There is, therefore, absolutely no reason why any one should have 
this disorder if only they will take care to have their meat tolerably well cooked. Some very interesting experiments were made by M. Colin lately, with regard to the American pork question, and he finds that two or three days' salting is sufficient to kill all those creatures which lie near the surface of the salted meat, although in large masses of meat it would take two or three months, or even more, for the brine to soak in decp enough to kill those parasites that lie in the centre of such a large mass. All the trichinous meat sent from America that has been examined, has been found to contain dead parasites only. Next comes a question of practical importance in regard to meat inspection. One fact only have I time to name, and I think you will regard it as of interest. You know that in Germany meat inspectors are appointed especially for the purpose of looking after trichina, and recently a Berlin correspondent wrote in one of our medical journals, that of I 54 pigs, the carcases of which were ordered to be destroyed, I4 were so because they contained trichina; but I 40 were destroyed because they contained measles. Please not to mix up the idea of "measles" as having anything to do with the discase of children which goes by that name. This is something totally different. I am not going to say a word this afternoon about measles; but I hope at my next lecture to show you some of these things, and to explain to you their importance in relation to this question. Meanwhile, I have only one more remark to make on this subject. Notwithstanding the remarkable precision and the infinite pains-taking exercised by the German inspectors in this matter, only the other day there appeared an article in a German medical journal by a Dr. Pütz, who really disputes the efficacy of the work done by these inspectors. $\mathrm{He}$ admits that a vast number of cases are found out by them; but he holds that sufficient and adequate protection is not afforded in spite of all these precautions. It seems strange, but it shows that in spite of every care there are always some little points which remain to be explored.

I have dealt thus at length with the trichina, not merely 
on account of the intrinsic interest attaching to the subject itself, but because, by this simple exposition of the facts of trichinosis, I shall be able in the few words that remain to me to explain more clearly the phenomena undergone by other parasites which do not directly injure us. Those parasites which indirectly affect us are of great importance, because they sweep off our flocks and herds sometimes in prodigious numbers, involving the loss in a single season of perhaps two millions pounds worth of food. These creatures are allied to the trichina to the extent that they belong to the same group of which we are speaking today, namely, the little earthworm-like parasites. Most of you have heard of these outbreaks-cattle, sheep, swine and deer dying by scores, not to say by hundreds, from parasitic affections of the lungs. In this way the farmer suffers great loss, and we ourselves suffer in consequence of the increased expense of food; the entire community being more or less affected by these destructive outbreaks. Now, the parasitic lung affections are generally all rolled into one, commonly called the "husk" or filaria disease. We need not be very careful about scientific names here; but let me inform those who have not looked into this matter, that in place of one filaria causing the destruction of sheep, there are four different kinds of filaria, earthworm-like creatures or round worms concerned, let alone other parasites of which we do not speak. On the diagram, I have endeavoured with the aid of a lady who has constructed two of those drawings for me, to give an outline of the structure of these four kinds of parasites. I had better give them some English names, which they have never yet received. On the sheet you see some twenty-nine drawings-Figs. I to 5 refer to what I call the common lung-worm of the sheep -6 and 7 may be called the red-tinted lung-worm; the scientific name for the first, is Strongylus filaria, the second Strongylius mescens; the first is about 3 inches long, and the next is nearly 7 inches long when full grown. Then we have the third group, Figs. 8 to I6 inclusive, Strongylnes paradoxus-you may call it the puzzling or paradoxical 
lung-worm ; and lastly, all the remaining figures, 17 to 29 inclusive, refer to a very remarkable little parasite, which occurs also in the lungs, which you may call the hairlike lung-worm. You will observe two highly-coloured figures; the one below represents a sheep's lung with certain tumours on the surface, in which are rolled up numerous little parasites. This little hair-like parasite bears the scientific name of pseudalius ovis pulmonalis. It is a marvellous creature. Let me try in a few words to describe it. You see a little circle, Fig. I8, representing the worm as if placed under the cover of a microscope slide. Although you see only a little tiny dot marked there, the parasite as I have drawn it is actually magnified Ioo times. The head and spirally coiled tail are represented in Fig. 19, magnified I I,Ooo times. I could not give you the whole figure, of course, because if you were to uncoil this little creature to the full extent, so magnified it would be very much longer than this room; the drawing would be 30 yards in length. But, notwithstanding the exceedingly minute size of this parasite, it produces disease of the lungs, and is almost as destructive as the Strongylus filaria or common lung-worm, which carries off many of the animals of our country. The best way, perhaps, of conveying some idea of the actual size of this creature is this:- If you cut off one inch of a hair from your head, take the hair and split it up into five divisions, each of those divisions would practically represent the creature, when unrolled, in its normal size. It is one inch long, but it is so constantly rolled upon itself, that it looks like a fine speck under the microscope ; it is delicate and transparent like the finest glass; but nevertheless the female is full of eggs, and these eggs are of excessive minuteness. Two of them are figured here, Figs. 22 and 23. To make it at all visible, I have been obliged to magnify the egg 50,000 diameters. Now, Mr. Alois Koch, of Vienna-no relation to the Koch of Bacillus fame, with whose writings our Chairman is familiar, having himself antecedently and successfully worked in the same direction before the Berlin savant's fame was established-has 
published a beautiful memoir on this parasite, but I cannot dwell upon it.* The Strongylus filaria, is the parasite which is so destructive to animals in this country. The Pseudalius is also found here, for I myself years ago encountered it. Now, please to observe further that every one of these parasites, and hundreds of others which we have no time to speak of, has to go through a course of development, precisely in harmony in all its main features, with what I have described to you as occurring in the case of Trichina spiralis. Every worm requires a change of hosts. It must pass from the human territory to an animal in order to complete its life cycle, or cycle of development. Has anyone worked out the development of these lung parasites, which are destroying our flocks and herds by thousands? Has any money been advanced by any society in this wealthy country for any one to carry out these researches? Not one single penny. It is true that the Royal Agricultural Society has done great service by securing the researches of an able man, Professor A. P. Thomas, lately Professor Rolleston's assistant at Oxford, who worked out the history and development of another totally distinct parasite, which gives rise to the rot in sheep ; but that has nothing to do with this series of entozoa. Here are parasites as destructive as the rot-producing fluke and not one single investigation that I am aware of has been made, either in this country or abroad, with regard to their development. We want encouragement in these matters. Years ago an Agricultural Society in England actually did me the honour to keep me in correspondence for three weeks on the subject; but to be candid, when I stated to this wealthy society that the report of the investigation, to be of any value whatever, would cost them $£$ IOO, I never received another communication from them, and thus the whole thing fell through. However, nothing daunted, I

* Herr Alois Koch's memoir, "Die Nematoden der Schaflunge," was originally published in the "Revue fuir Thierheilkunde und Thierzucht," but it may be obtained separately of the publisher ; Wien, Alserstrasse 32. - T. S. C.

VOL. XII.-II. L. 
determined if I could to find a little time to work out the matter independently. Let me explain what I attempted. I worked on a parasite very like the Strongylus filaria, and it is one that lives in calves, being destructive to young cattle. It is the Strongylus micrumes. I will tell you what I did. I took from one of the bronchial tubes of a calf a number of the parasites; the females are about three inches long. From those I removed the eggs with their contained lavece or embryos. I then took the embryos and placed them in some very finely sifted earth, and then I put the earth in watch glasses beneath a bell jar, under which were some ferns growing. By-and-by an earth-worm gained access to one of these little watch glasses. I then examined carefully from day to day the little creatures inside the earth, but they underwent no change of organisationno perceptible change; but I found when I slit the tail of the worll off-an operation which any gardener performs every day, and is not sent to prison for so doing-that the little parasite that had got inside the alimentary canal of the earthworm had undergone a change, had increased in organisation. I, therefore, recognised a further stage, and could report progress. I then took these little creatures -there were only a few from this earth-worm-and I placed those which had advanced thus far on the dew drops on the fern under the bell jar, and then to my astonishment and delight, the activity of these creatures became strongly pronounced. They rushed about frantically to and fro, they increased in size and organisation, and, to cut a long matter short, by-and-by I found that they attained the form in which I could already recognise males and females. Thus far, therefore, that single experiment seemed to be useful. I had not enough specimens to complete the cycle. Please observe that these facts, as far as they go-I do not wish to place any undue stress upon them-may be useful as a guide to others who will in future undertake these experiments. Let us now deal with the facts which agriculturists tell us about their flocks. Here is a curious and interesting point; Mr. 
Beulah, a farmer at Brigg, in Lincolnshire (the only farmer I was ever acquainted with who was familiar with the use of the microscope) in a paper read before the Quekett Club, of which I was President at the time, stated some very interesting facts, which $I$ think you will see harmonise with the results obtained by my single experiment. He had a flock of seventy-two sheep, seventy of which were turned into a meadow on one particular day; eight days after, those sheep were all affected with the so-called husk or parasitic bronchitis, or parasitic pneumonia, call it what you will; and every one of them died. Two of the sheep were not allowed to enter the meadow, and they remained perfectly well. They did not graze there, and they did not take the disease. Clearly here was a case where the animals had contracted disease by feeding in a particular meadow. Now Mr. Beulah, like a sensible microscopist, went into the meadow, took up some of the grass and placed the dew of that grass, the moisture of the herbage, under the microscope, and he found that dew swarming with little creatures, little microscopic round worms, earthworm-like creatures, which from his statement appeared to correspond in almost every particular with those I had reared on the fern leaves under the bell jar. Putting, therefore, two and two together, I think we have made out a good case for further research.

I will only add in this connection that the parasite Strongylus flaria, of which I have a female specimen in my hand, is estimated by Mr. Beulah to contain-he counted themthree hundred thousand eggs holding young worms or embryos in its interior. Therefore, imagine if you can, for a single moment, the enormous amount of egg distribution which occurs from a flock of sheep carrying tens and hundreds of thousands of these adult parasites, every one of which gives forth three hundred thousand little lung parasites.

I will add one word more only, and that is this. If you cannot call these studies about parasites either beautiful or good, you must at least admit that they are true, and whatcver lcads to the enunciation of truth must in the long run 
be of benefit to the human race. Were you even to cast aside all utilitarian aims, all questions of public health, pounds, shillings and pence, and such like matters, there yet remains for those of us who devote our entire lives to these studies, those satisfactions, those experiences, those delights, which every cultured mind experiences when it is made the recipient of the inrush of new ideas, new conceptions, new convictions, and new knowledge in every form, based upon personal, continuous, unhasting and unresting scientific labour and research.

The Chairman, in proposing a vote of thanks to Dr. Cobbold, said it must be very satisfactory to them, and to the public also who would read the lecture, to hear on his high authority, that the much dreaded trichinosis could be so easily warded off, and that this disease, which had so much exercised the minds of our neighbours on the other side of the channel, was in reality never produced by American pork. He could easily understand that some, while admitting the importance of these studies, might be inclined to commiserate the Doctor on account of their repulsiveness. Those, however, who had witnessed the enthusiasm with which he had described some of his own researches, would feel that Dr. Cobbold stood in no need of commiseration. They would understand how even the most unpleasant and the most repulsive objects in nature became invested with the most intense interest when investigated by the light of science. They might be sure, therefore, that Dr. Cobbold in every fresh discovery he had made had experienced the most intense intellectual pleasure, whilst at the same time he felt that he was labouring for the good of his fellow creatures. 


\section{JUNE 25TH, I 884 .}

\section{SECOND LECTURE ON}

\section{PARASITES OF MEAT AND PREPARED FLESH FOOD.}

By Dr. Coвbold, F.R.S.

Sir Lyon Playfair, F.R.S., K.C.B., in the chair.

THOSE of you who were present at my previous lecture will remember that we dealt with a group of parasites, earthworm-like in form, and I sought to show you how these minute organisms were directly on the one hand, and indirectly on the other hand, injurious to man and beast. This afternoon I have to direct your attention to an entirely different group of creatures, more formidable in appearance and in some quarters of the globe, at least, even more destructive to human life. I allude to those singular parasites which are commonly called tape-worms and bladder-worms. The full grown worms are so-called because they have for the most part a tape-like form. Those that are round and bladder-like are the larval condition of the long creatures called tapeworms; but amongst scientific persons they receive a variety of names, some few of which we cannot escape using. Thus we speak of measles, which have nothing to do with the disease commonly so-called; but they are little vesicles, or small bladder worms, and we speak of the larger ones as hydatids, which are well known to those distinguished surgeons whom I see present. 
Now, it is important to observe that meat is oftentimes sent to market containing these creatures. Beef and veal, pork and even mutton, are liable to contain one or other of them. Even venison is not free. All kinds of venison may contain certain of these worms, and I have myself removed specimens of larval tapeworms from the flesh of the giraffe. I mention this because, although we do not obtain giraffe often as food, I have myself dined off giraffe, and can testify that its flesh is exceedingly delicate and nutritious. Some, perhaps, will say, why speak to us of these creatures which we are inclined to regard with a feeling of aversion? For the best of all reasons, because experience has taught us that when we bring the light of science to bear on natural phenomena, which for the untutored and barbaric mind produce something like a feeling of horror, all that savours of mystery quickly evaporates. As ghosts which are creations of the imagination disappear by ordinary candle-light, so the horror attaching to these things disappears when the torch of science is brought to bear upon them. It is in the scientific attitude that we must approach this subject; and let me, at the very outset, say that, but for experimental researches conducted on various animals, no good could have resulted from helminthic studies. Our feeding and other experiments, not necessarily involving vivisection (as the Chairman who has so well advocated our cause and labours in the House of Parliament well knows) form a necessary means of combating disease. It is on such grounds that instead of hiding our heads, ostrich-like, when the enemy appears, we think it a better policy, and a more ennobling one, to face the facts, to deduce our conclusions, and if possible, to stamp out the disorders arising from the action of parasites.

With these introductory remarks, I have to ask your kind attention to some of the more patent and obvious facts which meet those of us who look for these things in every day life. Three parasites especially concern us, one which is called the beef tapeworm, because it arises from 
the consumption of beef, another the pork tapeworm, because it arises from the consumption of pork, another, the hydatid-forming tapeworm, because in the larval or immature condition it forms large vesicles called hydatids. Most singular and most interesting are the facts of development in connection with these creatures. They may appear to

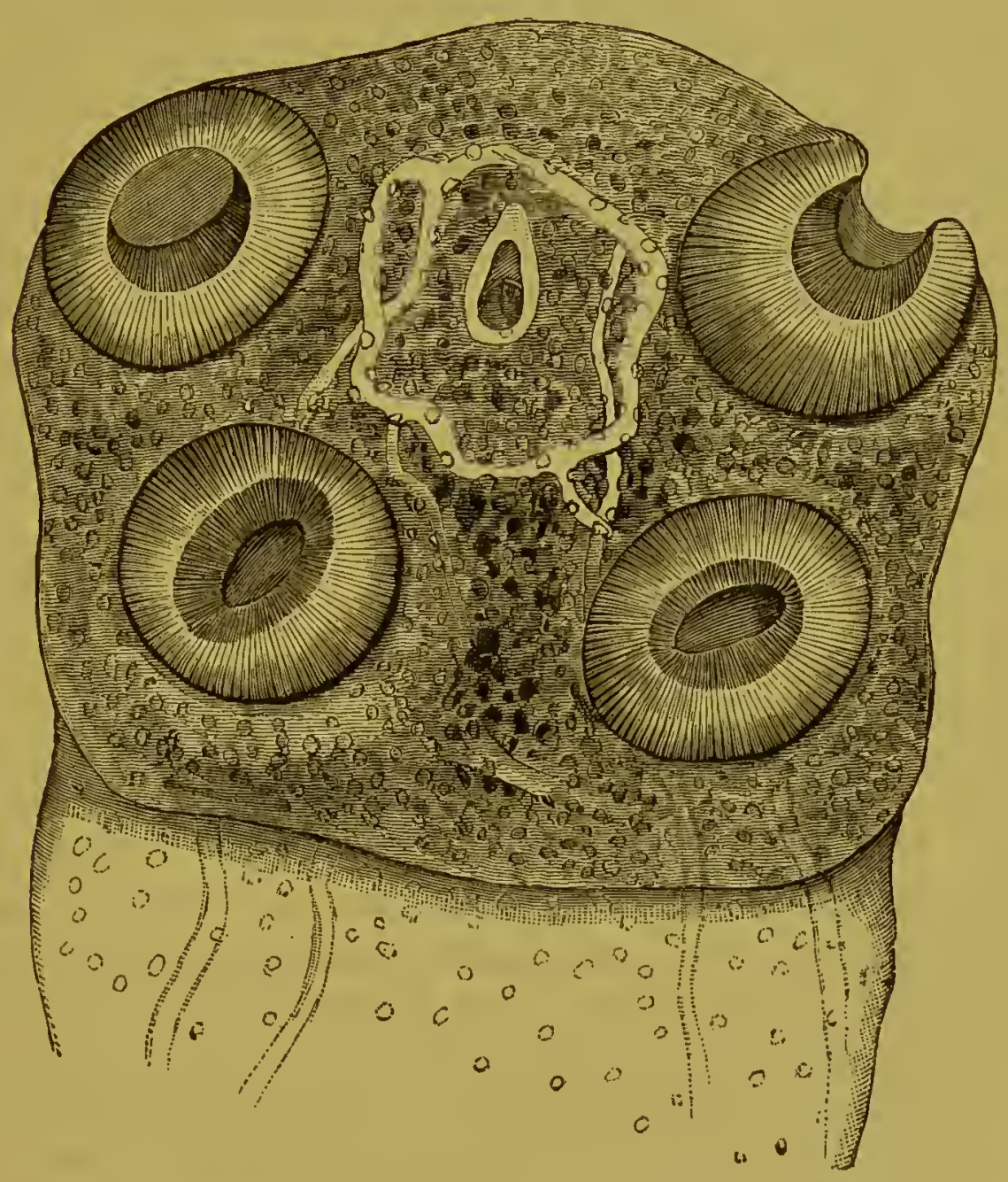

FIG. 4.-Head of the beef-tapeworm (Tania mediocanellata). Original.

some uninviting; but the phenomena of tapeworm development are in strict harmony with the facts observed by biologists amongst the more beautiful creatures known as compound medusæ or colony-forming jelly-fishes, which float on the ocean and attract the eyes of those who cross the mericlian to visit forcign lands. Observe 
the characters of this beef tapeworm. Here is a photograph of the natural size of a specimen, which is 24 feet in length, and by no means an exceedingly long worm. The so-called head is succeeded by a long neck and chain of segments together forming the so-called body. We cannot help people calling things by misnomers, by terms which convey wrong ideas and false conceptions of the true economy of these beings, and, therefore, it is needful that I should explain that the so-called head is not a head, it has nothing in common with a head, it is not even furnished with a mouth, much less with eyes and other organs. The tapeworm is a multiple creature. The head is adapted to anchor the rest of the creatures which form the chain of individuals to a portion of the alimentary canal of the human being. The head

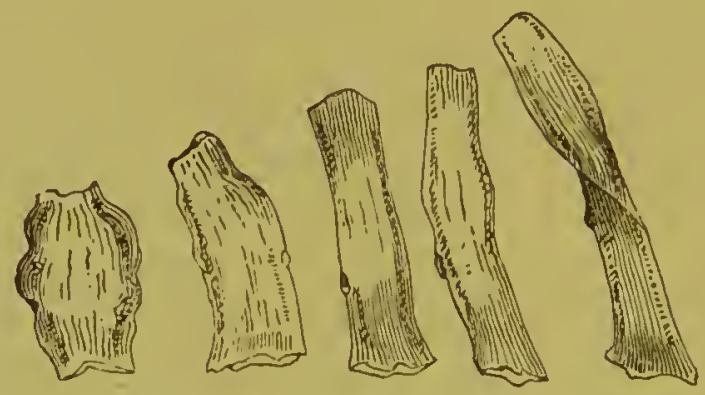

FIG. 5.-Group of zoöids or free proglottides of Tienia mudivinnellule.

After Leuckart. Natural size.

is a holdfast comparable to the float of the Portuguese man-o'-war, one of the compound medusæ of which I spoke just now. The tapeworm, which is an enlargement of this photograph, comprises I,250 zoöids, that is to say, separate individuals. They are arranged in single-file one below the other, and they all bud off from the head in succession, until in the course of two months the entire colony is formed. When it is perfect, each separate zoöid or individual passes off from the colony or chain of individuals, or goes about on its own account, passing a sort of semiindependent life in the outer world.

Now observe what all this means. Any one of the links, 1,250 in number, contains at one time, when perfect, fully 30,000 eggs. The $1,25^{\circ}$ are re-formed, to use round 
numbers, every two months, and the human bearer of this creature is thus made involuntarily to distribute per vias naturales, eggs to the number every year, of upwards of I 80 millions. It has been calculated-not by me-that 40,000 persons in London have the privilege, shall I say, of playing the rôle of host to these unbidden guests, because they persist in eating the roast beef of old England in an uncooked or underdone condition. That means, if you please, and I have taken some care not to exaggerate-the escape of 7 billions of germs in the form of eggs into the sewers, and if fresh sewage is distributed over the earth's surface, over our pastures, and fields, and meadows, all the cattle grazing in such infected localities, may get that parasite, and the result is, that in three months after such grazing, they have a condition of muscles such as you see figured in the diagram. It represents the left hind-quarter of a calf in which I reared these creatures by experiment. Here are some specimens on the table, which anyone can examine for himself, to see if the illustration is correct. These creatures are scattered broadcast, and they are so numerous in India, where they abound far more than they do here, that we may find in a single pound of flesh measles enough to give the tapeworm-parasite to half a regiment. This results from the habits of the people. I see present a medical man from India, Dr. Fleming, who sent me spccimens from an animal slaughtered in the Punjab for rations, I lb. of whose flesh from the psoas region contained no less than three hundred of the larvæ. There were measles or cysticerci enough to infect half a regiment, supposing each man only swallowed one tapeworm-larva. See what we have done in order to make this matter clear. You must not imagine that our neighbours on the Continent have done all the experimental work. Permit me to say, without egotism, that I have performed more expcriments with the beef-tapeworm than anyone on the Continent, in fact, as many as all of them put together. These experiments were performed before recent legislation dealt with the question of cruelty to 
animals. I have not repeated them since. What happened was this. I took some of the segments and fed a calf with them. When these eggs, say 30,000 to the segment, are conveyed to the stomach of the animal, they are liberated, and the gastric-juice acting upon their remarkably thick shells, dissolves them. The egg is exceedingly minute, only about $\frac{1}{800}$ of an inch in diameter. Out of the shell escapes a little creature with six hooks, two in the centre to dig with, and two pairs, one at each side, to tear with, and when these embryos are liberated in the stomach of the animal, they go on their migratory journeys. They pierce directly the walls of the alimentary canal, and make their way to the muscles. When they have got there they probably feel very comfortable and take a more or less prolonged rest. Whilst the young parasites are at ease, it is quite true that the host has been suffering. If a very large number have been swallowed by an animal, he feels a certain amount of irritation but the disease very rarely terminates fatally. When he recovers himself, which is usually the case, if you examine the flesh a few months afterwards you may find in one muscle alone, of the slaughtered animal, as many as 120 measles at the surface. Now if that animal had been sold to a butcher, sent out by him to different customers, anyone swallowing one of these larve is likely to contract a tapeworm. If he partakes of the meat in an uncooked condition, he will have this creature develop within him in less than three months-in two months, or say ten weeks. You will observe that the measle, which is called Cysticercus bovis, has a head furnished with four suckers and a little rudimentary fifth sucker by which it is destined to hold fast to the intestine. The measle is of no use to the ox or calf; but when it is liberated, and when it passes, with the beef which we eat, into our own stomachs, and the cyst is digested, then it fastens itself a few inches below the pylorus, and develops into a long tapeworm. We could not by any possibility have known of these facts, unless we had indulged in experiments, which have thus enabled us to point out whence these 
creatures come and whither they go. We have yet to see how they are to be avoided. Another fact only I notice in this connection. I have here figured the heart of a calf experimented upon, and you will cbserve that the substance of the wall of the heart itself is swarming with these creatures. We might almost imagine that the great Shakespeare himself must have been acquainted with parasites,

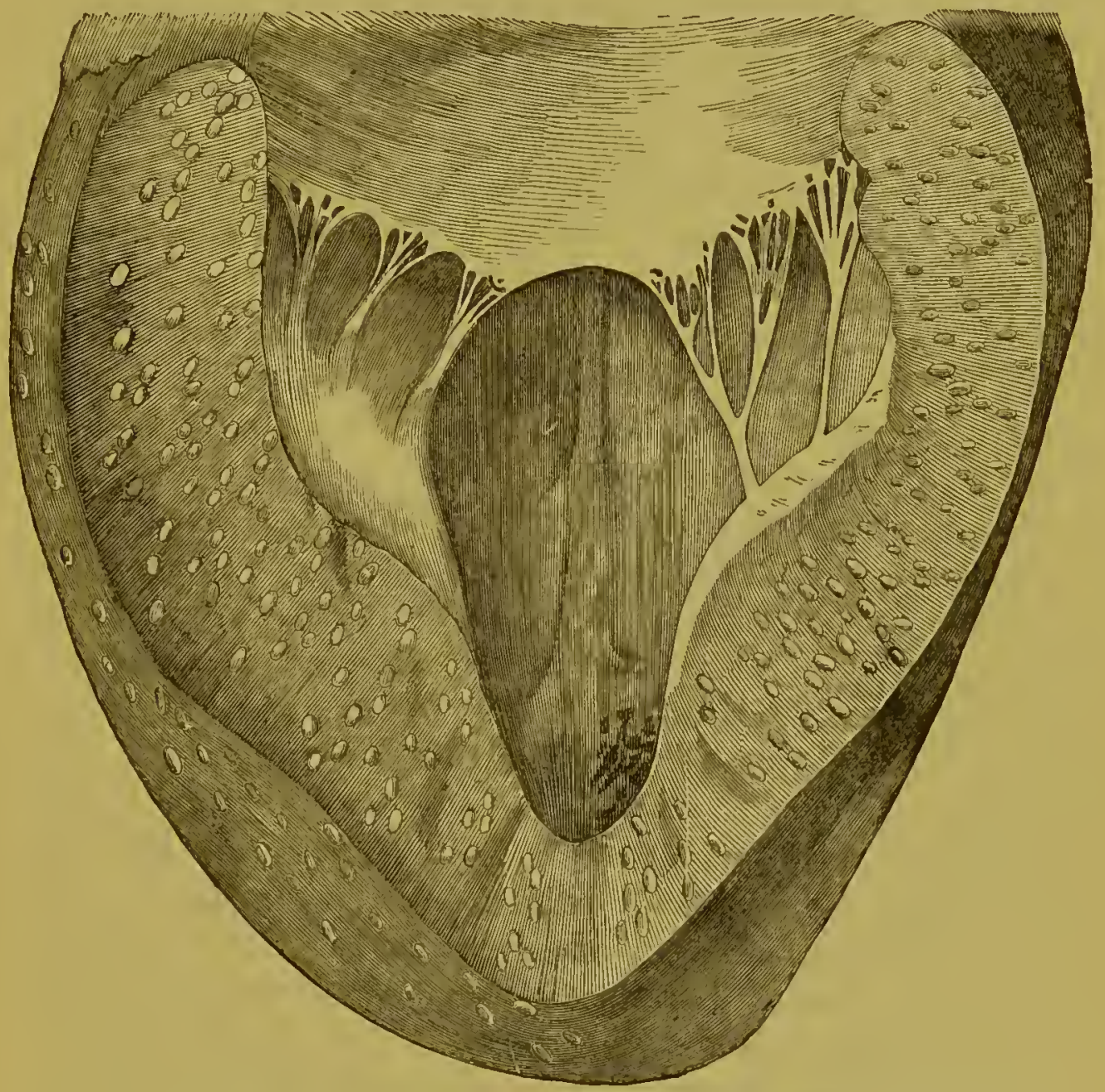

Fig. 6.-Part of the heart of a calf occupied by larvæ (Cysticercus bovis) of the beef-tapeworm. After Mosler. Natural size.

when he remarked that it is 'evil things that do fastest propagate.'

With these remarks on the beef tape-worm, I pass to the consideration of the pork tape-worm; but before I do so, it is as wcll to state a fact of practical interest. We want. 
to realise what is the proportion of animals containing these parasites. Of 13,8 I 8 beasts slaughtered in the Punjab during a certain year, as many as 768 , that is $5 \frac{1}{2}$ per cent., contained these creatures. Many delusions abound concerning the so-called pork tape-worm. If you cast your eye down the list of human entozoa, there you will see amongst the cestode parasites the Tenia solium, or pork tape-worm. Now the Tania solium, as far as my experience goes, is comparatively rare in this country. Out of many hundreds of cases of tapeworm I have only encountered it in about 3 per cent.; 97 per cent. of such human tapeworms belong to the beef tape-worm, and come from eating underdone beef; and only 3 per cent. come from eating underdone pork. But then you must bear in mind that my experience chiefly concerns the wealthier classes of the community; for amongst the poor, who are very fond of pork, and who do not scruple to eat it in an underdone condition, the relative percentage or proportion of pork tape-worm cases is much greater than that of beef tapeworms. Still, taking one set of cases, with the other, I believe that not 25 per cent. of the whole 40,000 cases supposed to exist in London at the present moment are referable to the pork tape-worm. It is fortunate for us that the pork tape-worm is comparatively rare, for it is a dangerous parasite. No one has ever seen a larva of the beef tape-worm migrating in the human frame, but the pork tapeworm behaves very differently. I suppose we must tell the whole truth, and therefore, at the risk of exciting some alarm, I will say that the larva of the pork tapeworm, the Cysticercus cellulose, has a disagreeable habit of passing to the vital organs, and even to the brain itself. I have several specimens here from the human brain. They caused the death of their hosts.

Perhaps you are inclined to speculate a little here. I fancy I hear someone saying, "I can now understand why pork was forbidden to be eaten in olden times;" and certainly we may all agree with the Jewish lawgiver that the swine is an unclean beast; but it is a delusion to imagine 
that swine are more infested by these parasites than cattle. In foreign countries it is just the reverse. For in the remote East, that is to say, as far east as Siberia, where Cossacks eat their meat in an underdone condition, almost everyone is a host of the tape-worm of beef. The prohibition of pork was a wise hygienic measure. I share this opinion with Küchenmeister, who in his biblical researches was aided by an eminent Hebrew scholar, M. Michël Dr. Küchenmeister came to the conclusion that the prohibition

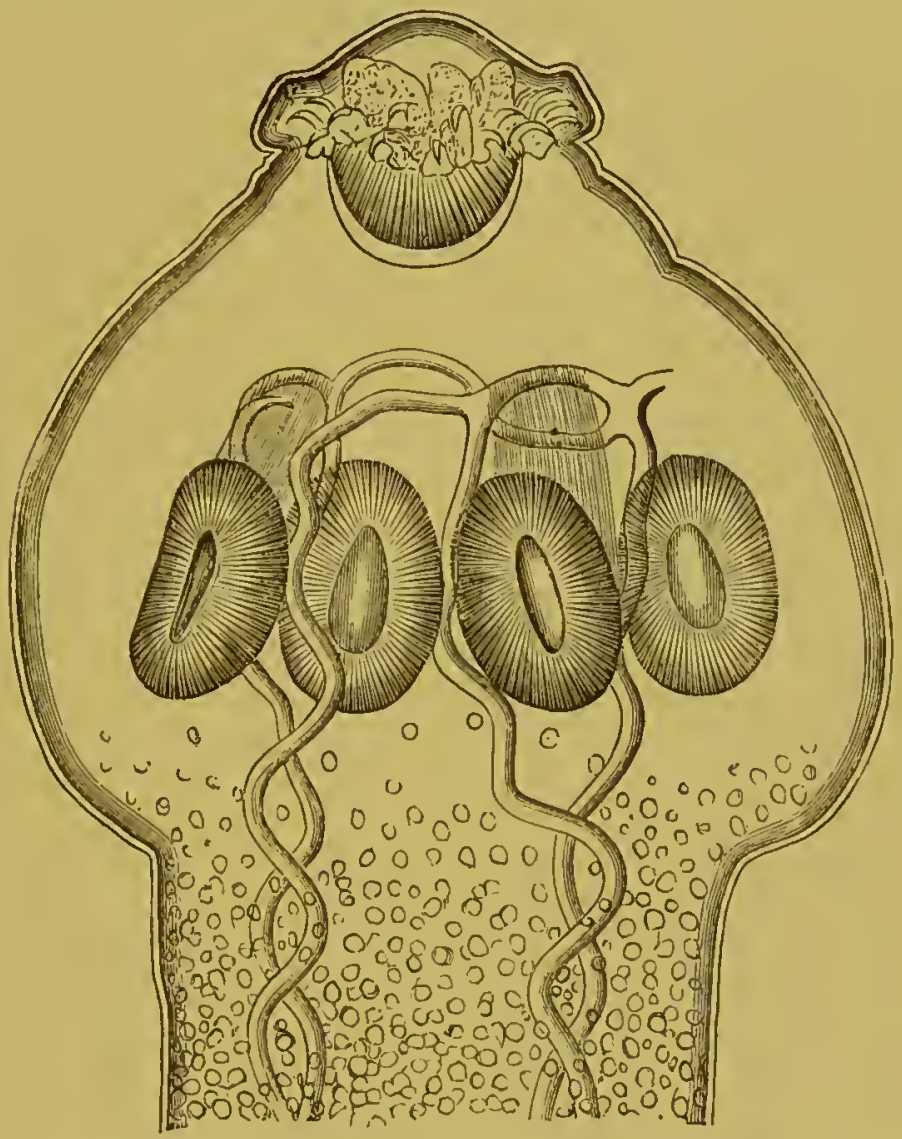

FIG. 7.- Head of the pork-tapeworm (Tania solium). After Van Beneden.

really depended on the fact that in eastern countries the flesh of swine had been observed to be swarming with these parasites; it is also worthy of remark that the flesh of other prohibited animals is apt to contain measles and similar parasites of this kind. The Mosaic record is valuable in many ways; and the parasite which is described by Moses as the fiery serpent figures on our list as the 
Guinea worm. A most admirable description is given of the behaviour of the creature, and of the misery it produces on mankind by the production of those burning fiery pains which appear to have suggested the name. Now to pass on to another matter altogether. When you purchase a Westphalian ham, examine it to see whether or not it is swarming with parasites. A gentleman sent me part of a Westphalian ham which was so crowded with examples of Cysticercus cellulose, that you could not place the blade of a knife into any part without running' two or three of the parasites through the body.

I pass on to another phase of our subject. I have said that we have two common tapeworms, namely the Tania mediocanellata and the Tania solium; but there is a little parasitic creature, which lives inside one of our domestic pets, the common dog, that is of the greatest importance. The tapeworm in question is called the Tenia -echinococcus, the larve of which infest man and animals, and are commonly known by the name of hydatids. These hydatids vary in size, from a pin's head up to that of a cricket ball, or even larger, and their prevalence is far greater in some countries than in our own. It is not uncommon for those who have their eyes about them, to encounter them in meat. I have on seven separate occasions seen measles in joints of mutton. The mutton measle is very like the Cysticercus cellulose, and a former colleague of mine at the Middlesex Hospital once brought me a mutton chop, which he was going to enjoy at a restaurant. In the centre of the chop was one of these Cysticerci. It is by no means uncommon for us to find hydatids in flesh served at table, and here it occurs to me to tell you that some droll experiences are occasionally encountered by those of us who work in this singular branch of biological science. Not a few have occurred to myself. During some experiments which I was making with a view of ascertaining whence these creatures came, and whither they went, I had an assistant who observed with care the facts of development of the parasites in a 
dog. We had fed the dog with some hydatids, to see if we could rear any tapeworms. Shortly after I observed that the attendant became very serious; and presently he said to me, "Sir, I have had my misgivings since you performed that experiment. I have had an uncomfortable feeling in the throat, and I really believe I have got, what you scientific gentlemen call the Echinococcus." I soon persuaded him that he was under a delusion; but that little incident was capped by another, which is certainly to the point. I was at a restaurant one day, and having ordered a plate of meat, immediately observed upon it the hydatid, which we call Echinococcus veterinornm, so familiar to veterinary practitioners. I said to the waiter, "Step this way, look there!"- "What is the matter, Sir ?" he said. "What is the matter!" said I. "Look there." He replied, "I do not see anything amiss." "Well," I added, drawing myself up, "you have brought me an Echinococcus." I need not dwell upon the alacrity with which the waiter and the Echinococcus disappeared. But I am now speaking of the Tania echinococcns of the dog. This, instead of being a large cestode parasite many feet in length, is so small that I have here on a microscopic slide one or two full grown creatures, measuring only a

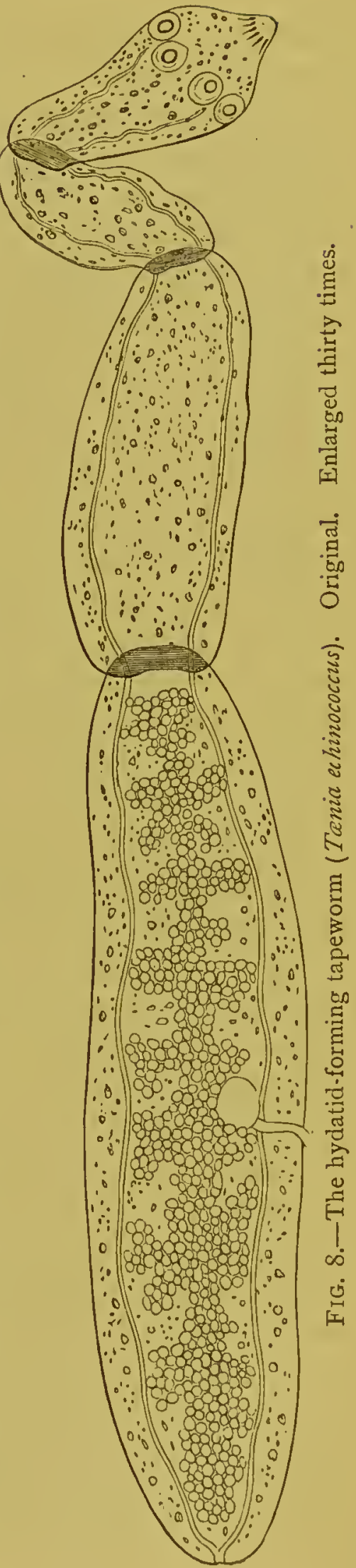


quarter of an inch in diameter from head to tail. This particular specimen was sent to me nearly thirty years ago by that eminent helminthologist, Professor Leuckart. Nine other kinds of tapeworm infest the dog. This worm is only a quarter of an inch in length and is very simple in its construction. It is reduced to a head, which is the uppermost zoöid, converted into an organ of anchorage, the second being a small zoöid, the third a little bigger, and the lowermost a ripe or perfect zoöid. A sexually mature zoöid when filled with eggs, contains probably 10,000 in number. Now, when a dog happens to be infested by this little parasite, wherever it goes it distributes the eggs of this parasite, in ways which I need not explain, but which must be palpable to every one. These eggs malie their way amongst the herbage, and are carried about by divers agencies, wind, rain, and even insects. The grazing cattle swallow the eggs. In about three months after that-though it is pretty nearly fifteen months before the parasites are fully developed - the organs of their bodies become stuffed with juvenile hydatids. From the little eggs which have undergone digestion in the stomach of the cattle there have escaped multitudes of six-hooked embryos, and these having passed through the coats of the stomach, have at length settled down in the liver and other organs. The figures on the diagram display these vesicles in great numbers. A little lower down is the liver of a full grown hog swarming with enormous hydatids. Another figure is that of the liver of a pig which was only four months old. How did these parasites get into these creatures? They came there by the animals swallowing the eggs, which had been distributed by the dog. Those hydatids, when they are perfectly developed, contain what are called Echinococcus heads. The head is something like the head of an ordinary tapeworm; it has a double row of hooks, and four suckers. The heads are very numerous; you may reckon 10,000 in one hydatid. Now, supposing a dog werc to swallow one of these hydatids from the liver of a pig, every one of 
the heads which that hydatid contained, whether it was $1000,10,000$, or 100,000 in number, would in the course of seven weeks develop into the hydatid-forming tapeworm. I have a portion of the alimentary canal of a dog, in which tens of thousands of tapeworms were reared by experiment.

Here let me remark upon a matter which should, I think, interest every one present; from a philosophical point of view it is worth referring to. When you get an egg from a highly organised being like a fowl, you know that out

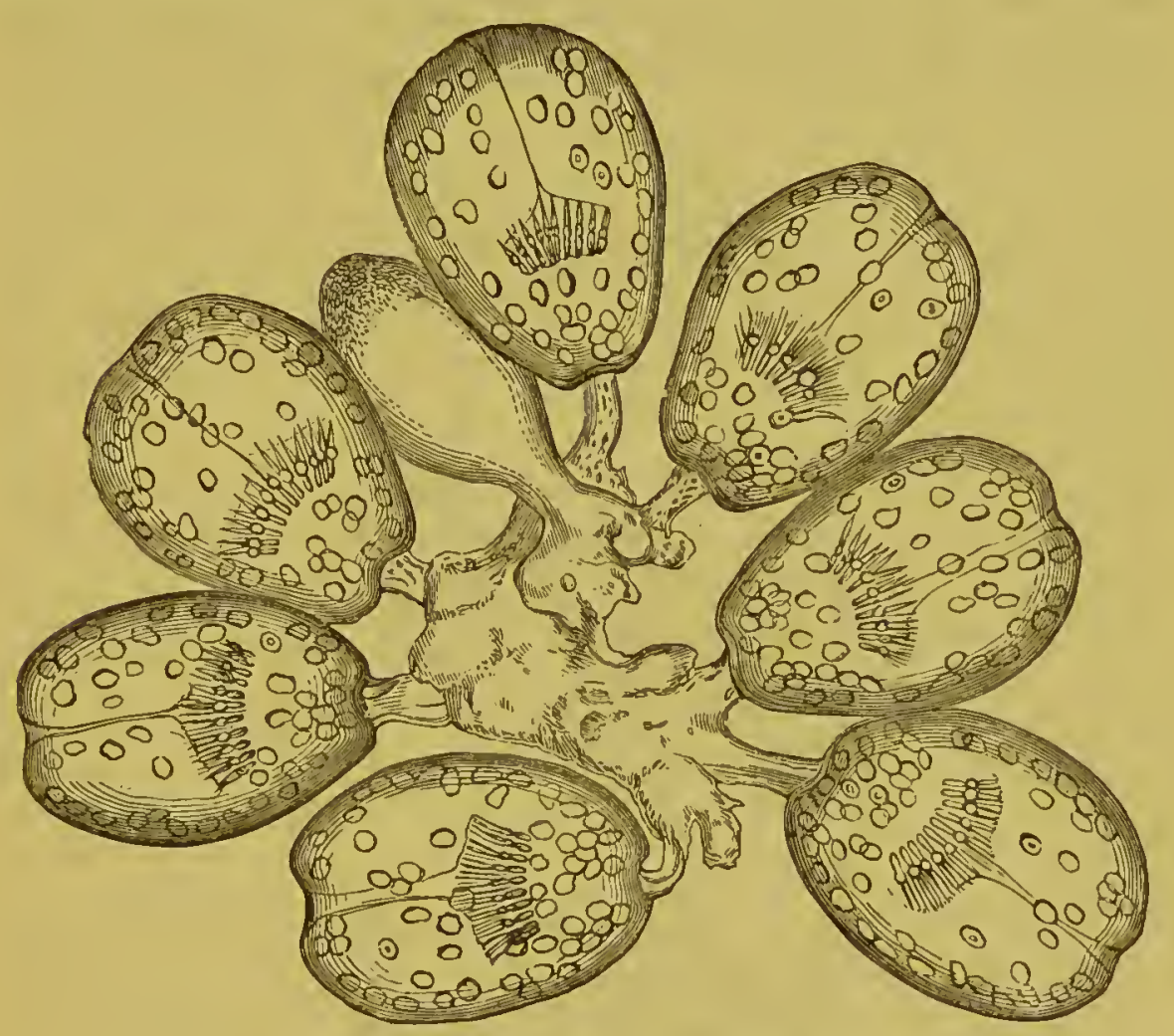

FIG. 9.-Group of Echinococcus-heads, from the interior of an hydatid.

After Busk. Magnified 250 diameters.

of that egg only one creature will come-the sum total of the products of a single egg forming what is called the zoological-individual. Babyhood, youth, manhood, and old age in ourselves are one and the same individual zoologically, although there may not be a single particle of matter now in our frames which existed when we were children. The egg of a tapeworm produces many individuals. Thus the egg of this Tania echinococcus develops

VOL. XII.-H. L. 
into one liydatid, and that hydatid may contain 10,000 heads, and as every one of those heads is destined to become a tapeworm it follows that in place of one of those eggs producing a single individual, you may get at least io,000 creatures.

Now there would be no raison d'être for our experimental labours if, by these labours we did not hope to put an end to suffering in mankind and animals. That is or ought to be the prime motive which animates us in all our work, and you will see that we have indeed a reason for this. Consider for one moment the prevalence of these parasite

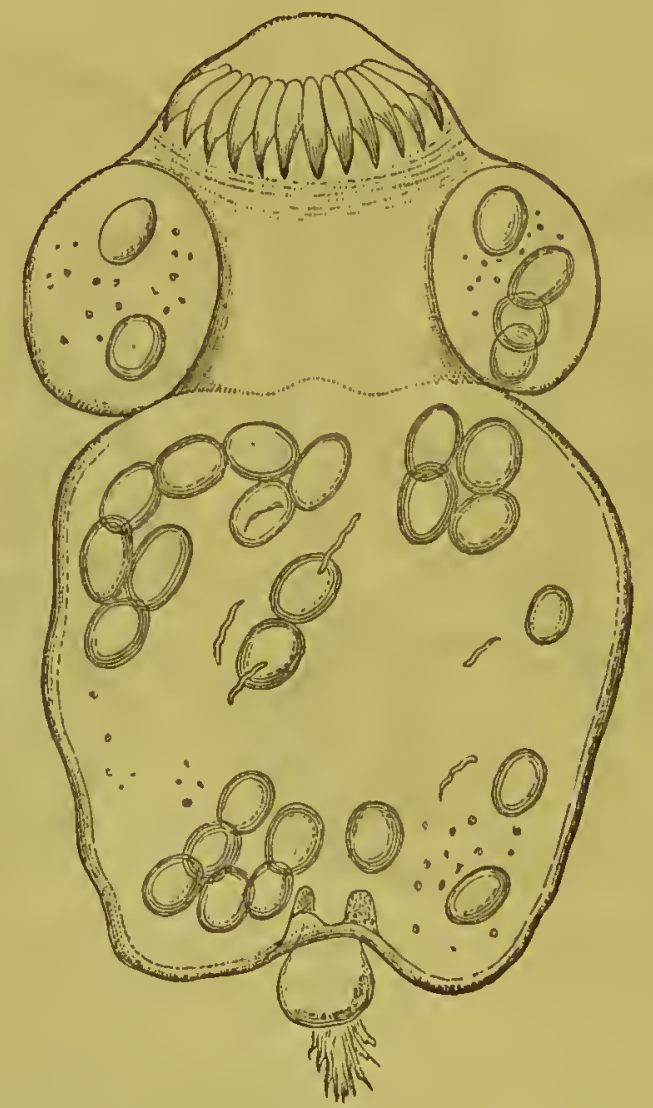

FIG. 10. -Echinococcus-head, isolated. After Huxley. Magnified 500 diameters.

creatures in India and elsewhere. In India, out of 2,109 animals slaughtered at Mooltan, 899 had got these hydatid parasites, and nearly all of them occupied both the lungs and the liver; they were in the liver in 829 and in the lungs in 726 instances. Now, how is this to be accounted 
for? How does it happen that Indian animals are so much infested? For the reason that the habits of the community in Hindoostan are not so highly civilized as obtains in this country. The eggs of parasites are scattered broadcast all over the country. If you go down to the side of some of the tanks and take an ordinary teaspoonful of the mud, and place it on a slide under the microscope, in some places you may actually find ova of parasites. Animals going down to drink of this water, swallow the eggs, and in a certain number of months the hydatids develop themselves in their interior. Is not this kind of instruction practical? Is there not a raison d'etre for our action, in trying to put a stop to disorders of this kind? But what obtains in India, is eclipsed by what occurs in Australia. There this disorder, the hydatid disease, is on the increase, and a work has recently been published by Dr. Thomas, of Adelaide, which is full of the most interesting details. The deaths in Australia from this cause are far more numerous than in this country or in India. It is in Iceland, however, that the prevalence of this disorder culminates. Dr. Krabbe killed Ioo dogs for the purpose of ascertaining the prevalence of the hydatid producing tapeworms in the Island, and his investigations showed that 28 of the dogs had the Tenia echinococcus. It, therefore, follows from this circumstance that the eggs are scattered broadcast every day, and as the result of this, the cattle not only get infected, but unfortunately the inhabitants of Iceland suffer by, the invasion of these parasites to such an extent that fully one-sixth of all the persons who dic annually there, perish from this parasite. There is indeed reason, therefore, why we should continue to investigate.

Now I come to the last part of my subject, namely that which deals with the question of prevention. The first thing which will occur to anyone who has thought the matter out, is that it is of the highest importance that meat-inspection should be conducted by competent persons. I confess to feeling some amazement when not many years 
ago I read in a paper that the meat market in Dublin was inspected by two policemen. I believe that all this is changed now. But for what reason these worthy men should have had so important a function as the inspection of meat added to their ordinary duties, is one of those things which I have never been able to comprehend. Clearly, every inspector of meat markets should have a thoroughly exhaustive and absolutely scientific knowledge of all questions relating to the diseases of food. If it is supposed that these gentlemen, many of whom are amongst the most cultured members of the profession to which I have the honour to belong, are competent to deal with this question in its entirety, I beg to state that during the past thirty years I have received scores, hundreds, I may say, without exaggeration, thousands of letters from people demanding information about parasites. Many of the inquirers were officers of health. I have received specimens of meat alleged to be swarming with parasites, which nevertheless contained no parasite. I have received other meat which was supposed to contain dangerous parasites, which really only contained perfectly harmless ones. Here it naturally occurs to one to ask how it is possible that gentlemen appointed to these offices should recognise parasites when they have never at any of the medical schools received any course of instruction in such subjects as helminthology. At the Royal Veterinary College I have for the last ten years been giving forty lectures every winter on the parasitic diseases of animals; but I know of no medical school in the metropolis, or anywhere else in this country where anything like systematic courses of instruction are given on this subject. There is an exception, in the case of the Middlesex Hospital Medical College, where during the thirteen years that I was connected with that institution, it was my pleasure to give a few lectures on parasites. For this I received the kind acknowledgments of my colleagues, and the hearty thanks of the students themselves. There is room for further improvement in this connection. Our friends the vegetarians 
flatter themselves that by not eating any meat containing these horrible creatures, they thereby save themselves from some of the many parasitic ills to which our flesh is heir. They will pardon me when I say that many of them only thus jump out of the frying-pan, as it were, into the fire; they consume vegetables which supply cellulose and protoplasm to the parasite which is of all others the most common in this country. All the harm which occurs from eating underdone meat can be avoided by the consumer; and all the harm which occurs by vegetable feeding can also be avoided if the few and simple indications afforded by the experimental researches of Perroncito, Lewis, and others are borne in mind. We have taken care to show what degrees of temperature are necessary for the destruction of parasites, whether they occur in meat or whether they occur in water or vegetables. It is of supreme importance to the community that they should have absolutely accurate and reliable information on this point. At the previous lecture I spoke to you of the low temperature at which the trichina would die, and how easy it is to avoid trichinosis. Now the fact is, that measles in pork and beef perish at a temperature of II $5^{\circ}$ Fahr.; at all events they cannot survive a temperature of $122^{\circ}$, if it be prolonged for one single minute. There is no excuse whatever for any one who becomes troubled by the parasites infesting meat. How is it with regard to vegetarians and water drinkers? Any one who will persist in drinking water that is not properly filtered, is liable to have the most formidable parasites invading him. A case in point, one of many within my own experience, occurred in Yorkshire. It was brought to my attention by a most amiable and cultured clergyman. In a parish it was observed that nearly all the children, and many of the grown people, were afflicted by a most formidable parasite (A scaris lumbricoides). Of course, it was desirable to know how this came about, and it is now all easily explained. The inhabitants of the village used the water of a little trickling stream, which passed through the parish, for domestic 
purposes. Into that stream ran still smaller streams, but not equally pure, from the piggerics. Now the researches of Schneider, of Berlin, have shown that the lumbricoid parasites which infest the pig are the same as those that infested the young people. The larve of the parasites escaped into the water; the water was used for domestic purposes unfiltered, and the consequence was that the people were attacked. It is only by the exercise of our sanitary knowledge, and by no other method that I know of, that we can escape these ills; and it behoves us as people who desire to progress, to look these facts in the face, and not to say frivolously, "Oh, parasites are horrible things, and we had better know nothing about them." It is not so. Who has not lately seen articles written in the papers about the parasites of mackerel, and what is called the "mackerel scare." Allow me to inform you that every fish is liable to contain parasites in its adult condition; the mackerel is attacked by fourteen species, twelve in its interior, and two which fasten on to its gills. If you were to swallow part of a mackerel containing hundreds and thousands of the little nematoid worms, as they are called-Filaria piscium-not the slightest harm would result, whether you ate the fish cooked or uncooked. There need be no scare about these fish; the slightest cooking is sufficient to kill the parasites. Permit one word of caution. I do not say there is no such thing as a dangerous parasite in any fish; but the occurrence of parasitism from this source is a matter of extreme rarity.

It only remains for me, in bringing these remarks to a conclusion, to express regret that it is barely possible for us to keep pace with our co-workers in biological science on the continent? If well meaning persons, who are not versed in the facts of parasitism, and who have not known what it is, year by year, to investigate these things, succeed in putting a stop to our experimental research, they will destroy the only possible means which we have in our power of stamping out some of the most terrible disorders which afflict man and beast throughout the inhabited globe. 
And I think that they are doing the gravest wrong who would blunt those legitimate weapons of warfare, without which weapons we cannot lay effective siege to the fortresses at present securely held by thousands of terrorcreating, disease-producing, blood, brain, bone, nerve, and tissue infesting organisms. Besides, there is another phase of this question. Fanatics object to all kinds of experiments on animals, but has it not been said, and rightly said, that one human life is of more value than many sparrows-and therefore by parity of reasoning, we may add, of many cats and dogs? If thus they put a stop to our progress in science, they check one of those necessary outcomes of civilised life which establish the power and progress of a nation, and they dishonour their own country by delegating to other nations those functions, which it is our manifest duty, and I might almost say our highest prerogative, to perform.

The Chairman, in proposing a vote of thanks to Dr. Cobbold, said that when he asked him to preside on this occasion he felt it his duty, as his Parliamentary representative, to accede to the request; but he wondered why he had asked him, and he felt that probably the explanation was, that being perfectly ignorant of the whole subject, he desired to instruct him. He certainly had derived much instruction from the lecture, as must all the hearers, though at one time it had struck him for a moment on looking at their faces, that he saw reflected back the vulgar feeling that passed through his own mind at the time, namely, that with regard to some of these subjects ignarance was bliss; but then he thought of something else, far more true-that science is safety-and that it was very desirable that we should know all that we can upon these subjects with the view of relieving evils, which were so common. Many of these entozoa were only known by the eye of science; their habits, their mode of growth were known through the revelations of the microscope, and no doubt Dr. Cobbold saw in all their bodies, magnified by the eye of science, the most wonderful processes going on. If one took a Lilliputian, and 
began to examine these things, you would see almost nothing. If you were to take a Brobdignagian, you would see a great deal more going on; but with the eyc of a microscope, such as Dr. Cobbold used, and, suppose a man to be magnified a thousand diameters, as he magnified the eggs of these creatures:-what would that man become? He would be about a mile high, and some of these creatures thus magnified in the same proportion would appear to be travelling through him like enormous sea serpents. That was, speaking figuratively, what Dr. Cobbold saw with the eye of science, and it was very important that men of science should thus see what was going on, and tell the community generally what to avoid. They must have all learnt from the lecture that there were many dangers to be avoided; but that they were, for the most part, perfectly preventible. With the knowledge which had now been communicated, he was sure they would all agree in returning a hearty vote of thanks to Dr. Cobbold for his exceedingly interesting lecture. 


\section{APPENDIX.}

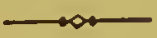

Special Catalogue of Drawings of Parasites exhibited on six sheets in the South Gallery; Class VIII., No. 206.

NoTE.-The source of every illustration is correctly given in this catalogue. Where no authority is quoted, the illustration is understood to be original and from nature. Most of the drawings have been executed by Miss Cobbold and myself.

T. S. C.

74, Portsdown Road, London, Fane I, I884.

\section{SHEET No. I. \\ TRICHINA AND TRICHINOSIS.}

Fig. I. Portion of trichinised flesh from a rabbit as seen under the microscope. It shows Trichinæ recently encysted, each cyst or capsule containing a single worm. From Pagenstecher. C. S. C. (in part). Magnified 400 diameters.

Fig. 2. Portion of human muscle, showing several lemon-shaped capsules that are nearly uniform in size, and completely calcified. Magnified 300 diameters.

Fig. 3. A solitary capsule from human muscle, with its contained Trichina spirally coiled. After Bristowe and Rainey. C. S. C (in part). Magnified about 850 diameters.

Fig. 4. Two polytrichinous capsules found in American pork. The cyst to the left shows two worms, and that to the right seven worms. Drawn in one figure from separate illustrations by M. Chatin, whose examinations of infected meat were made at Havre, in April 1881. Here enlarged to about 1,000 diameters.

Fig. 5. Group of abnormal Trichina capsules. Two of the cysts are united, so as to form one compound, hourglass-shaped, bilocular capsule, of which the lower division contains two worms, and the upper division three worms. On one side of this compound cyst is a smaller, narrow, curved, spindleshaped, unilocular capsule, containing a single worm. From American pork. After M. Chatin, Havre Laboratory, June 188ז. Highly magnified. 
Fig. 6. Remarkable abnormal capsule, in outline resembling the form of a tennis bat. After M. Chatin (viande américaine).

Fig. 7. Completely calcified Trichina capsule, with calcareous degeneration of the contents. After M. Chatin (viande américaine).

Fig. 8. Young male Trichina spiralis. After Pagenstecher. Magnified about I,350 diameters.

Fig. 9. Tail of the male Trichina, showing the lateral lobes and projecting cloaca. After Pagenstecher. Enlarged to nearly 4,000 diameters.

Fig. I0. Young female Trichina spiralis. After Pagenstecher. Enlarged about 1,700 diameters.

Figs. II-I3. Three separate stages of embryonal growth undergone within the body of the parent worm. After Leuckart. Here magnified nearly 4,000 diameters.

Fig. 14. A free Trichina embryo. After Leuckart. Magnified about 6,500 diameters.

Fig. I 5. A fully developed larval Trichina, removed from infested flesh. At this stage the worm already exhibits an intestinal canal, the lateral line, and the reproductive tract. After Leuckart. Magnified about 600 diameters.

SHEET NO. II.

NEMATOID PARASITES INFESTING THE LUNGS OF THE SHEEP.

Fig. I. Section of one of the lobes of the lung of a sheep affected with parasitic bronchitis or "husk." The branches of a large bronchial tube are seen to be stuffed with entozoa (Strongylus filaria). Enlarged from an old drawing preserved at the Royal Veterinary College. M. A. C. Highly magnified.

Fig. 2. Strongylus flaria, female. Only the anterior and posterior divisions of the body of the worm are here represented. After Alois Koch. Here magnified I 50 diameters.

Fig. 3. Tail end of a male Strongylus filaria, showing the hood and spicules. After A. Koch. Enlarged about 300 diameters.

Fig. 4. Egg of Strongylus flaria, containing an incompletely developed embryo. After A. Koch. Magnified about I,500 diameters.

Fig. 5. Embryo of Strongylies filaria, showing already a well formed intestinal canal. After A. Koch. Magnified about 1,900 diameters.

Fig. 6. Strongylus rufescens, male. The head and tail are here alone represented. After A. Koch. Magnified 200 diameters. 
Fig. 7. Tail of the female Strongylus rufescens. After A. Koch. Highly magnified.

Fig. 8. Strongylus paradoxus. This species is readily recognised by the curious globular vesicle appended to the tail of the female worm. The anterior and posterior ends of the body are here alone represented. After A. Koch. Magnified 225 diameters.

Fig. 9. Tail of the male Strongylus paradoxus, showing the long and otherwise remarkable spicules, which are also fish-hook shaped at the free extremity. After A. Koch. Magnified.

Fig. 1o. Fragment of one of the spicules (of the above) showing its external transverse markings or bands and fluted character. After A. Koch. Magnified about 1,00o diameters.

Figs. 11-14. Four eggs of Strongylus paradoxus, in different stages of development. The uppermost figure shows a perfectly formed intra-chorional embryo. After A. Koch. Highly magnified.

Fig. 15. Free embryo of Strongylus paradoxus, with an intestinal canal. After A. Koch. Highly magnified.

Fig. 16. Free embryo of Strongylus paradoxus. This figure was drawn from one of numerous living specimens forwarded to me by Dr. Bantock, of Chester, Nov. 2, 1864. Magnified about 2,300 diameters. All the embryos examined at the time displayed the characteristic button-like enlargement at the end of the tail.

Fig. 17. The right lung of a sheep extensively diseased by small nematode worms, and showing externally several walnutsized growths or tumours. There are also several smaller growths, resembling miliary tubercles. After A. Koch. M. A. C. Enlarged.

Fis. r8. Magnified representation of a very small covering-glass, beneath which one of the little worms removed from the diseased lung: above mentioned, is supposed to be placed. The little nematode, which is freely coiled upon itself, is the minute hair-worm, called Psendalizs ovis pulmonalis by Alois Koch. This entozoon was described by the late Dr. Edwards Crisp as a species of gordius. After A. Koch. Magnified roo diameters.

Fig. 19. Pscudalius ovis pulmonalis, male. Only the upper and lower ends of the worm are here represented, magnified to the extent of eleven thousand diameters. After A. Koch. This minute entozoon is, from its transparency scarcely visible to the naked eye, and when uncoiled it measures about an inch in length, its breadth being from $\frac{5}{50}$ to $\frac{\pi}{350}$ of an inch only. If the entire body were magnified to the extent shown in the drawing, the figure would reach the length of go feet. 
Fig. 20. Tail of the female Pscudalius ovis pulmonalis, showing the mode of termination of the intestinal tract and reproductive organs. After A. Koeh. Magnified about 10,000 diameters.

Fig. 2I. Another view of the tail of the fenale Psendalius, showing muscular and other structures. After A. Koch. Highly magnified.

Figs. 22-23. Eggs of Pseudalius, one showing a mieropyle at the upper pole, and the other a eoiled embryo in the interior of the ehorion. After Koch. Here magnified upwards of fifty thonesand diameters.

Figs. 24-27. Four representations of embryos of Pseudalius ovis pulmonalis, in different positions and separate stages of growth. In Fig. 24 there is a rudimentary generative organ; in Fig. 25 the remains of a cast off skin are seen ; in Fig. 26 the intestinal eanal is eommeneing to form; in Fig. 27, where only the lower half of the body is drawn, a eurved hook is seen at the tip of the tail, and there is likewise a small sub-terminal spine. After A. Koeh. Highly magnified.

Fig. 28. Representation of a solitary enbryo first observed and figured by me on Feb. 6, 1863. This larva, referable to Pseudalizes, exhibited a chitinous pharynx and rudimentary intestinal tract. Highly magnified.

Fig. 29. Caleareous remains of a dead and degenerated parent worm (Psendalizes), surrounded by an adventitious eapsule formed within the substanee of the lung. After A. Koch. Magnified about $\mathrm{I}, \mathrm{I} 50$ diameters.

SHEET NO. III.

THE BEEF TAPEWORM AND ITS MEASLE.

Fig. 1. Beef tapeworm or cestode derived by man from the consumption of measled beef or veal (Tania mediocanellata). In the full grown state the body or strobile eonsists of about I,250 segments arranged in single file. Each perfeet segment or proglottid represents a zoöid. The natural length of the worm is from 18 to 28 feet, but the lower segments are here enlarged to 3 diameters.

Fig. 2. Head of the beef tapeworm (Tania mediocanellata). It is viewed at an angle, so as to show three of the four suekers. Magnified 70 diameters.

Fig. 3. Another representation of the head of a Tania mediocancllata. The head is viewed from above, and seen to be destitute of hooks, but the figure explains the natural arrangement of the four suckers, as well as the position of the so-called 
fifth or supplemental sucker. The water vessels are also displayed, though incompletely. Partly after Küchenmeister. Magnified about 230 diameters.

Fig. 4. Section of the body or strobile showing two entire proglottides and part of a third segment. Magnified 6 diameters.

Fig. 5. One proglottid, and part of two other segments, prepared to show the water-vessels, the reproductive papilla, and the general disposition of the internal organs. After Blanchard (in part). Magnified 20 diameters.

Fig. 6. Seven detached or free proglottides that have quitted the human host of their own accord. They are represented in varying degrees, either of extension or contraction, as the case may be. In these states they are frequently mistaken for separate and independent forms of parasitic life. After Leuckart (in part). Magnified 4 diameters.

Fig. 7. A perfect egg of the Tania mediocanellata, showing the thick chitinous shell, and its contained six-hooked embryo or hexacanth proscolex. Magnified upwards of 6,ooo diameters.

Fig. 8. The heart of a calf that had been made the subject of a feeding experiment with the mature proglottides of the beef tapeworm. The external or serous surface of the organ is seen to be studded with measles. After Mosler. Magnified.

Fig. 9. Vertical section showing the interior of the same heart, and the measles scattered throughout the substance of the muscular wall of the left ventricle. After Mosler (by Mr. Jennens). The şo-called acute cestode tuberculosis thus artificially produced caused the death of the calf. Magnified.

Fig. Io. Representation of the partially dissected left hind quarter of an English calf, that was made the subject of a worm-feeding experiment in December I 864. The surface of the triceps adductor femoris muscle being exposed, exhibits at the surface I 20 measles, about the half of which are crowded together at the upper part. In this case the infection did not prove fatal to the animal. See Proceedings of the Royal Society May, I865. Enlarged from the original dissection.

Fig. II. One of the experimentally reared measles (Cysticercus bovis) within its capsule, through the walls of which the head of the parasite is distinctly visible. Magnified about 60 diameters.

Fig. I2. A Cysticercus bovis, or beef measle, removed from its cyst, with the so-called neck and body everted. The head displays all the characteristic marks of the head of the sexually mature beef tapeworm (Tania mediocancllata). It is unarmed, or destitute of hooks, but shows the spurious, central, supplementary, or fifth sucker. Magnified 65 diameters. 
Fig. I3. Inperfectly developed measle, removed from the heart of the English calf above mentioned. This aborted Cysticercus bovis was situated within the wall of the left ventricle, some twenty other imperfectly formed measles being also present. In addition to the ordinary calcareous corpuscles, the specimen exhibits threc imperfect suckers whose walls have undergone calcification. Divested of its cyst, the measle measured only $\frac{1}{14}$ of an inch. Magnified 225 diameters.

\section{SHEET No. IV.}

\section{HYDATIDS.}

Fig. I. The lungs and liver of a sheep infested with hydatids or echinococcus-bearing bladder worms (Echinococcus veterinorum). Copied from an original drawing by the late Mrs. Elizabeth Cobbold, of Holywells, Ipswich (from naturc, August 9th, 1818). M. A. C. Size increased by one half.

Fig. 2. The liver of a hog infested and much altered in shape by the presence of maturc or fully-formed hydatid growths. At the upper part a parent vesicle is cut to show the daughter vesicles escaping. Copied from a drawing preserved at the Royal Veterinary College. Case published by Professor J. B. Simonds. Enlarged by one half of the natural size of the affected organ. M. A. C.

Fig. 3. The liver of a pig studded with multitudes of immature hydatids, resembling and at first mistaken for ordinary measles. A cut at the centre of the organ shows that the vesicles are not limitcd to the surface. Six pigs of the same litter, four months old, were similarly affected, all of them having been sent to market and sold as food (without the livers). Drawn from a specimen sent to the Principal of the Royal Vetcrinary College by Mr. Thomas Olver, V.S., Truro. M. A. C. Enlarged to twice the natural size.

Fig. 4. Illustrations of the so-called "pill-box hydatid" of John Hunter. In the figure to the right the maternal hydatid is laid open to show the daughter hydatids within, whilst two of these secondary formations are represented by the figures bclow. Human specimens.

Fig. 5. A young hydatid of four weeks' growth escaping its capsulc. Aftcr Leuckart. M. A. C. Magnified 300 diametcrs.

Fig. 6. Immature hydatid of eight weeks' growth removed from its capsule. It exhibits the laminated, transparent, homogeneous ectodcrm, inclosing the vital internal membrane or granular endodcrm. M. A. C. Magnified 300 diameters. 
Fig. 7. An echinococcus head or scolex of the Tanir echinococcus, removed from the interior of a mature hydatid which infested the liver of a zebra that died (from an accident) at the Zoological Gardens. It shows especially the double crown of hooks, two of the four suckers, and calcareous corpuscles in the interior. After Huxley. Magnified about three thousand diameters.

Fig. 8. Three echinococcus brood capsules attached to and projecting from the endodermal membrane of a mature hydatid. The capsule to the left exhibits several echinococcus heads, some everted, others inverted, whilst the investing membranes of the other two brood vesicles have collapsed, leaving the "heads" and their pedicles or stalks exposed. After Leuckart. Magnified about 200 diameters.

Fig. 9. Group of echinococcus heads attached by their pedicles to the remains of a collapsed brood capsule. From a liver hydatid of the pig. After an original drawing by Professor George Busk, F.R.S. M. A. C. Magnified 600 diameters.

Fig. 10. Three examples of an hydatid-forming tapeworm (Tania echinococcus) of thirty-two days' growth. Reared by experiment in a dog which was fed with human hydatids. After Dr. J. D. Thomas, Adelaide, Australia. M. A. C. Magnified Ioo diameters.

Fig. II. Tania echinococcus. From a carmine-stained specimen presented to the exhibitor by Professor Leuckart. It displays the proboscis and hooks, the four cephalic suckers, the water vessels, and the three segments forming the body or strobile. The lowest segment or proglottid is mature, and therefore charged with eggs. Magnified about 300 diameters.

Fig. 12. Two hooks removed from the head of a mature Tania echinococcus. After Dr. H. Krabbe. Magnified about 3,60o diameters.

SHEET No. V.

THE LIVER FLUKE.

Fig. I. Mature Fasciola hepatica, or liver fluke, from the sheep. The illustration shows especially the uterine rosette, the germarium, vitellarium, spermarium, and other parts of the reproductive system. After Blanchard (by Mr. Jennens). Magnified 25 diameters.

Fig. 2. Mature Fasciola gigantea, from the liver ducts of a giraffe that died at Edinburgh (where it was being exhibited in 1854). The animal was "rot affected." The parasite is here seen from behind, and shows the water vessels injected with size and vermillion. Magnified 15 diameters. 
Fig. 3. Another example of Fasciola gigantca, viewed from the front or ventral surface. I have here injected the digestive system of the parasite with ultramarine. Coloured figures and descriptions were given in the "Edinburgh Philosophical Magazine," October I855. Magnified I 3 diameters.

Fig. 4. Egg of Fasciola hepatica, with contained ciliated larva, having its head directed towards the operculum. After Professor A. P. Thomas. Magnified 4,760 diameters.

Fig. 5. Free swimming ciliated embryo of the common liver fluke (Fasciola hepatica), showing the head papilla, ectodermal nucleated cells supporting the cilia, and the so-called eyespots. After A. P. Thomas. M. A: C. Magnified 3,500 diameters.

Fig. 6. Free ciliated embryo in the act of penetrating the body of a small snail (Limnea truncatula), the tissues of which are here tinted of a yellow green. The "epaulet like cells and ciliated infundibula" are well shown (by Professor Thomas). See his memoir in the "Quarterly Journal of Microscopical Science" for January I883. M. A. C. Magnified 3,500 diameters.

Fig. 7. An embryo undergoing metamorphosis within the body of a snail. After A. P. Thomas. M. A. C. Highly magnified.

Fig. 8. Completely metamorphosed embryo, transformed into a sporocyst, here seen at a very early stage of growth. After A. P. Thomas. M. A. C. Highly magnified.

Fig. 9. A fully developed sporocyst with numerous germs in the interior, one of which, to the right, is seen in the gastrula stage of evolution. At the upper end is shown an organised nurse or redia ready to escape the sporocyst. The tivo degenerating eye-spots of the ciliated embryo are still visible below. After A. P. Thomas (but here reversed). M. A. C. Magnified I, 380 diameters.

Fig. I0. A young redia, or organised nurse, taken from the body of its intermediate host. It exhibits the so-called collar and rudimentary feet, and also a powerful muscular pharynx leading to a simple digestive sac or stomach, which is " filled with the yellow remains of the liver cells of the intermediary host." After A. P. Thomas. M. A. C. Highly magnified.

Fig. II. A full grown redia which, in addition to the structures seen in the previous figure, displays germs in every stage of growth, one of them having grown into a daughter redia, another into a nearly perfect cercaria, and two others into incomplete cercariæ. After A. P. Thomas. M. A. C. Highly magnified.

Fig. I2. Free cercaria, showing the long tail, oral and ventral suckers, pharynx, xsophagus, digestive tubes, and large opaque cystogenous cells, which occupy a great part of the body 
substance. After A. P. Thomas. M. A. C. Highly magnified.

Figs. 13-14. Back and front view of two examples of Limnea truncatula. Drawn from specimens originally exhibited by me in

- October 1880, and declared at that time (on Leuckart's authority) to represent specimens of the intermediary host of Fasciola hepatica. Professor A. P. Thomas's subsequent researches showed that this view of the relations subsisting between the mollusc in question and the liver fluke, although originally based upon a misinterpretation and upon incomplete experimental knowledge, was correct. M. A. C. Magnified 25 diameters.

\section{SHEET No. VI. \\ VARIOUS FLUKES.}

Fig. I. Fasciola facksoni, from the liver of an elephant. It is viewed from behind, but shows the exserted whip-like cirrhus, and also the digestive tubes, which are naturally injected with bile, blood, and débris, derived from the liver ducts of the host. This parasite causes "rot " in Indian and Burmese elephants, often proving fatal to these valuable animals. See memoir in Linnæan Transactions, March 1882. C. B. (in part). Magnified 50 diameters.

Fig. 2. Distoma crassum, or the large Chinese fluke. The figure shows that this human intestinal parasite is furnished with two simple and undivided digestive tubes. The reproductive organs are conspicuous, especially the vitellaria. The species is rather common in China. See Linnæan Society's Journal, Zool. Div., vol. xii., 1876. Magnified 13 diameters.

Fig. 3. Distoma sinense, or the small Chinese fluke. The digestive tubes and organs of reproduction are well seen in this alnosit transparent parasite, which infests the human liver, and has been found not only in China, but also in India. The parasite was discovered by Professor McConnell (1874), from whose figure the illustration is taken. See the Lancet, August 1875. Here magnified 45 diameters.

Fig. 4. Distoma lanceolatum, or the lesser liver fluke of ruminating animals. In this species the digestive tubes are short, the vitellaria are remarkably small and narrow, but the uterine coils pass downward to the tail. This worm has been thrice observed in man. After M. Blanchard. Magnified 55 diameters.

Fig. 5. Distoma heterophyes, or the dwarf fluke of Egypt. This parasite infests the human intestine, and is distinguished by VOL. XII.-H. L. 
its minute size, and by the presence of a fish basket-like disc situated on one side of the large ventral sucker. It was discovered by Bilharz, at Cairo, in I 851 , and has only once since been re-obtained. Drawn from a specimen given to the exhibitor by Professor Leuckart. Magnified 260 diameters.

Fig. 6. Distoma lancea. This fluke infests the liver of the dolphin of the Amazon (Delphinus tachuschi), and it has been obtained by Dr. John Anderson from the short snouted dolphin of the Ganges (Orcella brevirostris). The present figure is copied from Diesing. M. A. C. Magnified about 90 diameters.

Fig. 7. Distoma campula. This small liver fluke infests the porpoise (Delphinus phocana), being first discovered by me in April 1855. It has since been found by Dr. J. Anderson in the dolphin of the Ganges (Platanista gangetica). In the porpoise (shot by the late Mr. Jardine Murray in the Firth of Forth) it had produced a diseased condition of the liver ducts (true "rot"). See Linnæan Transactions, I856 and I876. Magnified 90 diameters.

Fig. 8. Bilharzid homatobia. This remarkable parasite was discovered by Dr. Bilharz, at Cairo, in $185 \mathrm{I}$. It infests the portal vein and blood vessels of man, and probably of monkeys. I found it in a Cercopithecus fuliginosus, which died at the Zoological Gardens. A similar parasite has since been discovered by Dr. Sonsino in the ox and sheep (Bilharzia crassa, Sons.). In this genus of flukes the sexes are distinct, the female being occasionally found (dwelling parasitically, as it were) within a gynœcophoric canal, with which, as shown in the drawing, the ma!e is furnished. After Leuckart. Here magnified about 125 diameters.

Fig. 9. Diplozoon paradoxum. In this singular genus, in which the sexes are double, two originally free and immature hermaphroditic individuals become united, by means of hooks, back to back, the union subsequently becoming complete organically, so as to form a single compound individual. In this state the parasite is found on the gills of various freshwater fishes. After Von Nordmann. Magnified about Ioo diameters.

Fig. 10. Amphistoma papillatum. This fluke infests the large intestines of the Indian elephant. It is easily recognized by the fungiform papillæ lining the interior of the ventral sucker. Such parasites are called "masuri" in India, and they prove injurious to their hosts. See Linnæan Society's Transactions, 1882. Magnified go diameters.

Fig. II. Tristoma coccineum. In this curious genus of ectoparasitic trematode worms, there are three sucking discs, two small 
ones at the head, and a large one near the tail. The diges:ive tract appears in the form of a simple closed circular intestine. Partly from Blanchard, and partly from a specimen found on a sun-fish (Orthagoriscus mola) captured in the Firth of Forth. It is of frequent occurrence of the gills of the sword-fish (Xiphias). Magnified about I 5 diameters.

Fig. 12. Monostoma verrucosum, showing especially the water-vascular system. This fluke infests the cæca and large intestine of various water birds. After Blanchard. Magnified about I Io diameters.

Fig. 13. Brachylamus erinacei. Infests the intestine of the hedgehog. This fluke is probably identical with the Distoma linguceforme of Dr. von Linstow. After Blanchard ("Annales des Sciences Naturelles," I847. Highly magnified.

Fig. 14. Polystoma intergerrimum, showing especially the branched digestive tract and water-vessels. This species infests the urinary bladder of the frog (Rana temporaria). After Blanchard. Magnified about so diameters.

Fig. I5. Aspidogaster conchicolor, from the pericardial chambers of the common freshwater mussel (Anodonta anatina). This fluke displays a remarkably complete ventral sucker, elliptic in form, of great size, and furnished with partitions presenting a tesselated appearance. After Pagenstecher. Here magnified about 200 diameters. 



\section{CAN DLES.}

BY

LEOPOLD FIELD, F.C.S.

VOL. XII.-H. L. 



\section{JUNE 2OTH.}

\section{A LECTURE ON CANDLES. \\ By LEOPold Field, F.C.S.}

Sir FrEDERICK AbEL occupied the chair.

IN introducing the lecturer, the Chairman said: One of the personal lessons which we have already learnt in connection with this Exhibition, is the fact that we must not hastily assume that any subject is not intimately associated with the health of individuals and the community, and this is certainly the case with the subject of candles. I myself am old enough to recollect the great discomfort to the eyes, and more or less injury to the health, that the student sustained who had night after night to work by the dim light of the dip or mould candle, candles which gave rise to as much care, and as much tribulation of spirit as a spoilt child, and it was a great improvement when candles that did not require snuffing were first invented. I would just refer again to an illustration of the interesting manner in which improvements in candles have been connected with the public health. This improvement, great as it was, had to contend with what became a public scare in the public mind, for it was reported that snuffless candles gave out poisonous exhalations in consequence of the volatilisation of the arsenic or other poisonous ingredients used in the preparation of the wicks. I just quote this as an 
illustration, of which no doubt Mr. Field will give us many, of the interesting manner in which candles have been and are connected with the public health. We are sometimes told that candles ought to be things of the past, but we know this cannot be. In many cases where we can neither have gas nor electricity, candles can certainly hold up their heads in public. They certainly do not vitiate the atmosphere as much as gas, at any rate in proportion to the light given, and with regard to electricity, of course they have this great advantage, in convenience, of local application. Mr. Field has been intimately associated with some of the most important improvements in later times in the manufacture of candles, and I am perfectly sure that he will not fail to tell us a great deal that is interesting and instructive.

\section{LECTURE.}

Of the myriads who have visited this Exhibition there are assuredly many who have come with a higher object than that of furthering the sacred cause of science and public hygienic interest by their own gratification. No doubt there are many who come to enjoy the delightful combination of excellent music, playing water and beautiful grounds, with the pleasing consciousness that they are in some way or other promoting the object for which the Exhibition was opened in so doing; but many there are, doubtless, also, who come wanting to know and seek every opportunity of gratifying this laudable desire. But I have no doubt that by the time they have proceeded into the bowels of the Exhibition, and have passed through the Scylla and Charybdis of the food and drainage departments, they have exhausted themselves in wondering how stuffed pheasants on the one hand and tobacco on the other, mackintoshes, electric belts, and all the various essentials of life, can have anything to do with health, considering that they have lived perhaps forty or fifty years without ever having felt the need of them. When they come at last to Class No. 26, and see candles unblushingly displayed as 
active promoters of public hygiene, their pent-up marvel finds a vent in the question, "What on earth have candles to do with health?" I presume, although I have not been officially informed, that it is to answer this question I am here to-night; and I will endeavour to give as satisfactory an answer to it as possible, being of course a somewhat prejudiced party, and used during the greater portion of my life, like the memorable cobbler, to consider that there is nothing like a candle to be found in the arts and manufactures generally. But I think I shall show you really before the lecture has gone its full length, that, as far as we can see, no art has progressed step by step with the advance of civilisation as candle-making has, and that every great discovery in science, every new departure in manufactures, has been attended by a distinct improvement in the candle, and a greater modification of its use to the benefit of mankind. It is always an instructive thing to form a background for our modern science with the failures of our forefathers. It is a very agreeable thing to look back, and think from what a very poor lot we are descended. I think we cannot flatter ourselves in a more complacent manner than when we regard the attempts which were made by our ancestors to illuminate the darkness, which, then as now, environed them every evening.* Of course the need for light has grown with civilisation, and in the primæval condition there could not be nearly so great a want of candles as there is at present, considering that day was day, and that at night people generally betook themselves to their proper rest; a habit which is still kept up may be in the agricultural and rural districts, where daylight itself limits the labour which is confined to out-doors. But here, where even in summer we are liable to find day turned into night by the clouding of the atmosphere with fog,

* "What were the dark ages? Surely the sun rose as brightly then as now, and man gat him to his work in the morning. Why is it we can never hear mention of them without an accompanying fecling as though a palpable obscure had dimmed the face of things, and that our ancestors wandered to and fro, groping? "-Lamb. 
and where we have to burn not only the midnight oil, but every description of midnight combustible into the small hours of the morning, it follows that these appliances which administer to this evil state of society should be themselves of the most perfect kind. Therefore, when we look back and find the Romans and Greeks talking of candles when they mean lamps, and torches when they mean candles, and of lamps when they mean anything at all which will burn, we can find a thorough excuse for this slip-shod nomenclature in thinking that it made very little difference to them, and how they were willing to take up the first thing that would burn, kindle it, and make it serve their purpose.* Those gorgeously ornamented candlesticks which you see on the diagram, with the very little lamp at the top, show how much pains they bestowed upon the outside of the cup and platter, and how little thought they gave to its ultimate purpose. The earliest news that reaches us concerning these things is to be found in the old torches, slips cut from pine filled with resin, which in the old sagas of the Norsemen lighted up their Valhallas and their very disagreeable banquets. Here is a slip cut from a particularly resinous pine: it does not kindle readily, but when lit burns with an eager smoky flame; as it fills the room with smoke which condenses into small particles of carbon, which will most probably make their appearance on the garments of the audience, I will not keep it burning long. This we may regard as the first step. People cooked the precarious repast which they caught in the woods with branches they took from the woods; they observed that where the fat of what they were roasting fell upon the faggots there the blaze was fiercer and gave a brighter light, and this would, naturally, by no very intricate process of reasoning, lead them to suppose that where they took fat and coated wood with it, it would serve them as a

* For an cxhaustive account of the ancient modes of lighting, and disquisition on their nomenclature of illuminants, see 'Cantor Lectures,' Soc. Arts Journal, Jan.-Mar, $188_{3}$. 
light without the preliminary process of cooking. We see that this reasoning process was gone through to some extent. This link is a mere mass of cordage thoroughly saturated with resin and pitch. This burns much more certainly and freely; and civilisation so advanced beyond the age of the torch. On foggy nights this was (and is still) used to dispel the gloom by link boys; it is a very lurid light, difficult to extinguish, gives considerable smoke in proportion to the light that it yields, but that is not of very great account in the open air. But the link is not handsome, it is cumbrous, and its smoke is disagreeable. It therefore remained for civilisation to take another step and become more fastidious. Now I am not aware when first tallow and wax came into rivalry, but whenever it was they did not long remain so, for tallow at once took the subordinate place it still continues to occupy. Wax being of pleasant odour, and of hard consistency, readily assumes shape which it keeps through all climates and temperatures. Hence it was soon adopted by those classes who could afford it. It is yielded, however, in far smaller quantities than tallow, and necessarily the price would be higher. Therefore, this flambeau, which I next show you, was a piece of luxury in the old days. This has been disinterred from the cellars of our factory, where it has lain, I should be within the mark if I said a hundred years, for long before that time we bear on our books records of having supplied these flambeaux to ducal and lordly parties. I have coated a portion of it with fresh wax, to show you how it appeared when made, though probably the wax would not be so light in colour. This burns better and is more delicate and pleasant to manipulate than the piney torch or tarry link. These may be said to have formed the main illuminating agents perhaps to the I 5 th and 16 th centuries, that is, of the upper classes. The humbler grades we may presume confined themselves exclusively to tallow. They skimmed simply what fat remained to them from the kitchen, collected it, and on a certain day known as melting day, they took rushes, partly skinned them, leaving only a 
slender slip of skin to support the pith and then dipped them into the tallow until a sufficient coating had been obtained to enable them to stand upright. Thus we have the old rushlight, which is still burnt by some very conservative people as a means of dispelling the darkness and gloom of the sick chamber. For this purpose the rushlight is confined in a small cage of wire as you see here. This is an apparatus which is very old indeed, and gave me considerable trouble to hunt up, although no doubt it was at one time as familiar to us as a night-light is to us now. There is a rushlight, burning with a very modest flame indeed, in fact just enough to make the darkness visible, guttering in a pleasant unassuming manner; the major portion of the candle is already distributed over the saucer. No doubt this affords perfect safety from fire, so that an invalid could go to sleep with the comfortable feeling that he would not add the trouble of being roasted to all his other ills. Otherwise I do not think it possesses a high standard of merit, the smell is not agreeable, and the light is not brilliant. There, again, is a tallow candle of immense antiquity. It is the only candle now without a plaited wick, consequently this modest light here, which was lighted shortly before this ceremony commenced, had a fair proportion of new candle, but now it has guttered down to these very unseemly proportions for lack of snuffing. For that purpose, luxury afterwards provided a pair of snuffers and tray, and with this little apparatus our fathers felt themselves able to defy the darkness.*

It is all very well for us to sneer at our forefathers, but the question remained, are those advances that we have made upon them in this direction really more in conformity with the rules of science and the exigencies of what is really due to a proper candle? And perhaps the best answer to that will be got by asking, what is the real definition of a perfect candle? It was not certainly until the I9th

* G. Eliot dwells repeatedly on the different social status of the rival illuminants, wax and tallow. See 'Felix Holt,' c. V., and 'Amos Barton,' c. IV. ; also Mrs. Elton in Austen's 'Emma.' 
century was considerably advanced that science may be said to have taken the candle in hand. Wax and tallow continued in force entircly and solely till close to the end of the I8th century. Then the sperm fishery began. Spermaceti, in fact, pure as it is delivered to us by the whale, unadulterated, is the best and most beautiful material for candles that exists. It gives an intense and clear light, and gives the hardest candle, which cannot bend, and which only gutters under stress of adverse circumstance. The purity of it, its ready decomposition, and the readiness with which it burns, make it altogether the most desirable material for candles that there is. It has but one small objection, which, however, has been enough to damp its popularity, and that is, it costs nearly double as much as an ordinary candle. Spermaceti, of which I have a block here, is afforded by the sperm whale. It is a brilliant crystalline substance obtained from the head and blubber of the cachalot. I have here the various steps which the sperm undergoes in its progress from the whale to the candle. It leaves the head of the whale as a peculiar brown kind of paste, which, being examined closely, is found to consist of little scales intermingled with a greasy substance, which is really oil. It is put into bags, when the oil filters out by its own pressure, leaving the crystals behind; and after a long repetition of this process it comes to a greybrown matter that is called cold-pressed sperm. Then heat is applied, when it is still further pressed, and assumes the yellowish condition in which it is called hotpressed sperm. After several more processes it presents the beautiful white appearance I just now showed you. That is spermaceti, and its composition resembles to a certain extent that of other fats, except that, instead of containing glycerine as tallow does, it contains a substance called ethal, which is a characteristic constituent of spermaceti fats. Therefore, in burning spermaceti, as our forefathers did, they had attained the highest perfection to which a candle can go (as far as regards the material), and so far were quite on a level with us. The price, however, was and is against it. The 
dangers encountered by those who go after whales; the ferocity and swiftness of the leviathans themselves; their great scarcity, civilisation ever driving them further and further towards the south-all these things tend to render spermaceti dear and difficult to obtain. Consequently, when we recovered from the shock of the revolution which attended the end of the last and the commencement of this century, and had time to look about for means of utilising our novel tranquility, then pressure came from the side of the candle, as from all sides upon science, and science, in the person of Chevreuil, was not slow to answer- the call. It was in I8I I that he commenced his great researches, and from that time until 1825 he illuminated the page of history with a series of researches which revealed the chemistry of fats, hitherto a sealed mystery, and demonstrated in the most beautiful and practical manner how from the most disagreeable amongst the refuses, till then thrown aside as worthless, it was possible to obtain a brilliant illuminant of incredible whiteness.

Before I enter on this discovery I will explain, for a moment, what is absolutely essential in a candle, and I will show it you by a candle itself. I have here a wax candle burning. I have taken wax, not because it is the best substance for showing the essentials of a candle (because wax contains oxygen, hence is not so good for me as paraffin would have been, which contains none) : but because it is almost impossible to get a paraffin candle of that size, without a special mould. I will begin by dissecting the candle before you, and apply the question to it to show to us how this flame is put together. You will see the flame has a dark spot in the centre where the material which it melts in the cup and sucks up through the wick is brought into a vapour. If I apply this little tube to the centre of the dark spot you will see the gas will pass through the tube and appear in the form of vapour at the other end; in fact, I have established a little gasworks, and I can light the vapour coming through the tube, and produce a little flame. You see I am drawing off from 
the candle, instead of allowing it to be burnt at the seat of its combustion, this vapour, and carrying it away as in a gas pipe to a burner in an ordinary house. That is one step. The candle first of all when heat is applied melts the matter which is immediately in the vicinity. That matter being melted is subjected to the capillary suction of the wick, which is really a number of little tubes. There is a diagram on the wall showing a wick magnified. That is only a large representation of some of these threads cut through; you will see the matter is sucked up between the interstices by what is called capillary attraction, and reaches combustion. Now, if I apply this tube a little bit higher. just above the point where the combustible matter is coming into play, and the carbon is being set free (that is where the action has commenced), you will find that the vapour which comes out, instead of being white, is black; that is pure carbon vapour, and should in a wellconstituted candle go forth into the air as carbonic acid; it should be burnt up in connection with the oxygen, and not trouble us in the shape of smoke, as that candle is doing now.

There are two points, then, to be considered in making a candle. In the first place we have to apportion the wick so that the exact quantity of melted matter required shall rise through it, and in the next place, that the flame should be hot and large enough to burn exactly as much fat as it melts, and not be drowned by a superfluity. This problem it is which candle makers have set themselves to solve; and I think they may say to a certain extent they have succeeded as well as it is possible considering the very various and varying materials placed at their disposal. There is no object which is more difficult to render perfect than a candle, because its success depends on a number of factors from so widely different sources. If you cast your eye round the room you will see various plants and animals there depicted, and will have some idea of the immense extent of the domain which is laid under contribution to furnish materials for these little insignificancies which are 
burning on the table. From every part of the ocean, from everywhere where there is a beast, or a plant, or a fish, we derive some constituent of the candle itself; and when we have even got the outside of it perfect and readily fusible, readily combustible, without smoke, there still remains the wick, and that is a difficulty which has exercised the keenest intellects, and the greatest amount of research imaginable; although to most people the idea that there is any difficulty whatever connected with a little piece of cotton in a lump of fat has never struck them as a matter worthy of serious consideration. All these candles which are burning here, ranging from the best wax downwards -bees'-wax, spermaceti, stearine separated out from tallow, paraffin distilled from shale, and ozokerit derived from the mineral which bears its name-each has a different wick, each has taken different preparations to soak the wicks in, different manipulations in the putting of them in the candle, and different degrees of temperature in making and storage. Everything has to be most carefully and accurately considered. Yet it frequently happens after all this care and precaution that candles turn out unsatisfactory, when a cry of execration is raised against them, and people fly to an oil lamp, or gas, determined to have nothing more to do with these disagreeable, old-fashioned illuminating agents. But it is very hard, when you consider how difficult it is to make a good candle, and what a beautiful thing a candle is when it is really good. Take the substances one by one which furnish candles. Starting with tallow, I do not think I shall say much about that, because it is not a pleasant material to handle, to smell, or in any way to come in contact with, except on the back of the natural sheep. It has always been the synonym for something disagreeable, and although by careful pressure it can be made a very fair white solid, still ordinary tallow, as we know it, is not an attractive subject. Bees'-wax, on the other hand, is attractive to most people. The bee has long been held up in our domestic hymns as the symbol of all that is industrious and good-tempered. The 
wax that it yields, and the honey, are two objects which have long endeared themselves to everyone; therefore, I will just show you how bees'-wax is manipulated, and form a candle with it which I think will repay your attention for a few moments. The process has to be conducted now as it has been since wax candles began to be made in any serious quantity; we cannot boast of any great advance there, because every scientific means has been tried to bleach wax, and make it pliable by applying the discoveries of chemistry to it; still it remains the fact that the oldfashioned air bleaching does best after all. In fact, candles can only be made of wax that has been bleached by exposure to sun and moist air. I will first show you all the processes wax has to undergo before it can be made into candles. There are waxes which come to us from every part of the world; all different in appearance, smell, and chemical composition slightly. Yet we have to make use of them all, more or less, in order to get a perfectly bleached wax. We get yellow wax from Holstein, black wax from Cuba, grey from Gambia, mixed wax from Australia, and polychroic wax, which comes from America. There are colours innumerable, yet all these have to be taken as they come; they are collected by the bee owners, put into little sacks, sold to the traders, and the traders sell them to the shipper. They come to the market in dirty, unsightly lumps. These are first melted and boiled in a little acid water, which carries down all the dirt and dross. Thereupon the melted wax is placed in a little vessel which surmounts a pan perforated with small holes, and these holes play upon a revolving cylinder working in a trough of water. The reason for bleaching it is that a peculiar chemical process takes place by which the wax loses colour entirely, becomes changed, and all the colours which it has in the native state, which are due to some private idiosyncrasies on the part of the bee, disappear, and it assumes a whitish-yellow colour. The melted wax as it comes through these holes pours over the roller, and is thus parted into little shreds, which are cooled in the

VOL. XII.-H. L. 
water; it is thus obtained in the finely divided form necessary for bleaching. These small strips and curls offer considerable surface to the action of the air. This wax would now be spread in long linen bags in the open and subjected to the vicissitudes of the atmosphere, sometimes a month and sometimes only a fortnight. It depends entirely on the weather, but when that is propitious the process is not only very rapid but very satisfactory and perfect. I should observe that care is requisite in selecting the wax, because if certain kinds of wax are included it will not only not bleach, but on the contrary it even turns darker.

Now we will suppose the wax has been bleached, formed into square cakes, and is stored in the candle room ready for making into candles. This process is one under which the wax will not conform to any machinery whatever; it has still to follow the old manner of candle-making. There is a hoop from which are suspended the wicks, which represent to a certain extent the manner in which a wax candle is made; but you must imagine that the different stages represented by these different candles hanging on this hoop have to be gone through with all the candles. By successive coatings, of which it takes eight to make the next stage, they assume this skeleton, ghostly form; then they have further coatings applied, and get bigger and bigger, and so the candle increases in size until it arrives at the final stage and is ready for working. It takes about three days for a candle to pass from one stage to the other in warm weather. When the candles assume the proper proportions they are subjected to the process of rolling, which I shall have performed for you. A smooth slab, preferably of marble, is taken and kept as smooth and free from all corrugations as possible. The wax candles, which should be a little warm, are rolled on this slab, as you see, with a flat, heavy board; a small piece of wood, and a knife being all the appliances that are needful for converting the candle from that rough form which you saw at first into the beautiful shape of this 
church candle. That is about the largest size candle which is made, weighing about twenty-eight pounds, and costing when decorated, about fifteen guineas; and in front I have placed the smallest wax candle made, of which 400 go to the pound, and four of which cost one farthing, yet both are made in almost precisely the same manner.

[The process of rolling and trimming a wax candle was here exhibited.]

I now go on to the process of making candles after moulds were invented. Mould candles came into use about the middle of last century, being invented by Le Sieur de Brez, at least all tradition says so; and since then candles have been known as moulds and dips, the moulds being made of the better, harder tallow, so that to burn a mould candle was considered a sign of distinction and enlightenment. The mould is still adhered to, because some people like to cling to old customs, having prejudices of their own which are far too inherent to be upset by any demonstration or reasoning, and prefer the hand-made mould to the machine-made candle. Why, still remains a solemn mystery, but so it is, that they do prefer them. They are exactly the same in every way as the machinemade, but they are known by having a little wire mark across the butt. This, however, is all that their advocates look for, who burn them with great satisfaction, and imagine they are getting a much better result for the same money. Here is a small frame of moulds which has been made beforehand, and cooled in water; when cooled they shrink just enough to leave the tube and slip out with just a little tapping. You will see, when I show you how machine candles are made, what an immense amount of labour there is saved; and how peculiar it is that an invention which has marked and undeniable advantages on its side, has taken so long to come into use and full appreciation, so that we still produce a great number of these hand-made candles. It is not only the labour which is expended in getting them out, but also a far greater amount of labour in getting them in. Before such a candle 
can be made it is necessary that the wicks should be cut, whereby a great amount of wick is lost. Then these wicks are sent out generally to outdoor hands, who are able for a certain consideration to attach to the point a little eyelet of cotton. The labour is considerable, and it takes time, but still they make a decent sum by it, because the quantity is so large. All these wicks are by hand furnished with this little eyelet. A kind of crochet hook is pushed down the moulds whereby the eyelet at the end of the wick is caught dexterously in the orifice on the top and is drawn up through the pipe, where it is secured and held with a little piece of iron wire which retains it in position, and makes the mark ultimately on the butt of the candle by which these hand-made candles are distinguished. This operation is tolerably rapid, but still it is not very speedy, each one having to be done separately. Having drawn these wicks through, which now appear at the top of the pipe, a little piece of wire is passed through the eyelet, and the wicks are secured at the other end with a peg, when the pipe is ready for filling. You must imagine that all the pipes are treated in the same manner. When they are all fitted and trimmed they are filled with melted material, spermaceti by preference, immersed in water to cool, and extricated in the manner you have seen. Thus are made the wax and spermaceti candles which still linger with us, thanks to their intrinsic merits, and the conservation of their admirers.

Now comes the question of how we are indebted to Chevreuil, and what his discoveries were, and how they represent a very great stride in our powers of illumination. His first discovery was that tallow consisted of two bodies, a liquid and a solid; the liquid he called oleine and the solid stearine. Stearine and oleine and a great number of other bodies, as he showed, consisted of mixtures of fatty acids with glycerine. Therefore, tallow consists of a mixture of fatty acids with glycerine, and it is this which causes it to burn in such an imperfect manner, and causes such exceedingly inappetising odours, because glycerine when burnt, 
gives off a horrible vapour called acrolein. Now let us revert to the theory of the combustion of the candle. It has no still or ready-made oil to its hand, but has to do the whole of its work without any extraneous help whatever except that of the atmosphere. In gas, you have the still at the works, the fire, and the gas pipe which leads it to the burner, and thence into the air, every one of which appliances has consumed a portentous amount of labour, and has been the subject of no end of patience; yet the candle has none of them. In the lamp you have the oil already melted; in that candle you have it solid. The candle has first of all to expend a vast amount of heat in getting that solid into liquid, then it has to expend much more heat in turning the liquid into vapour, then to suck the vapour up into its own pipe, and ultimately bring it into its own atmosphere and burn it. There is all that to be done before the candle can give light. Now there is much nonsense talked by people who know nothing about candles. They say how ridiculous it is, and how far we are behind the age, because if we compare the amount of matter that there is in this paraffin with that in the oil lamp, a paraffin candle should give a larger amount of light for its bulk than so much oil, but yet it gives very much less. But the fact is, that all the heat is consumed in making it ready for burning, and there is little left to bring it up into a sufficiently high temperature to effect its combination with the oxygen of the air. That is the reason why I say that the candle labours under disadvantages. I have here two candles prepared especially, one with a very small wick, and the other with a very large wick; in the one the wick is so great that it has melted the paraffin, and is sucking it up, but the flame is not large enough to burn all the melted material which issues into the air in the form of smoke; that is simply on account of the wick being a certain size too large. There again you see a large candle, but the light is ridiculously small, and if I allowed it to burn much longer it would become smaller and ultimately go out, because the wick is not large enough to carry up all the 
liquid which its heat has melted. Therefore, that candle would ultimately become choked by its own greese. That is a simple illustration of how requisite it is to adjust the wick to the candle itself.

Now Chevreuil first of all showed that glycerine was a very undesirable element in the candle, and he proceeded to eliminate it. That is done by a series of processes, which are shown by two diagrams on the wall. One is by treating it with alkali, and the other by treating it with acid; both of these remove glycerine in a different manner; with the alkali the process is one of saponification. The fat is boiled in a large vessel with lime or some other alkali, and converted into what is called rock; this has removed all the glycerine, and the substance is then ready to be treated with acid. The acid removes the lime, setting free the fatty acids. I will show you the experiment-on a small scale. Here is some palm oil which I will treat with a little potash, make it into soap, throw it into water, and decompose it with acid. I use potash because that is an alkali which will make a soluble soap. Rock (oleate and stearate of lime) does not dissolve in water; but lime is used because it is much cheaper than soda or potash. Of course you know that oil and water are proverbial as two things that will not agree, the oil floating on the top of the water when added to it; but when it has been boiled with a strong solution of potash, it becomes soap which dissolves in water very readily indeed. I now throw that soap into water; there is a beautiful lather formed on the top, and the soap is readily soluble, which you know the fat by itself would not have been. Now, imagine this represents the rock formed of the lime and fatty acid. If I add a little acid to that solution you will see the lather vanish immediately, and it will become a milky fluid. By one shake the lather has vanished, and the solution has become perfectly milky. In a short time the oil will rise to the top again, which is really palmitic acid, so that I have taken the acid out of the palm oil, and left the glycerine behind. When we do that on a large scale the glycerine comes out 
in a very thin solution. This, when evaporated down in the still, assumes the appearance of that lovely substance which we all know under that name. That is Chevreuil's great discovery. Sulphuric acid is used as being preferable, but hydrochloric acid will also answer. This invention has been worked upon by Mr. Geo. Fredk. Wilson, of Price's Patent Candle Co., whose name certainly deserves to rank next to Chevreuil, for the marvellous effects his discoveries have had on the stearine industry. Mr. Wilson treats the fat in a different manner. He first of all mixes it with strong sulphuric acid, which has great power of carbonising; so that by this process we lose the glycerine altogether, because the sulphuric acid attacks glycerine much more readily than it does fats, and, therefore, if just enough acid be used the glycerine is destroyed without touching the fat. I have here a carbonaceous body, which we will take to represent the palm oil, or any oil, for this process may be applied to the worst, and otherwise intractable, fats, which cannot be utilised in any other way. Suppose we have such a fat here. I add a little strong sulphuric acid to it, and you will see that it blackens. In a few moments the carbonisation will have become complete, and the whole of this carbonaceous body will assume the form of fine spongy carbon. You will judge by the violence of the action which takes place that the process has to be conducted with great care on a large scale; but the result of it remains the same. The operation is carried on in a large tank, the matter thus treated is conveyed into a still, and distilled off in a current of steam, whereupon it produces this beautiful substance from which composite candles are now made-palmitic acid. Wilson's process is applied more especially to highly coloured inferior fats; the saponification process, by which we make stearine, is applied to good fat, and especially of fine colour. Here is a block of stearine, and when I break it across, you will see the beautiful grain it has. That was made from a block of tallow similar to that which you see in the corner. You notice the beautiful crystalline appearance. 
Anybody looking at it and comparing the two bodies together, would hardly believe that one was the source of the other. Although it is a most tempting subject to deal with, I must leave the question of saponification, and the work of Chevreuil, because there is to be a lecture on soap, wherein I have no doubt the theory of saponification will be treated at full length, and a most beautiful theory it is. I must now proceed to the last stage in the history of the candle, and that is the discovery of paraffin, and getting snowy paraffin from black earth, because it is really nothing else. It is long ago, about I830, that Reichenbach first obtained that peculiar white substance called paraffin from the tar of wood. Several other people worked upon it, but it remained for Rees Reece to take out his celebrated patent in 1850 for the distillation of peat; that is this peculiar half-coaly substance which furnishes but a small proportion of paraffin; still it yielded some. I have a diagram showing how that was done. The peat was placed in a cylinder, heated gradually, and the distillation products led through a series of pipes until they condensed and settled down into paraffinaceous oil. The next step was taken by Mr. Jas. Young, and his discovery has perhaps done more, after Chevreuil, to illuminate the world than that of anybody else. In a small garden near Castleton, in Derbyshire, he observed a little stream of oil perpetually running. This led him to make experiments, when he found that there was a kind of bed of shaley coal and petroleum bearing minerals underneath the oil-fount. He thought it must be the heat from the ground that distilled this coal, and consequently if he took coal minerals and distilled them he should obtain paraffin and oil. Upon this assumption he based a number of experiments extending over many years, which ultimately resulted in the production from this dark, uncouth mineral, apparently so intractable, of that lovely material, paraffin, of which here is a splendid sample which has come from the factory of Messrs. Young. When the problem was once solved there were any amount of hounds to follow on the scent, and 
one place after another started paraffin and petroleum works; but Scotland has remained the great field for this industry, for the good reason that it is about the only place where shale exists. America is now providing the continent and England to a certain extent with paraffin derived from petroleum, but still the Scotch, by unflagging ingenuity and industry, are holding their own even against the heavy influx of American goods. The applications of paraffin are deserving of much consideration; but I can only just draw your attention very briefly to the number of beautiful colours and shapes and sizes of paraffin candles which are upon the table here, which are worth a few minutes' notice. Here is a black mass of shale, and I have placed upon it as a most appropriate foundation, candles of all colours and sizes which have sprung from it, so that you may see the difference between the father and the children. I will briefly allude to the invention of the patent end, by which candles are freed from cumbrous necessity of paper wrapping to fit them in the candlestick. They are rapidly turned out from the machine here, and form a strong contrast to the hand-made candle. You have all no doubt seen Messrs. Price making candles in the building here, but their method of applying the patent end which they commenced making immediately our patent had expired, is not quite perfect, I think. Here is the patent end we used up to a very short time ago; the difficulty in making the patent end is that the butt is larger than the candle, and therefore you cannot pour it out into one mould; it would stick on withdrawal; therefore it had to be commenced in two pieces, and the butts were lifted off when the candle cooled. That is very cumbrous, but still was the only way known for a long time. After long and careful experiments, this beautiful little machine was invented by a workman in his spare time, by means of which, on moving a lever, the candles can be lifted out entire. The wicks are supplied from spindles below; and as one set of candles is lifted out of the moulds they draw the wick up after them for the next candle, 
and so the process is continued until the wicks are exhausted.

[The operation of the machine was here shown.]

I must apologise for having detained you past the hour, but it is difficult to get an infinite amount of matter into a short and finite space of time. To sum up the merits of the humble client whose cause I have been advocating: a candle, when perfect, surpasses all other illuminants in that its light remains constant without attention to the end, and that its products of combustion are harmless to health and furniture. The love of compact simplicity is inherent in man; and, hence, the candle, which is still, supply pipe, furnace and burner, all in all, and self-contained, will suffer little diminution of its popularity as long as man dispels his darkness by artificial light. Great names are closely associated with the progress of the candle; two especially, Young and Chevreuil. The former, of paraffin renown, has lately passed from among us; but the latter remains, and will shortly see the evening of his centenary brightened with the myriad lights which his wondrous skill evoked from sorry tallow to illumine a darkling world.

The CHAIRMAN then proposed a vote of thanks to Mr. Field for his very interesting discourse. It was marvellous that in the space of little over one hour he had been able to travel over the whole history of candles from their earliest stages, and to give something like an exhaustive, and very interesting, account of the most recent forms of candle-making. 


\title{
SOAP.
}

\author{
$B Y$ \\ C. F. CROSS.
}

VOI. XII.-II. L. 



\section{JULY 3IST, I884.}

\section{A LECTURE ON SOAP. \\ By C. F. Cross.}

Dr. WRIGHT in the chair.

The Chairman, in introducing the lecturer, said $\mathrm{Mr}$. Cross had devoted such time and attention to this subject as to have become an authority upon it. It was not necessary for him to waste time by dilating upon the value of soap, but he might be permitted to call attention to the fact that soap had been proposed as a standard of civilization, the state of civilization of a country being attempted to be gauged by the quantity of soap used per head; and he was glad to say that the result was very satisfactory so far as England was concerned.

\section{LECTURE.}

IT is scarcely necessary for me to point out that soap occupies a position in human affairs which is quite unique. Whether we take the cynical view of a well-known philosopher and confess that we are a race of "patient dustgrinders," or whether we lend ourselves to the more amiable philosophy which defines dust to be "the bloom of time," dirt, or located dust, remains one of the great facts with which we have to reckon, and soap the greater fact which makes the reckoning easy. Notwithstanding these con- 
siderations, however, the poetic aspects of our subject remain altogether undeveloped; and with perhaps one exception, ${ }^{*}$ no writer has thought fit to exceed the limits of the most ordinary prose, in discussing a substance, I would almost say an individual, exercising so wide an influence on social ethics. It may be that the traditional "washingday" has wielded a deterrent influence upon many who, but for this influence, might have sung the praises of soap, and that the surroundings of the wash-tub are too severely practical to yield to the refinements of language. But whatever its function in ministering to human wants, the substance itself, considered apart from the results which it achieves, will be found well worthy of study, from the standpoint, that is to say, of material beauty, beauty not necessarily of form nor of appearance, but that beauty which is almost the very law of existence of matter in its remoter and unseen configurations. In dealing with substances, or a substance, so as to get to understand its composition and properties, and to penetrate into that region where these beauties lie hid, we employ such knowledge and methods as go to make up the Science of Chemistry; and it is to the chemical examination of soaps to which I shall chiefly ask your attention. Our examination will naturally take the

* The one writer I have excepted is Liebig. He was fond of dwelling upon the social bearings of his science. He has written of soap as follows: "The quantity of soap consumed by a nation would be no inaccurate measure whereby to estimate its wealth and civilization. Political economists, indeed, will not give it this rank; but whether we regard it as joke or earnest, it is not the less true that of two countries, with an equal amount of population, we may declare with positive certainty, that the wealthiest and most highly civilized is that which consumes the greatest weight of soap. This consumption does not subserve sensual gratification, nor depend upon fashion, but upon the feeling of the beauty, comfort and welfare attendant upon cleanliness; and a regard to this feeling is coincident with wealth and civilization. The rich in the middle ages who concealed a want of cleanliness in their clothes and persons under a profusion of costly scents and essences were more luxurious than we are in eating and drinking, in apparel and horses. But how great is the difference between their days and our own, where a want of cleanliness is equivalent to insupportable misery and misfortunc." 
directions suggested by the questions: What is a Soap? What are the principles which underlie the process of its manufacture? What are the principles which regulate the various uses to which it is applied?

It is not unusual to preface an inquiry of this nature by an historical sketch, showing how such questions have been answered in times past; but we shall be following an excellent precedent in postponing such a preamble until we have made a study of the substance itself from the advanced position afforded us in our later developments of the science and art of soap-making. The advantage of this inverted method is that it enables us to follow history under the guidance of definite mental impressions, and thus to seize the salient features of progress, avoiding the less essential particulars which it would not fall within the scope of this lecture to discuss.

Assuming, therefore, as it is my privilege to do, that the acquaintance of this audience with soap does not exceed conventional limits, I shall proceed, in the development of a more exact knowledge, from the most elementary considerations. Soap is, in strict chemical language, a Salt, and it must be my first endeavour to make this definition comprehensible by all. A salt is a compound substance produced by the union of a base with an acid. In thus amplifying our first definition, we have employed certain terms which it will be necessary in turn to define. All substances are either simple or compound; they are either homogeneous or capable of resolution into components which are homogeneous ; all the destructive processes known to chemists, in effecting such resolutions, produce simpler substances, and ultimately the simplest, i.e., such as cannot be further destructed. I say destructed in place of destroyed because the latter word has come to enjoy the questionable privilege of meaning more than belongs to it by right of parentage. We destroy a house, and we undo the construction which made the bricks and mortar into a house ; in so doing we annihilate the house, but by no means the bricks and mortar. So we can destroy compound substances, but 
we cannot annihilate, nor indeed in any way alter their simpler components. Those forms of matter which altogether resist the action of destructive processes are known to us as elements. They are some seventy in number, each possessing distinctive properties, at the same time with such common resemblances as cause them to fall into natural groups. For our purpose, indeed, we may consider them as divided into two groups, the metals and the nonmetals. These terms, so far as they relate to external properties, will be sufficiently understood on the basis of our conventional knowledge of what constitutes a metal; it is only necessary to add that these external properties are correlated with those more recondite properties which are known as chemical. These simple substances, which are not metals, are known to us in various forms; some as invisible gases. Of these the most important is oxygen; the element whose presence in the atmosphereof which it constitutes one-fifth by volume-confers upon it its property of supporting life and combustion. With this element the members of both groups of metals and non-metals combine to form compounds which exhibit also a striking distinction in properties; the compounds of the non-metals with oxygen are the acids, of the metals the bases. This statement of generalities we need not qualify by the consideration of exceptions; we take them as typically true, and selecting a typical member from each group of elements, we shall first demonstrate their combination with oxygen. Of the non-metals we select phosphorus; of the metals sodium. In both of these elements the tendency to form a compound with oxygen is so strong that mere exposure to the air is sufficient to produce marked changes in the substances, these changes being the expression of combination with oxygen. Phosphorus, in this slow combination with oxygen, becomes, as every one knows, luminous, and if this combination is accelerated by allowing it to proceed in an atmosphere of pure oxygen, the light effects which attend it are extremely brilliant. On performing the experiment of burning phosphorus in 
oxygen, and bringing the white substance, which is produced in the form of dense clouds, into contact with water, we obtain a solution of this oxide of phosphorus. Applying to this solution the familiar test of the tongue we find that it is sharp or sour to the taste; it is, in fact, phosphoric acid in the condition of dilute solution. We also observe that it has the power of acting upon certain vegetable colouring matters ; litmus, for instance, a colouring matter obtained from certain lichens, it changes from blue to red. We have now therefore followed the element phosphorus from its elementary condition, in which it was a pale yellow waxy solid, through its combination with oxygen to form a white solid phosphoric oxide, totally unlike its parent elements, this waxy, solid, and gaseous oxygen, and into the condition of solution of this solid to form aqueous phosphoric acid.

We have now to follow our typical metal sodium through a similar series of combinations.

Like phosphorus it is very greedy of oxygen, so much so, that momentary exposure of the bright surface of the metal is sufficient to destroy its metallic lustre ; combination with oxygen taking place, and the product being a white substance having no resemblance to the metal, the latter becomes coated with this its oxide, and the surface of the metal is no longer recognizable as such. This opaque white mass was originally a portion of metallic sodium, which as the result of simple exposure, has undergone oxidation throughout its mass, and is now, in fact, oxide of sodium or soda. If this combination with oxygen is in any way accelerated, it takes place with evolution of great heat. Thus in placing the molten metal in an atmosphere of pure oxygen gas, the combination is so violent that it is attended by conflagration, or rather deflagration. The attraction of sodium for oxygen is so great, that it instantly withdraws this element from many of its compounds-notably its compound with hydrogen, which is water, in this case with so great an evolution of heat as to inflame the hydrogen gas which is set free. But in whatever way it obtains or

VOL. XII,-II. L. 
combines with the oxygen, the product of its combination is always this same sodium oxide or soda. On dissolving this body in water we obtain a solution which is not sharp to the taste as is the acid, but, with apologies to the musicians, flat or mawkish ; moreover it is slippery or oily to the touch and froths on agitation. Added to the solution of litmus, which has been coloured red by the phosphoric acid, it changes the colour to blue. Thus, then, the metal combines with oxygen, element with element, to form the oxide ; this oxide, which is termed a basè, dissolves in water, and forms in solution a body which, from the properties of the solution above named, is termed an alkali.

It will have been observed that the properties of these two typical oxides, the acid and the alkali, are in their more prominent features antithetical. Fixing our attention upon the more obvious of these, viz., their opposite actions upon the litmus colouring matter, we can make use of this as a stepping-stone to the understanding of a second order of chemical combination, viz., that of compound with compound. In this we shall find the soaps to be included. Adding the acid to the alkaline solution in presence of the litmus we shall arrive at a point when their opposite actions upon the colour are exactly balanced, a neutral purple tint taking the place of the pronounced blue or red which previously indicated the presence of excess of the alkali or acid. We also find that the solution affects the tongue in a manner quite distinct from that of the acid or alkali; the taste is that which we describe as saline. What are the matter-changes expressed in this suspension or neutralisation of active properties? To discover these changes it will be necessary to drive away the water, and thus to isolate the substance to which belong the inactive properties. In this way we obtain a crystalline solid having an appearance resembling that of salt; it is, in fact, $a$ salt, and since it is formed by the union of phosphoric acid and soda it is termed phosphate of soda.

We have thus followed the process of building up a salt from its elements, and we found it necessary to do so, 
because soap, although a very complicated compound, is a salt, and therefore to understand its composition some representative salt of a less complex character must be chosen for the elucidation of this type of combination. We may now recapitulate our demonstration in a diagram.

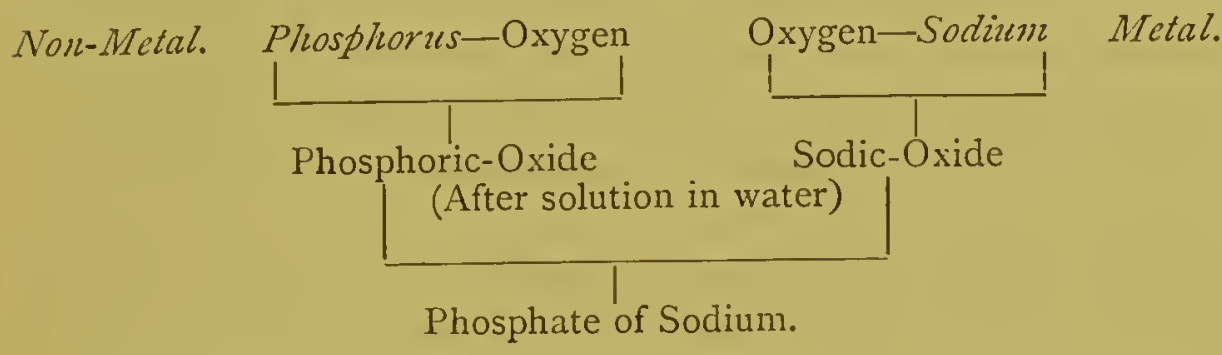

We further see in this study of chemical combination in what respects it differs from the merely mechanical mixture of substances. The products possess properties which cannot be said to be intermediate between those of the combining substances; they are altogether distinct. This we have already seen in the above illustration in regard to the chemical properties of the salt, as compared with those of the oxides which combine to produce it. The chemistry of soap will involve a distinction of this kind, which it will be well to point out in general terms here, viz., that a soluble salt is frequently formed by the union of an acid and base, one of which is insoluble. Before applying these data to the examination of soaps, we shall further need to extend them in the direction the reverse of that which we have hitherto followed, that is, to the decompositions of salts; for we shall find that it is the decompositions of soap which will best enable us to understand both its composition and modes of action. In decomposing salts, which we have shown to be built up on a dual plan and in two stages, we have usually to pass through corresponding phases backwards. We shall confine our attention to the reversal of the latter stage, i.e., the union of the acid oxide with the alkaline or basic oxide.

In saying that some acids or bases are stronger than others, it will be readily appreciated, as the simplest deduction, that if an alkali be presented simultaneously to 
two acids, or vice versâ, combination will not take place indifferently, but in favour of the stronger. So, too, if a stronger acid for example, be presented to a base after its combination with a weaker, it will turn the latter out, and concentrate the attention of the base upon itself. This is a law of attraction which enters into other relationships than those merely chemical, and one that scarcely needs demonstrative proof. It may, however, be of advantage to familiarise ourselves with its operation, by means of one or two examples. We add a solution of the soluble base or alkali, soda, to solutions of certain salts : copper chloride, iron chloride, nickel and zinc sulphates; these salts have been chosen as being formed by the union of a soluble acid with an insoluble base; if, therefore, the latter is a weaker base than the soda, being consequently expelled from its combination, it will manifest itself as an insoluble body or precipitate. Here we have four such precipitates of metallic oxides or rather oxides of metals ; since, moreover, they have characteristic colours, blue, orange-red, green, and white, it is easy to see how this reaction may be used in identifying the compounds of these oxides. Similarly also we may set free acid oxides by means of a stronger acid, and these being freed will at once manifest the properties which belong to them in the uncombined state. Thus I add phosphoric acid to a solution of carbonate of soda : carbonic acid is set free, and being a gas, escapes in the form of bubbles, i.e., with effervescence. Similarly phosphoric acid sets free silicic acid from its combination with soda, i.e., silicate of soda. Silicic acid is an insoluble body, and is thus seen to be separated as a gelatinous precipitate. We now pass by an almost insensible transition to the soaps themselves. The soaps are salts formed by the combination of the alkalis with fatty acids. These fatty acids are not the fats themselves, as ordinarily known to us, but are obtained from these by a process of resolution. The neutral fats, as these fats of natural origin may be termed, are indeed compounds of the fatty acids with glycerine, a species of salt, in fact, in which glycerine plays 
the part of base. The process of soap-making from tallow or other neutral fat, consists in destroying this combination by boiling the fat with a solution of an alkali; a saline combination of the akali with the liberated fat acid takes place, leaving the glycerine uncombined. It is with the compound of the base or alkali, and the fatty acid, that we have to do. These fatty acids are weak acids, and in their physical properties they closely resemble the fats themselves, chiefly in being insoluble in and even repellent of water.

On adding phosphoric acid to a solution of soap in water, the soap is decomposed and the weaker acid appears as a coagulum or curd. On raising the temperature of the solution this coagulum melts and rises to the surface as an oily layer; this solidifies on cooling to a cake which we can remove. The solution contains the soda, which previously existed in combination with this acid, now in combination with the phosphoric acid, as phosphate of soda. This salt we can isolate by drawing off the water in which it is dissolved; it is left as a crystalline residue. Supposing now that in this experiment we had taken a weighed quantity of soap, and had exactly neutralised the alkali which it contains, by the phosphoric acid added to decompose the soap; then if we weighed the fatty acid liberated and the amount of phosphoric acid necessary to neutralise, we should know the exact proportion of fat acid and alkali in the soap-the first, because it is actually isolated from the soap and is therefore a direct determination ; the second, because a given weight of soda neutralises a definite weight of phosphoric acid, and consequently the acid used indicates the presence in the soap of the proportional quantity of soda, which is an exact quantity. Since, however, we do not in this case weigh the constituent in the isolated state, but deduce its quantity from its effect upon a substance which we have weighed, the determination is an indirect one. But if the quantity of phosphoric acid used to neutralise the soda is an exact measure of its quantity, it might be asked, is not the fatty acid equally so? The exact answer to 
this question would lead us into a theoretical discussion remote from the scope of this lecture. Suffice it to say that while each of the fatty acids does combine with a quantity of soda which is invariable and peculiar to itself, commercial soaps consist of a mixture of the soda compounds of these acids which is necessarily somewhat variable, and therefore the quantity of soda is for this reason not an exact measure of the quantity of fat acid with which it is combined. But there is a further reason why we cannot deduce the quantity of soda from the weight of fatty acid isolated, which can be given here in connection with this subject of soap analysis, viz., that soaps often contain free or uncombined alkali, in addition to that which is held in combination by the fatty acid to form the normal soap. The presence of alkali in this form is in most cases highly objectionable for reasons which we shall subsequently detail ; it is therefore most essential to be able to rletect it.

It will be convenient to notice here a method for this purpose, as it will also familiarise us with an important property of the neutral soaps, viz., their insolubility in solutions of common salt. On the other hand, the presence of this substance does not in any way influence the solubility of the alkalis, nor their property of reacting with acids, nor of turning litmus blue. If now we add salt, or indeed a salt solution to a solution of soap, we cause the precipitation of the soap, which appears as a curdy coagulum. On separating this by filtration from the solution, the presence of any free alkali can be readily detected in the latter, and its quantity estimated by such tests with acid as have been already described.

The presence of free alkali in a soap usually results from a defective cleansing process of the finished soap. There is another and similar defect in manufacturcd soaps also the result of faulty processes, that is, the presence of unsaponified fat.* This abnormal constituent, though less objectionable than free aikali, necessarily lowers the

* Frequently present in toilet-soaps. 
quality of a soap; it is easily detected by taking advantage of any of its well-known properties. Thus on dissolving in water a soap in which it is present, it will rise to the surface as a fatty scum. Its actual separation from the water is effected by a method which is interesting, not only in itself but as typical of a large number of similar methods. The fats are soluble in certain liquids which in their turn are insoluble in, or inmiscible with water. Benzene is such a liquid, and its property of dissolving fats is one that is brought into frequent requisition. On shaking the aqueous solution of the soap, with its scum of unsaponified grease, with benzene together, the fat is entirely dissolved by the benzene, which moreover constitutes a distinct layer above, and is easily separated from the lower or aqueous portion by means of a separating funnel. This contrivance is simply a funnel to the narrow tube of which a glass stopcock is adjusted so that the flow of liquid may be sharply arrested at any given point. On evaporating the benzene, any fat which it had dissolved will be left behind and may be identified by an examination of its properties. In the example in question, the benzene containing the fat in solution is left behind in the funnel-after drawing off the aqueous portion to the last drop. We may mention here another application of this method to the analysis of soaps. The process of separating the fat acid by decomposing the soap in aqueous solution with a strong acid, melting the fatty acid, and afterwards removing it as a cake from the surface, is obviously crude. In the first place very few of the fatty acids would have cohesion sufficient to form such a cake; some of the fatty acid would in any case stick to the sides of the vessel, and thus cause a loss. By mcans of the fat solvents, however, which we are considering, the curd of precipitated fatty acid is dissolved, carricd to the surface with the liquid, which is of lesser specific gravity than the aqueous portion; the latter is drawn away and the solution of the fatty acid is isolated. By evaporating away the solvent, the fatty acid is left behind, and may be weighed with the certainty that 
it represents the whole of the fatty acid present in the original soap.

We have now considered soap as a salt, a body formed by the union of, that is, an acid and an alkali. We have seen that either of these several constituents may be present in abnormal quantity, and we have shown how they may be separated from the normal soap.

We may sum up these results in a diagram :-

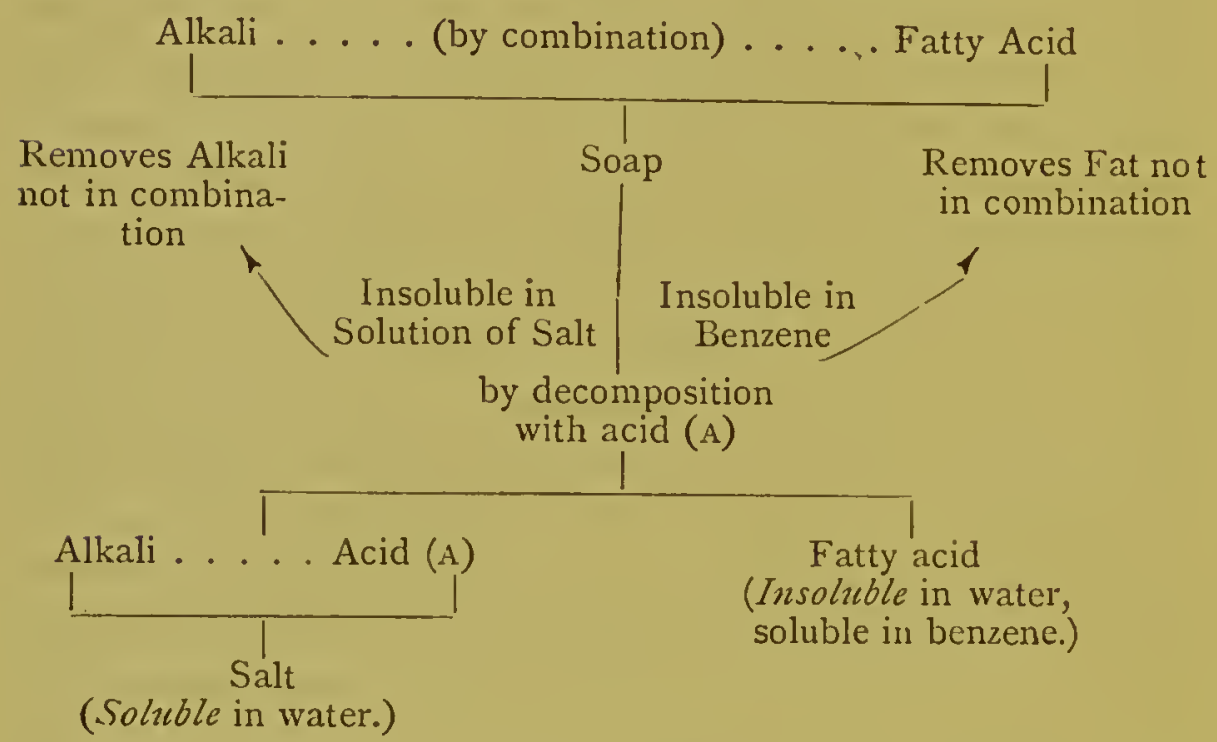

We have in the next place to turn our attention to soap as an article of commerce. The first thing that meets us on our voyage of discovery in this direction is water. The presence of water in soap is to be considered as resulting from two causes, the first of which only is of general application, viz., the natural affinity of the fat acid-alkali compound, the true soap salt-for water; the second, which is the natural affinity of man for money, is, we are glad to say, limited to a narrow field.

With regard to the first of these, the greater number of the salts which are soluble in water, in the act of separating from water, usually in the crystalline form, take up a certain quantity of water, which is definite and invariable and necessary to the crystalline structure of the salt. This crystalline water can in most cases be driven off by exposing the salt to a temperature equal to or below that 
of boiling water, and its expulsion is attended with the loss of crystalline structure, the salt falling to an amorphous powder. The crystalline character of soap, although such as to escape casual observation, is easily recognised by a careful inspection of its mass. It may be brought to a more obvious demonstration by dissolving the soap in alcohol and allowing this solvent to evaporate slowly, when it separates in the form of silvery crystalline scales. (Specimen shown.) Owing to the peculiar state of aggregation of the soap crystals the loss of its water of crystallisation does not appear to be attended by any change of structure. The soap dries on being heated, to a horny, more or less transparent, brittle solid, which may be reduced by grinding to a powder; such a powder is an actual dry soap. We shall speak subsequently of certain applications of this dry soap.

It is obviously simple to perform this operation of "drying in " upon a weighed quantity of soap and from the loss in weight to calculate the percentage of water in the original soap. It is only necessary, to ensure the complete expulsion of the water, to reduce the soap to fine shavings, in which condition it is rapidly and completely dehydrated or dried. The quantity of water present in normal soaps is from 16 to 35 per cent., according to their kind.

But, as we have already indicated, this quantity is often exceeded under the influence of a cause, the incidence of which is first upon the manufacturers. The love of gain, when indulged at the expense of others, is a vice which leads men to forsake art and take to artifice. In soapmaking it takes this form of perverting ingenuity to the production of highly "watered" soaps, * the artifice consisting in keeping up the appearances of the soap in opposition to the influence of the water, which is in the direction of causing diminished hardness and loss of the "graining" or "strike," peculiar to normal soaps. In the

* The practice of watering soaps has led to a saying amongst manufacturers, "Hc makes his fortune who makes water to stand upright." 
detection of this fraud, which we are glad to be able to say is not common, we have the à priori evidence of low price-by the irony of events most frauds comc to bc practised under the cloke of a simulated generosity-and $a$ posteriori, the evidence of a determination of water according to the method above described. It is scarcely necessary further to point out that the severe test of the wash-tub, soon reveals the true character of these fraudulent soaps, their lack of the genuinc substance causing them to "waste." In view of these facts, of which some of my audience will probably have been in ignorance, there should be no excuse for continuing to pay for water at the rate of a penny a pound or more.

To show that there is need of caution in this matter on the part of buyers of soap, I may cite one or two typical instances of watering soaps. The yellow soaps, which are perhaps the most commonly used for household purposes, are sold in several qualities, the sole distinction between which is in the quantity of water which they contain.

I have here a series of four soaps representing specific dilutions of an original tallow-resin soap by successive additions of water, in the following proportions.

To Io cwt. of the finished soap :

(1) 25 lbs.
Ioo lbs.
(3)

270 lbs.
(4) 560 lbs. water.

This varying percentage of watcr constitutes each of these soaps a spccific variety, sold under a spccial namc. I leave it to the intelligent public to decide what practical cnd is subserved by this, which is a standard custom of the trade. In low-priced cocoa-nut oil soaps the addition of water is often carried to a point far exceeding the limits of convention and established precedent. I have seen a good-looking hard white soap, which contained 70 per cent. of water, a soap which could be made for no purpose but that of deliberate fraud.

These instances will suffice to illustrate the elastic nature 
of the manufacturers' views on the subject of this very important constituent of commercial soaps.

We have now discussed the constitution of the normal soda soaps; we have seen that their normal constituents are alkali, fatty acid and water ; the two former in combination constituting the true soap substance, the latter being what we may term the "conditioning" constituent, or that which is necessary to the state which commerce has chosen as the most convenient for soap. We have seen that either of these normal constituents may be present in abnormal quantity, with a proportionate influence on the quality of the soap. We have also seen how these constituents, normal and abnormal, may be detected and their quantity determined.

It will be remembered, too, that this discussion grew out of a general consideration of the relationships of the constituents of simple salts, more particularly in regard to the substitution in combination, of either the acid or base by a stronger member of either group-acid for acid, base for base. Soaps are essentially compounds of strong bases with weak acids, and in consequence are by no means neutral in their reactions, but, as might be expected, allow the properties of the alkali or base to preponderate. Keeping to this strictly chemical view of the soaps we might include in the same group all similar compounds of weak acids, with the alkalis.

It will be useful at least to compare certain of these with the soaps, for the twofold reason that the comparison will throw light upon the mode of action of the latter, and also that compounds of certain such acid bodies, not of the fatty group, with the alkalis are ingredients in what must be considered normal soaps. The essential property of the soaps is the detergent action of their solutions, and this is obviously derived from the alkali which they contain; the fat acid cannot contribute otherwise than indirectly to this action, i.e., in virtue of its combination so modifying the physical properties of the solution as to promote its cleansing action, both directly and by influencing the surface of the 
substance to be cleansed. It is then in this secondary action that we shall see the superiority of the soaps proper over other compounds which are chemically similar. Of these we may mention Sodium Carbonate, ordinary washing soda. We have seen that this salt is decomposed by acids, gaseous carbonic acid being set free and replaced in its combination with soda, by the decomposing acid. The detergent action of a solution of this salt, which is well known to be similar to that of soap, obviously depends upon the influence of the alkali, the properties of which are only modified, i.e., altered in degree by its combination with the weak acid. While, for these reasons, it occupies an important place amongst detergents, it cannot be brought into the forms peculiar to soap; a hard crystalline surface and the absence when dissolved of the "lathering" property, or more correctly of the properties of which this is only one manifestation, determine its limited applications.

Sodium silicate or silicate of soda is a substance that deserves the attention of the consumer of soap, as it takes an important place as an ingredient of soaps.

Silica, the oxide of the non-metallic element silicon, is a body of weakly acid properties; it is known to us in the free state in the familiar forms of quartz and flint. Although so different in its physical characteristics from the carbonic acid which we have been considering, its chemical characteristics exhibit the closest similarity. Soda, or sodium carbonate, is formed by the direct union of carbonic acid gas with the oxide of sodium in presence of moisture. The soda soaps may be formed by the direct action of the solution of this oxide of sodium or caustic soda upon the fatty acids, in the cold; or if the fatty acids are presented to the alkaline solution, in the form of their glycerine compounds or salts, by long boiling of these with the former. Sodium silicate requires for its formation physical conditions of a different order, viz., such heat as causes the alkaline salts to be in a state of fusion. Under these circumstances silica unites with the alkali, expelling any acid with which it may have been combined, and the 
result is the formation of a glassy substance, the silicate of soda, which for this reason, and being soluble in water, is known as soluble glass.

Its solution is very viscous; in its more concentrated form it has the consistency of treacle. We have already seen that it is easily decomposed by acids, with separation of the Silicic acid as an insoluble jelly, and it therefore presents a very close analogy, both in composition and properties to the soaps. Its solution is inferior in lathering properties, its detergent action is not aided, as in the case of the soaps, by a softening action of the acid constituent upon the surface to be cleaned, and lastly it cannot be brought into a form so universally convenient as that of soap ; existing only as a glassy solid or a viscous liquid. Therefore it can only be used in the state of solution, or when incorporated with a sufficient proportion of soap as to allow the physical properties of the latter to preponderate. These considerations will enable us to appreciate the right side of the "Silicated" soap question. The wrong side consists, not in production by means of the addition of the silicate of a detergent of lower quality, but in not selling it at a proportionately low price. A silicated soap is an advantage to commerce, for there is much work which it can perform as well, if not better, than soaps of higher quality. But let there be a fair division of the advantage between manufacturer and consumer, and the Millennium will not suffer postponement.

In these soap-analogues the acid constituents are oxides of non-metallic elements. There are, however, certain metals whose oxides are exceptions to the rule of basicity; endowed, on the contrary, with the properties of an acid, and their acid affinities being of a weak order, they yield, with the alkalis, compounds analogous to the soaps.

Of these we may mention, stannate of soda, the soda salt of the oxide of tin (stannum) or stannic acid, the soda salt of the oxide of the rarer metal tungsten or tungstate of soda, the soda salt of the higher oxide of arsenic-an element which in its properties is intermediate between the 
metals and non-metals-or arseniate of soda. All these and similar compounds are employed in the form of solutions, the properties of the solid compound not being such as to procure for them any employment in this form. They are not used as detergents, excepting perhaps the arseniate, but for the purpose of impregnating fabrics of cotton and linen, either with the entire salt, or with only its acid constituent, in which case the fabric is first impregnated with a solution of the salt, and is then treated with an acid solution which removes the soda in combination, and leaves the acid metallic oxides, which are insoluble, deposited upon the fibre. In addition to these acids of the mineral world, which combine with soda to form soap-like substances, the vegetable or organic world furnish the soapmaker also with substitutes for the fatty acids. The most important of these are the acids of ordinary resin or colophonium. These acids partake of the resinous character of the parent substance. Although they are insoluble in water, their compounds with soda are soluble, the solution frothing strongly like that of the fatty soaps, which, in most respects, they closely resemble. The chief point of difference is in the granular character of the solid compounds which prevents their being compacted into masses having the sectile consistency of the fatty soaps. But they are nevertheless capable of being incorporated in considerable proportion with the fatty soaps, without sensibly affecting the consistency of the product; although they modify its colour and smell. Resin is chiefly used in the manufacture of yellow soaps, the peculiar colour and smcll of which is in a great measure due to the compounds in question. It is scarcely necessary to point out that no question of adulteration can be here raised. The resin acid compounds with the alkalis are valuable detergents, their applications being only limited by their inferiority in certain points to the fatty acid soaps. But this being duly recognised in the price demanded, there can be no suggestion of fraud.

Therc are a number of organic substances which have 
bcen employed similarly to the resins, but none occupy a prominent place as substitutes for the fatty acids.

We may therefore pass on to the second group of soap analogues, those which result from the combination of the fatty acids with the several alkalis and bases other than soda, the compounds of which we selected as typical, and from the practical point of view by far the most important.

Potash is a base so closely allied to soda that chemically speaking, in the greater number of cases the employment of the one or the other is a matter of indifference. Nevertheless the compounds of these two metals, potassium and sodium, or of their oxides, potash and soda, with the same non-metallic element or group of elements, often exhibit curious distinctions in properties. In the case of the fatty acids, the compounds with potash are the soft soaps, the most obvious distinction here being one of consistency. The fatty basis used in the production of soft soaps is usually a vegetable or a fish oil, which imparts a characteristic colour or odour to the product.

The potash soaps do not dry up as do the soda soaps on exposure to the air, but retain enough water to form a soft slimy mass. If dried artificially, the dry soaps on exposure to the air take up a very large proportion of moisture; in the case of the soaps prepared from the oils the quantity of moisture thus taken up is extremely large, often amounting to half as much again as the weight of the dry soap. In combining with water the soap regains its gelatinous form, whereas a dried soda soap remains a hard dry mass, even on long exposure.

The chief distinctions between these two great classes of soaps lies in their relationships to water. In their detergent actions they are, on the other hand, closely similar. The uses of the soft soaps are chiefly confined to manufacturing purposes. The average composition of these products will be seen in the subjoined results of analysis :

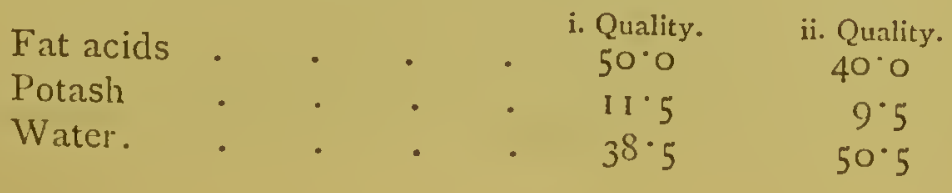


In the next place there are a number of compounds of the alkali ammonia with the fat acids, but the use of these is limited. Such compounds constitute the liniments which are employed in medicine for various purposes. Dilute solutions of ammonia, as, indeed, the dilute alkalis generally, exert the action on the fats which is known as emulsification; this consists in a breaking up of the fat into innumerably small globules, with the result of forming a milky liquid in which the fat is held in suspension. That the milky appearance of the liquid or emulsion is due to this cause may be easily demonstrated by means of the microscope In addition to soda, potash and ammonia, i.e., the alkaline bases, there are a number of metallic oxides which yield salts with the fatty acids. Thus on boiling olive oil with the oxide of lead (litharge), a mixture of the lead salts of its constituent fatty acids is obtained, lead soaps in fact, which receives a practical application in Pharmacy under the name of diachylon plaster. The oxides of iron and copper yield compounds with the fatty acids, possessing the colours characteristic of salts of these metals. Such coloured salts of the fatty acids appear to play some part in what is known as the mottling of soaps.

Such oxides as lime and magnesia also yield compounds with the fatty acids which are insoluble. We shall have occasion to speak of these subsequently.

Having now considered the constitution of soap both by means of the simplest types, and such as widen our conception of what is, chemically speaking, a soap, we have laid the foundation for the understanding of the principles upon which the application of soap is based. We shall consider such of these as are of widest interest and importance.

First, then, we have the most important, viz., the detergent action of the soaps in aqueous solution. When ordinary soda soaps are dissolved in pure water a slight decomposition takes place, a small proportion of alkali leaving its combination with the fatty acid, which now forms an acid salt, i.e., a salt containing less base than the normal, which is insoluble. Hence the turbidity of all solutions of soap in the 
cold. The tendency to decompose in this way causes a gradual supply of free alkali to goods which are washed with soap. This alkali acts upon the acid substances present in the goods-fatty or otherwise-and combining with them removes them in the form of emulsions or soluble compounds. At the same time the alkali exerts a specific action upon all organic surfaces, rendering them smooth or even slippery, and therefore less capable of holding foreign matters by surface adhesion. These are consequently removed. But, it may be asked, does the fatty acid contribute directly to the detergent action of soaps? We have seen that the property of being slowly decomposed by water ensures in the use of soda soaps a gradual supply of free alkali, and this supply being obviously regulated by the combination of the alkali with the fatty acid, we recognise herein an important indirect influence of the fatty acid upon the cleansing action of soaps. It is also evident that the fatty acids, which are continuously liberated from their combination with the alkali, will be brought into contact with the substances undergoing the cleansing operation ; indeed, when these are of an acid nature-and, in most cases, surfaces exposed to the air are more or less acid-the fatty acid will be liberated upon the surface as the result of union between the alkali and the acids in question. The fatty acids brought into contact with the surfaces of organic substances will tend to render them soft and smooth, and thus to lessen their adhesive attraction for foreign substances. Still this is rather an indirect effect, and the alkali would appear to be the sole effective agent in the cleansing work. But there remains to consider that property which is directly the result of the presence of the fatty acid in combination with the alkali, viz., the lathering of soap solutions. To understand the import of this property we may consider its most interesting demonstration which is afforded in the soap-bubble. It is only of late years that the sublime and the trivial have found another mecting point in this curious phenomenon. That which was one of the delights of our childhood-which to the poet became the type of the VOL. XII.-H. L. 
evanescent-to the material philosopher affords food for solid reflection and has been made the subject of recondite discussions. $^{*}$ The course of blowing a soap-bubble is a greater and greater attenuation of a soapy film, and the limits of this attenuation, i.e., the size of the bubble, is determined by the strength of the film, which is, in its turn, determined by the cohesion of the ultimate particles of soap. Now this cohesion, brought to demonstration by means of the bubble, upon an isolated portion of the liquid, is clearly a property of the solution itself, and must exert an important influence in overcoming the adhesion of foreign matters to surfaces.

These are the main points which we may select from amongst those properties of the constituents of a soap as well as the physical properties of the solution itself, which afford an explanation of its detergent action.

Thus far we have considered the detergent action of the soap solution simply; in practice, of course, this is aided by a number of mechanical means such as friction, with which we are all familiar. So, too, certain substances are sometimes added to soaps to promote their detergent action upon purely mechanical principles; such are sand and insoluble silicates which aid in cleansing simply by the attrition of the surfaces upon which they are rubbed. Such modifications do not fall within the scope of our present treatment of the subject, according to which any insoluble substance present in soap must be regarded as " foreign matter."

Having thus briefly considered the principles upon which rests the general application of soaps, we may proceed to consider certain particular applications, and the particular properties of which they take advantage.

Transparent soaps.-The pure soaps, i.e., the soda compounds of the fatty acids, are soluble in alcohol, whereas the saline and other impurities which accompany the best manufactured soaps, are for the most part insoluble. As these soaps contain water, it is necessary to dry them to avoid diluting the alcohol. On boiling the dried soaps

* See Inaugural Address of Lord Rayleigh. Brit. Assoc. I884. 
with strong alcohol a bright solution of the true soaps is obtained, and the insoluble impurities, falling to the bottom, may be easily separated from the alcoholic solution. From the latter the solvent is easily driven off on the application of heat, and if the operation be performed in a distillation apparatus, the alcohol may be condensed and recovered. When all the alcohol has been driven off, the soap, still hot, is obtained as a treacly mass, which cools to a semi-transparent solid. The muddy appearance which the soap presents at this stage is only lost after the lapse of a long time. In the manufacture of these soaps on the large scalc, the soap, having been poured into moulds and allowed to cool, is set aside for some months, during which time it is exposed to a temperature of about $35^{\circ} \mathrm{C}$. It thus becomes perfectly transparent, and after polishing is sent into the markets in the forms with which we are familiar. The passage from the semi-opaque to the transparent state is doubtless a result of crystallisation. The soap produced by this method, which, as we have seen, is a method of refinement of an elaborate and costly character, necessarily commands a high price, and, thanks to the imitative faculty of man, not a few spurious competitors. Respecting these latter we need not say much. There are certain soaps, chiefly those made from cocoa-nut oil, which, when mixed in the state of paste with sugar and glycerine, solidify on cooling to a transparent mass. Such a mixture, well scented and coloured, is being sold in quantity as a transparent soap. I append an analysis of one of these interesting productions :

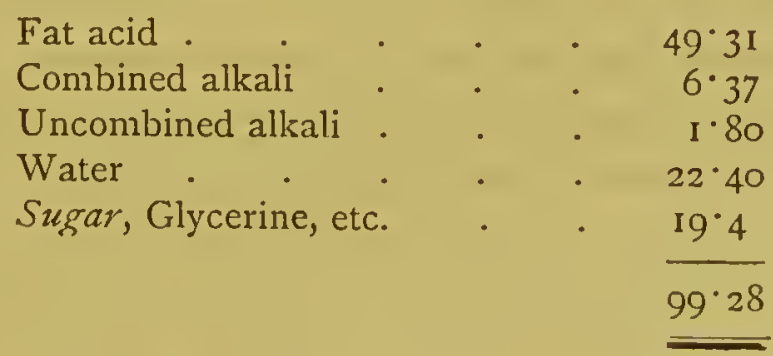

That such soaps should be sent into commerce to take rank with the refined product which is the basis of the 
genuine transparent soap, we can only ascribe to the ingenious conscientiousness by which certain manufacturers elect to regulate the ethics of their trade.

We can only warn the public against such "transparent" frauds by publishing their existence, and trust that common sense, reinforced by specific information, will succeed in disestablishing them.

Mottled Soaps.-Another curious phenomenon attending the crystallisations of soap, is that of mottling. Every fat used in soap-making is a mixture of the glycerine compounds of different fatty acids; these acids differ from one another in their physical properties, and so also, therefore, do their salts, notably in their solubilities, the quantity of water with which they combine, and the colour and appearance of the crystallised solids. When, therefore, a mass of finished soap is allowed to cool slowly, these differences are brought to light in the graining or mottling of the cooled mass. When, moreover, in addition to such regulations of the conditions of cooling, the fats used in the manufacture of the soap are especially selected with the view to bring these differences to a maximum, the mottling is so pronounced as to cause a veining of the soap similar to that of marble. The dark colour of these veins may easily be proved to be due to iron, in fact to compounds of iron oxide with the fatty acids, or iron soaps. This has long been known, and it has been customary to heighten this marbling in certain soaps by the addition of salts of iron during the process of manufacture. Still more meretricious methods have been followed for imitating this natural marbling of soaps, not so much for the sake of the particular effect, but because mottled soaps are necessarily of high quality, and the next thing to possessing this high quality is to possess the appearance which is its more obvious criterion. The necessarily high quality of mottled soaps results from the fact that to produce this marbling not only must the soaps be very carefully made and finished, but that the effect is obtained only in presence of a minimum quantity of water. The usual limit for water in 
a best mottled soap is $18-22$ per cent., and the soap, in the condition in which it is sold, often contains much less.

We should point out here that a good mottled soap differs in no essential particular, i.e., in regard to composition and properties, from a curd soap, which is a pure tallow soap and, in fact, the purest soap that is made. In a mottled soap the "goods" used in making the soap are less highly refined, and the process of making is not carried quite so far as in the curd soaps. A mottled soap is thus a curd soap in the making of which precautions are taken to preserve a mottled appearance in the finished soap. In making curd soaps, especially those of second quality, it may be mentioned that a mottled product is obtained in spite of precautions to the contrary. Curd soaps have the property of being remarkably resistant to the solvent action of water, and their use is attended with the minimum of "wasting."

For laundry work and for all ordinary washing purposes the use of mottled soaps is, therefore, to be recommended (by "mottled" soaps I need scarcely say I mean the naturally mottled soaps); further also because they are their own guarantee of being well made curd soaps, i.e., of a due balance of their constituents, and are produced at a cheaper rate than the true curd soaps; the consumer has, therefore, in these soaps a guarantee of a due proportion of price to value.

The practice of artificially mottling inferior soaps-even though there be not the slightest intention to defraud-is not to be commended. It is difficult to see any useful purpose which it subserves, and certainly it cannot be defended on art grounds. We would therefore ask consumers to aid in breaking down a bad custom-bad, because it wears an appearance of evil intent-by avoiding artificially mottled soaps. We would more especially instance the blue mottled soaps in which the marbling is produced by means of ultramarine blue incorporated into the soap paste. It requires very little insight to enable the buyer to detect an 
artificially marbled soap, and we hope no further showing to induce him to reject it when detected.

Having now considered these two classes of soaps which had important bearings upon general principles of our subject remaining to be elucidated, we can devote only a very few words to the larger number of soaps which lie outside these groups. Moreover it is the less necessary that we should for the reason that they express in the simplest manner the modes of combination of the alkali, with the acids, fatty and otherwise, which we have treated at length in the earlier part of this lecture.

The division of soaps into groups, according to the methods pursued in their manufacture, will enable us to treat the more concisely of their properties in regard to their applications. The two main groups of soaps, on this view, are those (I) that are finished by the process of "fitting." This consists in boiling the soap, after the process of saponification is completed, with water, and then allowing to stand for some hours, in order to remove the excess of lye and other impurities. (2) The second class of soaps, in which are included the curd and mottled varieties, are those that are "framed" directly from the process of boiling with alkali. We have already devoted some space to the special consideration of these soaps, and we have now only to point out, in comparing them with the fitted soaps, the influence of the different mode of finishing them.

In transferring the soap paste to the frames in which it is allowed to solidify, some portion of the caustic lye remains entangled, and although to a great extent expressed by the contraction of the cooling mass, a residue remains. A freshly cut mottled soap will consequently be found to be very caustic to the taste, and its use attended with injurious effects. This causticity disappears on keeping, probably owing to a completion of the saponification. In buying curd soaps, therefore, the consumer, keeping these facts in view, should avoid products which present this defect, and prefer those which time has 
robbed of their "sting." We may now proceed with our resumé of these various soaps.

i. Fitted Soaps.

Yellow Soaps.-Ingredients. Tallow, resin, with varying proportions of water.

Average composition of genuine soap :

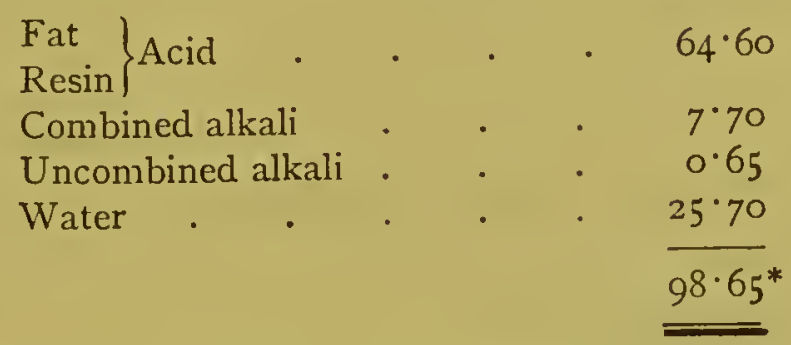

The lower qualities produced by increasing the water, the proportions of the other constituents to one another remaining unaltered.

Scouring Brown.-Ingredients. Tallow and resin, of lower quality than the preceding, water.

Average composition:

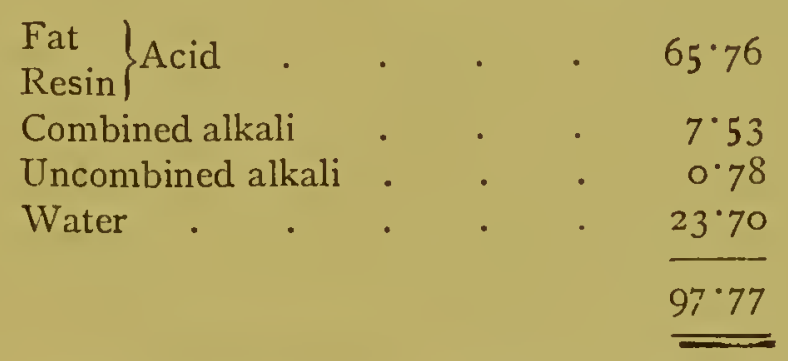

Brown Oil.--Ingredients. Olein (residue from the manufacture of stearin, and consisting of the oily or liquid constituents of tallow), and soda:

Average composition :

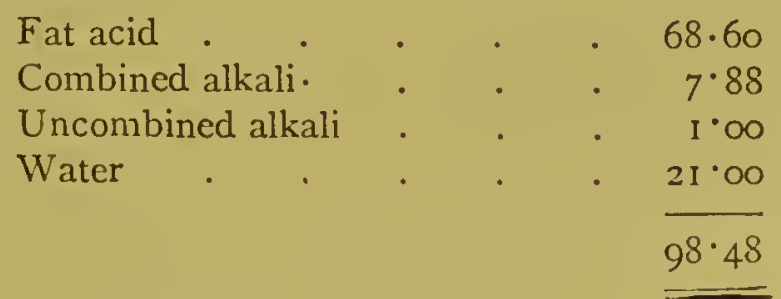

* This and subsequent analyses are of products exhibited in the building. 

soda.

ii. Curd Soaps, - Ingredients. Tallow (finest quality) and

Average composition :

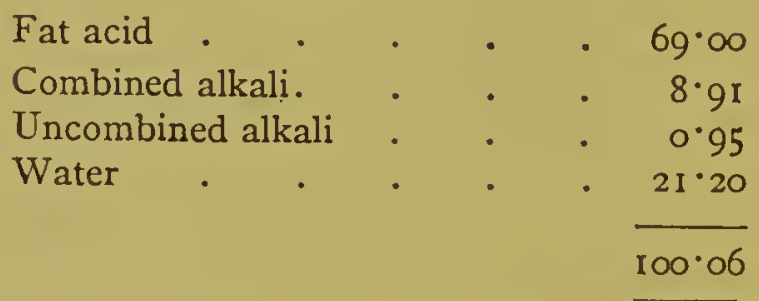

Mottled Soaps. (Best).-Ingredients. Tallow (second quality), soda.

Average composition :

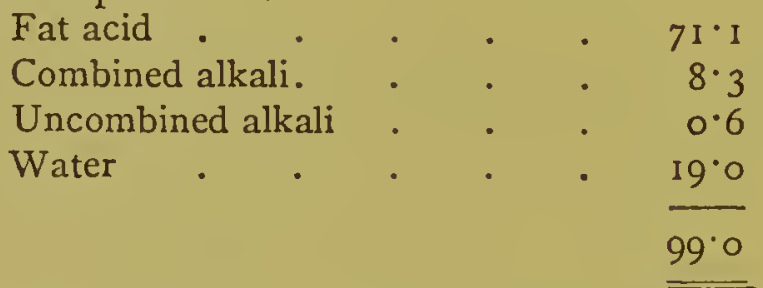

iii. Cold process Soaps. - A large number of soaps, especially those prepared for toilet use, are made without the aid of extraneous heat. The basis of these is chiefly tallow, cocoa-nut oil being also frequently added. The process of saponification, which necessarily is of longer duration, goes on for a long time after the framing of the paste. Excepting this important difference in the method of preparation, these soaps exactly resemble the preceding.

iv. Miscellaneous Soaps.

Cold-water Soaps.-These are soaps containing a large proportion of free alkali. The following is the composition of an excellent specimen :

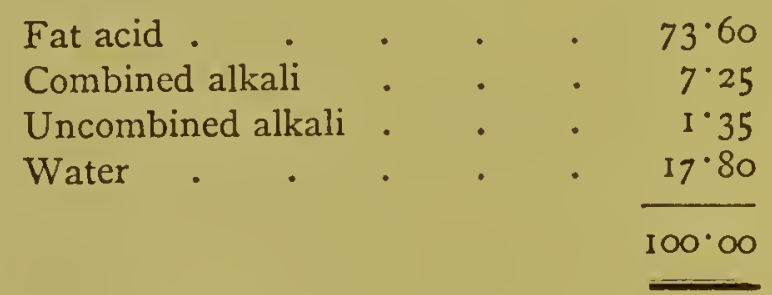

As indicated in the name these soaps are freely soluble in cold water; this property, however, in regard to many 
of the uses of soap, is anything but desirable. In cases when rapidity of solution is a desideratum these soaps are to be recommended, always remembering that they are abnormally alkaline, and necessarily wasteful.

Silicated Soaps.-Soaps containing silicate of soda are never so declared. It is a common ingredient in low-priced soaps, in which it is not to be considered as an adulterant, for the reasons already stated. Such low-priced soap, in which the percentage of water is normal, are to be recommended for common scouring purposes.

Marine Soaps.-Soaps made from cocoa-nut oil differ from those made from the ordinary fats in being by no means so insoluble in solutions of common salt. Hence their employment on board ship, and their special designation.

Of all soaps a genuine fitted soap is perhaps the safest to use, and in cases where excess of alkali is to be avoided, is especially to be preferred; whereas the curd soaps, notably the mottled varieties, will be found the most economical. In regard to the latter we may repeat the caution against using newly made products.

A simple test of "mildness" in a soap, i.e., the absence of undue causticity, is that of applying the tongue to a fresh section. The tongue is extremely sensitive, and a soap that does it no violence may be safely used for any purpose. Soaps which are to be used for manufacturing purposes, must be judged by a more complicated standard, into the consideration of which our limited time forbids us to enter.

We come now to consider more in detail the application of soap to washing purposes. We have already discussed the theory of the detergent action of soap, but we assumed in that discussion a condition which never obtains in practice, viz., the entire absence of dissolved mineral matter in the water employed. The distinction of waters into hard and soft is familiar to all, as is also the criterion upon which the distinction rests, viz., the greater or less soap destroying power of the water. We have now to consider 
this soap-destroying action as a necessary accompaniment of all ordinary washing processes. A hard water when used with soap is recognized by the difficulty which we experience in obtaining a lather. This eminently practical test has been adopted, with certain necessary refinements, in the exact estimation of the hardness of a water.

We have already seen that a soap is destroyed by anything which overcomes the bond of union between the acid and the alkali. We studied certain decompositions of soap in which this union was destroyed by adding an acid having a stronger affinity for the soda than that with which it is combined in the soap. This is a simple or single decomposition. We must extend our knowledge of decomposition to that which is by far its more general method. This is when two compounds, of two similar individuals each to each, e.g., $\mathrm{A} a$ and $\mathrm{B} b$, of which $\mathrm{A} B$ are members of one group, $a b$ of another group of compounds (or elements), are presented to one another, and cross combination takes place between the dissimilar constituents of each, A with $b, B$ with $a$. Thus we may take, for illustration, the decomposition of a soda soap by sulphate of lime or gypsum, a common constituent of natural waters.

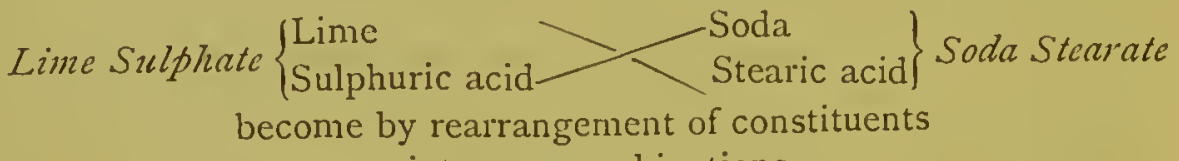
become by rearrangement of constituents into new combinations

Soda Sulphate and

Lime Stearate.

This mode of decomposition is especially common in the case of salts. It is most complete where one of the salts resulting from such mutual decomposition of two soluble salts is itself insoluble. This is the case in the decomposition which we have cited above, the resulting lime stearate or lime soap is insoluble. Since the hardness of waters is for the most part caused by the presence of salts of magnesia and lime, and its soap-destroying effect is due to such double decompositions between these and the salts constituting the soaps, as we have illustrated above, the laboratory test of the hardness of a water will require 
but little further explanation. A pure fatty acid soap (Castile soap is recommended) is dissolved in weak alcohol (35 per cent.), Io grains of the soap in I litre. In order to standardise this solution, as the process of ascertaining its exact value is called, a second solution is prepared by dissolving a known weight of a pure lime salt in a certain volume of water. A certain volume of this lime solution, or artificial hard water, being taken, it is observed how many volumes of the soap solution are required to produce with it a permanent lather; the strength of the latter being thus expressed in terms of the lime salt which it overcomes, it becomes at once the measure of the hardness of natural waters.

We shall now demonstrate this test in detail, at the same time we would recommend those who wish to study the subject more exactly to consult Wanklyn and Chapman's treatise on Water Analysis (4 Ed. i 876, p. 64).

The results of determinations of hardness are expressed by means of "degrees." Thus a water of 16 degrees of hardness is a water containing soap-destroying salts equivalent to 15 grains of carbonate of lime to the gallon; I 5 being I6 less I, the I degree having been found to represent the amount of soap required by the gallon of pure water to yield a permanent lather, i.e., after the soap has overcome the salts representing the I $5^{\circ}$, a quantity corresponding to I degree is required in addition for the formation of the lather.

Having explained the meaning of the degree, we may cite in illustration of the subject the determinations of hardness in the following waters:

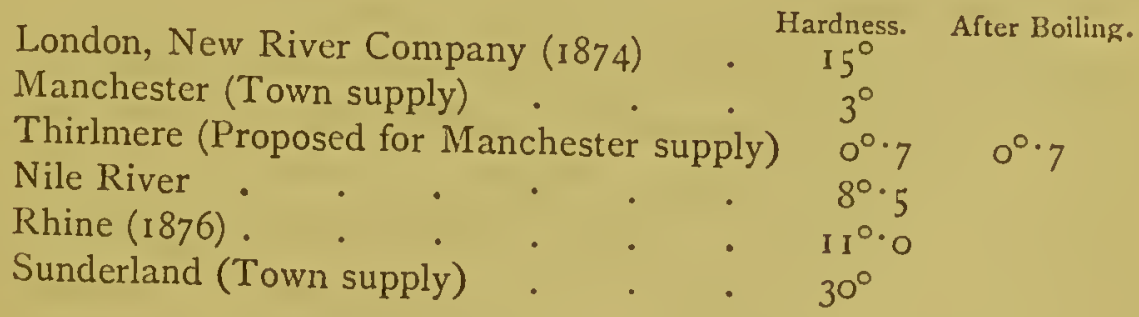

The water-supply of London is almost entirely drawn from the rivers Thames and Lea, and its average hardness 
is $15^{\circ}$. This represents a destruction of soap equal to about 2 lbs. for every Ioo gallons used for laundry purposes ; i.e., so much has to be paid as toll for the privilege of using the water, doing no detergent work whatsoever. The loss in other forms of washing is necessarily somewhat less.

The hardness in many waters is actually due to carbonate of lime or chalk, which, though insoluble in pure water, is soluble in water containing carbonic acid; all natural waters being more or less charged with the gases of the atmosphere, of which carbonic acid is one, and most of them coming into contact with chalk, it is easy to account for the presence of bicarbonate of lime in natural waters, (carbonate of lime on solution in water containing carbonic acid, becomes the bicarbonate or acid carbonate); on heating such waters the carbonic acid is driven off, moreover the bicarbonate is decomposed into carbonic acid, and the neutral carbonate, which, being insoluble, separates as a precipitate. Other decompositions also occur which cause the partial separation of the mineral constituents of waters. The deposition of mineral matter which usually attends the boiling of natural waters is known to most of us in its most obvious result-the "furring" of the household kettle. A very important subsidiary result is that the soap-destroying power of a water is always lessened by boiling, and sometimes very considerably. This fact led to an extension of the "hardness" test, a division of the total hardness, i.e., the hardness of the water in the natural state, into permanent and temporary hardness, the latter being the soap-destroying power lost in boiling. The value of this distinction is of a purely empirical order, and must not be overestimated; it is not for us, however, to enter into discussions of points which divide theorists, and we therefore accept the fact on its merits. In addition to the process of boiling there are various methods of removing the earthy salts from natural waters, attaining this result more or less completely. The commonest expedient for the purpose on the small scale is the addition of sodium carbonate or washing soda to the water. This reacts by 
double decomposition, in the manner already set forth, with the earthy salts, forming with them insoluble carbonates which are thus thrown out of solution. The result of this treatment is a diminution in the soap-destroying power of the water by the quantity of earthy salts decomposed. The oldest and best known methods of softening waters, on the large scale, is that of Clark. The more general cause of hardness is, as already explained, the presence of earthy carbonates, themselves insoluble in water, held in solution in combination with the carbonic acid of the water. Now by adding lime water, which is oxide of lime in suspension in water, to such a water, this carbonic acid is removed in combination with the lime, and the earthy carbonates previously combined with this carbonic acid, are precipitated. This is an interesting illustration of the principle "Similia similibus curantur." To remove lime by the addition of lime must strike us as curious; and although the explanation removes the phenomenon from the region of paradox, it does not surely the less appeal to our interest and wonder. This softening process may easily be carried out on the domestic scale. A little lime is made up into a cream and stirred into the water to be softened. In order to control the quantity of lime the water is tested with a solution of silver nitrate, which gives with lime a characteristic brown coloured precipitate. When more lime has been added than is sufficient for the desired effect, the water when tested will show that excess has been added by the brown precipitate which it gives with the silver solution. A further quantity of the original water is now added, until the solution when tested ceases to give the brown precipitate. Thus treated the water is allowed to remain some hours at rest; the suspended matters and the precipitate subside, carrying down with them also a large proportion of the organic impurities of the water, and the clear liquid softened and otherwise purified is ready for use.

We shall demonstrate this process by experiment, as the principles and practice of the method have considerable 
interest for all consumers of soap; at the same time, those who feel their curiosity or interest stimulated to the point of requiring further information, we would refer to the literature on the subject.

Before leaving this portion of our subject we would call attention to the more recent process of Mr. Maignen, which has already received considerable recognition at the hands of the scientific public. In addition to the hardness of waters due to the carbonate of lime, there is, as already indicated, the soap-destroying power of other salts of lime and magnesia-such as the sulphates and chlorides-to be reckoned with.

Maignen's process is directed to the removal of the whole of the earthy salts, and as far as I have been able to verify the results claimed by him, with considerable practical success. As the process is exhibited in its full working details, in this building, it will not be necessary to devote to it more than this passing notice.

The soap-destroying property of water properly understood will lead to certain simple modifications of the ordinary practice of washing, especially in regard to the removal of soap from cotton and linen goods after washing.

For the most effectual removal of soap we should rinse in warm, soft water; warm, by reason of the imperfect solubility of soaps in cold water, and soft, to prevent the formation of insoluble lime and magnesia soaps which would be precipitated into the goods. As, however, no water is absolutely free from earthy salts, it will be found advantageous to rinse in water containing a small quantity of acetic acid. It is a matter of common experience with those who handle textile goods in the operations of dyeing arıd bleaching, that to dry from an alkaline liquid, however perfectly the goods may, be rinsed in water, produces in them a dull surface and a heavy feel-this is notably the case with the animal fibres-whereas an acid bath perfectly corrects these defects. With cotton and linen goods, the defects are less noticeable owing partly to their constituent fibres being less sensitive, and partly to 
the after processes-starching and ironing-which communicate to them an adventitious finish.

With regard to the animal fibres, silk and wool, and the methods of treating them in the dye house, the necessity of an acid finish throws some light upon the washing of our own persons. Every one knows the discomfort attending washing with a hard water, and those who have delicate skins will have had occasion to notice unpleasant sensations resulting from washing with soap. So, too, in washing the hair with soap, it is a matter of common experience that when dried from the soap it loses somewhat in brilliancy and docility under the brush. These defects we shall have now no difficulty in meeting. In the first place, only the mildest soaps should be used for washing purposes; soft water is the next necessity, and lastly, when the removal of soap is a matter of difficulty, a rinse with warm water containing a little vinegar will be found an effectual aid. In regard to the selection of a toilet soap from amongst the endless varieties which compete for patronage, I must decline the invidious task of naming those which I consider the best, preferring merely to aid the judgment of the public by supplying general criteria. To those already given I would add, choose the simplest in appearance, colour, and scent and name. If then you have cause to suspect, call in the aid of technical knowledge.

Soap Substitutes.-In recent years a number of manufacturers have sent into the market preparations, designed to substitute the standard soaps-pseudo soaps, as we may call them. They are sold under various names which we need not mention. I have had occasion to analyse some of the better known of these products, with the result of confirming the anticipations which, on the basis of experience, I had formed concerning them.

Without specifying names I may put the public in possession of the results of my analyses.

"Houschold Soap Compound :"

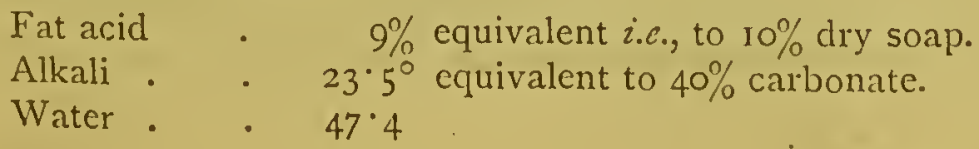


This so-called soap compound is composed of ( $\mathrm{I}$ ) water, (2) sodium carbonate or soda, and (3) soap. It is a fair type of the larger number of soap powders with which it has to compete. In two of these I determined the water to be $47 \%$ and $45 \%$ respectively; their composition was in other respects also closely similar.

Any further exposure of these impositions to the intelligent public would be out of place, not to say gratuitous, and for the rest there remains, and always, perhaps, will remain, a section of the public who would buy pump-water if it were sold in vessels of special shape and "get up," and advertised as of "superlative aqueosity."

In conclusion we may say a few words on the history of soap-making. The most primitive detergents are solutions of the ashes left after burning vegetable matter, solutions i.e., of the soluble portions of these. A simple test of any of these ashes, say of a cigar, with litmus, will reveal the presence of a soluble base or alkali. In the early ages of the world's history these were the only sources of the potash and soda, which we now prepare by our artificial methods; and in many nations these primitive sources of alkali have never been displaced. The earliest notice of the use of soap would appear to be in the Old Testament history, but the Hebrew words translated "sope" really signify the lye from the ashes of a plant, or perhaps also the juice of the plant itself. The first specific mention of the combination of an oil with this crude alkali is made by Pliny, who says, "Fit ex sabo et cinere. Optimus fagino et caprino; duobus modis, spissus ac liquidus." This soap, thus prepared from goat tallow and wood ashes, he further tells us was used for beautifying the hair, and, indeed, for the purpose of bringing it to resemble the fair hair of the Teutons. The difference he indicates between a hard and soft variety would appear to show that both a potash and soda compound were at that time already prepared.

Pliny was likewise acquainted with lead soap, of which he writes, "Molybdæna cocta cum oleo, jecinoris colorem trahit. ... Compositio ejus est libris tribus, et ceræ libra 
una olei tribus heminis." He also mentions its uses in the healing art.

A work, dating from the second century, entitled "De Simplicibus Medicaminibus," gives a more detailed description of these preparations, mentioning their uses both for detergent purposes and in medicine. A distinction is here also made between the softer and harder varieties, and further, they are named respectively the German and Gallic. This additional geographic feature is probably explained by the inore abundant use among the former people of the ashes of land plants, which are richer in potash, whereas the Gallic tribes used the ashes of sea plants, which are richer in soda. We have been made aware of the use of soap in the later period of the Roman Empire, by the discovery at Pompeii of a complete soapboiling establishment, together with some soap in a state of perfect preservation.

But little advance was made in the art of soap-making up to the end of the last century. Towards the end of the century it is worthy of note that Bergman employed a solution of soap in alcohol in the investigation of mineral waters. Early in the present century the manufacture of soap received an important stimulus (I) from the discovery by Leblanc of his ingenious method for the preparation of soda from common salt, and (2) from the researches of Chevreal into the constitution of the neutral fats, which demonstrated their true nature. In these two men therefore we recognise the founders of the modern art and science of soap-making, in the sense that the results of their labours alone made them possible. Up to the year I 852 the manufacture of soap still laboured under the yoke of an excise duty; and in that year, when it was abolished, the weekly production of soap in the United Kingdom did not exceed I600 tons. In I \& 70 we find the production had reached double this quantity, and in I 88 I had further increased to 4500 tons per week, or about 230,000 tons a year.

The Chatrian, in proposing a cordial vote of thanks to VOL. XII.-II. L. 
Mr. Cross for his interesting lecture, said that as an old lecturer he knew the difficulty of compressing large subjects into a limited amount of time, especially to a non-professional audience, who necessarily required more copious explanation than would be necessary in the case of those to whom all the details were familiar. Had time permitted, the question of soap adulteration would no doubt have been more thoroughly discussed. The lecturer had alluded to the abnormal quantities of water found in soap, and the amount of water which could be so introduced was really something astounding.

[The resolution was passed unanimously.] 


\title{
THE HISTORY OF ENGLISH DRESS.
}

\author{
BY \\ The Hon. LEWIS S. WINGFIELD.
}





\section{JUNE 24TH, I884.}

\section{A LECTURE ON THE HISTORY OF ENGLISH DRESS.}

By the Hon. Lewis S. Wingfield.

Mr. G. A. SAla in the chair.

IN studying the History of Civil Costume in England we are led to observe in the first instance that masculine attire has consisted always of a dress which was short or long, tight or loose, according to the manner of life which obtained at each particular period. For example, the Romans, who lived in a warm climate, and who in their decadence bore arms at intervals only, adopted luxurious garments which pleased the eye by grace of drapery, and were comfortable by reason of their looseness; while the hardy nations of the north-given to constant fighting and the exercise of the chase-found convenience in extreme brevity of skirt, and jackets clinging closely to the limbs. The vagaries of human fancy in the matter of costume are bounded by narrow'limits; which have widened not so very much as time has marched on. Changes have had to be rung so far as regards form (colours were in early days few and simple) upon the tight or loose, the long or short. The ancient Scythians wore trousers which much resemble ours of to-day. The smock-frock of the peasant who is expecting his franchise was in common use, trimmed just as 
it is now, in the fourteenth century, and even then it was no novelty, for in length and general aspect it was own brother to the tunic of the conquering Dane, which bore a strong family resemblance to the ordinary garb of the ancient Greek.

The Celtic tribes in the progress of their migrations to the British Isles had, like the more modern inhabitants of the South Sea, lost the ancient art of working metals. The Cimbrian savage, clad in the skin of the beast he had slain, issued in pursuit of his prey from a cave hollowed by nature, armed with reed arrows pointed with sharpened bones. The partner of his life passed her time in basket weaving, or in sewing together with leathern thongs, or vegetable fibres, the skins of such animals as had fallen victims to her husband's prowess. Clad by preference in the skin of the brindled ox, pinned together with thorns, ornamented with strings of jet and garlands of wild flowers, she attractively became the soother of his toils. The early inhabitants of our islands must have appeared to the wandering Phonicians much as the artless South Sea islanders appeared to the celebrated Captain Cook.

The result of commerce is the progress of civilization. No sooner did the Phœnicians effect an amicable intercourse with the nation of Britain than they communicated the use of metals. It is fair to presume that to the Phœnicians the Britons were not only indebted for improved implements of war, but for the first hints in the manufacture of cloth. We know that the best of them, even at this early date, were conservative in spirit and suspicious of new-fangled ideas. The inhabitants of Cornwall and the Scilly Isles had long assumed the cloth mantle and tunic, while their neighbours were still hanging back, and showing a decided bias in favour of the well-tried fur of the wolf and bear. Cloth of various kinds was manufactured in Gaul, and brought thence into Britain : a thick harsh fabric for winter cloaks; another of fine wool, dyed in various colours, chequer-wise, from which primitive habit may be traced the varied tartans still valued in the 
Scottish highlands. For a time these fabrics were made of animal substances only-hair and wool. Early human remains have been dug up from time to time clad in fragments of wool, coloured by vegetable dyes, blue, green, and purple. Others, covered with flexible filaments of flax or hemp, have been ascertained by the pots and ornaments buried with them to belong to a later date. Before the Romans entered Britain, the costume of its chiefs consisted of a Pais or close covering for the body-deriving its name from py inzeard, and ais the ribs, and which under the denomination Cota formed an important portion of Irish attire. Over the Pais was thrown a mantle or cloak. Below this came a pair of loose pantaloons, called Brigis, afterwards Braccae, from whence we derive the word still in use-Breeches. The feet were tied up in cowhide-called Brog (hence brogues); while on the head was placed a small round-peaked Cappa (whence cap).

From a very early period the inhabitants of our islands showed a predilection for maritime pursuits. Beginning with a coracle of wickerwork covered with skin, they progressed to boats hollowed out of trees, and were so intrepid as to navigate the German Ocean in their frail craft ; and, when these became sufficiently improved, travelled so far afield as Spain, whence they brought back ideas as well as goods. The Romans found them in possession of ships built of oak planks, so firmly riveted as to defy even the beaks of Roman triremes. Hence we are not surprised to see their chiefs and Druids in long and sumptuous robes, made of fine wool and linen bleached of the creamiest white, as being typical of truth and purity. Irish bards wore saffroncoloured linen, embroidered with patterns and devices; some of them assumed a species of belted plaid, in stripes of many colours, gay and sumptuous to look upon. In common with their British brethren, they wore the round conical cap, and long loose pantaloons not unlike trousers; and were very magnificent indeed in the matter of chains and jewellery.

The consideration of the arrival of the Romans on our 
shores, recalls to our minds the story of the Queen of the Iceni-the stout-hearted and much wronged Boadicea; and we happily possess a full and particular account, like that culled from a modern fashion book, of the costume which that lady wore. Thanks to the written accounts of Strabo and Dion Cassius, and sculptured figures on the columns of Trajan, and of Antonine, I am able to portray for you now a portrait of the Royal British heroine. She was a handsome, tall, full grown woman of stern countenance, with long yellow hair flowing loose over her shoulders. She wore the I'ais so much longer than that in use among men, that it took the form of a petticoat, and was woven chequer-wise in purple, light and dark red, violet and blue. Over this was a shorter garment, open on the bosom and leaving bare the arms. This was woven in shades of saffron-colours, and reached as far as the knee. On her shoulders was thrown an ample cloak, secured by a fibula, while from her neck depended a golden torque, and her arms and fingers were covered with bracelets and rings. This was her usual attire, says Dion; but when she went to war, like Pallas, she bore in her hand a lance, and protected her bosom with a heavy pair of bronze breast-plates. It is a curious fact that two such breast-plates were discovered on ploughing a field near the top of Polden Hill, Somerset. The diameter of each is $10 \frac{3}{4}$ inches; the weight $4 \frac{1}{4}$ ounces, and they are ornamented with lines like those tatooed on the face of a New Zealander, with a central nob on each, similar to that which we find upon classic-statues of Minerva.

Of the Romanised Briton, Tacitus observes, "The sons of the British chieftains begin to affect our dress," and he forcibly points out how strongly the adoption of a less manly habit as well as effeminate manners tended to rivet their chains. A sculptured stone was found at Ludgate, London, A.D. I669, which now graces the Oxford collection of marbles. That stone repeats in more elaborate form the Romanised Briton as pictured on ancient coins. He wears his hair in the Roman fashion; a loose tunic of Gaulish red 
fastened at the waist by a strap-girdle; and a cloak in lozenges of varied hue, caught up on the right shoulder to leave the sword-arm free. A-propos of sculpture I may refer to an authentic and very early Irish bas-relief, probably as old as the time of St. Patrick, which was found under the ruins of Kircullen Abbey, and which gives us the attire of a contemporary herald and an officiating priest. The Hydranus, or minister of the sea, appears in a long Druid robe of white; the herald is in his Truise (or trews, i.e., pantaloons of tartan) a yellow tunic, and a close hood with pointed end-there is nothing new under the sunwhich might have been worn by Chaucer more than three centuries later.

Having sketched for you Boadicea, I have much satisfaction in being able to append a companion portrait, drawn from equally reliable sources, of Hengist, the Saxon hero. The written description of the Welsh bard Aneurin tallies exactly with the figure of an Anglo-Saxon chief which exists in the Harleian MS. of the British Museum. He wears a Roman-shaped cuirass of scaly mail, a green kilt, a surcoat of fur, loose white linen drawers ; and, in guise of stockings, leg-bandages, such as were worn by our English soldiers two years ago at the battle of Tel-el-Kebir, as I can personally vouch. The heroic Hengist was fat and freckled, we are told; wore his long red hair flowing loose, ornamented with a wreath of amber beads, which on occasion he would exchange for a helmet, pointed at the top. His bull-neck was adorned with a golden torque and his arms with precious bracelets. Behind him floated a long cloak of deepest blue : in his hand he waved a bloodred banner.

Concerning the attire of the Danes, we learn from a basrelief that a king of the period wore loose trousers like those of the Scythians, with greaves in front of the tibiæ, which suggest the original idea of the modern cricketer's "protectors." The neck and border of his tunic were intricately embroidered. His body was shielded by a leather corselet, or zuanba, made of painted elk-skin, while 
on his head he wore a crown, and in his hand wielded a hammer, symbol of authority suggestive of the god Thor. I may perhaps here be allowed parenthetically to remark, that early Danish kings were in the habit of sending round the country a hammer as a sign or signal of summons, for which when they became Christians a wooden cross was substituted. From this we may trace the Scottish custom, so graphically referred to by Sir Walter Scott, of sending round a cross imbrued with blood as a warlike summons to the clans.

At first the costumes, military as well as civil, of the Anglo-Saxons and their Norman conquerors differed widely. While the arts of life remained stationary in Britain, social upheavals were shaking the continent. Political revolutions-intercourse with the Arabs and with Spain-brought about many modifications in European dress. These changes are plainly depicted on the Bayeux tapestry. While the Anglo-Saxons clung to the fashion of short skirts, and a general brevity of attire, the Norman lords swept about in long tunics and flowing mantles, adorned with appliqué ornamentation. Norman ladies put their Saxon sisters to shame by their comparative gorgeousness. Instead of the loose garments of the latter, they affected a robe, laced close, to display the undulations of the body. Their hair was in long plaits, wound in and out with gold chains, and even strings of gems. Ungallant religious satirists were hard upon the ladies, accusing them of painting their faces, and unduly tightening their waists. This leads me to a point which a mere man must approach with awe and bated breath, namely, the origin of the corset or female undergarment called stays.

Terence, the Roman dramatist, who was born 560 B.C., makes one of his characters speak of "town ladies, who saddle their backs and straitlace their waist to make them well shaped;" while other writers of the same era inform us that Roman women, married and unmarried, used wide girdles of stiff stuff, under which was a tight bandage that was fastened with a buckle on the shoulder. There exists 
in the British Museum a manuscript of the time of Edward the Confessor, which is adorned by a picture of the Fiend of Fashion. The figure wears an unmistakable corset tightly laced, and stiffened by two busks in front, from one of which the lace, with an ordinary tag at the end, depends; just such a garment as Swiss peasants wear now outside their dresses. Perhaps as early an instance of the use of the word corset as any in existence may be found in the household register of Eleanor, Countess of Leicester, which bears the date of May 24, I265: "Item; for nine ells, Paris measure, for summer robes, corsets, and cloaks for the same." We find the word again with reference to the wardrobe of Richard, King of the Normans, and Edward, his son, whose death occurred in the year I308; from which we are obliged to conclude that, even at that far distant date, stays were worn by gentlemen as well as ladies. A great number of ancient writings descriptive of female loveliness go clearly to prove that a slender waist was an indispensable element of elegance, and there can be no question that such being the case, no pains were spared to acquire the coveted beauty. Chaucer, who was very minute in his descriptions, speaks of a certain carpenter's wife as a well made young female whose "body was genteel and small as a weasel ;" while old Dunbar in his "Thistle and Rose" relates of Scottish belles, that "their waists were as small as wands." In the fourteenth century the Emperor Joseph of Austria, who was nothing if not an autocrat, became so alarmed by the fascinating lures thrown out by sirens for the capture of mankind, that he issued a special edict on the important subject of stays. He passed a law forbidding the use of the corset in all nunneries and places where girls were educated, and called in the Church to aid him in his laudable crusade, with a threat of excommunication against such treasonable and evil-disposed damsels as should persist in operating on their waists. Imperial anxicty startled the College of Physicians of that day into activity and zeal, and learned dissertations upon the crying sin of tightlacing were 
scattered broadcast among the people. Catherine de Médicis, being a woman, took a different view of the matter. She took a deep interest in dress, as well as in poisons, and introduced, among other things, the ruff into France. To her a thick waist was an abomination, and while she ruled at court, a thirteen-inch measure became the accepted standard which was to be attained at any cost. She even went so far as to invent a corset herself, which looks like some implement of torture employed by the Holy Inquisition. It was made of steel, inflexible as a suit of armour, cut out and wrought into an open work pattern, through which a needle and thread were passed and repassed in accurately covering the surface with velvet. It consisted of two pieces (like a warrior's breast and back-plate) opened longitudinally by hinges, secured by a hasp and pin, much like an ordinary box-fastening. At front and back a rod or bar of steel projected in a curved direction downwards, and on these bars depended the adjustment of the long-peaked body of the dress and the set of the skirt behind. No wonder the portraits of our early ancestresses look solemn and uncomfortable. Whalebone stays were first used in the time of Queen Elizabeth, and were much affected by her successor James, who insisted that all his courtiers, male as well as female, should cultivate the appearance of the wasp.

Probably one of the most harrowing of all the modish forms of screw-torture was the corset of George II., which we see so often represented in Hogarth's pictures, for the front part of it was made of wood. Before the discovery of whalebone, we can understand the use of steel; but why, so convenient and flexible a substance being at hand staymakers should have had recourse to timber, it is hardly possible to comprehend. Tailors of the time of George III. advertised "Codrington corsets," and "Petersham stiffners," for the benefit of gentlemen of fashion; and it is related of the Prince de Ligne, and Prince Kaunitz, that they were invariably encased in satin stays of expensive make, the former wearing black and the latter white. The doughty 
warriors of Gustavus Adolphus wore stays almost to a man. Thus much being said on a mysterious and delicate subject, let us revert to the march of fashion.

While the arts of life remained humdrum and uniform, so also did costume; but with the end of the eleventh century came the Crusades,- - a movement towards the East, which placed the remote West in direct contact with the cradle of the world and revolutionised manners and habits. Sumptuous striped stuffs camc into vogue, which in their turn suggested parti-coloured dresses. With the development of modes came into being parti-coloured hats, robes, leggings ; and the bizarre fashion remained common in one form or another as late as the time of the Tudors. With regard to women, Oriental dictation is first discernible in the adoption of the veil (sprung from the yashmak), which may be traced through endless varietics of shape-twisted under the chin, round the throat, over the head-changing, in course of time, into a cap and mentomiere, and finally into the ruff and winged neck-gear of Elizabeth. Wc may note in passing that from the period of the first crusade down to the fourteenth century the prevailing style of costume was much the same all over Europe. Extravagance and excess-owing to the arrival in various central markets of rich furs, silks, fabrics of gold and silver--called for special and local sumptuary laws to deal with special cases, and from that time forward divers nations assumed marked fashions of their own, reacting one upon another under influence of peculiar circumstances. Royal marriages often induced a change of mode. Montfauçon tells us that when Isabeau, sister of Charles le Bel, became the wife of Edward the Second, she amazed her loyal lieges by appcaring in "a hat of excecding height, narrowing towards the top, from which floated a veil of length and richness." When Catherine de Medicis arrived in France, she brought in her train many lords and ladies whose Italian modes and manners revolutionised her husband's court. Monstrelet waxes extremely scornful over the fashions introduced by Mary of Burgundy, wife of Maxi- 
milian of Austria. "Her gentlemen," he says, "clothed themselves shorter than had ever been done before-like unto monkeys-indecent and indecorous-cut holes in their coats to show their shirts; wore hair so long that they could not see, and padded out their shoulders like men deformed, visited of God."

Fashions in England progressed by quiet transitions until the time of Edward III., whose bellicose visits to France, naturally enough, affected the style of dress of himself and subjects. We read of richly broidered cotteshardies (jackets), of painted hoodes, numberless feathers, a profusion of jewellery. The middle classes soon vied with the Frenchified courtiers in extravagance, and carried their emulation to such lengths as to bring down on them a series of strict rules, which they, however, succeeded in evading. The eccentricity and gorgeousness of both male and female apparel reached their apogee during the succeeding reign of Richard II., against whose vain foppery a host of contemporary writers inveigh with exceeding bitterness.

"That lewd lad," writes one, "ought evil to thrive that hangeth on his hips more than he earneth. Unless the sleeves slide on the earth, he will be wroth with those that made them; eke if the elbows be not down to the heels .... But now is there a guise, the quaintest of all, a wondrous curious craft lately arrived, that men call carving the cloth all to pieces; so that seven good sewers, in course of six weeks after, may not set the seams or sew them up again. Girdles are some of them worth more than twenty marks. Shoes are snouted an ell long, like claws of devils, and fastened to the knee with chains of gold and silver."

A curious point to note with regard to this period, is that the long dagged robe was common to both sexes, so that from behind it was as impossible to tell a gentleman from a lady, as it sometimes is now, thanks to the ulster and plain round hat.

Henry IV. made a manful attempt to stem the tide of 
vanity and luxury-"all dagged and slashed garments cut in form of letters, leaves, or posies," were strictly forbidden,--but without much success apparently, for during the reigns of Henry IV. and V., we find lords with long pokes or sleeves that swept the ground, and robes or houp-pelandes, "cunningly worked, and gemmed." Longtoed shoes, woven leggings up to the waist (the first appearance of a stocking texture), and galoches or short boots, continued the mode under Edward IV. and Richard III. with little variation, but the jacket was now cut shorter, was much stuffed and padded, and crossstitched; while the sleeves were hewn in great slits for the display of finest linen. The length of the shoe varied according to rank; eminent personages wore them a foot long in front, princes two feet long. The miniatures in the Roman de la Rose give an admirable idea of the costume of this time. While men occupied their leisure with the redundancy of sleeves and toes, the minds of the ladies were fully engrossed by a wondrous series of head-dresses, We find a gold caul like a barrel, a horn-shaped hat, a mitre, a castellated tower, a cap like a heart. About the middle of the century appeared a lofty steeple half the entire height of the wearer, also a strange arrangement like the wings of a butterfly, which must have caused ladies who wore such things to enter a room sideways. The cotte-hardie continued in vogue, laced very tight, from beneath which escaped a flowing skirt of extreme length, emblazoned with the armorial bearings of the wearer, when she had any.

The natural adornment of the human head-the hairwas little prized. It was tucked away beneath the coif, and plucked out about the forehead that the brow might appear larger.

With the accession of Henry VIII. is associated, in the English mind, the commencement of the Renaissance, when a species of earthquake occurred which changed the face of the arts, and completely altered the fashions. With regard to dress, the beginning of the sixteenth century commends itself to the notice of the student as the time 
when the costumes which still obtain were born; for then were finally adopted garments fitting to the body, closed slecves, and boots, which followed more closely than heretofore the outlines of the foot.

Though shoes were made with an exaggeration of squareness, even this was more natural than the earlier peaked toes and extremities fastened to the knee. The bulbous shoe was soon to soften down like the bulbous sleeve, and it did not take so very many years to arrive at the graceful foot-covering assumed by the lords of Queen Elizabeth. With the beginning of the sixteenth century men finally abandoned flowing robes; women first took to themselves a hcad-dress which resembles in many points the modern bonnet; whilst their husbands (according to Randal Horne) began, for the first time, to don felt hats with brims, although, as a timid compromise, there lurked not uncommonly bcneath them, a skull-cap which bore a strong likeness to the discarded clapeau rond.

Gloves came into common use. In France they were worn by all well-drcssed people under the later Valois. The rolled slceves which we associate with Henry VIII. can be traced to the pageant of the Cloth of Gold; for, till the visit of Henry to France, no sign of any such fashion in England is to be found, whercas we know that Francis had alrcady adopted just that very fashion which came to him dircet from Germany. The hcavincss and unwicldly thickness which characterise the English dresses of I 520 or thcreabouts, arc clcarly traccablc to the growing commercial intcrcourse of our nation with the Dutch, Flemmings, and Walloons, who had learned to attire themselves after the pondcrous fashion of their Gcrman neighbours. The most interesting peculiarity of all those which we might consider, is the invention of "stuff-hosen"; an article of dress which ever since has been common to all classes, in the form of knee-breeches during the last century; as knickerbockers at the present day. This is how these nether garments came into bcing.

The Renaissancc brought with it a general hankering 
after splendour in apparel, which took at first the form of complicated slashing and embroidery. The jacket being richly puffed, it became necessary, for the sake of completeness of ensemble, to puff the shoes, and asso cre tight hosen which connected these with the jacket. But here came a difficulty, for hosen puffed and loaded about the hips could not be made to fit well below the knee. This led to a dividing of the hosen into two parts, called "haut de chausses," and "bas de chausses" (hence bas, the word still used for stocking), which were buttoned at the point of junction and covered there with a band which ultimately became the buckled knee-band of knee-breeches.

The Renaissance then was conspicuous for luxury and splendour, which took the form of pageants, processions, masques, and so on-of all gatherings, in fact, which might serve as an excuse for a display of magnificent personal adornment and splendid surroundings. Less tasteful than in preceding reigns, the costume of the sixteenth century was stiff and ungraceful, yet extremely rich and expensive. King Henry of the Golden Beard, handsome then, and young and débonzzaire, eagerly fell in with the prevailing idea, in which he was no little abetted by Thomas Wolsey, who seems, like many another parvenu already dead or to be born, to have been wondrously vulgar and ostentatious. He was fond of walking in processions, preceded by two crosses of silver (one in his quality of Archbishop, the other as Pope's Legate), with a pursuivant-at-arms solemnly bearing a great mace, whilst a gentleman of good family marched with his valaunce, and others bore silver pillars before him and all kinds of pompous devices.

Encouraged by king and minister, it is no wonder that the people ran into such extremes as to render needful abrupt and summary legislation by sumptuary law. The gown of a mere citizen's wife is spoken of as "stuck all over with silver pins." People were recklessly lavishing their substance on frippery; so Henry, with characteristic selfishness, enacted statutes which rescrved cxcessive

VOL. XII.-H. L. 
gorgeousness chiefly to himself. He bade his lords "closely to poll their heddes," though they might trim their beards at will; and further declared that none save the king might wear black jennet. None below the rank of baron might place "sunken golde-werke upon velvet;" none who did not possess at least 200 marks a year might wear velvet at all. No serving-man was to have in his coat more than three yards of stuff; no husbandman was to put on hosen above the price of 12 pence, on pain of the awful retribution for vanity of three days in the stocks.

The inventory of Henry's wardrobe is an amusing contrast to these enactments.

"Item, one gown of crimson vellat, browdered with pirles, having a rich brocade border of sattin and pirles; upon the sleeves of the same gown 28 diamonds set in golde, with 28 pairs of aigletts in golde." Again, "a cote of shamewe, with much goldsmith's werke, set out with precious camerike (cambric); a pair of sweet gloves, with orient stones and white vellat; also handerchers, browdered with golde, enamelled." Again, "29 Pairs of finist sleeves."

Sleeves were a separate portion of costume, buttoned on the shoulder or tied with points.

Miany of the wealthier lords appear to have evaded the laws set by their awful master-and if the lords, why not the ladies? Women chiefly adopted the French fashion, with skirts open in front, long or short behind, à volonté. Anne of Cleves wore a "short Dutch round gown;" while both Anne Boleyn and Catherine Parr are mentioned as delighting in "trains several yards long." The hideous bonnet, known as a French hood, scems to have been most in vogue, tine cause whereof is plunged in mystery. It was not from lack of hair, for at Anne Boleyn's coronation the dames discarded their favourite hoods and appeared with flowing tresses, surmounted by a golden circlet. Hall, too, describes Catherine of Arragon, on the day before her second marriage, as having her hair down her back, "goodly" to behold, and on her hedde a coronal, set with orient stones." The King, by the way, on that occasion had on a "cote of 
raised golde, the placard embrowdered with diamonds, emeralds, pirles and great wealthy stones."

James I. supplies a new shape of hat, which was to spread in the next reign into the beautiful head-gear of the Cavaliers, and narrow afterwards, into the modern wideawake. This hat is remarkable for a flat brim and conical crown. Being of an entirely novel form, we must go a-hunting to find its origin, and after some search, run it to earth in Spain, whence it was brought to France by the conspirators of the Ligue, where it became known as the Chapeau Henri Quatre. I may parenthetically remark that in cases of doubt, it is always well to try Spain, for the Peninsula, having been tolerably free from the Crusade Mania, and having vegetated in a secluded corner of Europe by itself, was always individual and independent as to the cut of its garb.

Henri Quatre of France, and his successor, Louis Treize, exerted marked influence over the fashions of England, for did not Henrietta Maria, wife of Charles I., introduce the dress and method of wearing the hair prevalent at the Gallic court, and did not Buckingham (lover of Anne of Austria) delight in attiring himself after the French fashion? If ever there was need of legislation in the matter of sumptuary surely this was the moment for it. At the commencement of the seventeenth century luxury surpassed itself. Bassompierre paid seventeen thousand écus for a dress wherein to dance in a ballet before his monarch. It was in bad taste to wear the same dress twice at court. Even the austere Louis Treize himself, when, to facilitate the transport of his army, he had given orders for all the baggage to be left behind, was mightily exercised and took anxious counsel with Monsieur de Puységur, as to how he was to spend three days with his sister, the Duchess of Savoy, and seem to appear each day in a different suit of clothes. The Chevalier de Grammont, during his exile in England, was in the habit of despatching a faithful valet to France every week, in order to bring him back a new and tasty suit. The Baron de Foeneste writes to his tailor (temp. Henri Quatre), "I want a pourpoint (doublet, or tight jacket) of five taffetas 
one on the other ; breeches containing at least eight elis (aunes) of stuff; a bonrrelet (circular pad) for my waist, and a pair of sontiers a cric" (shoes that creak when walking). By this time the garter, which in the days of Henry VIII. had first been exposed to view, had become very beautiful indeed. Charles I. brought it home after his travels, bedizened with lace, embroidery, huge knots of ribbon twisted into rosettes. Silk stockings, too (rare and precious phenomena under Elizabeth), were now worn by well-to-do people-of necessity, indeed, for woollen stockings would not have had a pleasing effect in combination with satin haut de-chausses.

Charles II. introduces us to new and distinct fashions for obvious reasons-his long exile abroad-his southern wife, and foreign mistresses-a reaction after a too protracted course of sackcloth and ashes. One cannot help wondering, en passant, why it should have become fashionable at this juncture to don great masses of false hair Nothing can be more becoming than the ample natural locks of the Cavaliers as limned by Vandyck and Dobson. Why should they have given place to edifices of net and horse-hair? Was it an extreme protest against the cropped pates of the covenanters? Or did the King of France, finding that he was growing bald, cover his own deficiencies and insist that others should follow the august example? We are told that ruffs grew out of a scrofulous complaint on a royal neckwhy should not periwigs have grown out of a thin parting? Certain it is that Louis Quatorze is chiefly responsible for the hideous fashion of general wig-wearing, which under different guises obtained until the beginning of our century. Skipping the first of the Brunswick kings, we find under George II. an endless variety of wigs. We read in comedies of "campaign wigs," the "story," the "scratch," the "busby," the "bag," the "brown George," the "riding wig," the "tie," the "queue." "The Venetian Ambassador is spoken of about I730, as having paid $£ 500$ for a periwig. Wigs of real grey hair were very expensive. A lady when she donned her ridinghabit assumed a brown peruke with curls, like a man's. 
The three-cornered hat (unlike the ones usually presented on the stage) was made usually of soft felt with a large brim looped by three loops to a button on the top. By its softness it could be crushed under the arm ; while each flap could be let down at pleasure, in case of wind or rain, or sun. Gay speaks in the Trivia of a "hat unlooped although it doth not rain," and Cibber, in one of his comedies, talks of a footman "unlooping his hat to protect his powdered head from the wet." This shows that servants wore powder as well as their masters, and that the theory is false which declares that servants went into powder when it became unfashionable with the quality.

Powder, it appears, was worn according to caprice from a very early period. We even find it referred to under Henri II. of France (contemporary of our Mary). Italian ladies of the fifteenth century wore red and gold powder. Charles James Fox once wore blue powder. During the Wilkes riots ladies not only altered their patches to portray their political opinions, but to the same end changed the colour of their hair. Patches, by the way, date from the time of Charles I.

It is a fact of which many people are unaware, that even during a distinctly powder period the use of powder was far from universal in England. Anybody who cares to study Hogarth's pictures can see for himself that people under George II. wore powder on gala occasions (not always then), rarely at home. Some abjured the practice altogether. When I had the honour of superintending recently the personal appearance of Miss Mary Anderson in a Louis Quinze play at the Lyceum, I was considerably lectured by dramatic critics for not putting her into powder. I had my own reasons for it, and ample authority to boot, for it is a well-known fact that neither Mesdemoiselles Le Couvreur or Clairon, twin-stars of the Comédie Française (as is recorded in the memoirs of Mademoiselle Du Thé), ever submitted themselves to the powder-puff.

The costume of Anne's time was the perfected result of British taste brought to bear upon Dutch modes, which in their turn were founded on those of France. 
In pictures of Dutch masters of the period we find undeveloped and incomplete, Anne boots, Anne coats, Anne periwigs. The female téte and dress, as well as the male wig, bear a close resemblance to those worn by the lieges of Louis Quatorze, carried from France into Holland.

The following description of the celebrated Lord Bolingbroke is amusing: " $\mathrm{He}$ was dressed in the extremity of fashion, and wore a light blue velvet coat, with huge cuffs richly broidered in silver, amber stockings, crimson shoes, fastened with diamond buckles; a diamiond hilted sword, with a long silk tassel dangling from the handle. His cravat was of point lace. His hands were hidden by exaggerated ruffles of the same costly material. His hat was laced with silver, and he wore his own brown hair in ringlets twenty inches long, tied behind with a long red ribbon. He diffused around him an odour as he walked, as if he had just risen out of a bed of roses." So much for a beau in Anne's time. Horace Walpole the elder thus describes a dress worn by King George I. : "A dark tiewig, a plain coat, vest, and breeches of snuff-coloured cloth, with stockings of the same hue." Not so simple, a little later, was the other Walpole's own visiting costume, "a lavender silk suit, the waistcoat embroidered with silver, worked in the tambour, partridge stockings, gold buckles, frill and ruffles of Spanish point."

We find specimens of gentlemen's muffs in two of Hogarth's pictures; "Arrest for Debt," and "Taste in High Life." The sporting Earl of March writes in I766 to George Selwyn: "The muff you sent by the Duke of Richmond I like prodigiously; vastly better than one of 'tigre' or a glaring colour." Horace Walpole writes in I 764 to George Montague: "I send you a decent smallish muff that you may put in your pocket, and which costs but fourteen shillings."

The following details, copied from the "Weekly Journal " of May I, I736, are graphically descriptive of the time. The penny-a-liner is speaking of the wedding of Frederick, Prince of Wales, the undutiful son of George II. 
"Their majesties then retired to the apartments of H.R.H. the Prince of Wales. The bride was conducted to her bed-chamber; the bridegroom to his dressing-room, where His Majesty did His Royal Highness the honour to put on his shirt! The bride was undressed by the princesses, and, being clad in a rich undress, His Majesty entered the room. The Prince soon after followed in a long night-gown of silver stuff, with a close cap upon his head of the finest lace; and then the Quality were admitted to view the bride and bridegroom sitting up in bed, surrounded by the Royal Family.

"His Majesty wore gold brocade turned up with silk, embroidered in colours with large flowers. The buttons and star were diamonds. Her Majesty wore plain yellow silk, laced with pearls and diamonds of immense value. The Dukes of Grafton, Newcastle, and St. Albans, the Earl of Albemarle, Lord Hervey, and other noblemen were in gold brocades, worth many hundred pounds the suit. The Duke of Marlborough wore white velvet and gold, with an exceedingly rich trimming of point d'Espagne. The Earl of Euston was in cloth sprigged with gold, the Duke of Montague in brocaded tissue. Waistcoats were universally in brocade with large flowers, of English manufacture. The ladies wore brocades of English make, with large gold and silver flowers. The sleeves were worn much lower than is usual."

Queen Caroline (consort of George II.) always displayed good taste. "A robe of purple velvet, made low in front; the upper part of the stomacher and short loose sleeves made stiff with point lace. Hair divided in the centre, raised in high and ample curls above the head, looped behind by a string of magnificent pearls, and descending in clustering ringlets down her back." Here is another dress of the same period: "A blue and gold atlas gown, with a wrought petticoat edged with gold; shoes of silver, laced with gold ; a lace cap and lappets."

"At the drawing-room next day modish belles were variously attired with all the richness and grandeur imagin- 
able. Many had heads dressed English in fine Brussels lace, made on wires with small, narrow rolls, and the hair pinned to large puff-caps, and but few were without powder. Some few had hair curled down on the sides; pink and silver knots universal. Gowns were in gold and silver stuffs, some in coloured silk, or gold and silver nets. Some wore large bunches of flowers on the breast; most were exceedingly brilliant in jewels.

"The men in gold stuffs, flowered velvets, trimmed and laced, and embroidered. The cuffs are broader than ever. The wired plaits of the coat stick out very much to imitate the ladies their hoops. Wigs of all sorts. White stockings and shoes worn by both gentlemen and ladies."

With regard to the hoop, we trace it in various forms from the date of Elizabeth, when it was called a farthingale. Sometimes it spread at the bottom, sometimes at the top. At all times it was inconvenient, and was never worn in a carriage. In a sedan chair sometimes, when paying visits, a lady pulled up her hoop on both sides of her like wings. In one of Hogarth's pictures such a lady may be seen. In the London Chronicle of I763, we are told of a mysterious article of attire called a cork hoop (akin to the modern "dress-improver"). Ladies sewed large pieces of cork under the straps of their stays in order to make their waists look finer, and over this edifice hung what was technically called a "bell," a stiff frame of basketwork or osier:

The costume of the clergy of the last century appears to have been less staid than it is now. Swift thus describes his own dress to Stella: "My dress was light camlet, faced with red velvet, and silver buckles."

Sir Walter Scott declares that the usual attire of the medical profession included "a scarlet cloak, wig, sword, and amber-headed cane."

I find in an old magazine a complaint from a husband who declares that he has married a "sham," - a lady of comely proportions who en déshabilléc shrinks into a divarf. "Her 
head-dress measured eighteen inches, her shoes elevated her six inches. Her circumference decreased as alarmingly as her height; for on the removal of the stiff stomacher and hoop, the stately pyramid of silk and satin who had swept about all day dwindled into an insignificant pigmy of half her artificial size."

Thus, in full dress, the lady of fashion was six feet high ; in her dressing-gown and slippers only four!

There was a time during the reign of George III. when fashion went more mad than usual, and created a monstrous and amazing head gear, called a tête. It was a custom to shave the head in order that a wig might sit more neatly, and a prodigious edifice of false hair came into being which on gala occasions replaced the modest "bob" or "nightcap" wig.

It is recorded of Miss Ashe that (about I760) she went to sleep as she was returning from a party, and that a miscreant cut a slit in the carriage-leather and stole her "head," which was the cause of grievous lamentation, not only on account of the expense of a first-class "head," but because upon the one which was stolen were fastened all the jewels which the luckless lady possessed.

Some ladies built their têtes upon their own skulls, mixing their own hair with a vast quantity of false, and the result will not bear too close investigation. When we consider that the great labour of arranging such a structure hindered its being often refreshed, we are not surprised to read that it was retouched each day and anointed with pungent odours . In the London Magazine for August, I768, a correspondent on this subject says, "I went the other morning to visit an elderly aunt of mine, when I found her pulling off her cap and tendering her head to the ingenious Mr. Gilchrist, who has lately obliged the public with an excellent essay upon hair. He asked her how long it was since her head had been opened or repaired. She answered, 'not above nine weeks.' To which he replied that that was as long as a head could go well in summer, and that therefore it was proper to deliver it now; for he confessed that it began to be a 
little hazardé." The description of the opening of the head which follows is not fit for repetition.

Absurdity reached its acme about 1775 , when the Macaronies came into existence.

When squires were squires in England, and came up to London to see a little life, a club was founded for them in St. James's Street, which was (and is) called Boodle's, but which was long familiarly known as 'The Topboot and Worsted Stocking Club.' To rival Boodle's dinners was not a difficult matter, since they seem to have consisted of uncouth legs of mutton, roasted geese, and buttered applepies. Something better than mere booby squire-archy must have been among the members, for Gibbon was one, and a hundred years ago the great historian wrote his letters there. It was the poor cookery of Boodle's that gave rise to the 'Sçavoir Vivre Club,' the palates of whose members could not bear, nor their stomachs digest, the mutton, geese, and apple-pies of the club, which still exists. The members of the 'Sçavoir Vivre' showed that they knew how to live, by composing or importing new dishes from reconditeforeign parts, and they showed that they knew how to dress, by creating the most eccentric of costumes. Among their imported dishes was macaroni. It became such a favourite dish at the club, and was so invariably brought to table, that the clubbists themselves became celebrated as "Macaronies." In dress they wore a toy cocked hat, goldlaced buttoned and tasseled, over hair fashioned into a foretop two feet high at least above the head, immense sidecurls, and a clubbed tail. Tight striped silk breeches, and an equally tight coat and waistcoat, kept their frail componen, parts together. Their tasseled canes were as long as those still carried by state footmen when they swing behind a carriage going to court on a drawing-room day. Like Tiddy Bob, they had a watch in each fob, with cable chains, and a pound of seals at the end of them. Their white neclcloths displayed a front bow as large as a cauliflower ; and they daintily walked about in white silk stockings and diamond-buckled pointed shoes, in all weathers. Come 
rain, come rack, for a Macaroni to wear a greatcoat was to confess his unworthiness of being a member of the august brotherhood. As equestrians, they figured in the park on little ponies, and looked as if they lacked strength to get on anything higher. The female Macaronies carried heads top-heavy with hair of their own and other people's-hat, feathers, and a world of knicknackery-windmills, ships in full sail, toy coaches drawn by four horses in spun glass. Their dress clung almost as closely to the body as the gentlemen's to theirs. But they dragged after them a long, gold-embroidered train, which gave them the aspect of the wheeling crocodile.

The Macaronies and the Macaroniesses, as they were called, turned days, nights, hours, and seasons topsyturvy. Having earned our gratitude by establishing macaroni as a common dish in every house they died out. Requiescant in pace!

The ladies of the Regency continued the practice of wigwearing, though, in consequence of a powder tax, they wore them of a more or less natural hue. Sir Thomas Lawrence complains that a lady sent him her wig one day instead of arriving in person, in order to shorten the number of her sittings. The peculiar hideousness of the costume of the Regency is due chiefly to the fact of the continent having been long closed to the British fair by reason of Napoleon's wars. Straight pelisses of striped silk were modish. A body and skirt were not usually of the same colour. Summer and winter alike, gowns were of the thinnest texture, trimmed with tawdry ribbons. Dresses were put on damp that they might cling the closer to the figure.

In winter they assumed a muff and tippet or long boa, which comforts were rendered useless by the unseasonable cobweb-nature of the rest of their garb, for while the hand and neck were kept warm, the body was in a state of seminudity. Madam Osgood was the fashionable dressmaker of that day, and from her advertisements in the Lady's Museun I cut a concluding extract. Here is the gala 
attirc of an ingénne: "Robe of white crape; train peppered with roses; low white shoes with diamond rosettes; bunches of silver tassels; a scarf of maiden blush." A married lady's dress is thus suggested: "An Egyptian robe of evening primrose shot with day primrose. Sleeves and apron trimmed with silver acorns. White satin hat, with a high Regency plume and diamond aigrette. White gloves and shoes, and earrings and armlets of gold." A curious mixture of metals here. To this ravishing description Madam Osgood adds:- " Though hats are most fashionable, jewels are tasty for an evening soivée. Everything that is rare, superb, and expensive, is well adapted for the ornamentation of our belles. Some French dresses have recently been imported by the maittresses à danser, but they are too eccentric for English fancy." Dear Madam Osgood! Bless her memory! Eccentric, forsooth. How about that Egyptian robe with the Regency hat and feather?

Male costume of the present day is ugly enough certainly, but it is less frightful than many styles which once were de rigueur, and has at least the advantage of being comfortable and easily adapted to the season. Female costume has seldom been so becoming as now, for ladies may range at will over the entire gamut of the mode, and cull from any reign the details which may suit their beauty. Thanks to increased knowledge and a long course of fancy-balls, there is nothing that can be called "outré." A damsel may appear in public in an Elizabethan coif, a Mary Stuart ruff. and Queen Anne petticoat, without the smallest danger of being mobbed or evilly-entreated, or being accused of bad taste or even of lunacy.

The CHAIRMAN : In fulfilling the very grateful task of proposing a vote of thanks to our accomplished lecturer, Mr. Wingficld, I am sure that I am only echoing the feeling of the entire meeting in saying that we have listened to his address with interest and amusement; for he has not only divcrted us, he has also enlightened and instructed us. 
If you will allow me in the briefest possible manner to point out how much useful instruction there has been in his address, I would, in the first place, draw attention to his frequent and cogent remarks concerning former dresslegislation and sumptuary laws. By solemn edicts our ancestors were forbidden to wear long toes or expensive furs, or in fact any apparel which was then considered to be beyond their degree; in fact, our forefathers were subject to a continual tyranny in the matter of wearing apparel, and it strikes me there never was such a period as the present, when entire liberty and independence reigned in female dress. There is no longer any sumptuary legislation; and the tyranny of fashion, whatever may be its madness, no longer considers to be outré, or an offence worthy of the sending to Coventry, of a lady for the dress she wears. As Mr. Wingfield truly says, she may appear in a farthingale and ruff of the time of Elizabeth; she may dress if she chooses in a Gainsborough hat, or Duchesse hat, or $\dot{a}$ la Kate Greenaway, à la Randolph Caldecott, à la Millais; which last comprises, I think, as regards the cheeks, a good deal of carmine; she may dress à la Andrea Mantegna; and $\dot{\alpha}$ la Sandro Botticelli; so long as she dresses picturesquely, so long is she in the fashion. That was not the case when I was young; for I have followed the march of the fashions nearly fifty years, and I can recollect when not to be in the fashion was to be sent to Coventry. One point I would mention is that we are far in advance of our expensive and costly predecessors in the way of dress, that we do pay some kind of attention to health, and as this is the Health Exhibition it is naturally the theatre where costume should be exhibited in its relation to the laws of health. Thirty or forty or forty-five years ago it seemed to me, in society, as a youngster, that one out of every four English girls was afflicted with that dreadful malady called consumption; and I am strongly of opinion that the prevalence of the discase, not yet stamped out, but still diminished from 
its former virulence, was due to the tight-fitting dresses and the thin textures, to which Mr. Wingfield alluded, and to the two curses at the time of English costume, bare shoulders and thin shoes. Young ladies went about in thin shoes with low heels, and with bare shoulders when they were great gawky school-girls of fifteen; they continued the practice until they married; and the consequences were pulmonary consumption and decline; maladies which can be now mastered to a very great extent. On the other hand, we have during the last two generations devised and invented numerous articles of costume directly conducive to the maintenance and preservation of health, such as Balbriggan hosiery and Balmoral boots; all these things were unknown to our grandmothers and even to our mothers, but we have them now, and I think, with all due deference to yourselves, you owe them in great measure, not to the fair sex, but to the unfair or sterner sex. Early in the eighteenth century, either in the Tatler or Spectator, there appeared a letter from correspondents solemnly asking the Editor, "Sir, what have you to do with our petticoats?" With all deference, I submit that we men have everything to do with those garments. We invent them; the Chevalier Claussen's seamless petticoat has made the tour of the whole world; the crinoline is not the invention of a lady, albeit the Empress Eugénie brought it into fashion. It was brought into use first by a man. The fashions which you ladies admire in Myra's Fournal and Le Follet are all drawn by men; but I admit that there is a reservation and an exception to what I have ventured to point out. I do honestly confess that man, though he has invented countless dresses, fabrics, cosmetics, corsets for the use, and sometimes for the abuse, of the female sex, dyes, boots, and so forth, is utterly incapable of building a bonnet. That is a mystery far beyond our ken. Take a girl of the middle class; she throws upon the table, like so many potato peelings, pieces of ribbon, net, flowers, and gauze, 
and makes a bonnet of them. I defy $\mathrm{Mr}$. Caldecott, $\mathrm{Mr}$ Millais, or any other artist to make a bonnet as a milliner's girl can make one. The secret of its conception must have descended to her from our common mother Eve.

Mr. LEVY LAwSON seconded the vote of thanks, which was carried unanimously.

Captain DE CARTERET BISSON then moved a vote of thanks to the Chairman, which was seconded by Mr. J. L. TOOLE, and carried unanimously. 



\section{CHILDREN'S DRESS.}

MisS ADA S. BALLIN. 



\title{
JULY I 4TH, I 884.
}

\section{A LECTURE ON CHILDREN'S DRESS.}

\author{
Miss AdA S. Ballin.
}

Doctor Robert LeE in the chair.

In beginning a lecture on dress I hope I may be allowed to remark that people are apt to look upon the subject in a wholly frivolous way. For my present purpose I will divide mankind into two classes, the people who think, and the people who do not think. Now the people who think, the intellectual part of the population, look upon dress as something beneath and quite unworthy their attention; the people who do not think regard it wholly as a means of display. Yet dress should be looked upon from a scientific point of view. It is in truth one of the great powers which preserve or destroy Health, and its influence is increasingly felt from birth to death. The first danger a new-born infant has to encounter is from the external cold. This danger is increased by the fact demonstrated by Milne Edwards, that the power of generating heat is at its minimum in all animals immediately after birth, increasing as the individual developes, and its strength and activity become greater. Moreover, the younger a child is the more readily it parts with its heat, because the smaller it is, the larger is its surface relatively to its bulk, for the area of a body varies as the square of its dimensions, while its mass varies as their cube, and the surface of a human body is an evaporating-con- 
sequently a cooling one.* The following example will make this point clearer. A cube one inch in the side has six square inches of surface to one cubic inch of bulk, while a cube ten inches in the side has six hundred square inches of surface to one thousand cubic inches of bulk, so that the surface of the small cube is ten times greater in proportion to its contents than that of the large one. Now supposing a child to be one-tenth of the size of its mother, besides its feebler powers of generating heat, it will have just ten times as much surface in proportion to its size by which to lose heat than that mother has.

The action of cold on the surface of the body is very complex. In the first place it prevents the flow of blood to the skin by causing contraction of the muscular fibre which lessens the calibre of the small arteries of the skin, and so impedes the flow in the capillaries. It also produces reflex nervous action, which causes the little arteries to contract still more violently, until the circulation beneath the skin of the part is stopped entirely. This is what happens when on a very cold day your finger is as you call it "clead," and it is the first stage of frost-bite in which the part actually dies and comes away. Now when the blood does not circulate near the skin, the action of the skin as an excretory organ is stopped, and its work of getting rid of waste matters from the blood is thrown upon the other excretory organs, the lungs and the kidneys, these become overworked, and disease results. Besides this, when the blood cannot pass near the surface of the body, it has to go somewhere else, and the consequence is that the internal organs get too great a supply, and are thus rendered very liable to become inflamed. Now as the lungs in infants are especially active they more readily become diseased than any other organ, and the liability of children to inflammatory diseases of the respiratory organs

* Many passages in this paper will doubtless be familiar to my readers, as I have quoted freely from my articles on "How to Clothe Children," published during November and December last in Health Nos. 34,35 , and 36 . 
is terribly increased by the barbarous way in which they are generally dressed.

From all that I have said, it ought to be very clear that children should be better protected from the coldmore warmly clad-than grown people. But what do we find when we look around us? Herbert Spencer said years ago, "What father, full grown though he is, losing heat less rapidly as he does, and having no physioiogical necessity but to supply the waste of each day--what father, we ask, would think it salutary to go about with bare legs, bare arms, and bare neck?" Yet this is exactly what most people allow their children to do, ignoring the fact that, even if colds and the more serious diseases I am about to mention are escaped, injury must result to growth or structure--for, owing to the insufficient clothing, much of the nourishment which ought to supply the development of the organism has to be expended in keeping up its temperature.

Every year thousands of children fall victims to lung diseases, which are very much more common during childhood than at any other time of life, as you will see clearly from the fact that out of 379 fatal cases of pneumonia - that is, inflammation of the lungs-in London and some country districts, 228 , or nearly two-thirds, were children under three years of age. But in order to give you a fuller idea of the mischief done, let me quote the Registrar-General's statistics: from these we see that in one year alone (the year I87I) * more than I 8,000 infants under one year died in England and Wales from pneumonia and bronchitis. If that is not a massacre of innocents, I should like to know what is. And yet this mortality does not represent a hundredth part of the mischief done, for we have to take into consideration all those thousands who, although surviving these diseases, and

* Here and further on when speaking of convulsions I quote the year $187 \mathrm{I}$, for convenience, having no later statistics at hand. I believe 87 I to have been a year of average mortality as regards the diseases mentioned. 
others such as scarlet fever, measles, whooping-cough and croup, the dangers of all of which are vastly increased by exposure to cold, have been permanently injured by them. I have not the slightest doubt that if only the amount of trouble spent by mothers on personal adornment, and on ornamenting their children's clothes, were devoted to preventing the exposure of children to cold, the mortality from these diseases, and the cruel mischief done by them, would be reduced to almost nothing., "We have met with none competent to form a judgment on the matter who do not strongly condemn the exposure of children's limbs," says Herbert Spencer. Alas, then, to judge from the manner in whieh we see children generally dressed, how many millions must be incompetent to form a judgment on the matter!

But I have often been told, when remonstrating with mothers for exposing their children, "O I don't believe in codling, this sort of thing hardens them and makes them strong." This theory of hardening is a fallacy from beginning to end. From one point of view only can anything be said in its favour, and that is, that allowing there are already too many people in the world, it will be an advantage to get rid of as many of the weakest of new comers as possible. By adopting the "hardening" plan the weak ones certainly go to the wall, though I think mothers, even while defending the theory, will hardly appreciate the advantage of this result; but then the survivors are just as certainly injured in health or in development. Exposure means loss of heat, and loss of heat produces dwarfishness, as proved by the stunted and hideous figures of the dwellers in the arctic and antarctic regions, and by the dwarfed vegetation of cold countries.

Dr. Inman has said that: "If you coddle an infant and take care of it, it will very likely grow to be a strong and healthy adult, but if you try and harden it by exposing it to cold, and not clothing it properly, etc., you must not be surprised if you soon have to measure it for a long box."

Whenever I read a sentimental poem about some sweet 
infant that has gone to a better world, or hear some mother with tears in her eyes declare that her little one "is an angel now," I say to niyself, ten chances to one that child died, as thousands die every year, wholly from neglect of laws of hcalth, which it is the bounden duty of every mother and nurse to know and obey, and of which 999 out of a thousand are absolutely ignorant. Often, when women are priding themselves on being the best of mothers, they are, in utter ignorance, actually killing their children in a far more cruel way, because the torture is more prolonged, than if they strangled them or cut their throats.

The warmth of clothing, whether for children or adults, should be regulated by the thermometer, not by the season of the year; and in kind and quantity clothes should be "sufficient in the individnal case to protect the body effectually from an abiding sensation of cold, however slight," as Andrew Combe wrote.

But even though warm, clothing should never be heavy, nor should it ever restrict any of the natural or acquired movements of the body. Before going into details as to what I consider the most healthy mode of clothing children, I wish to urge the total abolition of what Prof. Humphry calls "a sort of baptism to the numerous evils of fashion in dress," to which the vast majority of infants are subjected -viz., the binder, or swather. I cannot do better than quote Prof. Humphry's words on the subject from his address at the Congress of the Sanitary Institute of Great Britain : * "Those mischievous two yards of calico.... constrict and hinder the expansion of that very region of the body where heart and lungs, stomach and liver... are struggling for room to grow and do their work." It hampers the breathing, and may even occasion rupture by preventing due expansion of the chest when the child coughs. It interferes with digestion, and when the stomach is distencled with food, causes pain by its unyieldings pressurc. Dr. Humphry continues :- "A more pernicious

* Held at Glasgow from 25th to 20th of September, $188_{3}$. See $T / w$ Sanitury Record for October, I883, p. 151 . 
device can hardly be conceived than this relic of ancient nursedom, and it is impossible to estimate the number of deformed or pigeon-chests, of hampered stomachs, livers, lungs, and hearts, with their varied attendant life-enduring infirmities and curtailment of life that must result from the use of these 'swathers,' as they are called, for which there is not the slightest necessity."

For the first few days after birth a strip of fine flannel with raw edges may be bound, but not tightly, round the abdomen; after that time till the infant is 3 or 4 months oid a piece of flannel put once round and tied with strings is quite enough. The rollers that are commonly used under the delusion that a baby requires to be kept in a proper shape are a relic of the happily, almost extinct custom of swaddling babies, the only advantage of which was that a mother might safely hang up her swaddled baby on a nail, and go out for a walk quite certain that it could get into no mischief till she came back again, for it couldn't move an inch. Too tight clothing may press upon and irritate the breasts of young infants and produce enlargement of the mammary glands, which may even go on to abscess. This is often caused by a binder which is too broad, or slips up, or by a string of the dress tied too tightly across the chest. In case of such enlargement occurring the cause should be at once removed, and a pad of medicated wool placed over each breast to protect it. While urging all mothers who use rollers or binders for their children to abandon the practice, I warn them to be careful how they make the change. A piece of the roller should be cut off every day so that the thickness round the child may be gradually decreased. A chill would almost certainly result if the roller were to be left off entirely at once. Here, as elsewhere, it is of the greatest importance to remember that sudden change is dangerous.

The nervous system in infants is extremely unstable, and liable to be injured by disturbances which to us would appear slight. Thus fatal convulsions have been produced by cold exposure to the night air, by excessive heat, or 
even by a badly placed pin or painful constriction of the dress. Convulsions are so terribly fatal to infants that the utmost care should be taken to avoid anything which is likely to cause them. As an awful example, let me tell you that according to the Registrar-General's Statistics for England and Wales during the year I87I no less than 20,089 infants died of convulsions.

The necessity for avoiding a source of great danger, which is often incurred in dressing children carelessly, will, I think, be fully impressed upon you by the following cases. Trousscau the great French physician, was called with Dr. Blache, to see a child who had for some hours been in convulsions for which he had been put in a warm bath. Dr. Blache, on removing the child's cap, saw a piece of thread across his head, and on trying to take it away pulled out a long needle which had entered the brain; the convulsions ceased immediately, but the child died soon afterwards of water on the brain. A similar case is recounted by Underwood, where the cause of the convulsions was not discovered till after death, when, on the cap being removed, a small pin was found sticking into the anterior fontanel. Trousseau in his Clinical Lectures,* relates another case, where a son of a French Professor of Medicine having died of convulsions, for which no cause could be assigned, a post-mortem examination was held, when a needle was found transfixing the liver. Such cases as these are, doubtless, very common; owing however to the unreasoning but wide-spread predjudice against postmortem examinations, the true cause of the death is generally never discovered. As this prejudice raises unnecessary hindrances to the progress of the healing art, I take this opportunity to protest against it.

Babics' clothes as a rule are made according to a bad old fashion and have four great faults. I. They are not made high enough in the neck to keep the chest and shoulders warm; 2, they press on the arms, and so prevent them from being moved freely; 3 , they are made so that they cannot

* Ncw Sydenham Socicty's cdition, vol. i. p. $3+3$. 
be put on without the child's being turned over and oversome even having to be passed over its head; 4, they are too long, full and heavy. The clothes ought, however, to be made : I, to cover every part of the body alike ; 2 , to rest upon the collar-bones so that the arms may be quite free; 3 , they should be made so that they can be put on without turning the baby once; 4, they should be short and light so that it can move its legs quite freely. Two or three kinds of infants' clothes have been invented to fulfil these conditions. Those invented by Mr. Day; assistant-surgeon to the Royal Hospital for Women and Children, consist of three articles. First a fine flannel vest reaching to about four inches below the feet, which should be protected by woollen socks, wrapped round the infant and tied in front with tapes; next a calico shirt with sleeves nearly to the wrist, to reach four inches below the vest; and lastly, a robe made in the same way, that is to fasten down the front. The robe and shirt may be fastened with small buttons as the vest will protect the slin from their pressure, and the robe nay be trimmed according to taste. With these garments dressing is a simple matter. All that has to be done is to lay the shirt on top of the robe, the vest on the shirt, and then slip the child's arms through the arm-holes of all of them together, fasten them up, and you have finished. Thus all risk is avoided of entangling the baby in its clothes or straining it by an unnatural position while being dressed, or making it sick by turning it over and over. In order to prevent any pressure round the waist, I venture to suggest that the belt round the middle of the vest, as in his pattern, should be omitted, as it is quite unnecessary; but, if further fastening should be required, another pair of tapes can be sewn lower down. The only disadvantage of making the clothes to fasten in front is, that unless the back is cut very wide, the child's arms will have to be turned backwards in order to pass them through the arm holes. This is dangerous, as infants arms may easily be clislocated at the shoulder. 
I hope soon to be able to publish patterns of hygienic baby-clothing to be made on a plan quite different to any that I have yet seen. It would, however, be useless to describe the plan here, as either a pattern or engravings would be necessary before any one could tell how to cut them out.

When from unusual tenderness of the skin, or any other cause, flannel irritates or induces too much perspiration, the vest should be made of spun cotton or even calico. The short shirts usually worn by babies are objectionable since they only serve to keep one part of the body warmer than the rest of it. I especially advocate the use of drawers even for very young infants, as, if they are worn, the socks can be made to reach them, and the other clothes can be made quite short without occasioning any risk of chill. Drawers for infants have also other advantages which would be appreciated by mothers and nurses; but it is necessary that they shall be changed frequently, and they must on no account be made of waterproof material, as some that I have seen are made. A very suitable material for the purpose is what is called swansdown ; flannel is also good.

Much mischief may be done by the excessive relaxation induced by children being clothed too warmly in hot weather. If on the one hand the child is bathed in perspiration, or on the other if the skin feels hot and dry, without your being able to account for it in any other way, you may conclude it is too warmly dressed. Rashes such as those, the popular names of which are "prickly heat," "red gown," and "red gum," may be caused by the use of over-warm clothes in the summer.

Infants' heads are generally kept too warm, which, considering the natural tendency to nervous excitement and the rapid circulation of infancy, is a very bad practice. Nervous excitability is so increased by the head's being kept very warm, that any accidental irritation is under these circumstances much more likely to be followed by spasmodic or convulsive fits, than under any other 
conditions. Infants do not need caps indoors, where the temperature is generally uniformly high. Moreover, the pillow on which they sleep should not be so soft that the part of the head in contact with it sinks into it and becomes overheated and perspires freely, while the rest of the head is comparatively cold. This is a frequent cause of colds. Bedclothes should be light, and never tucked in so tightly as to hamper the child's movements. In cold weather a down quilt is very nice, and the child should wear a little woollen spencer, so that it can uncover the upper part of its body without risk of chill. As I have already said, children lose heat very rapidly, and as the circulation is slower during sleep, they require then to be clothed even more warmly than during waking hours; but excessive heat must be as carefully avoided as debilitating cold. As, however, the little ones cannot tell you whether they are too warm or too cold, you must ascertain the state of affairs by passing your hand over their skins.

New-born infants as a rule sleep with the mother in order to benefit from the warmth of her body. This plan, however, is a dangerous one. In the first place, children sleeping with arults are liable to breathe contaminated air ; secondly, an accidental displacement of the bedclothes may easily suffocate them; thirdly, they may run the risk of being, as it is called, "overlain."

At an inquest held in St. Pancras, on the I2th of March last, upon the bodies of two children who were found suffocated in bed with their parents, the coroner, Dr. Danford Thomas, stated that he held every year between I 20 and I 50 inquests upon children who had met their deaths in this way. In Birmingham the borough coroner held four inquests on the ISth of October on infants who had been overlain in bed, and he remarked that, in order to avoid such large sacrifice of infant life, cots for children should be provided, as enforced by law on the Continent. The line between the accidental and intentional disposal of infants is allowed to be very indistinct. These facts I quote from the Lancet for October 27th. Mothers, when they take 
their children into bed, should put them back into their cots directly they have been fed. After the first week or two, if an infant wants more warmth than can be got from clothing, a hot water-bottle, hot brick, or sand-bag wrapped in flannel may be put in the bottom of the cradle.

Cradles or cots should be raised to a level with the mother's bed, and should never be made to rock. A bad practice is unfortunately very prevalent, of which the mildest form is rocking a baby, or walking up and down with it until it goes to sleep, while the most aggravated form is to jump it up and down when it cries, by way of pacifying it. No doubt the treatment is effective in that it makes the baby go to sleep or stop crying; but it does so simply by a process of stupefaction. Indeed it might be made so effective that the child would never cry again at all, so thoroughly might the shaking disturb the brain as to stop the vital processes.

Fathers especially are fond of tossing their children high up into the air, turning them head over heels, \&c. Now just imagine the nervous shock you would suffer if some great giant were to treat you in this way, and then you will have some faint idea of the injury done by this practice to infants, whose nervous systems, remember, are much more easily disturbed than ours. I have little doubt that many an embryc poet or philosopher has literally had his brains addled in this way.

I read a very good illustration of the commonest form of this practice, as carried out by mothers, in a comic paper. Said a gentleman to his wife, who for the last hour had been shaking her baby up and down on her knee, "My dear, I don't think so much butter is good for the child." "Butter? I never give my Tootsy Wootsy butterwhat an idea!" "Well, you know, you gave him a good feed of milk, and now you've been over an hour clutrning it! "

If parents could only be made to understand the mischief they do to the brains, hearts, and digestive systems of their children by the idiotic custom of jolting and tossing them 
about as if they were wooden toys instead of very complicated and delicatc organisms, they would surely speedily abandon so harmful and irrational a practice.

But to return to the question of clothing. The garments I described just now are admirably suited for summer wear, and can be supplemented for out-of-doors by a cloak of cashmere or merino, or some fancy material with a hood to match; but for cold weather warmer clothing is required. The flannel vest should then have over it another made in the same way, but with sleeves to the wrist, and more than one of these can be put on if it is very cold; all should fit carefully round the throat. I have seen very nice vests for infants knitted of fine wool ; these have the advantage of stretching with every movement, while they are warmer than flannel, since they cling closely to the figure. They may be made in the way described, and used either as vests or as wraps under the robes. If the child is thoroughly warmly dressed underneath, the mother may use a robe of any material she likes; but I strongly deprecate the habit of dressing a child in thin clothes in cold weather, and then wrapping it up in a shawl, which cramps its movements, or keeping it near the fire, which makes it very liable to take cold directly it is in a cooler atmosphere.

Children should not be kept at home because it is cold, but should have on warm outdoor things. A very pretty and cheap outdoor garment for a child of any age up till five or six may be made of some thick white woollen stuff. For infants this should reach two or three inches below the robes; after the child can walk it may be made to the ankles. Both this and the summer cloak should have sleeves so as not to impede the movements of the arms, as capes do, and should fasten down to the bottom. Capes are very undesirable, since their weight hangs too heavily from the neck and shoulders, and they open and leave the chest exposed, and allow the cold air to get up underneath them and attack the armpits and chest. Hoods should always be worn, as very young children suffer much from 
ear-ache, especially baby-boys, whom "pestilent custom" condemns to have to wear unprotecting, stiff, and uncomfortable hats. The hood may be made to match the jacket, or either knitted or crocheted in white wool, in either case lined with white sarsenet, as coloured materials should not come in contact with the skin, for reasons which I am going to explain later on.

While I am on the subject of out-door garments, I should like to say a few words as to the mode of out-door exercise for children who cannot yet walk. I think it better for children to be wheeled about in a perambulator than carried in the nurse's arms. If they are properly dressed, I do not think there need be any fear of their thus being more liable to take cold. If the child is carried, it is usually cramped by the nurse's arms and frequently held in unnatural positions, as with its head hanging over the arm, so that a spectator fears the neck may be dislocated, or with its feet turned inwards, \&c.

The head hanging over one side in this way may impede the breathing, or even cause serious disaster. Hufeland mentions a case in which death resulted from a sudden jerk to one side of an infant's head. The nurse, too, finding the child heavy and that she gets tired, curtails its outings, and instead of spending several hours in the air, as it ought, the time dwindles down. Then, again, if the child is carried, it may inhale the exhalations of the nurse's body, which are not always of the sweetest, and of her clothes, which are not always of the cleanest. But when I recommend perambulators, I do not mean the old-fashioned and, unfortunately, still very common kind, with a seat, and a strap across to keep the baby in ; where the head most often hangs over the side of the machine, or the body tends to collapse in a heap on the floor of it. I mean one of the light four-wheeled machines now coming into use, where the infant can recline at full length, or the older child can sit up without restraint; which has no seats, but a sort of mattress at the bottom, on which the child can cither lie or sit; which runs with but little vibration on 
indiarubber-cased wheels, and is sheltered from wind and rain by a hood. For wintry weather a fur rug may be placed in these, effectively protecting the infant from the cold.

If, howevcr, it is decided that a baby shall be carried, care must be taken that it shall lie as straight as possible along the nurse's arm. It must not be carried in a sitting posture until it is about five months old. As if it is carried so too early, the spine is overtaxed, and the pressure on the chest caused by the hand supporting it is likely to be injurious. It must be borne in mind that the bones of a young infant are little more than gristle, and are liable to bend and so becomc deformed. After about five months the sitting posture may be allowed for a few minutes at a time if there is no suspicion of rickets, and if the child seems to like it. Care must be taken, too, in carrying a child, that no part of its body bc compressed in any way. Moreover, the arm on which it is carricd must be changed from time to time, otherwise deformity may result from leaning always on one sidc, or a tendency may be contracted to turn the eyes in one direction or squint.

Boys and girls should be dressed alike until the boys are breeched. From the time when, as nurses say, "They begin to fecl their feet," they should wear next the skin a garment of flannel or spun cotton-linen, silk, and calico are bad, be the wcather warm or cold, because they do not absorb the perspiration. Over this should come a long-sleeved and high-necked bodice. fitting to the figure so as to give support without pressure; the drawers and petticoat, or petticoats, should be fasiened on to this, so as to distribute thcir weight equally. Combination-drawers and vest are very convenient and gooi, provided the cdges ovcrlap each other where they fasten, so that no part shall be exposed; and then the petticoats only-which should reach to the ankles-need be fastened to the bodicc. Socks ought never to be worn, and the stockings should be pulled up about a couplc of inches over the ends of the drawcrs which ought to fit round the linee, and bc fastened with sus- 
penders to the bodice under the petticoats, as the pressure of garters is injurious: it interferes with the circulation of the blood in the legs. Garters if worn very tight have even been known to produce varicose veins.

A very pretty and most durable winter dress for a young child can be crotcheted or knitted out of thick Berlin wool; it should, like all children's dresses, be made to reach throat, wrists, and ankles, not according to the absurd fashion of making dresses low where they ought to be high, and high where they ought to be low. In choosing materials, care must be taken to avoid weight while securing warmth, and above all, they should be inexpensive and strong, so that the child may not suffer from being forbidden healthy play lest its clothes should be spoiled. It must be a poor sort of mother's love-and yet it is a very common one-which prefers the welfare of the clothes to that of the child. If a woman wants a block to set fine clothes on, let her get one made of wood or wax, but not turn her little boy or girl into one.

We come now to the question of colour for children's clothes; white is most certainly the best, and none but white garments should be allowed to come in contact with the skin. White dresses may also be worn with the greatest advantage both in summer and winter. But when we talk about children's wearing white clothes, as a rule mothers are apt to object "But we should have to be always changing them, white gets dirty so soon." Now this objection to my mind points out one of the greatest advantages of white clothes. Of course every one must know that white does not get dirty sooner than any other colour, it simply shows the dirt more. Now besides outside dirt, the clothes absorb a great deal of refuse matter from our bodies, every day about two pints of dirty water pass through the pores of our skin in the form of sensible and insensible perspiration, in this there is about a quarter of an ounce of poisonous matter. Besides this the sebaceous glands give out a quantity of oily matter, and the chief part of all this refuse and impurity is taken up by the

VOL. XII.-H. L. 
clothes. Hence, if clothes are not frequently changed, children or adults are in a manner poisoned by their own excretions : for as Dr. Richardson says, "Health will not be clothed in dirty raiment." But there is a decided tendency in the human mind not to be ashamed of what cannot be seen, so people will wear, and allow their children to wear, clothes thoroughly impregnated with filthy and poisonous matters, as dirty as they can be, because, forsooth, they are of a dark colour and people can't see that there is anything wrong with them. Thus drešses and coats and trousers and petticoats may be worn unconcernedly for months, when if their colour, had only been white their wearers would have been ashamed of their dirty appearance in less than a week, and they would have been speedily despatched to the laundress' or cleaner's.

Clothes can hardly be changed too often, and if they are made of white materials we are constantly reminded of that fact. Moreover dyes bring new dangers, as poisonous matters are often employed in the processes of dyeing. For instance, every one has heard of the use of arsenic in dyeing, and although I believe it is not now used so much as formerly, it is just as well to be on one's guard against it. It is arsenic which produces that beautiful bright-green known as Scheele's green. The colouring principle of the aniline dyes, of which the worst are the red and yellow coraline, is a very active poison, and produces an eruption on the skin which has more than once been mistaken for erysipelas, but which disappears when the irritating cause is removed. Some time ago Dr. Woodland called attention to a number of cases of eruptions on the legs and feet, for which he had been consulted. His suspicions were aroused by finding all the patients had worn red stockings, and on analysing these he discovered a compound of tin which had been used as a mordant in fixing the dye. Each time articles dyed in this way are washed, the tin salt becomes more and more soluble. The skin excretions attack the oxide of tin, and thus a poisonous compound is formed. Some colouring substances 
unite directly with the fibres of the material to be dyed, and require no mordant to make them fast. Indigo is one of these so-called substantive colours. So indigo blue is a very safe colour for your own or your children's clothes. But nearly all vegetable colours require mordants, and the principle mordants are salts of iron, tin, and alumina. As we have seen, the salts of tin are used in red dye. Yet such is the wanton ignorance on this subject that red flannel is frequently worn next the skin by preference, and in every chemist's shop we see dozens of "chest protectors," made of material dyed with this poisonous stuff, in spite of the fact that so long ago as I876 Dr. Richardson published a case of disease resulting from the wearing of such a "comforter," together with some strong censure of the use of the aniline dyes. There is a sort of idea that red flannel posesses some mysterious curative properties superior to any other colour. As example of this popular error, I remember being very much struck by a highly-educated gentleman who was suffering from a severe cold on the chest, informing me that his mother had told him to put on a thick red flannel next the skin, and that if the flannel were not red it would do him no good. I have noticed also that among the poorer classes red is decidedly the favourite colour for children's clothes; and I fancy I am about right in stating that of patients applying for relief at children's hospitals, nine out of ten will be found to be wearing some article of clothing coloured red.

I advise all my readers to inspect a collection which $\mathrm{Mr}$. Startin, of St. John's Hospital for Skin Diseases, shows, in the Eastern Quadrant of this Health Exhibition, of a series of articles which have produced skin diseases through the injurious colours they contain. Speaking of these poisonous dyes, Mr. Startin says :- "During the last few years articles of dress, especially those worn next the skin, such as stockings, socks, gloves, drawers, \&c., have been coloured with dyes derived from coal tar, among which are magentas, reds, violets, blues, and yellows of great beauty. And so long as they are worn externally they produce no impres- 
sion save admiration, but their application to articles of dress such as named above, and worn in contact with the body, has shown that they are capable of producing irritation and eruptions of the skin, and in some instances constitutional disturbance. Many of these aniline dyes, as they are called, are derived from benzol and other products of coal tar, from which are obtained reds, blues, and magentas of great beauty, some of which, when brought into contact with the skin by means of the perspiration, act as powerful irritants, more in some instances than others. The dye is soluble in the perspiration, and hence it becomes absorbed into the skin. Some of the magenta dyes also contain arsenic, that compound being used in their preparation. It sometimes happens that the colour and pattern of the sock is transferred to the skin, and is represented by lines and figures of inflammation. This inflammation is sometimes propagated to different parts of the body in the same individual, and is often of a very severe and intense character, and still greater annoyance often results by reason of its recurrence after the skin has apparently recovered."

Boys should be breeched as soon as they begin to run easily. Jersey suits are most healthy and comfortable, and may be worn from three years old till the child is six or seven. They stretch to every movement, and are very durable besides being inexpensive, they should be worn with combinations and stockings, the warmth of which nay be graduated according to the weather. Scotch suits for boys which are so fashionable, and so much admired, are an abomination owing to the way in which they expose the legs. I know a curious instance of a little boy six years old who wears a Scotch dress, his legs have never been covered since he was an infant. As an infant he was one of the finest children I have ever seen, and has always enjoyed good health, yet he has hardly grown an inch, nor increased in weight since he was three years old. His mother often complains to me of his smallness, and asks what she can do for it, to which I always answer "cover up his legs." 
And then I cite the case of his little sister who being a delicate child has always had her limbs well protected, and is now about the best grown child of her age that I know. Yet I cannot make that lady understand the influence which to my mind has determined the development of these two children. She cannot or will not believe that the saving of heat in the one assisted her growth, while the other's constant loss of heat hindered his. And yet all the other conditions affecting the two children are so identical that I positively cannot assign any other cause for the difference between them.

A very pretty and nice dress for boys when breeched is the sailor's suit, which, by its looseness, allows free movement, is very durable, and covers all the limbs. The jacket must not, however, as is sometimes done, be cut low in the neck, or, if so cut, it must be filled up with a thick white flannel, so as to keep the warmth equal. Under the suit flannel drawers and vest or combinations should be worn. Sailor suits should be made with trousers, and may be worn till the boy is old enough to wear ordinary trouser suits.

It is a pity that little girls as well as boys should not enjoy the freedom of Jersey-knickerbocker and sailor suits ; but prejudice is against this at present. Skirts made to the ankles would protect little girls' legs; but the disadvantage of long skirts is, that they are in the way when children are running and romping as they ought to do. About the best dress I know of for girls from three years upwards, is Miss Frank's kindergarten frock, which consists of a sort of smock over a divided skirt. Next the skin combinations of thick or thin material, according to the weather, should be worn. Next this a flannel or linen body, on to which two sets of buttons are sewn, one above the other, to the lower buttons the suspenders of the stockings, which should be woollen, are to be fastened ; to the upper buttons the divided skirt is attached; over this comes the smock which completes the costume. Bonnet or hat and stockings may be made to match the material of the dress, 
which is as pretty as it is healthy. Dressed in this way girls can romp about or go in for gymnastic exercises with the utmost freedom and comfort.

This sort of dress can be made very easily and cheaply if one has a pattern, and if it were only generally adopted by the little girls of to-day a vast difference would be found between the health of the young ladies of ten years to come and those of the present time. Moreover, girls who in childhood had been clothed in this way would never submit when grown up to the unhealthy and uncomfortable forms of dress which are generally dictated by fashion. If the laws of health were better understood by women, the time and consideration which they devote to getting new clothes for themselves and their children need not be misspent, as it now too often is. A little care and thought in the planning of dress might make it both healthy and elegant.

The progress of women towards a more healthy form of dress than that now generally adopted is hindered rather than helped, by certain ladies who, calling themselves the apostles of rational dress go about in costumes so utterly hideous, and to many people's minds immodest, that they bring ridicule upon the principles they advocate, instead of gaining converts to them. Can young girls be blamed for not wishing to make themselves laughing-stocks? What we want is reform, not revolution. We want in dress to obtain the maximum of health with the maximum of beauty; for health and beauty should go hand-in-hand.

If our girls were taught the laws of health and a few of the principles of art as known to the ancient Greeks, they would soon see "what a deformed thief this fashion is," and would laugh at the squeezed-in waist, crinolette, and foot mangled and crushed by the high heeled and pointed boots of recent times, much as we, now, who call ourselves civilised, ridicule the Australian with his nosepeg, or the Bongo negro who drags his lip down with a plug, and distends the lobes of his ears with discs of wood in order to increase his personal attractions, or the foot of a Chinese 
lady artificially deformed in accordance with a fashion which is after all only a slight exaggeration of our own.

This digression has led me to the subject of boots, which is a very important one, as even without wilful adherence to fashion the vast majority of feet are deformed by wearing boots which cannot be said to fit the feet at all, and are, in fact, made in absolute defiance of the shape given by nature to those organs. "It is mainly due to the special development of the great toe, in a line with the long axis the foot, that man is enabled to exercise the attribute of standing erect."* The conventional boot, however, seems purposely constructed to divert the great toe from its natural position; it aims at making the foot look as if both sides were symmetrical. Now there is certainly a love of symmetry in the human mind; but art is not required to make the feet symmetrical. One foot is the complement of the other, and the two taken together, when placed side by side, make a sort of dome of which the two great toes, which should be parallel to one another, form the apex. The boots then should be made to the natural shape of the foot, and square toes, though not so objectionable from a health point of view, are equally bad, artistically speaking, as the pointed ones. Plenty of room should be given in the leather above the great toe, for, as Mr. Ellis remarks, "It is obvious that where a flexible material is fixed on both sides and left loose between, it can be drawn furthest from the surface to which it is attached in a line midway between the fixed parts. For this reason the highest part of the foot, which is in the inner side, will have a tendency to go to the middle line of the foot where most room can be made." The high ridge of the last, and consequently of the boot, should then be made on the inner margin, and if the line of the seam or laces of the boot be carried along this

* See Lancet, June 21, I884, pp. III3-III5. Mr. Ellis, M.R.C.S., On the Physiology of the Feet.' 
ridge the unpleasant effect of an inverted appearance of the foot, which a straight line would give in such a position, is avoided. Toe caps should not be used as they give most room in the middle linc. The great toe is so commonly and so easily diverted outwards that socks and stockings should be made with a straight inner line and otherwise to fit the foot. In considerable distortion a separate stall can be made for the great toe both in the stocking and in the boot.

Till the child begins to walk white woollen crotcheted or knitted socks are all that it requires. After it begins to walk the boots or shoes should be made in the way I have described to fit exactly on the fect, and of a soft yielding kid, so that there shall be no pressure on any part. Too roomy a boot is liable to chafe both stocking and skin. The most important points are that:

The inner margin should be straight to the big toe.

The toe should be of a natural breadth.

The heels, if any are worn, should be broad, low, and under the natural heel.

The waist of the sole, answering to the arch of the foot, should possess a certain amount of elasticity.

There must be no roughness on any part of the inside, or corns will result; and the boots must be given up dircctly they are beginning to be outgrown. They should be laced or buttoned, and should cover the ankle so as to give it support. This is especially important for children inclined to be ricketty, and for such weak legs the boots should be made very high, and only taken off when the child goes to bed. In decided cases of rickets inch-broad strips of thin steel may be inserted between lining and leather from the top of the boot right down each side of the ankle; these may be made as high even as the knee, and will be found more comfortable, being very much lighter than the irons usually worn for incipient bandy legs.

I have given so much time to discussing the question of boots, because it does not generally receive that attention 
which its importance demands. Not only does deformity result from the use of improper boots, but from the discomfort arising from them the natural activity of childhood is impeded, and the whole constitution suffers accordingly.

However desirable economy may be, it must not be practised in the following cases, for then it would be injurious to health. We must not grudge paying our laundresses' bills, or if we cannot afford to have every article worn by our children washed twice or thrice a week, we must turn up our sleeves and wash them ourselves. We must never let children wear clothes they have outgrown. Boots must always be made to fit, by good makers, and of the expensive material I have described-what is called glove-kid, and each child ought to have two pairs, which should be worn on alternate days, in order to prevent that moulding of the foot to any peculiarity in the shape of the boot which may occur if it is worn constantly.

The little ones must have clothes suitable for every kind of weather, so that they may never be kept indoors because they have nothing fit to go out in. They must have changes of clothes in case they come in damp. And last, but not least, however great the damage may be to clothes, nothing must induce us to interfere with the little ones' romping play.

From the foregoing it is clear that the first principles to be obeyed in the clothing of children are the prevention of undue loss of animal heat by the use of apparel so contrived that it shall not hamper their movements, and CLEANLINESS. Both these principles may be obeyed equally by rich and poor; for clothes may be made even more easily on a rational plan than in the common way, and soap and water are decidedly inexpensive; but people must devote time and thought to the subject.

By the observance of the broad principles which I have endeavoured to lay before. you, it will be possible to avoid the snares of prejudice and old-fashioned customs morc 
honoured in the breach than in the observance, but which unhappily are now too widely adopted. It will be possible, by intelligently watching the necessities of child nature to provide for its contingencies, and thus obtain the most favourable conditions under which children can -start on their life-career so that they may become strong and healthy men and women and useful members of society instead of puny hangers-on at the skirts of life.

The CHAIRMAN said he was sure he should be expressing the feeling of all present if he thanked Miss Ballin for the extremely sensible and practical way in which she had dealt with the subject. No doubt this was a matter of great importance for two reasons, one because they did not realise as much perhaps as they ought, how far the welfare and the intellectual development of people were due to the influences of very early childhood; and the other reason was, that if they thoroughly appreciated the principles which Miss Ballin had put before them they would very soon have the means at command for carrying them out. By that he meant to say that they would have the facilities for dressing children conveniently and appropriately. Those difficulties had been hitherto great, but if they recognised the principles they would soon have the means at command. Before so many ladies it might be dangerous to make the remark which he was going to make, but it had struck him throughout the lecture that if the men had the care of the children they would not have had such a state of ignorance. He felt perfectly certain that men were not the slaves of fashion to the same extent that women are. Taking some of the lower animals, and comparing them with human beings, the mortality amongst them was really dreadful, for theer was no animal in the world that lost its young as woman did. It was disgraceful to a country like England that they should lose more than half the children under I 2 years of age. If they encouraged the principles which had that day been enunciated, and encouraged those who were 
putting into practice in the manufacture of simple dresses these principles, it would not be long before the prejudices which now existed would disappear.

A vote of thanks to the Chairman concluded the proceedings. 



\section{TEXTILE FABRICS.}

BY

WILLIIAM MORRIS.

VOL. XII.-H. L. 



\section{JULY I ITH, I884.}

\section{A LECTURE ON TEXTILE FABRiCS. \\ By William MorRis.}

The Chairman in introducing the Lecturer said he had very little diffidence in so doing as Mr. Morris did not require introduction from any one. It was a case of "good wine wanting no bush." Every one interested in the decoration of houses knew something of the good work which Mr. Morris had been doing during the last twenty years, and some day the history of what, at one time, appeared a mad enough venture, would not only be profitable, but amusing. In our days when young men left Oxford and Cambridge, they took to the army or the bar as a profession; but twenty years ago Mr. Morris entered upon a venture which seemed likely to end in loss of money and discomfiture, although fortunately it proved not to be the case. He hoped those present would not take the lecturer's account of himself too literally, for he had been pleased to style himself only a dreamer of idle dreams. Mr. Morris was not a mere dabbler or dilettante on the subject which he was to lecture upon; he had worked for many years on "Textiles," both printed and woven, and he was connected with a school which had made his name familiar to every one. Mr. Morris was a practical dyer and printer, and he worked at the loom; and the Science and Art Department set great store upon his experience and judgment. 


\section{LECTURE.}

THE subject I have to speak on is a sufficiently wide one, and I can do little more than hint at points of interest in it for your further thought and consideration; all the more as I think I shall be right in supposing that, except for anyone who may be present being actually engaged in the manufacture of textiles, you, in common with most educated people at the present day, have very little idea as to how a piece of cloth is made, and not much as to the characteristic differences between the manufactures of diverse periods.

However one limitation to my subject I will at once state: I am going to treat it as an artist and archeologist, not as a manufacturer, as we call it; that is, I shall be considering the wares in question from the point of view of their usefulness, using the word in its widest sense, to the consumer, and not as marketable articles, as subject-matter for exchange: I must assume that the goods I am speaking of were made primarily for use, and only secondarily for sale; that, you see, will limit me to an historical discourse on textile fabrics, since at present those wares, like all other wares of civilised countries, are made primarily for sale, and only secondarily for use.

Now before I begin to speak of the actual history of this important art of weaving, I will run through the various forms of it which it comprises. But first of all it may be necessary to explain three words which I shall be compelled to use-warp, weft, and web; because I have noticed that the writers of leading articles and poetry are sometimes a little vague about the way they use these words. Well the warp is the set of strained threads (sometimes vertical, sometimes horizontal) on which the work is founded; the weft in the thread which is wafted in and out across this warp, and the woof or web is the product of the two.

As to the kinds of weaving; first there is plain weaving in its simplest form, where the weft crosses the warp regularly and alternately; of that I need say no more, 
because I have to speak mostly of the characteristic ornament of the different periods, and this plain weaving is not susceptible of ornament-woven ornament I mean. To obtain that the weft must cross the warp at regular intervals, but not alternately, on the surface either warp or weft must predominate to make a pattern.

To speak broadly, in the most ordinary kind of patternweaving the threads come to the surface in a regular and mechanical manner. I have not time to explain all the ways in which this is done, but must ask you to accept that simple statement and allow me to call this kind common figure-weaving. Sometimes, as a subdivision of this common figure-weaving, the warp comes chiefly to the surface, which makes a satin; and also sometimes these warp threads are caught up over wires with a sharp edge which are pulled out as the work goes on, leaving a surface with a raised pile, that is velvet.

In the next kind of weaving the weft crosses the warp alternately indeed, as in plain unpatterned weaving, but instead of being carried in one stroke all across the web, ends or returns wherever the colour changes, so forming a kind of mosiac of coloured patches; this is tapestry, using the word in its narrowest sense. As a detail of this work I ought to mention that in tapestry-weaving the weft is put in so loosely, driven home so carefully, that the warp is entirely hidden by the weft.

That work may be considered as a subdivision of this kind of weaving, where thrums of wool, hair, or silk are knotted into a plain canvas as the work proceeds, so as to form a pile with their cut ends; this is carpet-weaving.

Lastly comes a kind of ornamental web, in which the ornament is not produced by weaving, but by painting by hand or printing combined with dyeing (in various ways) in the piece; we call these printed goods, chintzes and so on. Needle-worked embroidery is another way of ornamenting a cloth; but I shall not deal with this form of ornamented cloth.

Now all these manners of weaving have been practised VOL. XII.-H, L. 
from time immemorial, and are in use to-day, with no more variation of method than what comes from the application of machinery for lifting up the threads of the warp, as in the Jacquard machine, now universally used in civilised countries, and the use of steam-power for throwing the shuttle; these variations of method are of little or no interest from the artistic point of view, and are only used to get more profit out of the production of the goods; they are incidental changes, and not essential.

However, ancient as all these methods are, the oldest way of ornamenting a cloth otherwise than by merely painting on it with a pigment (not dyeing), or by embroidery, must have been the tapestry method, as it requires but a very small amount of technical, though often much artistic, skill : the figured webs of the Homeric poems were probably of this kind of work; in the British Muscum there is a scrap of cloth of the ancient Central American civilisation so woven ; the patterned cloths of the north of Europe before the fourteenth century were mostly tapestries; the South Kensington Museum has a precious fragment of such work of the eleventh or early twelfth century; among peoples of higher industrial skill, the common figure-weaving took the place of this (technically) rude work for ordinary recurring patterns, but tapestry was still used for producing what may fairly be called woven pictures; webs whose elaboration and want of repetition of pattern would scarcely allow of any reasonable effect being produced by mere mechanical weaving.

The painting or printing of cloths is doubtless a very ancient practice, I mean to say, the painting them with dyes, not pigments; the minute and elaborate figure ornament which is shown on some of the Egyptian sculpture, has, to me, a look of being done by means of this art; it is a confirmation of this probability that Pliny, in a now famous passage, notices the fact that Egypt, in his day, practised a certain art of figuring cloth, his description of which leaves no doubt that it was what we should now call madder printing or painting; of this art I 
shall have to speak in the notice of dyeing which will conclude this lecture.

So here we have to consider, to leave out plain unornamented weaving, Ist, Common or mechanical weaving, including satin, damask, and velvet ; 2nd, tapestry including carpet weaving, and $3 \mathrm{rd}$, painting or printing with dyes.

Let us consider briefly the practical history of these three arts.

And first the mechanical or common weaving. With wares so perishable as woven cloth, it is not wonderful that we have little real record of the stuffs of antiquity; because the descriptions of the poets and writers of the time cannot be depended on for accuracy, as they of course assumed a general knowledge in their audience of the articles described; the vase-painting and sculpture of the central Greek period gives us at all events some idea of the quality of the stuffs worn at the period, and in so doing fully confirms the beautiful and simple description of the fine garment in the Odyssey, which is likened to the inner skin of an onion: a figure of speech which, taken with the representations of delicate cloth in the figure-work of the time of Pericles, and earlier and later, gives one an idea of something like those mixed fabrics of silk and cotton which are still made in Greece and Anatolia; only you must remember that the early classical peoples at least did not know of either silk or cotton ; so that flax was probably the material of these fine garments; and we know, by the evidence of the Egyptian tombs, that linen was woven there of the utmost delicacy and fineness.

I don't suppose we need doubt that mechaticical patternweaving was practised by the Greeks in their earlier and palmy days, but only, I fancy, for the simpler kinds of patterns in piece goods, diapers and so forth. I conclude the running borders to have been needle-work, or, may be, dyed painting. We have a few representations of looms to help us in looking into this matter, which, however, do not prove much; they are all vertical, and at first sight look nearly like the looms used throughout the middle ages, 
and to-day at the Gobelins, for tapestry weaving. In one which is figured in a tomb at Beni Hassan in Egypt, the details of an ordinary high-warp tapestry loom are all given accurately; but the weavers seem to be weaving nothing but plain cloth; in this loom the cloth is being worked downwards as in the ordinary tapestry loom.

In another representation, taken from a Greek vase of about 400 B.C., Penelope is seated before her famous web, which is being worked in an upright loom; there is only one beam to it, the cloth-beam, and the work is woven upward; the warps are kept at the stretch at the bottom by weights looking too small to be effective; the web is figured, has a border of the ordinary subsidiary patterns of classical art, and a stripe of monsters and winged human figures. It seems to have been concluded that this represents actual tapestry weaving, but too hastily perhaps, as the high-warp loom only means a certain amount of inconvenience in foregoing the mechanical advantages of the spring-staves worked by treadles. Also this Greek loom of 400 B.C. is in all respects like the looms in use in Iceland and the Faroes within the last sixty years for weaving ordinary cloth, plain or chequered.

So much, and little enough, of the loom-work of the early classical period, a time when the merely industrial arts, which were, you must remember, mostly carried out by slave labour, were despised; when private luxury scarcely existed; a fact most happy both for the decency of general life and the glory of the arts.

Doubtless the ingenuity of the industrial arts gained much during the later and imperial days of Rome; but there is little direct evidence in the remains, artistic or literary, of the time itself. Pliny, who is very particular on the subject of dyeing, helping us nothing in the matter of weaving.

However, perishable as the actual woven wares are, the art is particularly conservative in design, and when we get nearer to our own epoch we have a certain number of specimens preserved to us from the tenth century downward, which not only show us how people wove in those 
days, but give us more than a hint of the fashions of centuries before their time. A very small fragment of cloth found at Sitten, in Switzerland, gives us doubtless a type of a late Roman figured stuff; the pattern which repeats in a smallish space, is of a woman seated on a fish-tailed, leopardheaded monster, amongst conventional foliage ; the point of it, as an illustration of our history, being that it is designed wholly in the classical manner; so that whatever the date may be, it is absolute evidence, as far as it goes, of the kind of work of the later classical times.

However it is now time for us to leave this somewhat barren desert of vague poetical descriptions, hasty and generalised drawings on vases or tombs, and very rare scraps of the woven goods themselves, and march into the more fruitful country of the early middle ages, which give us quite direct evidence of the arts of weaving of the days of the Byzantine empire. Now you must remember that whatever share the city of New Rome took in actually producing works of industrial arts under her emperors, she was at least the foster-nother of those arts for all mediæval Europe, and from her came that influence which brought about the new art of Europe, whose origins are obscure enough till they meet and are fused at Constantinople into a style which for centuries after was world-wide; this was natural enough. Looked upon as a European city, Byzantium was for long the only great city of Europe that was really alive and dominant in peace and war; as a mistress or an enemy she dealt with all the great birthcountries of art and letters, nay, of human life. India, Mesopotamia, Syria, Persia, Asia Minor, Egypt-the ideas and arts of all these countries touched her, and mingled with the remains of the older art of Greece, from which the academicalism of the long Romano-Greek period had not crushed all the life, sorely as it had weighed upon it. Byzantium then, the Byzantium of Justinian, and onwards, we must look upon as the capital of the industrial arts, from the sixth to the thirteenth century, and in none of them was her influence more obvious than in that of weaving. One 
event alone which took place there revolutionised this art in Europe, the introduction of the silkworm in the sixth century, which event has also made it more possible to judge of what was done in early times, because the material having the advantage of not being liable to be moth eaten, some specimens of early date have been left us.

It would take us too long to discuss the much disputed question of the actual date of some of these scraps, such as those found in the tomb of Charles the Great at Aix la Chapelle; it is enough for us that, as I have said, they undoubtedly represent the design of the stuffs of Justinian's period, and through that period throw light on the fashions of old Rome, and even of classical Athens. These earliest Byzantine or quasi Byzantine stuffs are most commonly figured with contiguous circles or wreaths, which enclose divers subjects; sometimes the chariot-race in the Hippodrome; or the consular sacrifice, the Byzantine emperors, as consuls of the Republic, being the chief figures; the lion hunt in the emperor's arena or the park of the Great King; the gladiator again dealing with his lion in the arena, and probably doing duty for Samson in the eyes of the devout Byzantine christian;--all these subjects take us away into classical times. But there are other subjects within these Byzantine or early mediæval garlands which carry us further back, and hint at a time before the dawn of history, much simpler though they be on the surface; for often these circles are inhabited (to use an heraldic phrase) by beasts, winged or otherwise, griffins, elephants, and birds opposing one another, again in heraldic phrase, on either side of an upright object, sometimes branched variously. Now, though you may think that this is a very natural way of filling a circle ornamentally, yet I think it has been conclusively proved that these beasts and their dividing object are symbols of ancient worship, the object being perhaps translated by the Zoroastrians as the holy fire, though originally signifying the holy tree, which has played such a curious part in ancient symbolism, or betokening of mysteries. 
So then Constantinople takes us back not only to the time of the Cæsars, on one side, but on the other also to that of the Great King of Persia, to the kings of Assyria, the monarchs of Babylon, and far beyond them to the Arcadian people and their astronomical lore.

But if Constantinople was the capital of the weaver's art till the twelfth century, during the next two centuries Palermo took her place. The chroniclers tell us that just in the middle of the twelfth century, Roger the Norman, king of Sicily, in a raid he made on the eastern empire, took Corinth, Thebes and Athens, where there was still a considerable silk-weaving industry, and that part of the booty which he carried off from those towns consisted of the silk-weavers themselves, and their families, whom he took back with him to Palermo and established in a royal factory attached to his palace, bidding them teach their mystery to his own people. From that time till past the middle of the mediæval period Sicily was the great workshop for silk goods.

Although this story has been much accepted, told, as it was, gravely and circumstantially, it must be looked upon as a legend founded on the undoubted fact that in the thirteenth and fourteenth centuries Sicily was the head-quarters of the silk-weaving craft. The population of Sicily consisted largely of Saracenic tribes, who kept amongst them the skill in the industrial arts which they had acquired (chiefly, no doubt, from Byzantium, though not always directly) in the early middle ages; besides, Sicily had been a most important outwork of the Byzantine empire in its palmy days-was, in fact, much more important than the towns of Greece proper; and was not at all likely to have lacked its due weaving craft. Altogether it seems extremely unlikely that Roger should have been the first of the Norman kings to set up a royal weaving-shed, especially as the Norman kings from the first had affected to imitate oriental customs, reigning, as I have said, among a population which was really oriental; and this custom of a royal factory, connected as it was, with the 
establishment of the seraglio, which, 'tis said, the Norman kings were not slow to adopt, would have seemed a necessity to a monarch at Palermo long before the time of Roger's raid on Greece. You may note at this place that these weaving-sheds of oriental potentates turned out those rich stuffs which were especially used for presents and robes of honour, and had Arab writing intermingled with the design; a fact which has served to date some of these webs beyond dispute, as the writing sometimes includes the name of the reigning prince. A word or two on these written stuffs will have to be said presently.

Anyhow, however the manufacture was established, there is no question that in the fourteenth century Palermo was head-quarters of the silk-weaving craft, and most happily we have abundance of evidence of the kind of work produced there, for a great many fragments have been preserved to us in the treasure-houses of the churches of that and the succeeding century. Nay, even in England, in spite of the Reformation, some evidence is left us of the long way that these beautiful goods travelled; for on the backgrounds of painted panels in the richly adorned screens of our East Anglian churches, and on the robes of the saints depicted thereon, are figured patterns more or less accurately taken from these Sicilian webs, which doubtless formed part of the vestments of the sacristy.

North Germany, where the reformation went on in its earlier days more peaceably and with less destruction than in England, has, however, been the great storchouse of these invaluable treasures, the sacristy of the Church of St. Mary at Dantzig being particularly rich in them. The museums at Vienna, the Louvre, and the South Kensington Museum here are well stocked with examples, which I must say, as to ourselves, are not treated with the respect (by the public, I mean,) which they deserve. For I must tell you that these stuffs, designed in the heyday of medixeval art, uniting the wild fancy and luxurious intricacy of the east with the straight-forward story-telling imagination and 
clear definite drawing of mediæval Europe are the very crown of design as applied to weaving.

To a certain extent they preserved the older fashions, and repeated, though not servilely, the patterns of the Byzantine epoch; the writing on the webs seems to have been used by them as a sort of trade mark, implying that they were of fine oriental manufacture ; only, for the most part, it is mere sham vriting, a scrawl which has borrowed certain obvious forms from the real Arabic letters, whose graceful and energetic curves fitted them specially for this kind of written ornament; for the rest, the resource and the ingenuity of structure, the richness of imagination in these stuffs is amazing; beasts, birds, and compound monsters are frequent, often arranged in opposition on each side of the holy tree or holy fire aforesaid; but often simply passing their lives in the scenes of nature, and generally admirably drawn as to their characteristics, though of course generalised to suit the somewhat intractable material; then we have castles, fountains, islands, ships, ship sails, and other such inanimate objects; finally the weaver uses the human form often enough, though seldom complete; half women lean down from palm-trees, emerge from shell-like forms amongst the woods with nets in their hands, spread their floating hair over the whole pattern, water their hounds at the woodland fountains, and so forth; now and again definite winged angels are introduced; in one whole class of designs a prominent feature is the sun-dog, as it used to be called in the older English tongue, a cloud barely hiding the sun, which sends its straight rays across the design with admirable effect.

And all these things are drawn at once with the utmost delicacy and complete firmness; there is no attempt to involve or obscure anything, yet the beauty of the draiving and the ingenuity of the pattern combined give us that satisfying sense of ease and mystery which does not force us to keep following for ever the repetition of the pattern ; in short, in most of the designs of this place and period 
there is nothing to desire either for beauty, fitness, or imagination.

From Palermo the art of silk-weaving found its way into the more northern parts of Italy, and settled definitely at Lucca, the centre of a great silk-growing district, whose manufacture overlaps that of Palermo in date, so that it is not casy to state with any certainty whether such or such a piece of goods was woven at one city or the other; but as the years passed a kind of design peculiarly graceful, but not so strongly accentuated as in the earlier patterns, marks this school; these patterns are generally founded on the vine; birds and animals are often introduced into them, but do not play such a prominent part as in the earlier cloths. As to the technique of these webs of Sicily and Lucca it is on all sides admirable, and in nothing more so than its simplicity; so fertile was the designer, his work so crisp, elegant, and powerful at once, that it would have been the height of bad taste to complicate or huddle it up with tormenting the web into ribs or stripes or honey-combs or herring-bones, or long weak floats of silk; these are the poor refuges from barrenness of invention, which a less artistic age is driven to, and has used, and still uses in a most profuse and wearisome way. One peculiarity I may note about all these early stuffs; gold is freely used in them, but the gold thread is not like that of our time and some centuries back, to wit, a thin ribbon of gilt silver twisted round a floss silk core, but is made by gilding strips of fine vellum and twisting that round a core of hemp or hard silk; this plan has both its advantages and disadvantages, it does not wear as well as the wire twisted thread, but also is not so apt to tarnish. The Chinese still use similar gold thread, only by substituting gilt paper for gilt vellum do not make so good an article.

Before passing to the next century, I must mention that all this while much silk ware was made in the east. At Cairo and thereabout was a manufactory of striped silk in which the Arabic writing, real and finely designed, played a 
great part; in this work the gold was always flat strips of the gilt parchment which marks the special manufactory. In all cases you must remember there was at this time no essential difference between the ornament of east and west; even in architecture the resemblances are more noticeable than the differences; but of course, in the lesser art we are considering, the needs of climate and manners had not the same influence as in architecture; accordingly we find not only the same details but the same patterns in use in Persia and Syria as in Sicily and Italy. It is also interesting to note that pieces of Chinese damask are not seldom to be found as the grounds of needle-embroidered ecclesiastical vestments, whose patterns are identical with those even now woven there.

As to Northern Europe, doubtless the ornamental weaving, which was mostly worsted, was chiefly tapestry work; but it seems that some kind of figured stuff other than that was made. In the edicts of St. Louis mention is made of "tapisserie à la haute lisse," "tapisserie saracenois," (of which more anon); and also of "tapisseries nostrez," which last are obviously goods made in a long picce for cutting and joining. My own impression is that these "tapisseries nostrez" (judging by the context) were like the rudely flowered stuff traditionally made by the Italian peasants to-day, in the Abruzzi, for instance, and of which the Roman peasant women's aprons are made. This impression is chiefly founded on the fact that exactly the same make of cloth is woven in Iceland for coverlets, saddlecloths, and the like, the inference being that it was formerly in use very widely throughout Europe ; it seems, however, that early in the fourteenth century there was some sort of silk-weaving and even velvet-weaving in Paris, but I imagine it to have been either plain weaving or tapestry, and the velvet to have been made like a carpet. One may note as showing clearly that the East made mechanically woven cloth and the West tapestries, that when the unlucky Frenchmen who were taken by Bajazet at the rout of Nicopolis, in the year 1396 , were arranging their ransom with him, and were trying to find out with what rarities 
they would be likely to soften the heart of their conqueror, they were told that he had a turn for the fine tapestry of Arras, "if so be they were of good ancient stories;" fine linen of Rheims would not come amiss to him either, or fine scarlets (more of those afterwards), "for," said their friends, "as to cloths of silk and gold the king and the lords there in Turkey have of them enough and to spare."

The fifteenth century brings us to Florence and Venice, where the splendid cloths were wrought which were used so profusely in the magnificent stateliness of the later middle ages. This is a part of the subject that wants treating clinically, so to say; that is, we should be alongside some of the fine specimens in the best museums in order to make you understand it properly. Nothing can exceed the splendour of some of these Florentine and Venetian webs, whose speciality was a particular kind of rich velvet and gold, often with one pile raised on the top of another. In these cloths the vellum-twisted gold gives place to gold thread as we know it, but gilded so thickly, that it is not uncommon to find specimens where the gold is very little, if at all, tarnished.

Rich and splendid as these cloths are, they have, to a certain extent, lost some of the imaginative interest of the earlier designs; it would not be true to say that they depend on their material for the pleasure they give, because in these great patterns, founded on vegetation of the thistle and artichoke kind, there is a vigour and freedom that is most delightful and captivating; but they are more architectural and less picture-like than the Sicilian stuffs; the strange monsters, the fairy woods and island shores, the damsel-peopled castles, palm trees, and shells, the lions drinking at the woodland fountain, hawk, swan, mallard, and dove, the swallow and her nestlings, and the hot sun breaking through the clouds, all these wonders and many another have given place to skilfully and beautifully arranged leaves and tendrils. As we shall see, later on, picture-weaving had reached its height by this time, and there was something of a division of labour between the two kinds of weaving design; at the same 
time the design was absolutely pure and suitable to its purpose, no atom of corruption had crept in.

Now as to the relation of this design to that of the east, they still marched close together, until the false taste of the Renaissance began to affect the later medireval work. Throughout there is more of distinct elegance in the eastern work, and that more especially in that kind of design which we call Persian.

The sixteenth century saw the change in woven work which fell upon all the architectural arts. I have said that weaving is conservative of patterns and methods, and this is very obvious of this great period of change; one may say that the Oriental-gothic feeling, which was the very wellspring of fine design in this art, lasted side by side with divers new fashions, some of which were merely the outcome of the general pseudo-classical feeling, and showed in detail rather than general arrangement of the pattern, and some pieces of fantastic ugliness, which indicated only too surely the coming degradation of the weaving art.

By the first years of the seventeenth century that degradation had befallen the art in Europe ; in fact, it was becoming, or had become no longer an art, but a trade, as we very properly now-a-days call work which is really but an acciclent of the profit-market. I need not, therefore, trace its degradation further, though that degradation was checked, to a certain extent, by the traditions of the better. times, and some good work was done, until the great flood of the vileness of the eighteenth century swamped everything, and prepared the way for the inanity of the nineteenth; which, in its turn, let us hope, is doomed to prepare the way for a new life once more, even in this small corner of the result of man's intelligence, the textile arts.

Having thus gone very briefly through the story of mechanical weaving, I must now turn back to take up the other sicle of weaving, and talk of it as producing something which we must call pictures for want of a better word. I have said that in the early days of Greek civilisa- 
tion the more claborately figured cloth must have been either embroidery or tapestry; of course in the later classical times, when the mechanical arts had attained a great degree of perfection, some of this elaborate work might have been done in the mechanical loom, but judging from Ovid's description of the contest between Minerva and Arachne, which at least admits the possibility of weaving quite an elaborate picture, (for they at least were not embroidering), tapestry work must have been practised in classical times. But we need not dwell very long upon these times of uncertain evidence and guess-work, since we have in later times such abundance of clear material for carrying out our enquiries. It is at least pretty certain, as I have already said, that all the more elaborate figured hangings actually made in the North of Europe before the end of the fourteenth century were woven in the tapestry loom; a piece of such work, North German, or perhaps Scandinavian, of the beginning of the twelfth century is preserved at the South Kensington Museum and is itself a portion of a larger piece at Lyons. The design of this piece is practically an imitation in tapestry of the mechanically woven patterns of the south-cast of Europe; its design being of that kind of contiguous circles enclosing monsters, of which I spoke before. It is worth while noting that patterns of exactly the same character have been traditionally used in Iceland till within the last IOO years, only by that time they have got to be done by means of worsted embroidery upon linen. Now of course you understand that these tapestry cloths were done always for special decorative purposes; for wall-hangings and curtains, I mean, their thick, heavy, and rigid texture unfitting them for use as garment cloth, to the same degree that it would fit them for use as hangings; as on the one hand the northern craftsmen, who had to work chiefly in wool by-the-by, as I have remarked, had not learned the special mystery of the mechanical figure-weaver from the east, so also this kind of wall hanging would be likely in the cold damp climate of the north to take the place of 
the wall-pictures which so commonly decorated important buildings in the south of Europe. This, in fact, happened, and the use of tapestry hangings grew commoner as pictures grew more elaborate; the earlier pictured tapestry hangings partook of the simplicity of the paintings of the time, as one can clearly see by the one or two precious relics of that period which we have left. These simple pictured cloths were no doubt woven all over the north of Europe, but one of the chief places of manufacture in the thirteenth and fourteenth centuries was Paris. I have mentioned the edicts of the time of St. Louis which show that the craft of tapestry weaving, "tapisserie a la haute lisse" as they call it, was an important craft at that time. Later on, in the second half of the fourteenth century, the tapestry weavers are frequently mentioned at Arras, which city, as you know, has given its name to the whole art, Tournai, Valenciennes, Lille, and Douai ; Flanders, in fact, was taking the place in tapestry weaving which it filled to the last. In the last years of the fourteenth century there is much mention made of the craft, and the names of two designers are mentioned, John of Bruges, and Nicholas Battailles, who were both in the employment of Charles the Fifth of France.

There is fortunately a piece of tapestry still in existence of this period, a portion of a great hanging made for the Cathedral of Angers. It represents scenes from the A pocalypse, arranged in frames and divided by figures of the prophets twice the size of life; it is a grand and monumental work, severe in style, and decidedly belonging, especially as to its scheme of decoration, to the fourteenth rather than the fifteenth century, though it was not finished till about I453. Of about the same period are certain cloths made in Germany on a small scale, not above 4 feet high or so. These are quaint and playful in subject and design, and have a domestic sort of look about them; in fact, I think they were made at the houses they were intended to decorate. The subjects are chicfly secular-scenes from romances sports and pastimes, the occupations of the months, and so forth; they were probably meant for what 
were called dorsars, i.e., cloths to hang at the backs of the diners' benches in the hall; the South Kensington Muscum has some good specimens of these.

From the middle of the fifteenth century the art of tapestry weaving went on vigorously, and we have many specimens left us of the time, at least of the latter half of the century. It may interest you to hear what some of the subjects of the tapestries were which Sir John Fastolf left behind him at Caistor in Norfolk. You must remember he was a powerful country gentleman, of second rank say.

Imprimis $\mathrm{j}$ clothe of Arras, clipped the schipherd's clothe.

Item $j$ of the Assumpsion of Oure Lady.

Item $\mathrm{j}$ clothe of IX. Conquerouris ("the Nine Worthies, doubtless).

Item $\mathrm{j}$ clothe of the Siege of Faleys for the west side of the hall.

Item $\mathrm{j}$ clothe of Arras with III. archoways on scheting a doke in the water with a crossbowe.

Item $\mathrm{j}$ clothe of Arras with a gentlewoman harping by $\mathrm{j}$ castle in the midst of the clothe.

There are a great many more in the inventory from which this is taken, but these will serve as specimens of the woven decorations of the walls of Caistor Cast' - in the middle of the sixteenth century.

One of the finest pieces of tapestry left, by-the-way, you will find under the minstrels' gallery in the Great Hall at Hampton Court, somewhat in the dark; it is in good preservation, and the colour is very beautiful, the drawing is both refined and vigorous, much resembling in style the piece preserved at Berne which is said to have been designed by Roger van der Weyden. Of about the same period (say 1460) is a piece at the South Kensington Museum of the three Fates standing on a prostrate lady. This beautiful piece is a representative of a particularly pleasing kind of decoration, where figures are introduced on a background of conventional flowers, the finest specimen of which, to my knowledge, is in one of the smaller rooms at the Hotel de Cluny at Paris, but unluckily the guardians of that fine museum have nearly hidden it with heavy pieces of furniture. I think we must consider this kind of work as belonging in spirit to the 
fourteenth century, though it lasted right into the sixteenth.

Well, tapestry went on getting more and more elaborate, and reached its turning point about the first years of the sixteenth century, of which period the South Kensington Museum has now, I am happy to say, some very noble specimens, equal in fact to any of the time. The tapestry of this period, however, though so much more like a picture than that of the earlier period as to be crowded with figures, and to deal freely with all explanatory accessories, houses, chariots, landscapes, and so on, nevertheless is carefully designed on the principles proper to the art. The figures are arranged in planes close up to one another, and the cloth is pretty much filled with them, a manner which gives a peculiar richness to the designs of this period. The opposing fault to this being the arrangement of figures and landscape as in a picture proper, with foreground, middle-distance, and distance, which plan of arrangement, in a woven hanging, in which the peculiar qualities of a picture must be lackirg, gives a poor unfilled-up look, and at a far greater expense of labour and ingenuity than went to the production of the more conventional arrangement.

We have now come to the end of the Gothic period of this noble art of picture-weaving. The middle of the sixteenth century saw the above-mentioned change take place, and thenceforward the faults, which accompanied the degradation of all the arts from that time onward, had their influence on tapestry, which, however, died hard, so to say. $U_{p}$ to the first quarter of the seventeenth century tapestries were still made, which, though they had lost all the romance and direct beauty of the Gothic period, had some claims to be considered decorative objects. The following period saw the execution of works (at an enormous expense) which were a very bad substitute for the yellow wash of a stable. $U p$ to this time the execution, at least, of these pictured cloths had been pure and reasonable, had not attempted in any way to imitate the execution of the brush. But from the times of the

VOL. XII.-II, L. 
Grand Monarque and the establishment of that hatching nest of stupidity, the Gobelins, all that was changed, and tapestry was now no longer a fine art, but an upholsterer's toy.

We will leave it in that mud of degradation to have a few words with its congener-carpet-weaving. Now as tapestry was entirely a western art, so is carpet-weaving altogether an eastern one. 'Tis clearly an art of the peoples who dwell in tents or tent-like houses; of dusky rooms with no furniture save a few beautiful pots, and a gleaming brass dish or so; of dry countries where mud is a rare treasure reserved for the sides of wells or tanks, and where people kick off their slippers and walk barefoot when they come into a house.

I think it is a doubtful point as to whether carpets proper were made in Europe before the seventeenth century; although some learned men think that the Tapisseries Saracenois, mentioned in the edicts of Louis IX. time, were true piled carpet-work, and it must be said that their reasoning seems rather convincing. Anyhow there is no direct evidence of carpet-making in mediæval Europe, where, as a matter of course, foot carpets would be little used in the rough and very out-a-door life then led; but from the middle of the fifteenth century there is abundant evidence of the importation of eastern carpets into Europe, the most direct and satisfactory of which is given us by the pictures of the period, in which such goods are often figured ; these show us carpets, doubtless made in Asia Minor, of geometrical designs always, the prototypes of which were obviously floor-mosaics; both the Flemish painters and the Italian paint these things with much accuracy and enjoyment. But besides these carpets there was undoubtedly another kind of design being carried out at the time, whose head quarters was Isphahan in Persia: this kind of design was elaborate, flowing, and founded on floral forms, very commonly mingled with animals, and sometimes with human figures; in short, the geometrically designed carpets above mentioned have a direct analogy with the earlier 
Byzantine silk stuffs as to design, and this flowing Persian style with the freer designs which were woven in the looms of Palermo. Of these latter flowered carpets $I$ do not pretend to fix the dates with any accuracy, but among the specimens I have seen, I will undertake to say that there are representatives of at least three different styles before the degradation of the art; the first being a pure flowing style, following closely in detail the forms of the finest oriental architectural work, e.g., the plaster ornament at Cairo; the next affecting much the same detail, but blended with animal form ; the third purely floral, flowing, and very fantastic and ingenious in the construction of its patterns; this last I think brings us in date to about the time of Shah Abbas, (the upholder of the greatness of the restored Persian monarchy about the time of our Queen Elizabeth,) and his immediate successors, i.e., from 1550 to 1650 or so. After that the degradation began, but it took a very different form, as always is the case with Eastern art, than it would have done in Europe, where all degradation of art veils itself in the semblance of an intellectual advance; in the East, on the contrary, haste, clumsiness, rudeness, and the destruction of any intellectual qualities are the signs of degradation, a tendency in fact to mere disintegration. As to this special degradation of the carpet-making art, the thing to note about it is that it has as its subject matter all the different styles I have mentioned; the Byzantine or floor-mosaic style, the flowing fourteenth century, the scroll and beasts style, and the floral style. From the disjecta membra of these four are knocked up, so to say, the traditional designs which are found in comparatively modern Eastern carpets, which in spite of all degradation are still generally very beautiful things, not altogether lacking in some sense of logical congruity, and generally good in colour.

It would be an endless task to follow all the ramifications of this art in the East; but I must just say that the Mussulman conquerors of India carried it to that peninsula where it took root and flourished till quite our own days chiefly using the more floral side of Persian design, but in

O 2 
some places curiously blending with it forms taken from the native art, Buddhist or Brahminical, and in others infected by the eccentric art of modern China. Modern commercialism, since the days when I was a young man, has laid its poisonous touch upon this useful industry, and to-day it is almost ruined as an art; those importers who have any taste having to exercise great pains and patience in getting fair specimens of it for sale at home.

I have now gone briefly through the tale of woven ornament, but before I say a few words on what may be called the artistic ethics of this art, I must very hurriedly speak to you of the art of dyeing, since upon that is founded all the ornamental character of textile fabrics. In doing so I will, for convenience sake, use the present tense, but must ask you to translate it into the past, as this art most of all among the subsidiary ones has been turned into a trade, even to the extent that the public is beginning to be conscious of their loss in this respect, though it is quite helpless to remedy it; also I must ask you to remember that I am speaking as a dyer and not a scientific person.

Blue, red, yellow and brown are the necessary colours from which a dyer makes all his shades, however numerous; all these colours are furnished by natural substances, which have, however, to be modified by the dyer's, or, if you will, chemist's ingenuity. Of blues there is only one real dye, indigo, to wit; this dye in the ancient classical, and the European mediæval countries was obtained from woad, the Germanic name for an indigoferous plant, which can be grown in rich soils as far north at least as Lincolnshire; whereas the true indigo can only be grown in tropical or sub-tropical countries; indigo, as long as it keeps its colour and nature, is insoluble and therefore unfit for dyeing; it has therefore to be turned into white indigo by means of deoxidation, which is effected (I must be brief and not exhaustive here) chiefly by fermentation; the white indigo is then soluble by alkalies; this deoxidation is called by the dyers "setting the blue vat"; and this setting by means of fermentation, the oldest and best way, is a very ticklish 
job, and the capacity of doing so indicates the past master in dyeing.

The next colour in importance is red; two kinds of substances produce it-Ist. The powdered root of plants called in the Germanic tongues madder; of the madder producing plants there are several kinds, e.g. clavers or goose grass, galium verum (our lady's bed straw) and wood-ruff, but they are all poor in dyeing matter, the true madder having to be carefully cultivated in good soil. 2nd. There are the insect reds-kermes or coccus, the scarlet of the ancients, which lives, or grows rather, on a prickly oak on the Mediterranean Shores; the lac insect, chiefly in India, and cochineal in Mexico and South America. Of these, madder dyes a dullish blood-red; kermes, a central red tending towards scarlet; lac a coarse violent scarlet, and cochineal (used variously) crimson and scarlet.

Next comes yellow - which is vegetable again, and again of two kinds ; one bright yellow from lemon upwards, the other brown yellow ; weld is the representative of the first ; the others are extracted from wood barks chiefly, and are all more or less astringent.

Now these reds and yellows are dyes of a very different quality from indigo; the textile fibres have little or no affinity for them, and have before they are dyed with them* to be impregnated with mineral substances for which the dyes have an affinity; these are principally alumina and tin ; so used we call these metals mordants; the widest spread and most ancient mordant is the alum of commerce. The fibres being steeped or boiledin these mordants, the dyeing forms a lake on the surface of the fibre, and the trick is done.

The browns are, Ist vegetable astringents; the extract of walnut root, or walnut hulls is the representative of that; and 2nd mineral from the solution of iron; the oxide of which, by-the-by, i.e. yellow ochre, can be formed on fibre, and is especially useful in cotton and linen dyeing as a brownish yellow or buff dye.

* Or sometimes as in cochineal scarlet dycing the mordant is mixcd with the dip bath. 
The other colours are made by mixtures of those above ; green, e.g. is first dyed in the blue vat, then mordanted and dyed yellow; purple, blue vat again, mordanted and dyed red; black, blue vat, mordant, and red, mordant, and yellow, or blue vat and brown. The blue vat has to be continually in use for obtaining all kinds of sub-shades.

One famous and historical dye has been extinct for hundreds of years, the ancient purple, the use of which seems to have died out in the earliest middle ages; it was extracted from certain shell-fish, and was a very permanent and beautiful dye, varying in shade from violet to a fine solid and somewhat sombre red-purple.

You must be more careful to distinguish this dye from the other famous ancient one than some of the poets have been. This is the Al Kermes or coccus above mentioned, which produces, with an ordinary aluminous mordant, a central red, true vermillion, and with a good dose of acid a full scarlet, which is the scarlet of the middle ages, and was used till about the year 1656 , when a Dutch chemist discovered the secret of getting a scarlet from cochineal by the use of tin, and so produced a cheaper, brighter, and uglier scarlet, much to the satisfaction of the civilised world ; which by-the-way has, for the last 300 years, always greeted with enthusiasm every invention which would tend to make its clothes and dwellings uglier and more inconvenient.

I regret that I have but a short space to say a very few words about the last textile which I mentioned to you, dyepainted or printed cloth, to wit, and which I could hardly say anything about till I had given the foregoing short account of dyeing, with which art it is so intimately connected. I have mentioned the fact that Pliny makes it clear to us that this art was known to the ancient Egyptians, but it most probably had its origin in India, a country of all others fittest for following the art, on account of its peculiar climate, and its wealth of dyeing materials; whether or not the art was practised in mediæval Europe in any form is doubtful, but it does appear at least possible that some of the 'stained cloths,' which we have oftenest supposed to 
be merely pigment painting in distemper, were dye-painted. . In the middle of the sixteenth century the art was firmly established in Persia, whose elegant, and beautiful patterndesigning from that time forth has made certain forms of ornament quite familiar to us in the chintzes that were freely imported into England from the end of the seventeenth century onward ; for it goes without saying almost, that this Persian ornament conquered everything of cotton printing in India, except the cloths which were made for special purposes, figured with the personages and scenes of the Brahmin mythology. It is hardly worth while as an artist going into the history of this art in Europe ; since whatever was really fine in it was little more than a literal copy of Indian or Persian originals; of which latter one may say that the peculiarities of the manufacture gave opportunities for special freedom of design, and very beautiful colour, founded on the two most important dyeing drugs madder and indigo.

I did not mean from the first to include the pleasing art of embroidery in this discourse on textiles; so here we will end our sketch, and will conclude with very lightly considering the artistic ethics of the subject, as I promised. Don't be alarmed, it is but a word or two as to the general quality of the design of textiles in good periods; you will find that, whatever merits there may be in textile ornament, flows always from an instinct for the fit use of material amongst men of simple and manly lives; which instinct is so strong in pure times of art, that its effects are most obvious to us when the designer, who in those days was also the weaver, was thinking least of his materials, when he was wrapped up in the invention of his design and the beauty of its hues; it was in second rate times of design, such as in that period of splendid Florentine velvet weaving I have told you of, that the material was as much thought of as the design, or it may be more so; when in fact the design was used for the display of splendour of material.

In the times of the degradation of the art, with the 
history of which I have not thought it worth while to trouble you, people by exaggerating this fault fell into another which seems at first sight almost the opposite one; they gradually forgot that the material had anything to do with the design at all, in fact they often spent time and pains to make, for instance, woven silk look like printed paper and so forth. Moreover, in the fine time of art what the designer thought of was always in some way to appeal to the imagination; in other words, to tell some story, however imperfectly; he had not time, therefore, for the petty ingenuities of the later days, he was determined to let us know what he had in his mind, and he, unconsciously maybe, well understood that he was to use fair colour and beautiful form in the simplest and most direct way in order to carry out his purpose. So treated, the design of even a scrap of cloth becomes elevated by human intelligence, and has in its humble way distinct intellectual value; it becomes a thing which no intelligent unprejudiced man has any right to pass by with contempt, as a piece of mere frivolity; and I must say point blank, that unless we can elevate our design into this region of fancy and imagination, we were better to have no ornament at all ; for to my mind as a mere commercial necessity, a bit of trade finish, it is unspeakably contemptible. 'You may easily imagine that I have not time to give you even any hints as to the way of elevating our ornament on wares, nor perhaps would this be quite the best place in which to treat the subject, which it seems to me if properly treated would lead us into very serious matters indeed.

One hint, however, I should like to give you; I am myself an ornamentalist, a maker of would-be pretty things. Yet I will not try to press on you the fact that there is nothing like leather; rather, I would say, be cautious of over ornamenting your houses and your lives with cheap unenduring prettinesses; have as few things as you can, for you may be sure that simplicity is the foundation of all worthy art; be sure that whatever ornament you have is proper and reasonable for the sort of life you want to lead, 
and don't be led by the nose by fashion into having things you don't want. In looking forward towards any utopia of the arts, I do not conceive to myself of there being a very great quantity of art of any kind, certainly not of ornament, apart from the purely intellectual arts; and even those must not swallow up too much of life. As to ornamental art (so-called), I can, under our present conditions, looking forward from out of the farrago of rubbish with which we are now surrounded, chiefly see possible negative virtues in the externals of our household goods; can see them never shabby, pretentious, or ungenerous, natural and reasonable always; beautiful also, but more because they are natural and reasonable, than because we have set about to make them beautiful. We needn't think that this will be an easy matter to bring about, but when it is brought about, I do believe some sort of genuine art and ornament will accompany it, it may be in rather a Spartan way at first; from that time onward we shall have art enough, and shall have become so decent and reasonable, that every household will have become a quiet daily unadvertised Health Exhibition. 

THE

\title{
PHYSICAL EDUCATION OF GIRLS.
}

\author{
BY \\ MISS CHREIMAN.
}

VOL. XII.-H. L. 



\section{JULY $25 \mathrm{TH}, \mathrm{I} 884$.}

\section{A LECTURE ON THE PHYSICAL EDUCATION OF GIRLS.}

By Miss Chreiman.

His Grace the DUKE OF BUCKINGHAM AND

CHAndos, K.C.S.I., in the chair.

My Lord Duke, LAdies AND Gentlemen-I have been requested by the Executive of the Literary Department of the Health Exhibition, to speak to you on the subject of gymnastic and other matters of physical training for girls and women; and I have been further asked to confine my remarks principally to the present need and late progress of physical education, and to give some particulars of the kind of exercise my experience has led me to adopt.

Firstly then-for I propose to keep as nearly as possible to the lines laid down for me-

\section{The Present Necessity for the Scientific Physical Training of Girls.}

You will all agree with me, I think, that this our age has special need of wise, and noble, and healthy women; that the present conditions of female life-its widening responsibility and intense competition, the lengthened curriculum of "higher" education, errors of fashion, all the difficulties of want of space and want of time-present special hindrances to the attainment of that bodily perfectibility upon which the moral, intellectual and physical strength and beauty of womanhood so. largely depend; 
and that the cumulative privileges and tyrannies of civilisation need some opposing force to stay the constitutional undermining and physical degeneracy which are in acknowledged progress.

In order that we may look at facts as they are, will you call to mind, for a moment, twenty of the "finest "women of your acquaintance? In how many cases do their daughters give promise of becoming as tall, as broad chested, as erect, as free from nervous irritability as their mothers? Very few, if your experience coincides with mine.

It has been said that perfection of form, grace of movement, and according to age, full respiration, are natural to infancy, and watching the gambols of our very little ones we can well believe it; but with our artificial environments, most certain it is, that fatal failings are often inherited, or induced at a very early age, and progressively developed. Can our elder girls breathe properly? I know that members of the profession of medicine, and teachers (on scientific principles) of singing and elocution, will say they cannot. Respiration is an involuntary and normal act, yet our doctors say that long continued ill-health, and ultimate death are the frequent results of continuously impeded expansion of the lungs; our teachers say, that many of the faults attributed by singer or speaker to weakness of the voice are caused by a bad method of breathing, and the absence of that masterful control over the respiratory apparatus, without which it is impossible for any one to speak or sing with perfect self-possession and accurate response of will, whilst by those whose business it is to train to severe exercise, we are told that the distress experienced is oftener due to embarrassment of the lungs than to muscular fatigue; and we all know that a beautiful voice has long been considered a special, instead of a common, gift, and that individually and nationally we have, in great part, lost, as our solace and rest amid the trials and labours of life, the stimulus of eloquence, and the tranquilising, energysing, elevating and recreative influence of song.

Walking ought-after the period of infancy-to be as 
easy and natural as respiration, but I am quite sure no one will assert that our girls walk well. We must have noticed the poke of the head, the contraction of the shoulders, the slackness of knee, the stiffness of the back, the jumpy, hip wobbling, mincing gait, and general absence in one way or other, of that firm, easy and graceful carriage which is not only dignified and pleasing, but which contributes so eminently to the facility and agreeableness of the act of walking, both for work and recreation.

Then, sitting is worse than walking. Mothers constantly tell me that they find it impossible to induce their daughters to "sit up." It has been asserted that the maintenance during long hours of the erect position, to which their grandmothers and mothers were compelled, has tended to the weakening in their offspring of the overtaxed muscles of the spine; but this assertion does not appear to be substantiated by observation; certainly the inadaptability of children's seats to all purpose of rest, tight stays, high heels, heavy clothing, insufficient exercise, and bad positions in the various occupations of life (as sleeping, writing, reading, drawing, practising on the violin, piancforte, harp, etc.), have much to do with the difficulty, and its evil evidence in increasing weakness, disordered functions, want of spirits, and commencing deformity, is very painful to those who can read it.

I dare not think that the many thousands of young wives who are "too delicate" to "nurse" their babies, actually fail (in what was, not long since, considered a by no means optional duty,) from such health failure as the omission would seem to imply. Is it not more probable that civilization's unreasoning compliance with Society's and Fashion's demands, and its unwholesome fostering of distaste for domestic trouble-taking (except in the matters of entertainment and decoration) is making that function of motherhood, obsolete? Whatever explanation be the true one,considering that neither nature nor science has yet supplied a trustworthy substitute for the infant's natural food,-_" a pity 'tis, 'tis true."

Together with this threatening degeneracy of female 
physique, have come increasing educational and social demands for constitutional robustness, and a progressive sense of the advantage of that physical vigour without which the duties of womanhood cannot be efficiently performed. Amongst the many wiser female guides and guardians of our girls, it is to be feared that there are still not a few with whom the old fallacies that the body should be sacrificed to the mind, and that a hearty enjoyment of such games as ensure activity and increase appetite, is unladylike, still linger ; but whilst some good parents "of the old school " still teach their daughters to regard their bodies very much as a lobster may be supposed to regard its shell, our girls have ceased, or are fast ceasing, to cultivate delicacy in order to render themselves attractive, and happily almost all men of education have ceased to consider pallor interesting, and to admire a tiny distorted foot and a pinched waist-for knowledge has dispelled mystery in the matter-and understanding the laws upon which the healthy action of the animal economy depend, they know that the girl whose face is adorned with nature's choicest colours, possesses in fuller measure than her pallid sister, and will longer keep, the cheeriness and energy and beauty of youth; they know something of the value of good circulation, respiration, and digestion, and the good spirits that accompany them, as elements of domestic happiness ; and they know, too, that the paralysing process of compression must ere long result in making duty toilsome, sleep unsound, temper uncertain, dyspepsia certain, and beauty a dream of the past. Whilst in both sexes there is an improved though still defective capacity for apprehending their obligations to society in this matter of health, and for recognition not only of the immediate and sensibly felt results of the observance or disregard of hygienic conditions, but also of the fact that future personal enfeeblement and hereditary disease, or augmented vitality and entailed health, are the certain, intensified remote results of those feebly felt, but daily operating influences, whose potency is only in their permanence.

Chief amongst life's debilitating influences is inaction, 
and one of the chief means of preserving health, increasing strength, improving the mental faculties, and aiding the arrest of deformity and the cure of disease, is the one with the necessity of which we are to-day concerned, viz., muscular exertion.

The body is strangely tolerant of inaction, considering that its every part is weakened by it. Inaction impedes the circulation, impoverishes tissue, diminishes vital heat, checks the action of the skin, impairs digestion, and disorders the nervous system; it were almost to be wished that it possessed, like hunger and thirst, and cold and weariness, some power of protest, by immediate importunate sensation, and, like them, were capable of enforcing attention to the body's need, and of so securing, by the vigorous action of every part of the system, the circulation of enriched and aërated blood, prepared from regular supplies of fresh food, imperative demand for which would only be the more surely made.

"The muscles, then, are the grand instruments by which man acts on the external world. Life itself is sustained by the constant exercise of muscular power; and were either the heart or the muscles of respiration to forget their part for a few minutes, existence would be at an end. Without the aid of muscular power, man's grandest conceptions and most energetic resolutions would remain unfulfilled; Shakespeare and Milton would have been mute as the statues which now represent their forms, and the immortal creations of their genius would have been lost to the world for ever. To replenish the blood exhausted of its nutritive principle by exercise, a greater quantity of food is required, and to prompt us to attend to this condition, the appetite becomes keener and more imperative, and the power of digestion proportionally vigorous. The food taken is more speedily digested, and its absorption from the surface of the intestines and transmission into the circulatory current are more rapid. That the blood so improved may be properly and quickly animalised in the lungs, respiration becomes deeper and VOL. XII.-H. L. 
more frequent, thus admitting a larger quantity of air and freer circulation through them than before ; and the blood in this way renewed, and re-endowed with the pabulum of life, imparts fresh nutriment and vigour to all the organs of the body, and fits them for that active exertion which the proper discharge of his duties imperatively requires from every member of the human race." *

Someone has said that if only a few of the advantages which result from exercise were to be procured by any one medicine, nothing in the world would be more anxiously sought after.

Dr. Graham transcribes the following story: "Ogul, a voluptuary, who could be managed with difficulty by his physician, on finding himself extremely ill from indolence and intemperance, requested advice. 'Eat a Basilisk stewed in rose water,' replied the physician. In vain did the slaves search for a Basilisk, until they met with Zadig, who, approaching Ogul, exclaimed, 'Behold that which thou desirest; but, my lord,' continued he, 'it is not to be eaten; all its virtues must enter through thy pores. I have, therefore, enclosed it in a little ball, blown up, and covered with a fine skin; thou must strike this ball with all thy might, and I must strike it back again for a considerable time, and by observing this regimen, and taking no other drink than rose-water for a few days, thou wilt see and acknowledge the effect of my art.' The first day Ogul was out of breath, and thought he should have died from fatigue; the second he was less fatigued, and slept better; in the eight days he recovered all his strength. Zadig then said to him, "There is no such thing in nature as a Basilisk, but thou has taken exercise, and been temperate, and hast therefore recovered thy health.'"

Attention cannot be too early paid to the training of the body, its systematic and progressive culture should progress jointly with that of the mind, and the exercise of playground, garden and gymnasium become a part of educational routine. 
The Kindergarten system of teaching has fully recognised the wisdom of giving play, exercise, conversation, singing, and instructive manual occupations a large part of the time usually devoted to books, and it is most profitably spent both as regards the minds and bodies of our little ones.

Girls should play oftener, and to a later age, than is customary with the majority of them. Moderately exciting social games, and the shouting and laughter which accompany them, furnish varied and vigorous muscular action, and a pleasurable mental and nervous stimulus, which are invaluable. Tennis, cricket, croquet, skipping, swinging (the swing being kept in motion by self-exertion, not the passive movement). Battledore and shuttlecock, hop-skotch, and "touch," "puss-in-the-corner," " nuts and may," "oranges and lemons," and "fox and goose," may be mentioned. But good and necessary as such games are, they give the left side of the body too little work, and do not sufficiently tend to the development of the thorax, to take the place of scientific exercise at any time during the period of growth.

In addition to games, archery, the lighter work of gardening, and some amount of domestic work, are good.

The exercise of rowing assists largely in imparting a graceful carriage and free play of the muscles of the back. It should not be engaged in at too early an age, on account of the strain thrown upon the joints.

I have been told that, in addition to its general tonic effect, horse exercise is of special value in several chronic diseases, resulting from the impaired action of the viscera of the abdomen, and is preventive in incipient disease of the chest. Growing girls should be provided with saddles with reversible pummels, so that they may be seated alternately on the off and near side of the horse.

Both as an exercise and a safeguard the art of swimming should be thoroughly acquired, but it would be well if some means were taken to prevent girls remaining for too long a time in and about the swimming bath. I fear that 
irreparable damage is thus done to the constitutions of girls, who "begin to decline without any apparent reason;" and that it is a matter in which consequence fails to get connected with causation, unless the damage be of so immediately serious a nature as to bring the sufferer under medical care. Girls shiver and have headache, look pale and feel languid, lose appetite or digestive power, but no lesson is learned by such gentle remonstrance; there is an opinion amongst them that, "if I am up to my chest in water I cannot take cold," and "taking cold "-the kind of cold that makes itself evident in cough, and throat and nasal discomfiture, seems to be the only evil recognisable by them as connected with this form of excess. One minute's conversation with any physician would convince parents of the extreme danger of this. In one bath of which I know, gentlemen are limited to twenty minutesladies "may stay in as long as they like."

When learning to skate, it is desirable to acquire the habit of bringing the weight of the body somewhat forwards - the weight less upon the heels than upon the fore part of the feet, and one advantage of this is that falls are likely to be forwards, and their force can be broken by the hands.

It is to be regretted that dancing, in large well-ventilated rooms, or in the open air, during the hours of the day, and costumes adapted to exercise, is not more frequently engaged in.

With regard to

\section{THE Kind OF EXERCISE MY EXPERIENCE HAS} LED ME TO ADOPT,

I must premise that my pupils are all of the upper or middle class, requiring and desiring, as the result of their training, not huge biceps and great lifting and climbing powers, but harmonious muscular and functional vigour, ease and accuracy of muscular action, symmetry of form, the grace that results from well-managed strength, and an increased fitness for the enjoyment of every pleasure, and the discharge of every duty of life; and 
that I am increasingly of Dr. Combe's opinion that, "If we examine the attitudes and motions of the body which occur in the better class of gymnastic exercises, and in fencing, dancing and swimming, we shall find that they are no less graceful and beneficial to the young who engage in them, than pleasing to those by whom they are witnessed-just because they are in harmony with nature, or, in other words, with the structure and mode of action of the joints, ligaments and muscles by which they are executed. But it is far otherwise with some of the anomalous exercises which were at one time so fashionable, and which are not yet extinct in schools and gymnasia, and seem to have for their object the conversion of future men and women into foresters, firemen, or savages, rather than into beings who are to continue to have the use of stairs, ladders, carriages, steamboats, and the other conveniences of civilised life. It is, no doubt, a good thing for a boy to be able to climb a perpendicular pole or a slippery rope, when no other means present themselves of attaining an important object at its upper end ; it is an equally good thing for a young lady to sustain her own weight hanging by one or both hands, when there is no possibility of resting her feet on terra firma; and where boys and girls are strong enough to take pleasure in such amusements, there is no great reason to hinder them, provided they are impelled to them, not by emulation or any secondary motive which may lead to over exertion, but by the pure love of the exercise itself. But the case is altered when such extraordinary evolutions are not only encouraged but taught to all indiscriminately, whether they be strong or weak, resolute or timid. We have only to reflect for a moment on the structure of the shoulder joint, and on the sphere of action of the muscles surrounding it, to perceive that the position of the one and the strain upon the other caused by such exercises, are so forced and unnatural as to exclude the notion that the Creator can have intended either to be practised, except upon occasions of urgent necessity. The very violence of the effort required to sustain 
the body when hanging by the hands, is far beyond that moderate exertion which adds to nutrition and strength; in delicate subjects it may even induce relaxation and stretching of the ligaments and blood vessels, and thus lay the foundation of future and fatal disease. But in all violent evolutions we need only look at the dragging and distortion which they produce, and which form such a painful contrast to the ease and grace of all natural motions and attitudes, to perceive that they are out of the mode of nature, and that neither health or elegance can result from them."

When some few years ago my attention was forcibly called to the need of improved physical training for girls, I visited the different gymnasia of England, and found in the one at Liverpool much that I required. This fine gymnasium is now the property of the Young Men's Christian Association. It was then under the management of a council, Mr. Henry Coulson being the lessee and master. I worked (privately) for its diploma, and was, when the gymnasium closed, the only lady holding one.

This diploma represents able and careful instruction, and (as I was desirous to be able to make a wise selection of exercises from experience as wide and inclusive as possible) a good deal of practical study there and elsewhere -but is of no higher value. I hope that for the teachers now being trained for this branch of Physical Education, we may succeed in getting examinations by the University of London. Surely the nation's health is of sufficient importance to warrant such protection of Physical Education.

Well, I learned how to exercise the head and trunk, and arms and legs; but when I commenced to teach, I found that the fingers and feet, and the larynx and lungs, ought to have their special exercise too; and, that, as I necessarily rejected many of the exercises of the gymnasium, and my bright English pupils require variety, and, as they progress, some sense of difficulty, I had very much to add; and the system, partly original, partly eclectic, which has resulted, has been practically illustrated in the gymnasium of this 
Exhibition by a class of pupils under Miss James, and at my demonstrations in this (Albert) Hall, held by desire of the Ladies' Sanitary Association, and the Executive of the Health Exhibition. I hope and believe that these free open practices, which my pupils have very kindly enabled me to hold from the commencement of my work, have been of service to the cause of physical education.

One of my aims, and that of the ladies who so efficiently assist me, is to make every lesson thoroughly enjoyable, as we believe the recreative benefit of movement to be largely in proportion to its enjoyment.

Another is to get, during every hour's practice, the maximum of muscular exertion compatible with the strength and capability of the class, without incurring any possibility of strain or undue fatigue.

The ultimate object of the exercise (as already mentioned) being ever in mind.

Private lessons have sometimes to be given to delicate pupils, as exercise must be adapted to their condition from day to day, but the usual instruction is to classes meeting in large, lofty, well-ventilated halls, which can be kept cool in summer and warm in winter. A low temperature, as sometimes recommended, is not well, as moderate warmth is favourable to muscular development.

The gymnastic costume worn by my pupils is a short princesse robe of navy blue satara cloth, with knickerbockers of the same. (Satara cloth is a soft, light, durable woollen material.) A broad sash of "cardinal" cashmere is also worn, this being made use of as a support during certain exercises, and as a throat and chest wrap in passing to the dressing-rooms after exercise. Now that jerseys are so neatly made, they are sometimes substituted for the upper part of robe, a skirt attached to a bodice of thin woollen material being worn beneath them. The costume can be readily adapted for ordinary school wear. Stays, unless of such hygienic make as to allow of perfectly free movement and full respiration, are forbidden, as are also "heels."

We usually "open work" with a vocal march, or gym- 
nastic song. It is not altogether easy to find songs which are adapted to movement and suitable for elder girls. I have found it necessary to write most of those we use ; perhaps as we progress this difficulty will be removed. Some of my own series of movements are "free"-as the finger and wrist, feet and other series-and we make use of German, Spanish, and Swedish "free" exercises, gymnastic dances, games, \&c.

We also use light dumb-bells, bar-bells, poles, clubs, rings, skipping-ropes, hoops, balls, \&c., for series of movements. There are various obvious advantages in the use of light and portable apparatus. Somewhat similar light apparatus has been largely adopted in the gymnasia for ladies in America, with (I am told) very excellent results, the exercise being visibly beneficial, greatly enjoyed, and increasingly popular. This is satisfactory, as the need of our transatlantic cousins is even greater than our own.

Certain series of dumb-bell and bar-bell movements are commenced at an early period of the training of most pupils; they are extremely useful in all stages of development, the muscles of the back, shoulders and chest being well exercised by them.

Club exercises we never give, until pupils have acquired considerable muscular control, and are supposed to have realised experimentally the physiological advantages of good position. They are then of considerable value, and their progressive difficulty, together with the beauty of the circular movements executed with them, make them a favourite series.

Movements of resistance are executed by the opposed action of two pupils of fairly equal strength, with, or without, wooden rings, \&c. The effort of resistance on the one part, and that of overcoming resistance on the other, increase the physiological effects of the exercises.

My ball exercises, of which there are several series, some of them of considerable difficulty, were arranged chiefly for home practice. They are useful in providing varied and graceful exercise, and for unconscious cultivation of 
accuracy and precision of movement, sense of "time," and regulation of force expenditure to the desired result, and I am told that they have a beneficial influence upon the nerves of vision. The apparatus for these is an indiarubber air ball about three inches in diameter.

Sometime ago Mr. Charles Roberts, F.R.C.S., called my attention to the fact that many growing girls become flat-footed, and suggested the addition of special series of exercises which should, by strengthening the muscles, joints, and ligaments concerned in the important functions of support and progression, lessen the tendency to this deformed condition of the feet. We will show you some of the exercises that I have since tested, and found to meet the requirement; and I may add that the steps of the sailor's hornpipe and the Scotch dances are most excellent for strengthening the feet and lower limbs-I am now making them part of our course. We should bear in mind that by loss of the arch, the beauty, elasticity, strength and usefulness of the feet are seriously diminished.

I have lately added to our respiratory and laryngial gymnastics. Some of the new exercises have been selected from those used in German schools of elocution and for the relief of asthma, stammering, \&c. I have reason to hope that increased healthfulness will result wherever such exercises are regularly and carefully practised.*

We are told that strength and beauty of voice was an outcome of the physical training of the Greek School. May it not be an aim of our modern training? Voice cultivation for public reading, speech and song, must, of course, be in the hands of the professor of singing and elocution; but it is lamentable that their work should be hampered and hindered, as it is, by a previous disregard of all acoustic and physiological principles, so that the pupil goes to the professor with induced weakness, bad habits of breathing, and faulty or indolent action of the muscles and apparatus by which articulate sounds are produced. Surely this

* I am indebted to Mr. F. Helmore, author of "Speakers, Singers, and Stammerers," for information"as to proven beneficial results of such exercises, as used by himself, during his long experience. 
ought to be prevented. Respiration is a function essential not only to good voice but to good life; power of movement, capacity of endurance, and all else of physical well being depend upon it, and whenever it is imperfect it cannot have too careful attention from parents or teachers. We are told that "the neglect of muscular activity displayed by the majority of singers and speakers, and the laziness with which they open their mouth and use their lips and tongue, is a frequent cause of stammering and other voice failure;" and that "a man of good physical capacity may be trained so that the voluntary muscles of the arms and chest are powerfully developed, with a contractile force proportionate to their size, and yet his respiratory power may be so disproportionate that he can not run a hundred yards without gasping;" and again, " that the habitual faulty use of the respiratory and vocal muscles produces congestion of the vascular supply to the mucous membrane, disorder of the secreting follicles, irritation of the sensory nerves of the throat, and uncertainty of action of the vocal muscles, each resulting in hoarseness and deterioration of power both to produce and to control the desired tones; so that all functional exercise occasions fatigue and nervous depression, with the addition of injury to the general health. Chronic throat disorder is thus established, which if neglected is obstinate of cure.*

The muscular apparatus concerned in the requisite movement of the jaw, tongue and lips, might be strengthened and rendered controllable by adapted exercise; and lung gymnastics, regularly practised, would give the needed power of methodic prolonged inspiration and expiration.

The lower ribs, which have about ten times the mobility of the upper ones, are generally tightly dress-bound with women, the great majority of whom never thoroughly inflate their lungs; and the congestion of the unused air cells, and consequent imperfect oxygenation of the blood, go far to produce dyspepsia, nervous disorder, consumption, and kindred evils.

In our first exercises the power of advancing and retract* MacLaren, 'Physical Training.' 
ing the abdomen during inspiration and expiration, whilst the ribs are as nearly as possible stationary, is practised.

This is followed by various abdominal and costal breathing exercises, respiration being generally through the nostrils, but occasionally, for special physiological reasons, through the open mouth. Rarely, and only in combination with the costal and abdominal, clavicular inspiration is practised, in order to extend the expansion of the chest to its fullest limit.* These exercises are alternated, or accompanied with arm movements, \&c.

Ordinary expiration and inspiration occupy less than two seconds. After some practice each process may (during exercise) occupy from twelve to twenty secondsand such full respiration greatly strengthens the intercostal muscles, diaphragm, \&c., and increases the size and elasticity of the lungs.

The respiratory movements of the larynx, by which the size of the glottis. is alternately increased and diminished, are improved or impeded similarly to those of the thorax.

In these exercises the "rhythm of the vital vibrations" must be preserved; whenever we prolong "the period of tension" at the expense of "the period of relaxation" fatigue occurs and danger begins. All respiratory exercises must be gently commenced, and very gradually increased, in order that reciprocal action between the heart and lungs may be established.

The function of the hand is so distinctive and important that it is strange that its training was so long overlooked, and is receiving but little attention even now that much has been spoken and written of the lack of exercise for the fingers in the ordinary occupations of life-and their consequent weakness and painful fatigue in the special occupations of which they are the agents; and it is known that the progress of pianoforte-, violin-players and other artists would be greatly facilitated, and the tendency to stiffness of the joints, cramp, paralysis, and other complaints of draughtsmen, writers, carvers, painters, watch-makers, type-

* Lennox Browne and Emil Behnke, 'Voice, Song, and Speech.' 
setters, stenographers, needlewomen, and all other workers who maintain themselves by the continuous use of certain sets of muscles, would be greatly lessened, if not prevented, if all the muscles of the hand were gymnastically exercised with sufficient regularity to make and keep that useful member strong and flexible.

No apparatus is necessary; elasticity, freedom, and force may be given to the muscles, joints, ligaments and tendons, of wrist, palm, and digits, by the habitual practise of very simple antero-posterior, transverse, and circular movements of the wrist, and by flexor, extensor, and rotatory movements of the fingers.

The exercise of beginners should be conducted with the greatest method and care; the general capacity of the pupil should be ascertained, and any local weakness well considered.

After twelve years of age, jumping and leaping exercise should, I think, be very sparingly indulged in by girls.

Excess is to be as carefully guarded against as insufficiency; strain, inflammation, irregular action and paralysing exhaustion of muscle, brain, and nerve, and of all the organs dependent upon their healthy action, are the damaging consequences of frequent (sometimes of a single day's) excess.

In series of movements the left side of the body should have precisely the same amount and variety of exercise as the right side. Head and trunk movements should, as a rule, be slowly executed.

Exercises which operate directly upon the internal organs, deep breathing, running, laughing, singing, reading aloud, \&c., and such arm movements as increase respiration, are generally beneficial to weak-chested girls; but existence of any weakness of the heart should be ascertained, and only adapted exercise given to pupils so suffering.

Girls should on no account attend classes in the hope of cure of spinal weakness, slight or otherwise, without having first taken medical advice. Some class exercises are not adapted even to the kind of curvature for which exercise is so beneficial. 
Pupils, as well as teachers, should be informed that the time for the "hardest" exercise is neither at the beginning or end, but towards the middle of the practice ; that exercise should increase the action of the skin, and any check to perspiration after practice must be carefully guarded against; that good appetite should result from exercise, but substantial meals must not be taken either immediately before or after it, and that failure of appetite and languor are symptoms of excess.

The necessity for exercise continues through life, and should be regular and active up to a much later age than is commonly the case. Our physicians say that at no period of life is systematic exercise more imperative than between forty and fifty, as at that time the wear and tear of life is lowering the vital power, circulation is slower and feebler, and if exercise be neglected, local congestions and functional derangements result, of which some of the symptoms are flatulence and constipation, insomnia, vertigo, and premature old age; or perhaps hysteria and causeless depression, the commencement not unfrequently of insanity or intemperance.

I believe that for most girls, one or two hours per week of well directed scientific exercise are sufficient, if commenced at an early age and regularly continued; and if outdoor exercises and games are also engaged in. When muscles are exercised to their fullest capacity, the physiological effects of such exercise are sufficiently permanent to be carried on, as it were, by its recurrence at regular intervals, which must not be too distant, but certainly need not be daily.

I have been asked to say a word in defence of musical accompaniments; and, although it scems to me that music might very well be left to speak for itself, I gladly say that we find it not only an inspiriting accompaniment, but a powerful incentive to exercise. Suitable music allies itself, as it were, with movement, is of itself mentally recreative, and supplies that pleasurable excitement which, if not an essential condition of healthy exercise, is a 
nerve and muscle stimulus, which adds fourfold to the energy and enjoyment of every pupil, and acts as an inspiration to the indolent and fceble, to whom movement is not, of itself, pleasurable. Those of you who have danced without music, will understand this. Even the sailors' "Yo-heave-ho," \&c., is of evident value in adding grace and harmony to their work.

My hope is that before the lapse of many years we may have gymnastic halls for girls in every district of every town, under the management of women of education and refinement, fitly trained (not hastily and partially taught to teach "a system" of exercises)-trained for the work of physical education, and, in co-operation with visiting teachers and medical examiners, able to assist mothers in all matters of physical well-being. In these Halls the apparatus may be of the simplest; but do let us have plenty of space, plenty of air, and for decoration, forms of beauty in sculpture and painting.

The health of our women is of the highest domestic, social, and national importance: and, happily, no longer content with ignorant, selfish participation in life's mighty marring, trusting to "a Providence that shapes our ends, rough-hew them as we will," our women in tens and hundreds are stepping up on to an intellectual platform high enough to overlook their responsibilities, and, if too late for themselves, to desire for their children the "excellence of perfect adaptation and thorough efficiency in all the relationships of life." When the majority of our mothers and daughters have a higher ideal of life and a truer and more definite standard of domestic and social morality, physical progress will be assured.

I sometimes wish that, as scholastic "marks" have such a mighty influence on scholastic effort, a mark value could be given to symmetrical growth. In all cases in which bad positions during home and school life are habitual, and head and neck are poked forwards, or the spinal column bent to front or side, the muscles that are subjected to the undue tension are strained beyond their power of 
contractility, maintenance of an erect position by and by becomes impossible, even by effort, and more or less of deformity must result. If bad position were merely unsightly I would not recur to this matter, but it is so little regarded by many of our girls, and so important, that I am impelled to do so. Good position during sleeping and waking hours is exceedingly favourable to health, and in proportion to habitual departure from it are the functions of the thoracic and abdominal viscera impeded, and circulation of the blood, respiration, tone of voice, normal sightedness, and even, to some extent, power of attention and use of the limbs impaired.

As regards impairment of vision alone, this matter imperatively demands attention, both as a cause and an effect. Some oculists so fully recognise this that they prescribe chin supports for their patients.

An idea is prevalent that the condition of shortsightedness is compensated for by increased durability of sight. It seems to me desirable to have decisive medical testimony on this matter. I see the disadvantage of reduction of focal length every day of my life, and can but think that if it ever have any advantage over normal vision in the matter of duration, it must be by its better conservation, and not by loss of normal power; and I strongly advise girls to lift up their books, \&c., towards their eyes, and not bring their heads down to (almost upon) their books, and to gradually increase the distance between the two, as in some cases of induced myopia more or less of normal power may be slowly regained.

If we could make a dropped shoulder as costly in marks as a dropped "h," and get all lack of functional ability or symmetrical growth regarded as disabilities which culture should remove; and if progressive development until the narrow-chested girl breathe her proper volume or air; the weak tissued acquire substance and contractile power ; stiff or protuberant joints receive correction, and want of local power give place to harmonious strength ; if, too, preservation of sight and improvement of 
other special senses could be provided for by methodical instruction, tested by periodical examination, and acknowledged in reports and diplomas; physical failure would cease to be the shameful accompaniment of intellectual success: and in possession of "knowledge not purchased by the loss of power," our girls might perhaps come to believe, with Charles Dickens, that "the power of knowledge is to bear and forbear, to learn the path of duty, and to tread it, to engender that self-respect which does not stop at self, but cherishes the best respect for the best objects; to turn an always enlarging acquaintance with the joys and sorrows, capabilities and imperfections of our race, to daily account in mildness of life and gentleness of construction, and humble efforts for the improvement, stone by stone, of the whole social fabric."

But for this we must wait until the British public, having learned how much better and easier is prevention than cure, and how costly, individually, and nationally, are feebleness and failure, parents and teachers combine in desire to make mental and physical vigour the result of educational training.

I know that some of you, looking at your bright young daughters, will feel that notwithstanding all that can be said of the excellence of Grecian, and the comparative neglect of modern physical training, no girl of other time or state, "could hold her own for a moment against the beauty of a simple English girl of pure race and kind heart;" and I fully agree with you : but the more is the pity that our British capacity for well-being is not better recognised. The popular English theory of health seems to me to resemble the popular English theory of ice. People say they are in perfect health, much as they say they are "as cold as ice." They have never considered that ice has as many temperatures as there are climates on the face of the earth, and, as Sir Francis Head told us, "if an Englishman succeeds in filling his ice-house, he fecls satisfied that his ice is as good as any man's ice; in short, that ice is ice, and there is no use in anybody attempt- 
ing to deny it: but the truth is, that if two ice-houses were to be filled, one with Canada ice, the other with English ice, the difference between the quantity of cold stored up in each would be as appreciable as the difference between a cellar full of gold and a cellar full of copper ; in short, the intrinsic value of ice, like that of metals, depends upon the investigation of an assayer (extra cold being added to, and retained by the mass); and a cubic foot of lower Canada ice is infinitely more valuable, that is contains infinitely more cold than a cubic foot of Upper Canada ice, which contains infinitely more cold than a cubic foot of English ice ; and thus, although each of these four cubic feet of ice has precisely the same shape, they each, as summer approaches, diminish in value, that is to say, they each gradually lose a portion of their cold, until long before the Lower Canada ice has melted, the English ice has been converted into lukewarm water." Degree of health is as little a "fixed quantity" as is the temperature of ice, and power of resistance to adverse influences has but little more place in the popular theory concerning it.

In our opinion, national health is not-whilst we have infancy and youth with a high rate of mortality, adult life without maturity, and early old age "sans teeth, sans eyes, sans taste, sans everything."

It is less of prodigal production, and yet "more life and fuller that we want"; less, possibly, of physical and intellectual feeding, and more of the pleasurable digestion by which minds and bodies grow; less of impulsive action under accidental or regular excitements, and more character building, by ennobling habits formed by the wholesome occupation of all our. faculties.

I believe that our chief duty, for the honour of our God and the common weal of our country, is to teach our girls that if one thing is to be more plainly read in life's failures than another, it is that nature's laws are perfect and undeviating in their action, and the choice of good or evil the crowning dignity of manhood and of womanhood. We VOL. XII.-H. L. 
must teach them that human health is a matter of law, that the health and capability of parents greatly influence the health and capability of their offspring ; and give them such information of the wonderful mechanism of man, and the beautiful process of life, that they may know that it is a Christian woman's duty to be pleasing in person and courteous in manner-and realize how important to those who will be the mothers and teachers of the next generation, are perfection of structure and function, accuracy of judgment, readiness of ear and eye and hand; because it is in their beginnings, before their symptoms are perceptible to untrained guardians, that physical, mental and moral disease may be averted, and the progress of healthful life assured-because it is in the first struggles of scarceconscious existence that holy aspirations may be strangled or strengthened, and genius supported by sympathy or dwarfed by indifference or misapprehension to fitful onesided deformity.

Surely, when the majority of our mothers and daughters realise these things, there will be no more closing of the gateways of knowledge, "till in the void left by ignorance, prejudice has taken up its seat;" but our girls will soon know more than we could tell them in many lectures, of the value of pure air, and large lungs to receive it, of the need of continued, adapted systematic exercise for the preservation of health of body and mind ; the danger, too, of its onesidedness and excess-of diet, with all the elements that the body requires for its nourishment-of clothing, that shall minister to their grace and comfort, instead of fettering them in crippling servitude to itself; surely, too, they will soon know enough of hereditary and other disease, to make them desire consultation with their physicians about prevention as well as cure, and (if we could but make a sense of beauty and of proportion one of the outcomes of our training, they might learn enough of the marvellous possibilities of human development, and the range of objects eliciting their interest and offering to add 
to the measure of their enjoyment; to delight in the certainty, that education is a matter, not of a few years, but of all time, and that,

they may feel

"With faculties still growing,"

"That whatsoever point they gain, they yet Have something to pursue."

Speaking generally, men seem to me to have sounder ideas on these matters than women; they certainly desire a long period of working capacity for themselves, and an increasing number of them appear to agree with Shakespeare, that he amongst them who wins a helpmate fitted, and able to fit others, for long and happy life,

"Hath achieved a maid that paragons perfection,"

and

"Is as rich, in having such a jewel, As twenty seas, though all their sands were pearl, Their waters nectar, and their rocks pure gold."

[Since date of the above lecture I have promised to open a Training College, in which girls who desire to become professors of physical education, may be fitted for such work as has been mentioned above.

Those Sanitarians and Educationists who have urged this agree with $\mathrm{me}$ in hoping that nationally helpful work may be developed, and much health benefit result.]

20 Gwendwer Road, West Kensington, 



\section{OLD AND MODERN POISON LORE.}

A. WYNTER BLYTH, M.R.C.S. 



\title{
JULY I5TH, I884.
}

\section{A LECTURE ON OLD AND MODERN POISON LORE.}

\author{
By A. Wynter Blyth, M.R.C.S.
}

Dr. B. W. Richardson, F.R.S., in the chair.

The Chatrman : Ladies and Gentlemen, I understand it is the order of proceedings that I should introduce Mr. Blyth, but I think it would be much more in order that he should introduce me, considering that it is the first time I have had the pleasure of coming to one of these meetings ; but without further preface I will call upon him to read his paper.

Mr. Wynter BLyTh.-The modern word toxicology has a deep significance, it can be traced back to an ancient root, meaning "bow " or "arrow," or in a wider sense some "tool" used for slaying. The oldest poison lore was that of primitive races in various parts of the world, who, in remote unhistoric time, took a lesson from the snake, and remedied the imperfection of their weapons by steeping them in venom.

The arrow poison of the Gauls is said to have been hellebore; that used by certain American Indians is curarine, a vegetable extract from plants of the strychnos order. Some races adopted snake poison, and others putrid 
blood; this last producing a disease termed in our day septicæmia, or blood poisoning. In this way the septic poisons may have been very early known.

Weapons soiled with the blood of former wounds would be found more deadly than clean, freshly-made weapons; and starting from this empirical fact, the arrows or spears would be steeped in all manner of offensive pastes and smeared with the vegetable juices of those plants which were deemed noxious; and as the effects were mysterious, they would be ascribed to, the supernatural powers, and covered with a veil of superstition. The poisonous properties of arsenic, opium, henbane, aconite, and a few others were known to the ancients and handed down by oral tradition as a part of priestcraft, long before they were reduced to writing; the exact amount of knowledge thus transmitted in this way can only now be a matter of inference. On an Egyptian papyrus preserved at the Louvre, M. Duteuil read, "Pronounce not the name of I. A. O. under the penalty of the peach." Now peaches, as peaches, are perfectly harmless, but prussic acid can be distilled from them; the Egyptians were the first known to have practised distillation; hence, under the dread threat of the peach, it is clear enough that they meant prussic acid; this is probably the earliest evidence extant of the actual separation of a poison in a more or less pure state by a chemical operation. No mention is made of prussic acid among the early Roman writers, yet there is good reason to believe, that a knowledge of the deadly Egyptian distillate of peaches passed to the Romans. A knight, in the reign of Tiberius, accused of high treason, swallowed poison and fell dead at the feet of the senators; no poison but prussic acid, and that in a tolerably concentrated lorm, would have this effect.

The early treatise of Nicander of Colophon (204-I 38 B.C.), to which followed Dioscorides, however, shows that whatever use or abuse might be made of a few violent poisons, Greek and Roman knowledge of toxic substances was stationary, primitive and incomplete. 
The Asiatic races used poison more than the northern or western nations; the ancient practice of the Hindoo widow-self-immolation on the burning pile of her husband is ascribed to the necessity the Brahmins were under of putting a stop to the crime of domestic poisoning. Every little conjugal quarrel was liable to be settled by this form of secret assassination, but the law seems to have effectually stopped the practice. The Asiatics knew the properties of arsenic, aconite, opium, and various solanaceous plants, but were not acquainted with prussic acid.

The part that poison has played in history is considerable. The pharmaceutical knowledge of the ancients is more graphically and terribly shown in the deaths of Socrates, Demosthenes, Hannibal, and Cleopatra, than in the pages of the older writers on poisons. In the early part of the Christian era, professional poisoners arose, and for a long time exercised their trade with impunity. In A.D. 26 poisoning was so much in use as a political engine that Agrippina refused to eat of some apples offered to her at table by her father-in-law, Tiberius. It was at this time that the infamous Locusta flourished. She is said to have supplied, with suitable directions, the poison by which Agrippina got rid of Claudius; and the same woman was the principal agent in the preparation of the poison that was administered to Britannicus by order of his brother Nero.

It was the custom of the Romans to drink hot water, and as no two men's tastes are alike, great skill was shown by the slaves in bringing the water to exactly that degree of heat which their respective masters found agreeable.

The children of the Imperial house, with others of the great Roman families, sat at the banquets at a smaller side table, while their parents reclined at the larger. A slave brings hot water to Britannicus, it is too hot; Britannicus refuses it. The slave adds cold water, and it is this cold water that is supposed to have been poisoned; in any case, Britannicus had no sooner drunk of it than he 
lost voice and respiration. Agrippina, his mother, was struck with terror, as well as Octavia, his sister. Nero, the author of the crime, looks coldly on, saying that such fits often happened to him in infancy without evil result; and after a few moments' silence, the banquet goes on as before. If this were not sudden death from heart or brain disease, the poison must have been either a cyanide or prussic acid.

In those times no autopsy was possible; although the Alexandrian school, some 300 years before Christ, had dissected both the living and the dead, the work of Herophilus and Erasistratus had not been pursued, the rudiments of human anatomy were only known, while as to pathological changes and their true interpretation, such knowledge had no existence. It was not, indeed, until the fifteenth century that the Popes, silencing ancient scruples, authorised dissections; and it was not until the sixteenth century that Vesalius, the first great anatomist, arose.

In default of pathological knowledge, the ancients attached great importance to mere outward marks and discolorations. They noted with special attention spots and lividity, and supposed that poisons singled out the heart for some quite peculiar action, altering its substance in such a manner that it resisted the action of the funeral pyre and remained unconsumed. It may, then, fairly be presumed that many people must have died from poison without suspicion,' and still more from the sudden effects of latent disease, ascribed wrongfully to poisons. For example, the death of Alexander the Great has been confidently ascribed to poison, but "Littré" has fairly proved that the great emperor, debilitated by his drinking habits, caught a malarious fever in the marshes around Babylon, and died after eleven days' illness. If, added to sudden death, the body, from any cause, entered into rapid putrefaction, such signs were considered by the people absolutely conclusive of poisoning - this belief prevailed up to the middle of the seventeenth century, and lingers still among the uneducated at the present day. Thus, when 
Britannicus died, an extraordinary lividity spread over the face of the corpse, which they attempted to conceal by painting the face. When Pope Alexander VI. died, probably enough from poison, the rapid post-mortem change was noted, and considerable stress is laid upon it by the historian Guicciardini-but we know that such changes are utterly untrustworthy, some poisons indeed such as arsenic, retarding putrefaction.

An essay might be written entitled Royal poisoners. Charles le Mauvais, King of Navarre, gave a commission of murder to Woudreton, to poison Charles VI., the Duke of Valois, brother of the King, and his uncles the Dukes of Berry, Burgundy and Bourbon ; the infamous document is still extant; it directs Woudreton to purchase sublimed arsenic, to sneak into the kitchen, larder, or any where else, and drop the powder into the soups or meats.

Charles IX. figures in the annals of human vivisection. There was a question whether bezoar was an antidote or not: the King decided the question by giving a cook convicted of some slight theft a lethal dose of corrosive sublimate, following it up with bezoar; sut the man dies in seven hours, although Paré gives him oil-a grim business. Our own King John, of memory far from spotless, is said to have shut Maud Fitzwalter the Fair, in the highest, chilliest den of the Tower, and when neither cold, nor hunger, nor solitude broke her strength, when she still disdained his shameful suit, he foisted on her a poisoned egg, of which she ate and died.

The part that dynamite is playing in this age was played between the fifteenth and seventeenth centuries in Venice and Italy by poison. The criminal dynamite school of the nineteenth and the criminal arsenic school of the fifteenth-in political basis, in reckless disregard of human life -are similar. The Council of Ten sat in Venice, decreeing the removal of this or that man. Curious enough, the proceedings of the infamous oligarchy were recorded in writing with the utmost fidelity and candour; and in the strangest minutes ever penned, we may read now, the reasons for and 
against the proposed assassination, the number of votes on either side, the sum paid, and the success. I will give one example and only one. On the fifteenth December, I 5 I 3 , a Franciscan brother, John of Ragubo, appeared before the Council of Ten, and offered his services to remove any objectionable person out of the way. For the first successful case he required a pension of I 500 ducats yearly, which was to be increased on the execution of future services. The presidents, Girolando Duoda and Pietro Guiarini, placed the matter before the "Ten" on the fourth of January, I5 I4, and on a division, ten against five, it was resolved to accept so patriotic an offer and to experiment first on the Emperor Maximilian. The bond laid before the "Ten " contained a regular tariff, appraising the value of the lives of most of the men of note of the day, and concludes-" The further the journey, the more eminent the man, the more it is necessary to reward the toils and hardships undertaken, and the heavier must be the payment." In the seventeenth century there arose a band of poisoners in Italy; the most notorious of whom was a certain Toffana; she used arsenic in solutions of various degrees of concentration; her solution was called Acquetta di Napoli. She is on fairly good grounds suspected of having removed, by means of Naples water, more than six hundred persons, among whom were two popes. With the Acqua Toffana, the Acquetta di Perugia played at the same time its part. It is said to have been prepared by killing a hog, disjointing the same, salting it as it were with arsenic, and then collecting the juice which dropped from the meat; the juice was considered far more poisonous than an ordinary solution of arsenic; and recent researches on certain compounds which arsenic forms with organic matters lend countenance to this view. Toffana had disciples; Hieronyma Spara formed an association of young married women, one of the objects of which was the assassination of their husbands.

Italian and Venetian annals are not alone stained with these detestable crimes. The curious may read in Voltaire's 
History of Louis XIV.'s reign, the crimes of the Chambre ardente, of St. Croix, de Brinvilliers, the priest Le Sage, and the women la Voizin and la Vigoureux-of these Madame de Brinvilliers was specially infamous. She is said to be the inventor of "les poudres de succession," and essayred their strength on the patients at the Hôtel Dieu. She poisoned her father, brothers, sisters, and others of her family, but a terrible fate overtook both her and her instructor and master in villany, St. Croix-St. Croix was suffocated by deleterious vapours from his own chemicals; Madame de Brinvilliers' crimes being known, she fled and took refuge in a convent, from which she was lured by a detective, who disguised himself as an amorous Abbé; she was beheaded and her body burnt near Notre Dame, in the middle of the reign of Louis XIV.

The old poison lore, mixed up with legend, myth and superstition, culminated in the use of arsenic. Arsenic white, tasteless, and deadly, capable of introduction into the human frame in all manner of subtle ways, of killing slowly or quickly, and of simulating the effects of disease was at one time almost synony mous with poison. For more than a century, after the properties of arsenic were to some extent popularised, there was no certain method known for its detection; and as late as 1836 , whatever evidence of arsenical poisoning might be afforded by collateral circumstances, the risk of detection by chemical analysis was not great; hence the invention of a certain test for arsenic is so important, that the date of its discovery marks a toxicological epoch, from whence we may fairly date the rise of the modern poison lore. The great chemist, Scheele, in the eighteenth century, observed that arsenic united with hydrogen and made a very peculiar and fetid gas. After him Proust also studied the gas, and observed that when arsenical tin was dissolved in hydrochloric acid, that the gas could be lit, and then when allowed to play upon a cold surface, stains of the metal arsenicum were deposited.

Trommsdorf next announced, in $\mathrm{I} 803$, that when arsenical zinc was introduced into an ordinary flask with water and 
sulphuric acid, an arsenical hydrogen was disengaged, and if the tube was sufficiently long, arsenicum was deposited on its walls. Stromeyer, Gay-Lussac, Thenard, Gehlen and Davy later studied this gas, and Serullas, in I $82 \mathrm{I}$, proposed this reaction as a toxicological test. Lastly, in I 836, Marsh, a chemist at Woolwich, published a memoir in the Edinburgh New Philosophical Journal, entitled "Description of a new process of separating small quantities of arsenic from substances with which it is mixed." On the basis of the work done by the pioneers already enumerated, Marsh arranged an apparatus of great simplicity, which is known under the name of Marsh's test; the method is now in use, and will separate, with certainty, a millionth of a grain of arsenic - thus the most tasteless and the easiest administered poison in the whole world is also the one which it is easiest to detect.

Modern poison lore is distinguished from ancient poison lore by its extent, by its exactness, by the laborious compilation and verification of its facts, by the application of various instruments of precision, both at the bedside and in the laboratory. In modern times the throbs of the pulse, the respiratory waves, and even the functional enlargements of internal organs, are made to record their own movements on strips of paper, moved by clockwork, and adjusted by mechanism of an ingenious character ; the number of degrees of temperature gained or lost is registered by thermometers; the channels by which the poisons leave the body is determined by chemical analysis, and by the same means we know much relative to the localization of a poison in different tissues.

It is just about as difficult for the toxicologist to say how many poisons there are at present known, as for the botanist to enumerate existing species. By varying methods of classification all kinds of numbers could be obtained in either case. In the following statement, I have counted such substances as lead, copper, arsenic, antimony, and the like, as single units; each of the metals named enter into a very large number of combinations, all of 
which are more or less poisonous, and which, if each compound were cnumerated, would swell the total to a big figure. In like manner, although in the common foxglove (digitalis) there are several poisonous principles, yet they are so nearly allied that they may be all included under one head, and so on with other cases.

Inorganic solid poisons • • • • c c c c I9

Liquids, more or less volatile, and many anæsthetic, such as ether, chloroform, methylene, benzene, alcohol, etc. - is

Acids, both organic and inorganic . . . . .

Alkaloids • . . . . . . . 5 I

Glucosides • • • • • • • • • 20

Organic anhydrides $\cdot$ • $\quad \cdot \quad \cdot \quad \cdot \quad \cdot 2$

Complicated animal and vegetable poisons not yet fully

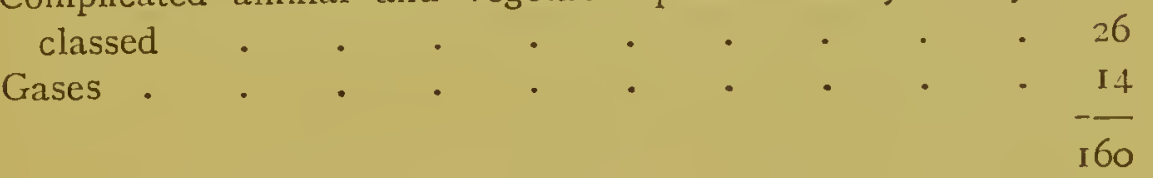

Proceeding in this way I get a total of 160 poisons, as about the number at present known to science; but not more than 40 of these ever figure in the Registrar-General's reports as a cause of death, and over 60 are chemical rarities, not existing in ordinary commerce.

Previous to the nineteenth century, more than 70 of these poisons were either unknown, or only known as vegetable extracts; it is the glory of modern chemistry, to have separated from plants most of the active principles in a perfectly pure state, and to have shown that what was formerly considered simple is really complex. Take for example, opium; it has been known as a narcotic from the earliest times; before $\mathrm{I} 8 \mathrm{O} 3$ no one ever imagined that it contained more than one active principle, but in 1803 Derosne separated from it morphine and narcotine, and at the present time no less than 2I definite principles, all having different physical, chemical and physiological properties, some, indeed, antagonistic, have been separated from this wonderful drug; or take aconite, that has been from the most remote times, the favourite poison in India; aconite, or the common monkshood, contains six allialoids; 
tivo of which alone seem to be physiologically active. Digitalis, the common foxglove, contains at least seven closely related and yet not identical principles; and, in short, it is now evident that poisonous plants generally contain a family group of poisons.

Life mainly rests on a tripod, heart, brain, and lung; some poisons act specially on the heart, others concentrate themselves on the lungs, and others ascend to the brain, but a great majority irritate and inflame the fine velvet lining of the great convoluted tube of the body, and only act indirectly on the cardiac, nervous and pulmonary systems. I have calculated that about I9 per cent. of the I60 known poisons act directly on the brain and spinal cord, either lulling to preternatural sleep or exciting to preternatural activity; $5 \frac{1}{2}$ per cent. affect the respiration, a little over 4 per cent. affect the heart primarily, while no less than 39 per cent. are irritants; as for the remainder, their action is so mixed that they seem to affect various organs at one and the same time.

I have no intention of describing to you the symptoms produced by toxic substances but take the opportunity of pointing out in a general manner the wonderful mimicry of disease produced by certain poisons.

The fatal bite of the Cobra de Capello not unfrequently produces all the effects of a somewhat rare malady known as glosso-pharyngeal paralysis, or in plainer English, palsy of the tongue and throat.

Atropine, the active principle of Belladonna, will produce a diy sore throat, a vivid rash on the skin, a quick pulse, a high temperature, with delirium : the resemblance to scarlet fever is completed by a slight desquamation, or subsequent peeling of the skin.

A large fatal dose of arsenic mimics cholera; there is the same excessive depletion of all the fluids of the body by one channel, the vomiting, the collapse, and rapid death. Phosphorus produces jaundice; strychnine simulates tetanus, and the symptoms have been mistaken many times for hysterical convulsions. 
Madness has been produced by lead. Last year I saw in Dr. Rayner's clinique at Hanwell some remarkable examples of this; in nearly all cases there were illusions of sight, one patient saw wind bags blown out to look like men. These apparitions, to his great terror, floated after him.

A more terrible form of brain disease has been produced by an artificial poison. Some years ago Mercuric methide was prepared in a London laboratory, and two young chemists, engaged day after day in its manufacture, became ill from breathing the vapour; complicated symptoms of brain disease appeared, which culminated in idiocy, and they both died.

Mercuric methide is not, however, the only poison which may produce insanity or idiocy. The Dhatoora of the Hindoos, which is identical with Belladonna, has in Indian history played the peculiar rôle of a State agent, and has been used to produce imbecility in persons of high rank whose mental integrity was considered dangerous by the despot in power. It usually, however, produces but a temporary insanity; in one case after a toxic dose a tailor sat for four hours moving his hands and arms as if sewing, and his lips as if talking, but without uttering a word. The "insane root that takes the reason prisoner" may be found among the solanaceous plants. In an ancient cloister the monks ate in error Henbane root, and in the night were all taken with hallucinations, so that the pious convent was like a madhouse. One monk sounded at midnight the matins; some who thereupon thinking it was morn, came into chapel, opened their books but could not read; others declaimed-some sang drinking-songs of a character not befitting the place; and the greatest disorder prevailed.

Several poisons produce ulcerations and skin diseases. The remarkable malady, first described by Dr. B. W. Richardson, under the name of the Bichromate disease, is another example of similarity between an artificiallyinduced affection and one which seems to occur spontaneously. Potassic bichromate is made on a large scale, and the workmen who inspire the dust through the nose

VOL. XII.-H. L. 
suffer from an inflammation of the septum, which ultimately may be destroyed by ulceration. It also causes painful skin affections-eruptions like eczema and psoriasis, and very deep and intractable ulcerations. The effects of the bichromate are not confined to men; the dust gets in any crack the horses at the factories may have about their hoofs and causes an ulceration from the effects of which even the hoofs may be shed.

If glosso-pharyngeal paralysis, scarlatina, affections of the skin, tetanus, insanity, and idiocy, may be either simulated or produced by drugs; on the other hand, certain diseases simulate the symptoms of poisoning, and the most rational explanation in these cases is that the body itself manufactures its own poison. One of the best examples is that known as "diabetic coma." In diabetic coma, there is first mental confusion, in which the person may wander aimlessly about the strcets, and have somewhat the appearance of ordinary intoxication; then follows irresistible drowsiness, and ultimately death,-altogether a series of phenomena which might be well mistaken for the narcosis of opium or alcohol.

The establishment of almost perfect antagonism between certain vegetable poisons belongs to modern poison lore; for example, atropine is antagonistic to pilocarpine ; atropine makes the skin dry, pilocarpine causes in five minutes a profuse perspiration; atropine dilates the pupil, pilocarpine contracts it. The heart of an animal arrested by atropine, can have its tick tick restored by the direct application of pilocarpine. Poisoning by pilocarpine is relieved and cured by atropine; poisoning by atropine is relieved and cured by pilocarpine.

The relationship between chemical composition and the direction of toxical activity also belongs to modern poison lore; the alkaloid strychnine, which causes powerful tetanus, may be changed by the chemist into another alkaloid which produces the opposite effect-paralysis; morphine, a drug producing sleep, may also be transformed by a very slight chemical metamorphosis into an emetic. 
In being obliged to avoid any detailed account of the symptoms of poisoning, I cannot omit to point out the errors of most of the popular descriptions. Few dramatists have been happy in the description of death from poison; the death of Cleopatra, described by Shakespeare as resulting from the bite of a venomous snake, is like no clinical description of fatal illness from bites of any class of sriakes.

In Philip Massinger's play- "The Duke of Milan," Francisco dusts over a plant with a poisonous powder; this plant Eugenia holds; Ludovico Sforza kisses her hand twice, and from this slight contact very rapidly dies -why, it is doubtful whether pure aconitine itself, the most powerful of all known substances, and only separated within the last few years, could be inhaled under these conditions in sufficient quantity to do harm.

Beverley, in Edward Moore's "Gamester," takes poison in the fifth Act, after which he makes several pretty long speeches, and ultimately dies suddenly, but, so far as we can learn, with considerable calmness. Nathaniel Lee, in his tragedy, "Alexander the Great," provides a poison for the destruction of the Emperor, which is described as of "exalted force."

"* * mixed with his wine a single drop gives death,

And sends him howling to the shades below."

Nevertheless, after taking the poison, Alexander walks about, declaims much, kills Clytus, and goes through the latter part of the fourth Act, and most of the fifth, comfortably enough; then raves in delirium, regains his senses, and dies after a very fine speech. There was no poison known to the writers of the plays alluded to which would produce symptoms in any way similar. At the present day there is, however, a liquid made by artificial means, the effects of which are stranger than those imagined by play-writersafter it is swallowed, the person walks about for an interval of time varying from a quarter of an hour to two hours; his skin, and even the whites of the eyes, become of a strange purplish livid colour, but he may feel fairly well, then the fatal symptoms set in with appalling suddenness, and he dies 
in a few minutes. For anyone who delights in constructing stories of sensation, these occasional effects of nitrobenzene, just described-the weird blue colour, the interval allowing of acts and rhapsodies, and the abrupt termination, afford considerable, although perhaps not commendable scope.

If progress has been made in the discovery of new poisons, and new methods of detection, so also progress has been made in the treatment of poisoned persons ; take, for example, the modern treatment of a patient suffering from a toxic dose of strychnine. In chloroform we have not a chemical but a physiological antidote. Death takes place from the terrific spasms affecting the breathing; if chloroform be inhaled, and the nervous system lulled to sleep, time is afforded for the elimination of the alkaloid by the natural channels, and a chance is given to an otherwise hopeless case. In turpentine we have a most wonderful antidote for poisoning by phosphorus; and the more complete, for it seems to follow and catch up as it were the phosphorus even when circulating in the blood.

Few of us contemplate the possibility of accidental poisoning in our own households; yet among the daily necessities of civilized life, very active poisons hold their place: bleaching powder, carbolic acid, salts of sorrel, and even some forms of washing blue are deadly enough, and from time to time are the cause of accidents; the proper antidotes for these ought to be in every house, and the elementary knowledge of the proper treatment of such accidents should be known by all.

There was an ancient myth, long believed, that certain stones changed their colour at the approach of poison, and that there was also a substance which would neutralise every poison. This is no longer thought probable or possible. Nevertheless, attempts have been made with some success to compound a liquid which plays the rôle of a multiple antidote. One of the best consists of a saturated solution of sulphate of iron IOO parts, magnesia So, animal charcoal 44 parts, water 800 . It is preferable to have the animal charcoal and magnesia mixed together 
in the dry state and kept in a well corked bottle; and when required for use, the saturated solution of sulphate of iron is mixed with eight times its bulk of water, and the mixture of charcoal and magnesia added, with constant stirring.

The multiple antidote may be given in wine-glassfuls once every ten or twenty minutes in recent poisoning by arsenic, zinc, opium, digitalis, mercury, or strychnine.

As to immediate treatment of other common poisons. - In poisoning by acids use calcined magnesia, or carbonate of soda; or any bland oil. In poisoning by caustic soda, vinegar should be given. A good domestic emetic is sulphate of zinc, which now may be bought of most chemists in the form of convenient tablets. With the simple remedies named: that is, multiple antidote, calcined magnesia, vinegar, sulphate of zinc tablets, and let us add, for phosphorus, a small bottle of French turpentine, a cupboard may be stocked, and thus, for a few shillings, precautions taken against an emergency which may arise at any moment.

The use of poison by man I have thus first traced to the barb of the arrow envenomed by vegetable extracts; later, poisons were used in a more subtle manner; the stroke in daylight was replaced by the poisoned chalice: but at the same time it was found that poisons were also medicines, and able, when used legitimately, to preserve as well as destroy life; later still the very essences of the plant world were separated as pure crystalline forms, and (aided by instruments of precision) their properties studied in all manner of ways. Rays of light, from the development of physiological and other sciences, were brought to converge upon the general subject; and modern toxicology, though far from perfect, has rendered the crime of secret poisoning a dangerous game to the player. An important part of modern poison lore has been built up by experiments on animals. All that has been done in the past in this direction I cannot justify; but these experiments have for the most part been undertaken by noble and humane men, for noble 
and humane purposes. If these experiments have increased the ways of death, they have multiplied the means of recovery; they have given to the physician many a potent elixir, charming away pain and restoring health; they have enlarged our knowledge of the action and nature of remedies, and have proved safeguards against illicit criminal practices. These experiments have shown that certain poisons are so potent and subtle in their action as to almost equal the wonders in tales told of charms condensed in necromancers' phials. The animal body can be played upon as if it were a machine. The strokes of the central pump can be slowed or quickened; the vital heat lowered or increased; the pupil of the eye expanded or narrowed; the limbs paralysed or convulsed; the blood sent to the surface or withdrawn to the interior; even the natural hue and colour of the body can be changed. If it be asked, cannot this strange science become, in the hands of an unscrupulous, abandoned and yet learned man, a power of destruction fearful to contemplate? The answer is, the risk of this is small. The higher kind of brain is a moral brain; the highest scientists are the most religious, it may not be a religion of special creeds, it may not even be a Deistical religion; but no one who has observed the phases of thought of the nineteenth century can with truth deny, that side by side with the evolution of physical and natural science, there has also been an evolution and practice of the purest doctrines of Krishna and Buddha ; if indeed it were not so, and the most exalted intellects abandoned themselves to the secret destruction of their fellow creatures, the results would be disastrous. As for the ordinary criminal mind, like that of the Comte le Pommerais, who specially prepared a then almost unknown alkaloid, or the surgeon Palmer, or still more recent semi-scientific murderers whose names I pass over in silence; there is absolutely no ground for believing that they could escape detection, however cunning they may think themselves, however rare the agent they may employ, the toxicologist has weapons and means at his command to diagnose the sickness of 
nature from that of malignant art, and to separate and identify the poison.

The Chatrman.-Ladies and Gentlemen, I rise to propose a vote of thanks to the learned lecturer, for the splendid address he has given us; I do not remember to have listened to anything more comprehensive for a long time.

As he has passed from point to point, he has led me to make a note or two bearing upon what I have thought over and studied in the same directions, and I am glad to say we appear to view the subject very much alike. He said towards the close of his lecture that there was a great deal which we might be thankful for, as well as a great deal which we naturally very much dread, when we think what may and does occur in respect to the use of poisons. That was very true. Poisons are not always so bad as they are made to be, bad as they are; for to use a saying from our great national dramatist Shakespeare :

"There is a soul of goodness in things evil, Would man observingly distil it out."

Now it is strikingly true with regard to some points which Shakespeare himself has brought before us. $\mathrm{Mr}$. Wynter Blyth said that the dramatist's ordinary mode of describing death from poisons was altogether inaccurate. That was quite true; when you see on the stage death represented from poisons very rarely is it that it is at all accurate. I have never in my life, with one exception to which I shall soon refer, seen anything like a case of accurate representation. Some time ago a man died night after night on the stage from the effects of strong drink, his death taking place in delirium tremens, but it was altogether a false representation of what takes place in nature, and no person ever did or ever could die in that way. But our great dramatist has hit the mark correctly in regard to one particular poison. We always see correct representations of the effect of that poison in the draught 
which Juliet takes, with regard to which there is an extremely interesting history. You will find in Shakespeare frequent reference to mandragora; and when Friar Lawrence is giving Juliet a poison, that poison is the wine of the Atropa Mandragora, a plant which grows well in the Isles of Greece. That poison is equivalent to our Atropa, our Deadly Night-shade, but it is a little different in its effect, and it has had a remarkable history both as a poison and as a medicine of great power. The atropa mandragora, was also a medicine; and the ancient Greeks understood its properties well. Dioscorides described it, with regard to its use and its mode of preparation, and Pliny the Younger, in a later day, followed Dioscorides. Mandragora was a narcotic, and it had this peculiar property, that it produced a long deep sleep which resembled death while it lasted, and afterwards life returned. Mandragora was actually used by the Greek physicians in the same way as we use chloroform in these days. They made a wine of it, which they called "Morion," death wine, and before persons were submitted to the cautery-the hot iron,-or the knife, they took a draught of this, and the operation was performed while they were under the influence of the wine, the formula of which remains to this day as Dioscorides and Pliny gave it. The use of the wine went out about the fifteenth century, yet, according to the description given by Dioscorides, I was enabled twelve years ago, on the late Mr. Daniel Hanbury bringing me some of the root from Greece, to make some of the wine and gain evidence as to its action that was strictly in accordance with that which the ancients described. It is this wine I feel sure which Shakespeare makes Friar Lawrence put into the hands of Juliet. Where he got the description of it from I think it is very difficult to tell; he got it, perhaps from a book written by Apuleius, "De Viribus Herbarum;" Shakespeare has represented Juliet as taking that poisonous draught, in a description which is correct as to the working of it, but when she asks, before she swallow's the poison which the Friar 
has given her to take, whether she shall hear "shrieks like mandrakes," he expresses a vulgar error. The mandragora was taken as some people take opium now, and they were called Mandragorates, that is, people who took mandragora ; and in the period of the recovery from it they shrieked. Shakespeare has got correctly a fact, incorrectly an induction; he thinks it is the plant itself, when pulled up from the ground, that shrieks. That is not accurate, it was the mandragorates who shrieked. There was another use to which this mandragora wine is thought to have been put. During the period of the Grand Sanhedrim, when the Romans were ruling the Jews, the Jewish women, it is traditionally believed, went to the crucified of the Roman people, and gave them mandragora to take on the cross, in order that the sufferings while on the cross might be allayed. Some would escape death in this way; and it is inferred that when it was ordered that the legs of the crucified should be broken, that order was due to the circumstance that some recovered from the crucifixion, because though they seemed to die they did not. In the history of mandragora we see an illustration of what Mr. Wynter Blyth has said, that poisons are not always so bad as they are thought to be.

In the Middle Ages, at the period to which Mr. Wynter Blyth has referred, when there was a very common practice of poisoning, the vegetable poisons seem to have been out of use; but a science seems then to have been established for poisoning, and I note that terms were used which were very curious in their way. The professors specialized the mode of action of the poisons, the haustu, gustu, odore, and another, called "contactu," they used those words to describe the effects the poisons produced by draught, by odour, by taste, by touch or contact. They used arsenic, as stated by Mr. Wynter Blyth, and also corrosive sublimate, although it is difficult to understand how they got anybody to swallow it; and some of them used cantharides, an animal poison, the same as the Spanish fly. That is bclieved to have been a very common poison, 
and it is thought that Sir Thomas Overbury, on whom the Rochesters practised those arts, was subjected to cantharides, though killed at last by corrosive sublimate.

It is said that sometimes cantharides was put into pepper, and arsenic into salt, and corrosive sublimate into sweets. Then again it is said by some, that very finely powdered glass was administered for poisoning; but I cannot conceive that to be true; it seems to me to be altogether impossible that any person could have been got to swallow powdered glass. In the Middle Ages arsenic, cantharides, and corrosive sublimate, seem to have been the principal poisons used. Then some poisons were said to have been administered by contact, and there are many stories of the use of poisoned rings-rings which were poisoned on the interior, and had a sharp point to them, so that when a person grasped the hand wearing the ring the poison was passed into his body. I believe that to be altogether without foundation, because there is no kind of proof that the ancients had such a subtle poison as that. We have hardly got such a thing now, and I think it can scarcely have existed in the Middle Ages. This idea of wholesale poisoning of people by poisoned water has passed down from the time of Tophania to our own day. Tophania, I may say, would not have been executed but for a stratagem on the part of her prosecutor. She was under the protection of the Church, she was protected by an archbishop, and it was not until a suggestion was made by her prosecutor, the Viceroy of Naples, that she had poisoned the wells of the town, that the people demanded her execution. That idea of poisoning wells has come down to our own time. In my boyhood I was shown a well which in I 832 was believed to have been the cause of an outbreak of cholera at that time in the village. I was told that a Jew peddler had unfortunately drunk the water of that well, when he was taking his simple midday meal near it, and on that fact all the evil was laid. It was believed the man had poisoned that well. That idea is found also in other countries, so that it has evidently survived down to our own time. Poisoning, when 
it is carried out intentionally in these days, is often perpetrated by means of vegetable poisons; aconite being, perhaps, most relied upon for the purpose, because it is difficult of detection. I think Mr. Wynter Blyth touched on a most important subject, when he directed our attention to poisoning which takes place by substances which affect the mind. He referred to one particular form of poisoning of this kind, poisoning by lead; and he also referred to the effect of mercuric compounds. But there is another substance used in trade, the dangerous nature of which it is important for us to remember, and that is bisulphide of carbon. That substance is used in making the soft india rubber bladders, which children use as toys and which you see men carrying about the streets. Bi-sulphide of carbon is employed in making the india-rubber soft, so that it can be more easily worked for the purpose required; and those who have to work with it are sometimes affected, unless the place is kept well ventilated, by a most peculiar disease of the mind, which has been well described, I think, only by Mr. Delpech. It consists of a peculiar delirium in the first instance, followed by salivation, want of power in the limbs, and cerebral paralysis. We have not had cases of this kind in our own country, but they have occurred in France; and it is most important therefore, wherever this substance is used, as it is in the preparation of india-rubber, that there should be the most perfect ventilation, in order that persons working in it may not be subjected for long periods to this vapour, the effects of which are so deadly. Mr. Wynter Blyth referred to another point of great practical interest when he mentioned the possible formation of poisons in the human body. He struck out, you will remember, a very marked line of comparison between the action of poisons upon men and the diseases simulating them. Now this is a subject of great moment, and I may perhaps mention that I have myself written an essay upon it, which I have always thought is one that some day will demand considerable attention, because of the close analogies which we find between the action of some poisons and certain diseases. 
Take somnambulism as an instance. I have not the slightest doubt that somnambulism is produced by the formation in the body of a peculiar substance, which may be derived from the starchy parts of the body, and has the effect of the chemical substance known as amylene. I believe that because I can produce artificial somnambulism by the use of that substance. Under its influence persons can be made to walk about unconsciously in the same way that the somnambulist does. Afterwards, when the effect goes off, the person becomes all right again; that is to say, when the effect of poison, for to that extent it is a poison, passes away. I remember the late Dr. Snow administering this curious substance to a boy, who was being operated upon by Sir William Ferguson; and while Sir William Ferguson was amputating the foot-that was the operation - the boy was playing unconcernedly with a ball, which he was throwing up and catching with the utmost precision. Other substances may be produced in the animal chemistry, which have strange effects; for instance, we have some substances which produce extreme melancholy. There is a peculiar offensive sulphur compound, called mercaptan. A little of that administered to anyone produces the intensest melancholy, tending almost to suicide. We can sometimes detect a similar offensive substance in the breath of patients who are suffering from melancholia. I have no doubt the day will come when it will be proved that many forms of mental derangement are due to substances resulting from mal-assimilation, and made in our own bodies.

I have touched upon a few points which our lecturer has brought before us; and I am sure I have not said half so much in favour of the admirable manner in which his work has been done as I ought to; but time presses, and Mr. Wynter Blyth will no doubt take the will for the deed. I will therefore propose at once that a hearty vote of thanks be given to him for the excellent lecture he has delivered to us.

Mr. Wynter Blyth briefly replied. 


\section{N D E X.}

ABEL, Sir Frederick, remarks by him relative to a lecture on "Candles," by Mr. L. Field, F.C.S., 55, 74

Agrippina, her use of poison, 233

Alexander the Great, cause of his death, according to Littré, 234

Alexander VI. (Pope), his death alleged by Guicciardini to have been due to poison, 235

Alkali, 82, 84, 85, 86, 88, 9 r

Al Kermes. See Kermes.

Amylene, the artificial production of somnambulism by this substance, 252 ; instance cited, 252

Ancylostomosis, a disorder caused by the parasite ancylostomum, I2

Animals, benefit to science of experiments thereon, 5, 39, 246

Arseniate of soda, 94

Arsenic, its use as a poison, 237 ; its detection by a simple test, 239, 240 ; effects of a fatal dose resemble cholera, 240

Atropine, resemblance in its effects to scarlet fever, 240 ; its antagonistic action to pilocarpine, 242

BENZENE, its property of dissolving fats, as applied in the manufacture of soap, 87

Bergman, his employment of a solution of soap in alcohol in the investigation of mineral waters, 113

Beulah, Mr., his observations relative to parasitic lung disease in sheep, 19

Bichromate disease, first described by Dr. Richardson, 241

Bisulphide of carbon, its deadly effects, $25 \mathrm{I}$

Blache, Dr., in reference to the death of a child caused by a needle entering the brain, 153

Bladder-worms, the larval condition of tape worms, 21 ; their presence in the flesh of various animals, 22

Boots, importance of the use of proper form and material, 167-169

Botalismus, a disease due to eating putrid sausages, 12

Britannicus, poison administered to him by order of Nero, 233, 234

CANDlEs, progressive improvements in their manufacture, 57 ; ancient modes of lighting, 58, 59; the rushlight, 59,60 ; the use of spermaceti in candle-making, $6 \mathrm{r}$; the essentials of a candle, 62,63 ; importance of an accurately apportioned wick, $63,64,69,70$; the process of making waxcandles described, $65-67$; the process of making mould candles, 67,68 ; 
elimination of glycerine from [ats, 70, 71 ; discovery of paraffin, 72 ; the merits of the candle as an illuminant, 74

Chatin, M., in reference to the discovery of trichina spiralis, 4 ; its presence in meat, 7

Chevreuil, M., his researches into the chemistry of fat, 62 , I I 3 ; the composition of tallow, 68 ; his treatment of fat for the elimination of glycerine, 70

Children, deaths caused by their being "overlain," I56; mischief done to them by tossing up in the air and jolting, 157

Clark's process for softening water, I09

Clothing, its warmth to be regulated by the thermometer, not by the season of the year, I5I; hygienic baby-clothing, I54, I55, I56, I60, I65; frequent changes of raiment necessary, I62; danger of dyed garments, $162,163,164$

Cobra de Capello, effects of its bite, 240

Coccus. See Kermes.

Cochineal, its use as a dye, I97

Cold, its action on the surface of the body, 148

Colin, M., experiments by him relative to trichinosis, 9 ; with reference to trichinous pork from America, 14

Combe, Dr. Andrew, quotation from him relative to the protection of children from cold, I5I; as to the value of gymnastic exercises, 2 I 2 213

Convulsions, mortality of children caused thereby, 153

Cossacks, reason assigned for their Jiability to beef-tapeworms, 29

Curarine, a poison used by certain American Indians, 23 I

DAVY, his studies relative to arsenic, 238

Day, Mr., infants' clothes invented by him, 154

Derosne, his separation of morphine and narcotine from opium, 239

Dhatoora, its rôle in Indian history, $24 \mathrm{I}$

Diabetic coma, an example of a disease which simulates the symptoms of poisoning, 242

Dickinson, Dr., relative to an outbreak of trichinosis in Cumberland, 10

Digitalis. See Foxglove.

Dramatists, their inaccurate delineations of the effect of poison, 243

Dress (English), a history of, I I 7-I43; various ancient costumes described, I 17-122; costume in medireval times, 123-I26; effect of the Renaissance on fashions in dress, I27-I29; sumptuary laws enacted by Henry VIII., 129, I30; new fashions introduced in the time of Charles II., I32; costumes of the Macaronies, 138, I39; male and female costumes of the. present day; 140

Duteuil, M., his reading of an Egyptian papyrus preserved at the Louvre, $23^{2}$

Fildar IE, certain minute nematoid parasites found in fish, 13,38

Foxglove, its poisonous principles, 239, 240

Frank, Miss, her Kindergarten frock for girls, I65

GAY-LusSAC, his studies relative to arsenic, $23^{8}$

Gehlen, relative to a test for detection of arsenic, $23 \mathrm{~S}$ 
Girls, their physical education, 205-227; walking, 206, 207 ; sitting, 207 ; debilitating influences of inaction, 208, 209; rowing as a tonic exercise, $2 \mathrm{II}$; horse-exercise, $2 \mathrm{II}$; swimming, $2 \mathrm{II}, 2 \mathrm{I2}$; slating and dancing, 212 ; gymnastic costume described, 215 ; methods of exercise, 215-220 ; musical accompaniments as a powerful incentive to exercise, 221 ; gymnastic halls for girls under properly trained women in every district of towns advocated, 221, 222 ; impairment of vision, 222, 223 ; popular theory of health, 224, 225

Graham, Dr., quotation from him in reference to the value of physical exercise, 2 ro

Guicciardini, the historian, in reference to the death of Pope Alexander VI., 235

HEAD, Sir Francis, quotation from him relative to intrinsic value of ice, 224, 225

Hellebore, used as an arrow poison by the Gauls, 23I

Henbane, instance of hallucinations produced by it, 24I

Humphry, Dr., quoted in reference to the clothing of infants, $15 \mathbf{I}$

"Huck," or filaria disease, a parasitic lung disease, highly destructive of domestic cattle, 15, 16; Mr. Beulah's observations in reference thereto, 19

Hydatids, the larval condition of various parasites, 21, 23; their presence in meat served at table, $30,3 \mathrm{I}$; course of development in living animals, 32,33 ; prevalence of hydatid disease in India, Australia and Iceland, 34, 35

INACTION, its injurious effects on the human system, 208, 209

Indigo, its use as a dye, 196

Inman, Dr., quoted in reference to the exposure of children to cold, 150

Inspectors of meat, importance of their having a thoroughly scientific knowledge of all questions in relation to the diseases of food, 36

KERMEs, or coccus, its use as a dye, 197,198

Kindergarten system, 210

Koch, Herr Alois (of Vienna), his memoir, 'Die Nematoden der Schaflunge,' I 7

Krabbe, Dr., his investigations into the prevalence of the hydatid disease in Iceland, 35

Küchenmeister, Dr., his opinion in reference to the prohibition of pork amongst the Jewish people, 29

LAC, its use as a dye, 197

Lamb, Charles, a quotation from him, 57

Leblanc, method discovered by him for the preparation of soda from common salt, 113

Lee, Dr. Robert, remarks by him relative to the lecture on 'Children's Dress,' by Miss Ada S. Ballin, I 70

Leptodera teres, a rhabditiform parasite, as the cause of an outbreak of fever on board the training ship 'Cornwall,' in 1879 , I0, I I

Leuckart, Professor, 32 
Lewis, Dr. T. R., experiments by him in reference to the destruction of trichina by heat, 13

Liebig, quoted in reference to the social bearings of soap, 78

Lister, Sir Joseph, Bart., F.R.S., remarks by him relative to Dr. Cobbold's lecture on 'Parasites of Meat and Prepared Flesh Food,' 20

Litmus, action upon it of a solution of oxide of phosphorus, 8 I

London Water Supply, I07, io8

Lung-worms, their description, I5, I6 ; life history, I7

MADDER, its use as a dye, 197

Mandragora, its use by Greek physicians as an anæsthetic, 248; the use of mandragora wine, 248, 249

Marsh, Mr., relative to a memoir published by him on the detection of arsenic, 238 ; his method for this now in use, 238

Measles, a discase due to parasitic larvæ, 2I, 26, 30 ; how this disease may be avoided, 37

Mercaptan, a peculiar compound, productive of intense melancholy, 252

Mercuric methide, insanity produced by this poison, 24I

Milne Edwards, MI., as regards the power of generating heat in animals immediately after birth, I 47

Morphine, 239, 242

Multiple antidote, its composition and administration, 245

Myopia, 223

NICANDER of Colophon, evidence afforded by him of the state of Greek and Roman knowledge of toxic substances, 232

Nitrobenzenc, its remarkable toxic action, 243, 244

Olulanosis, a disease due to the parasite olulanus, I3; instance of its occurrence in a family, I3

Opium, its various active principles, 239

Overbury, Sir Thomas, his death by poison, 250

Owen, Professor, his memoir in the Zoological Society's Transactions descriptive of the parasite named by him trichina spiralis, 4

PAGET, Sir James, his discovery of the parasite trichina spiralis, 4

Paraffin, its discovery and use in the manufacture of candles, 72,73

Perambulators for children, I 59

Perroncito, Professor, experiments by him relative to the destruction of trichinæ by heat, 13

Phosphate of soda, 85

Phosphorus, 80, 8I ; its simulation of jaundice, 240; turpentine as an antidote to poisoning by phospliorus, 244

Pilocarpine, its action antagonistic to atropine, 242

Playfair, Sir Lyon, F.R.S., K.C.B., remarks by him relative to a lecture on

'Parasites' by Dr. Cobbold, 39, 40

Pliny, quotations in reference to soap, I 12

Pneumonia (inflammation of the lungs), statistics of infant morlality from this cause, 149 
Poisons, antidotes for, 244,245

Pompeii, discovery of a soap-boiling establishment there, II3

Potash, 95

Potassic bichromate, diseases caused by its manufacture, 24I, 242

Prussic acid, its distillation from peaches, 232; probably known to the Egyptians and Romans, 232

REECE, Rees, his patent for the distillation of peat, 72

Reichenbach, his extraction of paraffin from wood tar, 72

Richardson, Dr. B.W., F.RS., I62, I63 ; remarks by him in reference to the lecture on 'Old and Modern Poison Lore,' by Mr. A. Wynter Blyth, M.R.C.S., 23I, 247-252; bichromate disease first described by him, 24I

Roberts, Mr. Charles, F.R.C.S., suggestion in regard to special series of exercises for strengthening the muscles and joints of the feet, 216

SALA, Mr. G. A., remarks" by him in reference to a lecture on "The history of English dress,' by the Hon. Lewis S. Wingfield, I40-I43

Scheele, his experiments with reference to arsenic, 237

Schneider, Herr, I I, 38

Silicic acid, 84, 93

Septicæmia, or blood-poisoning, how produced, 232

Serullas, relative to a toxicological test, 238

Startin, Mr., quoted in reference to skin diseases produced by coloured articles of dress, 163,164

St. [Gothard, outbreak of so-called "tunnel trichinosis," but really due to ancylostomosis, 12

Soap, its chemical definition, 79 ; its chemical combinations considered, 7988 ; as an article of commerce, 88-96; detergent action, 9I, 96-98; transparent soaps, 98-100; mottled soaps IOO-IO2; analyses of various soaps, I03, IO4; cold water soaps, IO4; silicated soaps, IO5; marine soaps, I05; how to test "mildness" in a soap, I05; soap substitutes, I I I history of soap-making briefly sketched, I I 2 , I I 3

Sodium, 8o, 8 I

Sodium Carbonate, 92

Sodium silicate, 92

Somnambulism, views expressed by Dr. Richardson respecting its cause, 252 Spencer, Mr. Herbert, quotations from him, I 49, I 50

Stannate of soda, 93

Stromeyer, studies with reference to arsenic and the tests for its detection,
238

Strychnine, its symptoms sometimes mistalien for hysterical convulsions, 240 ; its antidote, 242,244

TAPEWORMS, 2I, 22; the beef tape-worm described, 24 ; injury caused by them, 25 ; experiments with regard to the phenomena of their development, 25, 26, 27; the pork tape-worm, its comparative rarity and dangerous nature, 28 ; its habit of penetrating to the vital organs, 28 ; the VOI. XII.-H. L. 
prohibition of pork amongst the Jews, 28, 29; the tapeworm of the dog, 30-35

Textile fabrics, I76-201; various methods of weaving, I76-I79; practical history of mechanical weaving in ancient times briefly sketched, I79-18I ; and in the early middle ages, 181-186; tapestry weaving, 190-194; carpet-weaving, 194-196; colour used in dyeing, 196-198

Thaxstead, outbreak of an epidemic there due to eating sausages, II ; not a case of trichinosis, I I

Thenard, his studies with reference to arsenic, 238

Thomas, Dr. (of Adelaide), in reference to the hydatid disease, 35

Thomas, Professor A. P., his researches into the history and development of the rot-producing parasite, I7

Thomas, Dr. Danford, relative to number of inquests held by him upon children suffocated in bed, 156

Toffana, her use of poisonous solutions, 236,250

Toxicology, its derivation, 231

Trichina spiralis, a parasite directly injurious to man, 3 ; its description by Professor Owen in the Zoological Society's transactions, 4 ; its discovery due to Sir James Paget, 4 ; investigatious into its course of development by Professors Virchow and Zenker, 5 ; effect of experiments on animals in reference to the checking of disease, 5, 39; ordinary appearances presented by the trichina in flesh, 6,7 ; its life-history, 8 ; apt to be confounded with other minute parasites, 12 ; experiments with reference to the degree of temperature necessary to ensure its destruction, 13, 14; inspectors appointed in Germany, 14

Trichinosis, experiments by M. Colin relative thereto, 9 ; instance of an outbreak in Cumberland, Io

Trommsdorf, his experiments with reference to arsenic, 237

Trousseau, case related by him in his 'Clinical Lectures,' of death from convulsions caused by a needle transfixing the liver, 153

Tungstate of soda, 93

Turpentine, a wonderful antidote for phosphorous poisoning, 244

VEGETARIAN DIET, precautions against parasites equally necessary in this as in a flesh diet, 37

Vesalius, the first great anatomist, 234

Voltaire, details of various infamous poisoners given in his History of Louis XIV.'s reign, 237

WANKLYN and Chapman's treatise on water analysis, ro7

Water, an instance of the danger of drinking it in an unfiltered state, 37,38 ; its hardness, 106, 108; how "degrees" of hardness are expressed, 107 ; Clark's method of softening water on a large scale, Io9; Maignen's process, 1 IO ; water supply of London, 107

Wax, whence obtained for the manufacture of candles, 65

Wilson, Mr. G. F. (Price's Patent Candle Company), his process for the treatment of fats in the manufacture of candles, $7 \mathrm{I}$

Wolverhampton, reported case of two deaths from eating tinned salmon, 12 
Woodland, Dr., relative to eruptions on the legs and feet caused by the wearing of red stockings, 162

Wright, Dr., remarks by him in reference to a lecture on 'Soap,' by Mr. C. F. Cross, 77, I 13, I 14

Wurtz, Dr., relative to epidemics on the Continent due to trichinx, 9

Young, Mr. James, his experiments relative to the production of paraffin, 72

ZENKER, Professor, his investigations into the development and migration of trichinæ in the human frame, 5 
<smiles>CC#CC</smiles> 


\section{A}

\section{DESCRIPTIVE CATALOGUE}

ов тив

\section{OFFICIAL HANDBOOKS,}

CONFERENCE PAPERS, LECTURES, ETc.,

ISSUED BY THE EXECU'TIVE COUNCIL

OF THE

\section{INTERNATIONAL HEALTH EXHIBITION,}

I $\$ 84$.

"The authors have been carefully selected, and the information convejed is gentra'ly both useful and trustworthy."-Timcs.

"Among the actual results of the opening of the Health Exhibition, not the least inportant is the issue of a series of Official Handbooks that practically illustrate the science of health in all its manifold aspects........ The general exce!'ence of the first instalment of these handbouks yromises well for the value and completeness of the series; while the price at which they are issued, sliould assure the success they merit."-Saturday Rcuicas.

LONDON:

WILLIAM CLOWES AND SONS, LIMITED, Official Printers and Publishers to the Exccutive Council,

I3 CHARING CLOSS, S.W. 
Demy 4to. Illuminated Cloth, gilt edges, Ios. 6d.

The Changes and Development of Civil Costume in England.

From the Conquest to the Regency. With 24 Full Page Coloured Illustrations. By the Hon. Lewis Wingfield.

This Work forms a most elegant and suitable gift as a souvenir of the Health Exhibitiun. 


\title{
A LIST
}

OF THE

\section{OFFICIAL PUBLIGATIONS}

\author{
ISSUED BY THE EXECUTIVE COUNCIL
}

OF THE

\section{INTERNATIONAL HEALTII EXHIBITION.}

WMr. CLOWVES \& SONS, Limited, I3 Charing Cross, London, S.IV.

\section{OFFICIAL HANDBOOKS.}

Health in the Village.

By Sir Henry W. Dyke Acland, K.C.B., M.D., D.C.L., F.R.S., etc., etc. Illustrated. Second Edition. Price is.

Describes graphically an English Village in the 'Presanitation' period, and the misery of the people. It then states the Essentials of Heartir in an Agricultural Village; Dwellings; Water Supply; Removal of Refuse; Education; Occupation ; Recreation; and Care in Sickness. It gives illustrations from the properties of large Landowners, and compares Past and Present. There are 50 Woodcut Illustrations.

\section{Healthy Nurseries and Bedrooms, inchuding.} the Lying-in Room. By Mrs. Gladstone. Price is.

This book attempts to bring before the public the chief points in connection with the subject it deals with, in a popular form. Relying for scientific facts on thoroughly trustworthy authorities, the authoress has endeavoured to clothe them in language which will appeal especially to wives and mothers, while giving such exact clescriptions and directions as shall enable the suggestions to be carried out by an ordinary reader.

\section{Healthy and Unhealthy Houses in Town and Country. By WM. EAssie, C.E., F.I.S., etc. With an} Appendix upon the Water Supply and Discharge of Sewage for Country Houses. By Rogers Field, B.A., M.I.C.E. Illustrated. Second Edition. Price is.

The body of the Handbook deals with healthy and faulty sites for houses; the arrangement of houses as regards general convenience; proper and improper clrainage; with cletails of all kinds of sanitary equipments for a house from basement to attic; ordinary water supply and flushing of drains, and instructions to householders, etc., in town and country. The Appendix treats upon the secretion of, and the supply of, water for country houses, and for methods of disposing of the sewage. 


\section{Healthy Schools.}

\section{By Charles E. Paget. Price is.}

Refers to general considerations of site ; building and planning; ventilation ; lighting and warming ; arrangement of offices; and regulation of desks and seats in schools of all kinds. Deals with the special diseases apt to arise from neglect of such considerations, and points to the great advantages of good playgrounds; reviews the questions of fceding, school-hours, and the controlling of infectious illnesses.

\section{Healthy Furniture and Decoration.}

By Robert IV. Edis, F.S.A. Illustrated. 2nd Edition. Price is.

Preliminary Remarks-Unhealthiness of Wooden Houses-Ventilation and con. structive decoration-Healthiness of electric lighting in comparison with gas, oil lamps, and candles-Present bad system of leasehold tenure-Diseases attribatable to badly built and filled houses-Sanitary decoration-Healthy treatment of floor and wall surfaces-Influence of colour on the optic nerves-Paper hangings-Washable papersUnhealthiness of stuff hangings-Constructive fittings-Arrangement of different rooms - Iealthy treatment of walls and fittings.-Bedrooms and Nurseries-LavatoriesMantel-pieces-Smaller fittings of the house-Ornamental plaster-work-Leather papers, etc., for wall covering-Conclusion.

\section{IIealth in the Workshop. \\ By James B. Lakmman, Esq. Price is. \\ CONTENTS.}

PART I.-Progress of Factory Legislation from First Act in 1802 to Last Act in 1883-Causes which led to each extension-Diseases and mortality consequent on employment in certain trades-Successful efforts to free children from ignorance and oppressed toil-Improvement in physical vigour and development.

PART II.-Accidents : their causes and extent-where most frequent-why under more stringent regulations not reduced in number nor severity. Dangerous Machineryhow fenced-Cleaning machinery when in motion-Advice to operatives.

PART III.-Sanitation: where most neglected-Effect of employment in noxious trades-Unconverted divellings used as workshops prejudicial to health-Industries where females are employed in unsuitable work-Degeneracy and deformity of operatives - Gradual restoration to former condition of sturdiness-Deficiency of closet accommodation, and appliances.

PART IV.- Ventilation : neglect of general defect in structural arrangement of workshops-Temperature-Overcrowding-Artificial warming-Mechanical ventilation -Diffusion of air-Examples of modes of ordinary ventilation.

\section{Manual of Heating, Lighting, and Ven-} tilation. By Captain Douglas GalTon, C.B., F.R.S. Illustrated. Second Edition. Price Is.

Ventilation and Warming combined : Purity of Air ; Movement of Air ; Warming of Air. Town air is impure from Organic Matter and Smoke-Methods for diminishing impurity, provicling pure air, and removing vitiated air in houses are shown-Heating by open fires, warm air, hot water, steampipes, and gas explained. Light arises from incandesence - Vitiation of air by lighting is explained.

\section{Diet in Relation to Health and Work.}

By Alexander Wyinter Bly'th, M.R.C.S., F.C.S., \&c. Price is.

Division I.: First Principles-Food and Work. Division II. : Food Equivalents - Divisions of Food-Digestibility of Food. Division III.: Flesh and Milk. Dicision
$I V .:$ Chief Sources of the Carbohydrates. Division $V .:$ Leguminous VegetablesFruits. Division VI.: Tea, Coffee, Cocoa, and Chocolate. Division VII.: The Principles of Diet-Diet in relation to Work-Diet in Dcrclopment-Dict in Mcntal Exertion-Diet to rcduce Fat-Diets to makc Fat. 


\section{On the Principles of Cooking.}

By Sept. Berdmore. Price $x$.

Introduetion-Eilements-Utensils-Verbs which illustrate Principles-Choice and Preservation of Meats-To Roast-To Bake-To Grill-To Fry-To Boil-To Simmer - To Stew (Soups)-To Stew (Sauces)-To Braise-To Baste-To Brown and Clarify -'To I'lavour-'To Serve-Pastry-Kickshaws, or Hors d'CEuvre-Salads-Conelusion.

\section{Food and Cookery for Infants and Invalids. \\ By Catherine Jane Wood. With an Introductory Chapter by}

W. B. Cheadle, M.D. Price $x$.

Food : Its uses in the economy of nature-Component parts-Relative proportions. Infants : The mistakes in feeding; quantity, time and mamer-l'he results of those mistakes -In Growth-In Physique-In After Life-Rational Feeding and its great importance. Invalids: From what Cause-How affeeted by Food-Diseases whose aggravation or cure is affected by Food-Characteristies of Siek Dietary-Cookery.

\section{Alcoholic Drinks.}

By John L. W. Thudichum, M.D., F.R.C.P. Price rs.

Wines of France, Germany, Austria and Hungary, Spain, Portugal, Atlantic Islands, Italy, Greece, Cyprus, The Crimea, Asia, Africa, America and Australia; British or Domestie Wines; Beer; Distilled Spirits ; Liqueurs.

\section{Water and Water-Supplies; and Un-} formented Bevcrages. By John ATTField, Ph.D., F.R.S., etc.

Price Is.

This I-Iandbook includes a very full aecount of the sourees, natural properties, (pualities, etc., of all descriptions of water, "the basis of all beverages"; treats of the water-supplies of the eity and the eountry; and embraces the preparation, purity, wholesomeness, ete. of aërated drinks, tea, other "teas," eoffee, eoeoa, and ehocolate. $A$ ehapter on milk is added.

\section{Salt; and other Condiments.}

By J. J. Manley, M.A. Price is.

llistury of their Use in Ancient and Modern Times-Traditions, Customs, Superstitions, $\Lambda$ ssociations eonnected with-Sourees of Supply-Opinions, Aneient and Moder'n, as to Dietetie value, and Hygienic and Medieinal properties.

\section{Legal Obligations in Relation to the Druell- ingrs of the Poor. By Harry Duff, M.A. With a Preface by} Arthur Cohen, Esq., Q.C., M.P. Price is.

A summary of the law at present available for the prevention of overcrowding; the removal of nuisances; the clemolition and reeonstruction of unlealthy houses; showing the persons upon whom such obligations rest, and the manner in which they ought to be diseharged, both in the metropolis and other parts of England.

\section{Our Duty in Relation to Health.}

By G. V. PoOre, M.D., F.R.C.P. Price is.

This book is intended to show that each individual is morally responsible to himself and his neighbours in the matter of health; that national health depends upon the health of inclividuals; that health largely depends upon personal thrif and eeonomy, and that withont the intelligent assistance of individuals public authorities ean do little. "Our Duty" is diseussed in Five Chapters, The llousc, Water, Air, The Right Use' of Re'fusc, and Jiurial. 


\section{Laboratory Guide to Public Health Inves- tigation. By W. Watson Cheyne, F.R.C.S.; and W. H. Corfield, M.D., M.A., F.R.C.P. Illustrated. Price is.}

The work done in this laboratory deals with the life history of the minute fungi and bacteria, more espeeially with those which are parasitie on plants and animals. The study of fermentations is also included. The eause of the various communieable disease is the chief matter of study, as well as the study of the means required for destroying the virus, of interfering with its growth, or of converting it into a useful vaccine material.

\section{Physiology of Digestion and the Digestive Organs. By Arthur GamGeE, F.R.S. Illustrated. Price is.}

\section{Fermentation.}

By Dr. Duclaux. With a Preface by M. Louis Pasteur. Price is.

The object of this book is the general study of ferments. It deals suecessively with their functions in the world, their influenee on health and disense, their various modes of nutrition, their analogy with the constituent eells in the bodies of the higher animals, and the description of their eontest with these cells.

\section{Infectious Diseases and their Prevention.}

By Shrrley F. Murphy, M.R.C.P. Price is.

Infectious diseases cannot be prevented unless their nature is understood.-Reasons for believing that they are caused by the growth in the body of living organisms.-Cireumstanees under whieh these may be introdueed into the body, and the means for preventing such introduetion.-Methods of rendering the body proof against infection. - Destruetion of infection.-General precautions.

\section{Cleansing Streets and Ways in the Metro- polis and large Citics. By Williani Booth ScotT, M.Inst.C.E. Price Is.}

\section{London Water Supply.}

By Colonel Sir Francis Bolton, C.E. Price is.

\section{CONTENTS.}

General Introduction-Notes on Water Supply.-Water Filtration.-System of the London Water Supply: I. Rivers, Springs, and Wells; 2. The Metrcpolitan Water Companies; 3. The Sources of Supply.-The Water Examiner.--Statistics of Supply.

History and Description of the London Water IVorks-The Kent Vater Works : On eertain WVell IVaters in the Chalk Distriet. - The New River. - The Last London Water Works. - The Southwark and Vauxhall Water Worlis.-The West Middlesex Water Works.-The Grand Junetion Water Works. - The Lambeth Water Works.-The Chelsea Water Worlis.

ApPEndix-Memorandum.- Kates of Supply.-Statutory Powers as to Dividends.

The ExHIBITION OF IS84.

\section{Fires and Fire Brigades.}

By Captain Eyre M. Shaw, C.B. Illustratud. Price is. 
Athletics; or, Physical Exercise and Recreation. Part I. By the Rev. EDward WARre, M.A. Illustrated. Price Is.

Athletics, or physical exercise in relation to health.-True view.-Greek and Roman.-Development in individual-child, boy, man.-Use and misuse.-Development of Athletics social.-History of, in England.-Public Schools, Universities.-Games.Rowing.-Training necessary.-Other pastimes.-Drill.-Volunteers._Exercise for children and elderly people.-Athletics in Board Schools.-Towns. - Working Classes.

Athletics. Part II.

Cricket, Football, Lawn Tennis, and Health. By the Hon. E.

Lytrleton, M.A., and Gerard F. Cobb, M.A. Price is.

Introductory.-Games not really appreciated in England; the small number who play.-The benefit of exercise considered medically.-Games fulfil the requisite conditions better than taking a walk.-Importance of bealthy games for women.-Various difficulties considered: How to obviate them.-The example of Germany.-How a cricketer should live.-Mr. Gladstone on the importance of chewing food.

\section{Dress, and its Relation to Health and}

climate. By E. W. Godwin, F.S.A. Illustrated. Second Edition.

Price Is.

This Handbook traces the changing fashions in dress from B.C. 2000. As far as the limits of the work allow, the modes of each period are described; with illustrations taken from contemporary sources. Many fashions are referred to climatic necessities or love of ornament; in this, as in other arts, beauty and fitness being not always reached or ever quite forgotten.

Accidental Injuries: their Relief and Immediate Treatment. How to Prevent Accidents becoming more Serious. By James Can'ule, M.A., M.B., F.R.C.S. Iluistrated. Second Edition. Price Is.

This Handbook is intended as a guide, in simple language, from which the public may learn how to render efficient aid at the moment of injury. Not only are wounds, bruises, and broken bones, events of every-day occurrence, but a number of minor ailments, which might be relieved by the knowledge of some simple common-sense rules, are taken into consideration, and dealt with in a popular and yet not in a superficial manner.

\section{Ambulance Organization, Equipment, and Transport. By Surgeon-Major E. J. H. EvatT, M.D., A.M.D. Illustrated. Second Edition. Price Is.}

This Handbook describes in a popular manner the system of Ambulance Organization at work in the army for the relief of the sick and wounded in war. It also describcs municipal ambulance systems. It dcals briefly with the Red Cross organizations, and the various eivil ambulance associations. It then describes the various equipments used in ambulance aid, stretchers, mule carriages, ambulance waggons, railway sick transport, marine ambulance arrangements and beds, with a short chapter on ambulance tents.

\section{Schools of Art; their History, Work,} Aims and Infuences. By John Sparkes, Esq. Price is. CoNTENTs : National Art Tendencies in the Past-Origin, Progress, and Develop-
ment of Schools of Art-The Select Committee of 1835,1849 , and $1864-$ Formation of Schools of Design-Department of Practical Art-Department of Science and ArtPresent Constitution and Objects of Schools of Art-Their Influence in Manufacturing
Industries and National Taste, \&c.

The Conference Papers and Lectures-the subjects of which are enumerated in the following pages-may also be obtained in a separate form uniform with the above Handbooks. 
The following is the arrangement of the Handbooks, Conferences, and Lectures, as they will be published in Volumes:-

\author{
Price 7s. 6d. per Volume.
}

\title{
HEALTH IN THE DWELLING. \\ V.OLUME I. (Published.)
}

IIEALTH IN THE VILLAGE. By Sir Henry W. Dyke-Acland, K.C.B., D.C.L., M.D., F.R.S., Sec. Sec. Iilustratad.

IIEALTIIY NURSERIES AND JEDROOMS, INCLUDING TIE LYING. IN-ROOM. By Mrs. Gladstone.

IIEALTHY AND UNHEALTHY HOUSES IN TOWN AND COUNTRY. By William Liassie, C.E., with an Appendix by Rogers Field, C.E. Ilhustrated. HEALTHY FURNITURE AND DECORATION. By Robeit W. Edis, F.S.A. Illustrated.

IIEALTHY SCHOOLS. By Charlcs E. Pagret, M.R.C.S.

HEALTH IN THE WORKSHOP. By James B. Lakeman, one of IIer Majesty's Inspectors of Factories.

VENTILATION, WARMING, AND LIGHTING FOR DJMESTIC USE.

Dy Captain Douglas Galton, C.B., F.R.S., \&c. S.c. Illustratel.

INDEX TO VOLUME.

\section{VOLUME II. (In the Press.)}

MANSION IIOUSE COUNCIL ON TIIE DWELLINGS OF THE I'OOR.-The Lord Mayor, President; John Hamer, Secrctary. 3, Queen Victoria Street, E.C.

"The Population of London and its Migri-tions "- "The Treatment of the London Poor""Overcrowding "- "Suburban Dwellings and Cheap Railway Fares"-" On the Creation of a Building Fund"- "Some Difficulties of Sanitary Legislation in the Metropolis""Suggestions to the Royal Commissioners."

KOYAL INSTITUTE OF DRITISH ARCHITECTS.

Ewan Christian, Prcsident; William H. White, Secretary. 9, Conduit Street, W.

"The General Subject of the Construction of Houses with regard to Sanitary Arrangements"

- "The Sanitary Arrangement of Houses in London during the last 120 years"-

"Driinage under Dwellings"- "The Impermeable Construction of Roofs, Walls, and liasement Floors, with a reference to Ventilation and Warming incidental thereto""The Construction of Chimneys"- "A Suggestion with regard to the Construction of Doors so as to affurd opportunity of Escape from Fire; and another on an economical mode of Fireproof Construction, adapted in several instances in Public and Private Buildings"- "Sanitary Aspect of Internal Fittings and Decoration "- "The Iygienic value of Colour"- "Collection, Storage, Management, and Distribution of Water for Domestic Purposes."

SOCIAL SCIENCE ASSOCIATION.-Sir Richard Temple, Bart., G.C.S.I., C.I.E., President; J. L. Clifford-Smith, Secretary. I, Adam Street, Adelphi, W.C.

"What conditions are essential for" a Healthy Dwelling, whether in an urban or in a rural locality, and how far is it desirable that they should be rendered compulsory by legislation?"- "What, if any, restrictions in the interests of health should be enforced in connection with the employment of girls and women in Workshops and Factories?""Is it desirable that notitication of Infectious Disease should be obligatory?"- "Is it desirable to legislate further respecting the duties of Medical Officers of Health ?"

INDEX TO VOLUME.

\section{VOLUME III. (In the Press.)}

HEALTIIY HOUSES. By T. Pridgin Teale, F.R.C.S.

FOUL AIR IN IIOUSES, By Professor W. H. Corfield, M.D.

IIEALTHY FURNITURE. By Robert W. Edis, F.S.A.

is

DOMESTIC USE OF GAS. By Harold B. Dixon, M.A.

ry VENTILATION IN CONNECTION WITH WARMING

By Captain Douglas Galton, C.B., F.R.S.

SMOKE ABATEMENT. By Emest Hart, M.R.C.S.

IIEALTHY TOWN AND COUNTRY IOUSES. IBy W. Eassie, C.E.

IIEALTH IN TIIE WORKSHOP'. Ly James 13. Lakeman, one of IIes Majesty's Inspectors of Factories.

ANGLO-SAXON HOUSES. By Professor J, Frederick Hodgetts.

INDEX TO VOLUME. 
Price 7s. 6d. per Volume.

\section{HEALTH IN DIET.}

Volume IV. (In the Press.)

PHYSIOLOSY OF DIGESTION AND THE DIGESTIVE ORGANS. By Professor Arthur Gamgee, M.D., F.R.S. Illustrated.

DIET IN RELATION TO HEAL'TH AND WORI. By Alfred Wynter Blyth, M.R.C.S , F.C.S. Mlhustrated.

ON THE PRINCIPLES OF COOKING. By Septimus Berdmore.

FOOD AND COOKERY FOR INFANTS AND INVALIDS. By Miss

Wood; with a Preface by Robert B. Cheadle, M.D., F.R.C.P.

WATER AND WATER SUPPLIES; AND UNFERMENTED BEVERAGES.

By Professor Attfield, Ph.D., F.R.S.

SALT AND OTHER CONDIMENTS. By John J. Manley, M.A.

ALCOHOLIC DRINKS. By John L. W. Thudichum, M.D., F.R.C.P.

IINDEX TO VOLUME.

\section{VOLUME V. (In the Press.)}

CENTRAL CHAMBER OF AGRICULTURE.-Henry Chaplin, M.P., President; Major P. G. Craigie, Secretary. 7, Arundel Street, Strand, W.C.

"The Sources of our Meat Supply."-_"The Causes which have Checked the Development of our Home Production of Neat." " "Home-grown Meat Supply and the Increased Production of Home-grown Meat." - "The Means of Securing the Supply of Meat to Jargely-populated Centres."

INSTITUTE OF CHEMISTRY.-Professor William Odling, M.A., F.R.S., President; Charles E. Groves, F.C.S., Secretary. Somerset House Terrace, W.C.

"Food Adulteration and Analysis," with Appendix.

BRITISH BEE-KEEPERS' ASSOCIATION.-The Baroness Burdett-Coutts, President; Rev. H. R. Peile, M.A., Secretary. Royal Horticultural Gardens, S. W.

"Foul Brood and its Prevention."-_Adulteration of Honey."

INDEX TO VOLUME.

\section{VOLUME VI. (In the Press.)}

THE DIGESTIVE FERMENTS AND CHEMICAL PROCESSES OF DIGESTION. By Professor Arthur Gamgee, M.D., F.R.S.

PRACTICAL DIETETICS. By Professor F. de Chaumont, M.D.

CHEMISTRY OF BREAD MAKING. By Professor Charles Graham, D.Sc.

SCIENCE OF COOKERY. IB Mattieu W. Williams, F.C.S.

PURE MILK. By G. W. Wigner, F.I.C., F.C.S.

THE`ENGLISH DAIRY. By Professor J. P. Sheldon, F.C.S.

II THE DANISH DAIRY. By Alexander Mariboe. 
Price 7s. 6d. per Volume.

\section{HEALTH IN RELATION TO CIVIC LIFE. \\ VOLUME VII. (In the Press.)}

"OUR DUTY" IN RELATION TO HEALTH. By George Vivian Poore, M.D., F.R.C.P.

INFECTIOUS DISEASE AND ITS PREVENTION. By Shirley F. Murphy, M.R.C.P.

ACCIDENTAL INJURIES : THEIR RELIEF AND IMMEDIATE TREAT. MENT. HOW TO PREVENT ACCIDENTS BECOMING MORE SERIOUS. By James Cantlie, M.A., M.B., F.R.C.S. Illustrated.

AMBULANCE: ORGANISATION, EQUIPMENT, AND TRANSPORT. By Surgeon-Major G. J. H. Evatt, M.D., A.M.D. Illusiratel.

CLEANSING STREETS AND WAYS IN TIIE METROPOLIS AND LARGE CITIES. By William Bocth Scott, M. Inst. C.E.

FIRES AND FIRE BRIGADES. By Captain Eyre M. Shaw, C.B. Illustrated. LEGAL OBLIGATIONS IN RESPECT TO DWELLINGS OF THE POOR. By Harry Duff, M.A., Barrister-at-Law; with a Preface by Arthur Cohen, Q.C., M.P.

SCHOOLS OF ART. THEIR ORIGIN, HISTORY, WORK, AND IN. FLUENCE. By John Sparkes.

INDEX TO VOIUME

\section{VOLUME VIII. (In the Press.)}

SOCIETY OF MEDICAL OFFICERS OF HEALTH.

Subject (combined): Domestic Sanitation in Metropolitan and Rural Districts. Industrial Diseases: Spread of Infcctious Discases. Notification of Infectious Diseases: Disposal of the Dead: Cremation.

SANITARY INSTITUTE OF GREAT BRITAIN.

PARIKES MUSEUM OF HYGIENE.

r. Domestic Sanitary Arrangements of the Metropolitan Poor-ra. I'he Improvement of the Sanitary Arrangements of Metropolitan Houses. -2. Domestic Sanitation in Rural Districts. 2a. Sanitary Houses for the Working Classes in Urban Distric ts. - 3. Industrial Diseases. 4. Spread of Infectious Diseases.-( $(x)$ 'Through the Agency of Milk.-(b) 'Through other agencies. - 5. Notification of Infections Diseases. - (a) Its Importance and its Dificulties.5a. (6) The Right and the Duty of the State 10 enforce it. -6. Disposal of the Dead.6a. Cremation.

ST. JOHN'S AMBULANCE ASSOCIATION.

On the Carriage and Removal of the Sick and Injured.-On the Ambulancc Organisation of the Metropolis during Epidcmics.

SOCIETY UF ARTS-Water Supply and Distribution.

SourCes of Suppry.- "On the Area of Chalk as a Source of Water Supply." - "Water Supply in its Influence on the Distribution of the Population."- "On a possible Increase of Underground Water Supply."-"Water from thc Chalk."- "The Origin of Water Supplies.""Water Supply to Villages and Rural Districts."-"Water Supply."- "Sources of Water Supply."

Quality of Water. Filtration And Softening.-"Water for Domestic Use." “"The Softening of Water." "The Detection of Sewage Contamination by the Use of the Microscope, and the Purifying Action of Minute Animals and Plants."- "The Chemistry of Potable Water." "On the Purification of Water on a large Scale."

Methods of Distribution; Modes of Giving Pressure; House FitTings; Discovery AND PRevention of WAste, \&c., \&c.- "Water Distribution and Dual Supply."-" Modes of Distribution, with some remarks on Dual Supply."- "Water Supply for Fire Extinction." "Mode of Distribution of Water."

INDEX TO VOLUME.

\section{VOLUME IX. (In the Press.)}

ETHICS OF THE SIKIN. By Malcolm Morris, M.R.C.S.

AMBULANCE ORGANISATION IN WAR AND PEACF。 By Dr. Evatt.

ANGLO-SAXON DRESS AND FOOD. By J. Fred. Hodgetts.

OUR DOMESTIC POISONS. By Henry Carr, M. Inst. C.L.

IIISTORY AND RESULTS OF A DISPENSARY FOR SICK CIILDREN

THREATENED WITI CHRONIC DISEASE. By Dr. Gilbert of Havre.

IEALTH WORK AND PLAY IN VILLAGE LIFE. By Sir Henry IV.

Dyke Acland, K.C.B.

STREET ACCIDENTS AND THEIR AMELIORATION. By James Cantlie,

M.A., M.B., F.R C.S.

THRIFT IN ITS RELATION TO HEALTH; OR, THE RIGHT USE OF

REFUSE. By George Vivian Poore, M.D., F.R.C.P.

THE IREVENTION OF CHOLERA. By Professor F. de Chaumont, M.D.

RECREATION. By G. D. Darbishire, M.D. 
Price 7s. 6d. per Volume.

\section{GENERAL HYGIENE.}

ATHLETICS, OR PHYSICAL EXERCISE AND RECREATION. Part I. By Rev. Edinund Warre, M.A. Illastrated.

ATHLETICS. Part II. By Hon. Edward Lyttelton, M.A., and Gerard F. Cobb, M.A.

DRESS AND ITS RELATION TO HEALTH AND CLIMATE. By E. IV Godwin, F.S.A. Illustrated.

FERMENTATION. By Dr. Duclaux, Professor of Biological Chemistry at the Sorbonne. Illistrated.

PUBLIC HEALTH LABORATORY VVORK. PART I. WITII CATALOGUE AS APPENDIX, By W. Watson Cheyne, F.R.C.S.

PUBLIC HEALTH LABORATORY IVORK. PART II. By W. H. Corfield; M.A., M.D., F.R.C.P., and C. E: Cassal, F.I.C., F.C.S.

LONDON WATER SUPPLY. By Colonel Sir Francis Bolton, C.E.

\section{VOLUME XI. (In the Press.)}

MEDICAL SOCIETY OF LONDON AND NATIONAL HEALTH SOCIETY.

Dictaries-Duties of School Managers in relation to Epidemics-Preventive 'Treatinent of Epidemics in Public and High Schools-Grammar and High Schools, their Construction and Arrangement-School Dormitories-Effects of aPosture in Schools-Gymnastics in SchoolsGymnastics Feriencolonien - The Health and Physical Development of Idiots as compared with mentally sound children.

ROYAL METEOROLOGICAL SOCIETY.

Some relations of Meteorological Phenomena to Health.-English Climatological Stations. Cumulative Temperatures, \&c., as shown on the Diagrams exhibited by the Meteorological Office in the International Health Exhibition.-Some occasional Winds and their Influence on Health. - T'he Lquinoctial Gales-Do they occur in the Lritish Isles ?

ASSOCIATION FOR THE ORAL INSTRUCTION OF THE DEAF AND

DUMB.-The Earl Granville, K.G., President; A. H. Moses, Esq., Hon. Secretary. Address: II, Fitzroy Square, W. Subject: Oral Instruction of the Deaf and Dumb.

On the Oral Instruction of the Deaf and Dumb. On the Education of Incurably Deaf Children. SOCIETY OF TELEGRAPH ENGINEERS AND LLECTRICIANS.-

ELECTRIC LIGHTING-MUNICIPAL AND DOAIESTIC.

Electric Lighting in relation to Health.-Physiological bearing of Electricity in relation to Health.

EPIDLMIOLOGICAL SOCIETY OF LONDON.

Health in India-Change of Type in Epidenic Disease-Leprosy in India, and the best weans of preventing its increase.

\section{VOLUME XII. (In the Press.)}

PARASITES OF MEAT AND FOOD (TWO LECTURES). By T. Spencer Cobbold, M.D., F.R.S.

CANDLES. By Leopold Field.

HISTORY OF ENGLISH DRESS. By Ion. Lewis Wingfield.

TEXTILES GENERALLY. By William Morris.

CHILDREN'S DRESS. By Miss $\Lambda$ da S. Ballin.

OLD AND MODERN POISON LORE. By A. Wynter Blyth, M.R.C.S.

SOAP. By Charles T. Cross. 


\section{OFFICIAL CATALOGUE, GUIDE, ETc.}

The Official Catalogue. Price Is.

Contains a full list of the Vice-Presidents, Executive Council, General Com. mittee, Jury Commissions, etc., etc., with all the necessary Memoranda for the Guidance of Exhibitors. A detailed List of Exhibitors and their Exlibits, elaborately classified, indexed, and arranged with a view to easy reference.

The Official Guide. Price $3 d$.

With Coloured Plan and Illustrations.

This Gnide gives an accurate and concise account of the arrangement of the Buildings, and of the most noteworthy objects contained in them; pointing out the best and most expeditious way of making a complete tour through the Exhibition. It includes an excellent Coloused Plan, Coloured Pictures of the Old London Strect and of the Grounds, an exhaustive Index and copious Marginal Notes to facilitate ready reference, and an Introduction setting forth the purport and generai scheme of the Exhibition.

\section{Daily Programme of Music, \&c. Price Id.}

Contains all the arrangements for the day, including Meetings of the Conferences; Lectures, Lessons on Coolery, etc., in the Lecture Hall ; Practices in the Gymnasium; Organ Recitals, Vocal and Instrumental Concerts in the Albert Iall; Programme of the Musical Selections performed in the grounds by the various Military Bands, \&c., \&c.

\section{Recipes for Cheap Dinners. Price 3d.}

These handy and very practical Recipes are prepared by Mrs. CHARLES CLARKE, the Lady Superintendent of the National Training School for Cookery, and are in daily use for the Cheap Dimners served in the Dining Rooms in connection with the School at the Health Exhibition. The work is prefaced by a chapter showing the ubject and work of the National Training School for Cookery, Summary of Rules, \&c.

\section{Handbook to the Aquarimn. Price bet.}

Second Edition. Profusely Illustrated.

Contents :- Introduction.-Wistory of the National Fish Culture Association.-OObjecls of the $\Lambda$ ssociation. - List of Officers.-Complimentary Lists. - Description of the A quarium. -Description of the Fish Culture Department. - I he Cultivation of Salmonida. - The Cultivation of Coarse Fishes.-The Acclimatisation of Fureign Fuod Fishes.-Hints on the Construction and Management of Fish Ponds. - Natural Histury of the Fislies exhibited in the Tanks. - List of Loan Exhibitors.

\section{WILLIAM CLOWES \& SONS, LIMITED,}

OFFICIAL PRINTERS \& PUBLISHERS TO THE EXECUTIVE COUNCIL, I3, CHARING CROSS, LONDON, S. IV. 


\section{A T A L O G E}

OF THE

\section{OFFICIAL PUBLICATIONS}

ISSUED BY THE EXECUTIVE COMMITTEE

OF THE

\section{INTERNATIONAL FISHERIES EXHIBITION.}

The exhaustive range comprised by the Handbooks and Prize Essays, which are by writers of great eminence and authority, and the comprehensive nature of the Papers which emanated from the various Conferences, combine to render this Series an exceptionally instructive and condensed Library of Reference on all questions appertaining to Fish, Fishing Appliances, and the Fishing Industries of all Countries, brought down to the date of the International Fisheries Exhibition of 1883 .

\section{LONDON :}

WILLIAM CLOWES AND SONS, Limited, OFFICIAL PRINTERS AND PUBLISHERS TO THE EXECUTIVE COMMITTEE, I3 CHARING CROSS, S.W. 


\section{A \\ CATALOGUE}

$\mathrm{OF}$ THE

\section{FISHERIES EXHIBITION LITERATURE}

PUBLISHED BY

WM. CLOWES \& SONS, LXMITED, 13, Charing .Cross, S.W.

\section{THE INTERNATIONAL FISHERIES EXHIBITION}

LITERATURE. Complete in I4 Vols, each fully indexed. Demy 8vo. cloth. Price $£ 66$ s.

The Fourteen Volumes, as above, comprise the whole of the ImportanT Literary OUtcome of the Fisheries Exhibition, which is issued in a collected form with copious Indexes, \&c., by desire of the Executive Committee.

Any of the various divisions of this work may be obtained separately, at the following prices :-

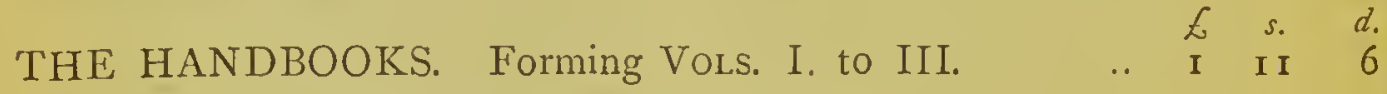
THE CONFERENCE PAPERS. Forming VOLs. IV. to VII. $22_{2} \quad \begin{array}{lll}2 & 0\end{array}$ THE PRIZE ESSAYS. Forming Vols. VIII. to XI. $\begin{array}{llllll}\cdots & 2 & 2 & \circ\end{array}$ $\left.\begin{array}{c}\text { THE OFFICIAL CATALOGUE } \\ \text { AND JURY AWARDS. }\end{array}\right\}$ Forming VOL. XII. . . THE OFFICIAL REPORT. Forming VOL. XIII. .. $\quad$ ○ 106 THE ANALYTICAL INDEX. Forming VoL. XIV. .. ०

A Complete List, showing the contents of each of these volumes, will be found in the following pages, and single copies of any of the Handbooks, Conference Papers, or Prize Essays, may still be obtained of the Publishers at the prices affixed, although the volumes of each division cannot be sold separately. 


\section{THE FISHERIES LITERATURE-VOL. I. \\ HaNDBOOKS-PART I. \\ CONTENTS:-}

THE BRITISH FISH TRADE. By His Excellency Spencer Walpole, Lieut.-Governor of the Isle of Man. I $s$.

MARINE AND FRESHWATER FISHES OF THE BRITISH ISLANDS. By W. Saville Kent, F.L.S., F.Z.S. is.

THE FISHERY LAWS. By Frederick Pollock, Barrister-at-Law, M.A., \&c. Is.

APPARATUS FOR FISHING. By E. W. H. Holdsworth, F.L.S., F.Z.S. Is.

THE PLACE OF FISH IN A HARD-WORKING DIET, WITH NOTES ON THE USE OF FISH IN FORMER TIMES. By W. Stephen Mitchell, M.A. Is.

A POPULAR HISTORY OF THE FISHERIES AND FISHERMEN OF ALL COUNTRIES FROM THE EARLIEST TIMES. By W. M. Adams, B.A. Is.

\section{THE FISHERIES LITERATURE-VOL. II. HANDBOOKS-PART II.}

CONTENTS :-

FISH CULTURE. By Francis Day, F.L.S., F.Z.S. is. ZOOLOGY AND FOOD FISHES. By George Bond Howes. Is. THE UNAPPRECIATED FISHER FOLK: THEIR ROUND OF LIFE AND LABOUR. By James G. Bertram.

THE SALMON FISHERIES. By Charles E. Fryer. I $s$. ANGLING IN GREAT BRITAIN. By William Senior. is. INDIAN FISH AND FISHING. By Francis Day, F.L.S., F.Z.S. is.

\section{THE FISHERIES LITERATURE-VOL. III. HANDBOOKS-PART III.}

CONTENTS :-

FISHES OF FANCY : THEIR PLACE IN MYTH, FABLE, FAIRY-TALE, AND FOLK-LORE. With Notices of the Fishes of Legendary Art, Astronomy, and Heraldry. By Phil Robinson. Is.

ANGLING CLUBS AND PRESERVATION SOCIETIES OF LONDON AND THE PROVINCES. By J. P. Whecldon. 1s.

SEA FABLES EXPLAINED. By Henry Lee, F.L.S., F.G.S., F.Z.S. is. SEA MONSTERS UNMASKED. By Henry Lee, F.L.S., F.G.S.,
F.Z.S. ${ }_{\text {Ls. }}$

PRACTICAL LESSONS IN THE GENTLE CRAFT. By J. P. Wheeldon. I $s$.

LITERATURE OF SEA AND RIVER FISHING. By J. J. Manley, M.A. Is. 


\title{
THE FISHERIES LITERATURE-VOL. IV.
}

\author{
Conference Papers-Part I. \\ CONTENTS:-
}

INAUGURAL ADDRESS BY PROFESSOR HUXLEY, P.R.S. $6 d$. NOTES ON THE SEA FISHERIES AND FISHING POPULATION OF THE UNITED KINGDOM. By Vice-Admiral H.R.H. the Duke of Edinburgh, K.G. Is.

PKINCIPLES OF FISHERY LEGISLATION. By Right Hon. G. Shaw-Lefevre, M.P. $6 d$.

FISH TRANSPORT AND FISH MARKETS. By His Excellency Spencer Walpole, Lieut.-Governor of the Isle of Man. $6 \pi$.

THE ECONOMIC CONDITION OF FISHERMEN. By Professor Leone Levi, F.S.A., F.S.S., F.R.G.S., \&c. $6 d$.

A NATIONAL FISHERIES SOCIETY. By C. E. Fryer. 6d.

RIVER POLLUTION BY REFUSE FROM MANUFACTORIES

AND MINES; TOGETHER WITH SOME REMEDIES PROPOSED. By

V. B. Barrington-Kennett, M.A., LL.M. $6 \pi$.

PRACTICAL FISHERMEN'S CONGRESS. Under the Presidency of Mr. Edward Birkbeck, M.P. 6\%.

SCIENTIFIC RESULTS OF THE EXHIIBITION. By E. RayLankester, M.A., F.R.S., F.L.S., F.Z.S., \&c. $6 d$.

\section{THE FISHERIES LITERATURE-VOL. V. Conference Papers-Par'T II. CONTENTS :-}

FISHERY INDUSTRIES OF THE UNITED STATES. By Professor G. Brown Goode, M.A., \&c. $6 \pi^{\circ}$.

OYSTER CULTURE AND OYSTER FISHERIES IN THE NETHERLANDS. By Professor Hubrecht. $6 \%$.

THE FISHERIES OF CANADA. By Louis Z. Joncas. $6 d$.

THE FISHERIES OF CHINA. By J. D. Duncan Campbell, Commissioner for China. $6 d$.

A SKETCH OF THE FISHERIES OF JAPAN. By Narinori Okoshi, Member of the Japanese Consulate in London. $6 d$.

NEWFOUNDLAND : ITS FISHERIES AND GENERAL RESOURCES. By the Hon. Sir Ambrose Shea, K.C.M.G., Commissioner for Newfoundland. $6 a$.

THE SWEDISH FISHERIES. By Professor F. A. Smitt, Royal Commissioner for Siveden to the International Fisheries Exhibition. $6 d$.

NOTES ON THE FISH SUPPLY OF NORWAY. By Frederik M. Wallem, Executive Commissioner for Norway to the International Fisheries Exhibition. $6 \pi$.

NOTES ON THE FOOD FISHES AND EDIBLE MOLLUSCA OF NEW SOUTH WALES, ETc. By E. P. Ramsay, Commissioner for New South Wales. $6 d$.

THE FISHERIES OF SPAIN. By Lieut.-Col. F. G. Solá, Executive Commissioner for Spain to the International Fisheries Exhibition. $6 d$.

THE FISHERIES OF THE BAHAMAS. By Augustus J. Adderley, Commissioner for the Bahamas to the International Fisheries Exhibition. $6 \%$.

WEST AFRICAN FISHERIES, WITH PARTICULAR REFERENCE TO THE GOLD COAST COLONY. By Captain C. A. Moloney, C.M.G. $6 d$. 


\section{THE FISHERIES LITERATURE-VOL. VI.}

Conference Papers-Part III. CONTENTS:-

FISH DISEASES. By Professor Huxley, P.R.S. $6 d$.

THE CULTURE OF SALMONID $Æ$ AND THE ACCLIMATIZA-

TION OF FISH. By Sir James Ramsay Gibson Maitland, Bart. $6 d$.

THE HERRING FISHERIES OF SCOTLAND. By R. W. Duff, M.P. $6 d$.

MACKEREL AND PILCHARD FISHERIES. By Thomas Cornish. $6 \%$. SALMON AND SALMON FISHERIES. By D. M. Home, F.R.S.E. $6 d$. COARSE FISH CULTURE. By R. B. Marston. $6 \pi$.

THE DESTRUCTION OF FISH AND OTHER AQUATIC ANIMALS BY INTERNAL PARASITES. By T. Spencer Cobbold, M.D., F.R.S., F.L.S. $6 d$.

THE FOOD OF FISHES. By Francis Day, F.L.S., F.Z.S. $6 d$. MOLLUSCS, MUSSELS, WHELKS, ETC., USED FOR FOOD OR BAIT. By C. W. Harding, Assoc. M. Inst. C.E. $6 d$.

THE ARTIFICIAL CULTURE OF LOBSTERS. By W. Saville Kent, F.L.S., F.Z.S. $6 d$.

CRUSTACEANS. By Thomas Cornish. $6 \%$.

\section{THE FISHERIES LITERATURE-VOL. VII. \\ Conference Papers-Part IV. \\ CONTENTS :-}

FISH AS FOOD. 'By Sir Henry Thompson, M.B., F.R.C.S., Éc. $\quad 6 d$. THE PRESERVATION OF FISH LIFE IN RIVERS BY THE EXCLUSION OF TOWN SEWAGE. By the Hon. W. F. B. Massey Mainwaring. $6 d$.

THE FISHERIES OF IRELAND. By J. C. Bloomfield. $6 d$.

IMPROVED FACILITIES FOR THE CAPTURE, ECONOMIC TRANSMISSION AND DISTRIBUTION OF SEA FISHES, \&c. By R. F. SEAL FISHERIES. By Captain Temple. $6 \%$.

STORM WARNINGS. By R. H. Scott, M.A., F.R.S. $6 \%$. SAVING LIFE AT SEA. By Richard Roper. $6 d$. FISH PRESERVATION AND REFRIGERATION. By J. K.
Kilbourn. $6 d$.

THE BASIS FOR LEGISLATION ON FISHERY QUESTIONS.

By Lieut.-Col. F. G. Solá. 6d.

FOREST PROTECTION AND TREE CULTURE ON WATER

FRONTAGES, ETc. By D. Howitz, Esq. $6 d$.

LINE FISHING. By C. M. Mundahl. $\sigma d$.

TRAIVLING. By Alfred W. Ansell. $\sigma d$. 


\section{THE FISHERIES LITERATURE-VOL. VIII. \\ Prize Essays-Part $I$. CONTENTS:-}

THE COMMERCIAL SEA FISHES OF GREAT BRITAIN. By

F. Day, F.L.S., F.Z.S. 5 s.

THE EFFECT OF THE EXISTING NATIONAL AND INTERNATIONAL LAWS FOR THE REGULATION AND FROTECTION OF DEEP SEA FISHERIES, ETC. By C. W. Morris. $3^{s .}$

SALMON LEGISLATION IN SCOTLAND, Etc. By J. M. Leith. Is. $6 d$.

\section{THE FISHERIES LITERATURE--VOL. IX.}

Prize Essays-Part II.

CONTENTS :-

IMPROVED FISHERY HARBOUR ACCOMMODATION FOR GREAT BRITAIN AND IRELAND. By J. C. Wilcocks. $2 s$.

THE BEST SYSTEM OF LIFE INSURANCE FOR FISHERMEN, ETc. By J. W. de Caux, Is.

THE RELATIONS OF THE STATE, WITH FISHERMEN AND FISHERIES, ETc. By C. E. Fryer. Is. $6 d$.

THE RELATIONS OF THE STATE WITH FISHERMEN AND FISHERIES, ETc. By F. J. Talfourd Chater, Is. 6 d.

THE HISTORY OF DUTCH SEA FISHERIES, Etc. By A. Beaujon. 4 s. $6 d$.

\section{THE FISHERIES LITERATURE-VOL. X.}

\section{Prize Essays-Part III.}

\section{CONTENTS:-}

THE NATURAL HISTORY OF COMMERCIAL SEA FISHES OF GREAT BRITAIN AND IRELAND, ETc. By Rev. W. Houghton, M.A., F.L.S. $7 s$.

IMPROVED FACILITIES FOR THE CAPTURE, ECONOMIC TRANSMISSION, AND IISTRIBUTION OF SEA FISHES. By H. P. Blake. Is. $6 d$.

A CENTRAL WHOLESALE FISH MARKET FOR LONDON. By J. J. Cayley and H. H. Bridgman, F.R.I.B.A. 5 s.

THE BEST APPLIANCES AND METHODS OF BREAKING THE FORCE OF THE SEA AT THE ENTRANCE TO HARBOURS AND ELSEWHERE. By W. A. Smith. Is. 


\section{THE FISHERIES LITERATURE-VOL. XI. \\ Prize Essays - Part IV. \\ CONTENTS:--}

THE PROPAGATION OF THE SALMONIDÆ. By J. Stirling. $i s$. THE PROPAGATION OF THE SALMONID $\approx$. By T. Andrews. Is. THE PROPAGATION OF THE SALMONID $Æ$. By W. Oldham

Chambers. Is.

THE SALMON DISEASE. By J. Clark. is.

THE SALMON DISEASE: ITS CAUSE AND PREVENTION.

By W. A. Smith. Is.

THE CULTIVATION OF FRESHWATER FISH OTHER THAN

SALMONID死. By R. B. Marston. Is.

THE PROPAGATION OF FRESHWATER FISH, EXCLUDING

SALMONIDA. By W. Oldham Chambers. Is.

THE HERRING FISHERY. By R. Hogarth. is.

THE HERRING FISHERIES. By R. J. Munro. is.

THE HERRING FISHERIES. By H. J. Green. is.

THE SCOTCH EAST COAST, ORKNEY AND SHETLAND, LEWIS

AND BARRA HERRING FISHING. By W. S. Miln. Is, $6 d$.

THE NATURAL HISTORY AND CULTIVATION OF THE SOLE.

By Rev. W. Houghton, M.A., F.L.S. Is.

OYSTER CULTURE. By Commander C. V. Anson, R.N., and

E. H. Willett, F.D.A. 2s. $6 d$.

OYSTER CULTURE. By Dr. P. P. Hoek. is.

THE BEST MEANS OF INCREASING THE SUPPLY OF

MUSSELS AND OTHER MOLLUSCS, ETc. By T. F. R. Carr. I $s$.

THE BEST MEANS OF INCREASING THE SUPPLY OF

MUSSELS AND OTIIER MOLLUSCS, ETc. By J. C. Wilcocks. Is. $6 \pi$.

THE INTRODUCTION AND ACCLIMATIZATION OF FOREIGN

FISH. By W. Oldham Chambers. Is.

THE FOOD OF FISHES, Etc. By G. Sim. is. $6 \pi$.

THE CURRENTS, TEMPERATURES, AND OTHER PHYSICAL

CONDITIONS OF THE SEA IN RELATION TO FISH. By W. Watt. Is. ANGLING CLUBS. By J. Skinner. Is.

\section{THE FISHERIES LITERATURE-VOL. XII.}

CONTENTS:-

OFFICIAL CATALOGUE.

THE AWARDS OF THE INTERNATIONAL JURIES. 
8 Published by Wilitam Clowes \& Sons, Limited.

\section{THE FISHERIES LITERATURE-VOL. XIII. CONTENTS:-}

OFFICIAL REPORT OF THE INTERNATIONAL FISHERIES EXHIBITION. By Spencer Walpole.

REPORT ON THE ELECTRIC LIGHTING. By William D. Gooch. APPENDIX A. - CEREMONIAL A'T OPENING OF INTERNATIONAL FISHERIES EXHIBITION AND ADDRESSES AT CLOSING. APPENDIX B.-STATISTICAL TABLES. RETURN OF NUMBER OF VISITORS DURING THE TERM OF THE INTERNATIONAL FISHERIES EXHIBITION.

APPENDIX C.-DIGESTS PREPARED BY INVITATION OF THE EXECUTIVE COUNCIL AS TO THE CONDITION OF TAHE FISHING INDUSTRY IN THE UNITED KINGDOM AND ABROAD.

\section{THE FISHERIES LITERATURE-VOL. XIV.} CONTENTS:-

ANALYTICAL INDEX TO THE WHOLE LITERATURE.

A Complete and Detailed List of the Literature published in connexion with THE INTERNATIONAL HEALTH EXHIBITION post-free on application.

WILLIAM CLOWES \& SONS, LIMITED, OFFICIAL PRINTERS AND PUBIISHERS TO THE EXECUTIVE COMMITTEE, I3, CHARING CROSS, S. W. 

